Doctorado en Conservación y Restauración del Patrimonio Arquitectónico Escuela Técnica Superior de Arquitectura de Madrid

\title{
La deformación del tipo \\ Construcción de bóvedas no-canónicas en España (siglos XVI-XVIII)
}

\author{
Rosa Senent Domínguez \\ Arquitecta \\ dirigida por \\ Enrique Rabasa Díaz \\ Doctor Arquitecto
}



Sólo el que ensaya lo absurdo es capaz de conquistar lo imposible*

UnAmuno, Miguel de. 1905. Vida de Don Quijote y Sancho. 



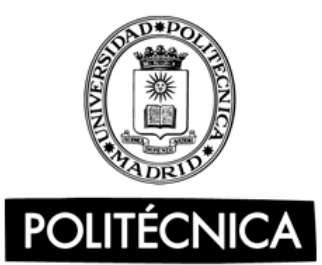

Tribunal nombrado por el Magfco. y Excmo. Sr. Rector de la Universidad Politécnica de Madrid, el día ......... de .......................... de 20...

Presidente:

Vocal:

Vocal:

Vocal:

Secretario:

Suplente:

Suplente:

Realizado el acto de defensa y lectura de la Tesis el día......de.... de $20 \ldots$ en la Escuela Técnica Superior de Arquitectura de Madrid.

Calificación:

EL PRESIDENTE

LOS VOCALES 



\section{Agradecimientos}

Son muchas las personas que me han acompañado y ayudado a lo largo de esta investigación.

Debo dar las gracias en primer lugar a Enrique Rabasa por haber sabido ver un tema de tesis a partir de un trabajo de doctorado, por guiarme durante toda la investigación y en especial por animarme a continuar en los momentos más difíciles. Puedo decir sin lugar a dudas que ha hecho más que cumplir con su obligación.

También quiero darle las gracias a Santiago Huerta y Gema López Manzanares, por haber despertado en mí la curiosidad por la Historia de la Construcción.

Los profesores e investigadores Miguel Ángel Alonso Rodríguez, José Calvo López, Rocío Carvajal Alcaide, Ana López Mozo, Rafael Martín Talaverano, Pau Natividad Vivó, Carmen Pérez de los Ríos, Miguel Sobrino e Isabel Tarrío han compartido generosamente su tiempo y sus conocimientos conmigo.

El profesor Joël Sakarovitch me acogió con amabilidad en el laboratorio Géométrie Structure, Architecture (GSA) de la École Nationale d'Architecture Paris-Malaquais durante mi estancia en París en otoño de 2011.

Para la realización de las tomas de datos he podido disponer de los instrumentos del Departamento de Ideación Gráfica Arquitectónica de la Escuela Técnica Superior de Arquitectura de Madrid. He podido contar también con los fondos y servicios de la Biblioteca de la Escuela Técnica Superior de Arquitectura de Madrid.

Esta investigación ha contado con una Beca de la Universidad Politécnica de Madrid dentro del Programa Propio de la UPM de «Ayudas para la realización del doctorado», obtenida en la convocatoria de 26 de octubre de 2009, y una ayuda para Estancias Breves, obtenida en la convocatoria de 23 de febrero de 2011.

Entre los años 2011 y 2013 he formado parte del Proyecto de Investigación «Construcción en piedra de cantería en los ámbitos mediterráneo y atlántico. Análisis de ejemplos construidos» (BIA2009-14350-C02-01).

Ignacio Oteiza, Juan Queipo de Llano y Amparo Garralón me ayudaron durante la preparación del número monográfico de la revista Informes de la Construcción. 
También quiero expresar mi agradecimiento a todas las personas e instituciones que me han permitido y facilitado la toma de datos de las bóvedas analizadas: a D. Jesús Ferreras, párroco de la Iglesia Parroquial de Alcocer (Guadalajara); al Cabildo de la Catedral de Santa María de la Encarnación de Almería; a D. José Díaz, Párroco de la Iglesia Mayor de Baza; a Don Tomás Otero Lázaro, Deán del Cabildo de la Catedral de Santa María de la Asunción de El Burgo de Osma (Soria); a Don Ángel Ortega, encargado del Patrimonio Artístico de la Catedral de Santa María de Calahorra; al Cabildo de la Santa Iglesia Catedral Metropolitana de la Encarnación de Granada; al Cabildo de la Catedral de Santa María de la Encarnación de Guadix; a Don Ildefonso López Lozano - Canónigo Penitenciario de la S. I. Catedral Basílica de Málaga; a Mme. Hélène Echaniz, del Service Culture \& Patrimoine de Narbona; a Don Luis Gómez Ramos y Doña Mónica García García del BBVA en Palma de Mallorca; a Doña Pilar Ribal Simó, Directora de la Fundació Palma Espai d'Art - Casal Solleric en Palma de Mallorca; al Col.legi de Sant Francesc en Palma de Mallorca; al Hospital de San Pere y San Bernat en Palma de Mallorca; a la dirección del Hotel Born de Palma de Mallorca; a la hermana Rosa del Colegio de la Santísima Trinidad de Palma de Mallorca; a M. Laurent Barrenechea, del Service Territorial de l'Architecture et du Patrimoine - Pyrénées-Orientales y al Cabildo de la Catedral de Perpignan; al Cabildo de la Catedral de Nuestra Señora de la Asunción y de San Frutos de Segovia; a D. Julián García, secretario del obispo en la Catedral de Santa María de Sigüenza (Guadalajara); a Don Santiago Orcajo, párroco de la Iglesia de Santa Eugenia de Villegas (Burgos) y a Don Juan-Carlos Izquierdo Domínguez, auxiliar del Museo catedralicio de la Santa Iglesia Catedral de Zamora.

Y por supuesto a mi familia, que me ha prestado su apoyo incondicional durante todos estos años. Sin su ayuda no habría podido realizar este trabajo. 
Una bóveda no canónica es una bóveda que se adapta a una forma distinta de aquella para la que ha sido inicialmente concebida. Bóvedas raras, anormales, no convencionales, habitualmente consideradas excepciones o casos particulares, resultan ser más frecuentes de lo inicialmente esperado.

El interés por este tipo de bóvedas surge a raíz de una investigación inicial sobre las bóvedas empleadas para cubrir espacios de planta anular, como en el caso de las girolas de las iglesias. Sin embargo, el problema de la bóveda anular no puede ser abordado directamente, sino como parte de una investigación más general sobre bóvedas que se deforman para adaptarse a una situación anómala.

El análisis de las posibilidades que un determinado tipo de bóveda brinda para resolver el abovedamiento de espacios de planta irregular, trascendiendo el problema de la planta anular, es lo que da origen a esta investigación.

La cuestión de las bóvedas deformadas forma parte de un contexto mayor, el de la deformación en arquitectura abovedada. Ante una contradicción, la deformación de la bóveda es sólo una de las posibles opciones que esta arquitectura ofrece para resolver un problema de deformación.

La tesis se estructura en dos partes: en la primera parte se analizan los conceptos de forma y deformación en el contexto de la arquitectura abovedada con objeto de sentar las bases para una teoría de las bóvedas no canónicas. El objetivo es establecer un punto de partida para la investigación en un campo que todavía no había sido abordado. En la
A non canonical vault is a vault adapted to a different form from that for which was originally conceived. These rare, abnormal, unconventional vaults are usually considered as exceptions or special cases. However they prove to be more frequent than it was initially expected.

Interest in this type of vaults arises from an initial research on the vaults used to roof annular spaces, such as ambulatories. Nevertheless, the annular vault question cannot be addressed directly, but as a part of a broader research on distorted vaults; a research on vaults deformed to conform an anomalous layout.

The analysis of the possibilities that a particular type of vault provides to solve the vaulting of an irregular layout, beyond the problem of the annular plan is the origin of this research.

The argument of deformed vaults is part of a greater context, the context of deformation in vaulted architecture. Facing a contradiction, deforming a vault is just one of the options that vaulted architecture offers to solve a problem of deformation.

This dissertation is organised in two parts: in the first part we analyse the concepts of form and deformation in the context of vaulted architecture in order to lay the foundations for a non canonical vaults theory. The objective is to establish a starting point for future research in a field that has not been addressed yet. In the second part, we analyse three types of vault from the perspective of non canonical vaults, 
segunda parte se analizan tres tipos de bóveda desde la perspectiva de las bóvedas no canónicas, a partir de un estudio de casos de bóvedas en España entre los siglos XVI y XVIII.

El estudio de la deformación en arquitectura abovedada se centra en el problema de la girola, por tratarse de un caso generalizado de deformación, directamente relacionado con el problema de las bóvedas irregulares y cuyo estudio, llamativamente, no había sido llevado a cabo hasta la fecha. Se propone una primera aproximación al problema de la girola, desde un punto de vista puramente morfológico, al margen de consideraciones históricas.

En el caso de las bóvedas deformadas, el análisis se centra en tres tipos de bóveda: la bóveda de crucería, la bóveda de arista y la bóveda baída. Estos tres tipos de bóveda, aunque basadas en criterios formales distintos, están íntimamente relacionados entre sí. Por un lado permiten resolver el mismo problema -planta cuadrada delimitada por arcos-, por otro lado es posible establecer una relación formal entre la bóveda de arista y la bóveda baída a través de la bóveda de crucería.

El estudio de casos recogido en la segunda parte de la tesis se fundamenta en dos líneas de investigación, la primera sobre soluciones teóricas de bóvedas no convencionales propuestas en los manuscritos y tratados de cantería, y la segunda sobre bóvedas efectivamente construidas, tratado de establecer una comparación entre teoría y práctica, confrontando el grado de relación entre ambas. Sin embargo este doble análisis sólo se ha podido llevar a cabo en contadas ocasiones. Constatamos que las bóvedas no canónicas reflejadas en los tratados son based on a case study of Spanish vaults between the $16^{\text {th }}$ and $18^{\text {th }}$ Centuries.

The analysis of deformation in vaulted architecture focuses on the question of the ambulatory, because it is a generalized example of deformation, directly related to the problem of irregular vaults. Remarkably, the analysis of these spaces had not been conducted to date. We propose a first approach to the question of the ambulatory, from a purely morphological point of view, setting aside historical considerations.

The analysis of deformed vaults focuses on three types of vault: the groin vault, the ribbed vault and the sail vault. These three types of vault, although based on different formal criteria, are closely related between them. On the one hand, they allow to solve the same problem - a square perimeter limited by arcs-; on the other hand, it is possible to establish a formal relationship between the groin vault and the sail vault through the ribbed vault.

The case study presented in the second part of this dissertation is based on two research lines: theoretical non conventional vaults solutions proposed on stonecutting treatises; and currently built vaults. The aim of this double analysis was to establish a comparison between theory and practice, comparing the degree of relationship between them. Nevertheless, this double analysis has only been carried out on rare occasions. It is noted that non canonical vaults reflected in treaties are few and hardly been employed, while the built solutions do not meet proposed theoretical models, expressing a divorce between theory and 
pocas y apenas se han llevado a la práctica, mientras que las soluciones construidas no responden a modelos teóricos propuestos, manifestando un divorcio entre teoría y práctica.

El estudio de estas bóvedas permite poner en cuestión la definición tradicional que relaciona los conceptos de 'bóveda' y 'superficie'. Al iniciar el trabajo nos encontramos con un modelo teórico extremadamente rígido que deja fuera un gran número de bóvedas, obligando a agruparlas bajo el término «no canónicas». El trabajo realizado pone en evidencia lo limitado del modelo. El problema no está en la presencia de bóvedas anómalas, que no se adaptan al modelo tradicionalmente propuesto, sino en la extrema rigidez del modelo. practice.

The analysis of these vaults allows us to question the traditional definition that connects the concepts of 'vault' and 'surface'. When we began this research, we found an extremely rigid theoretical model that leaved out many vaults, forcing to group them under the term of «non canonical vaults». This research evidences the limitations of the model. The problem is not the presence of abnormal vaults, which cannot adapt to the traditional model, but in the very high stiffness of the model. 



\section{Prefacio}

En el curso 2009-2010 realicé el Trabajo Tutelado en el curso «Traza y Cantería» con el profesor Enrique Rabasa, que formaba parte del programa de Doctorado «Dibujo, Historia y Construcción» del Departamento de Ideación Gráfica de la Escuela de Arquitectura de Madrid. Dicho trabajo, consistió en analizar el trazado de la «Voûte d'arête en tour ronde» del Traité de la Coupe des Pierres de JeanBaptiste de La Rue (1728), comparándolo con los trazados propuestos por otros autores (figura I).
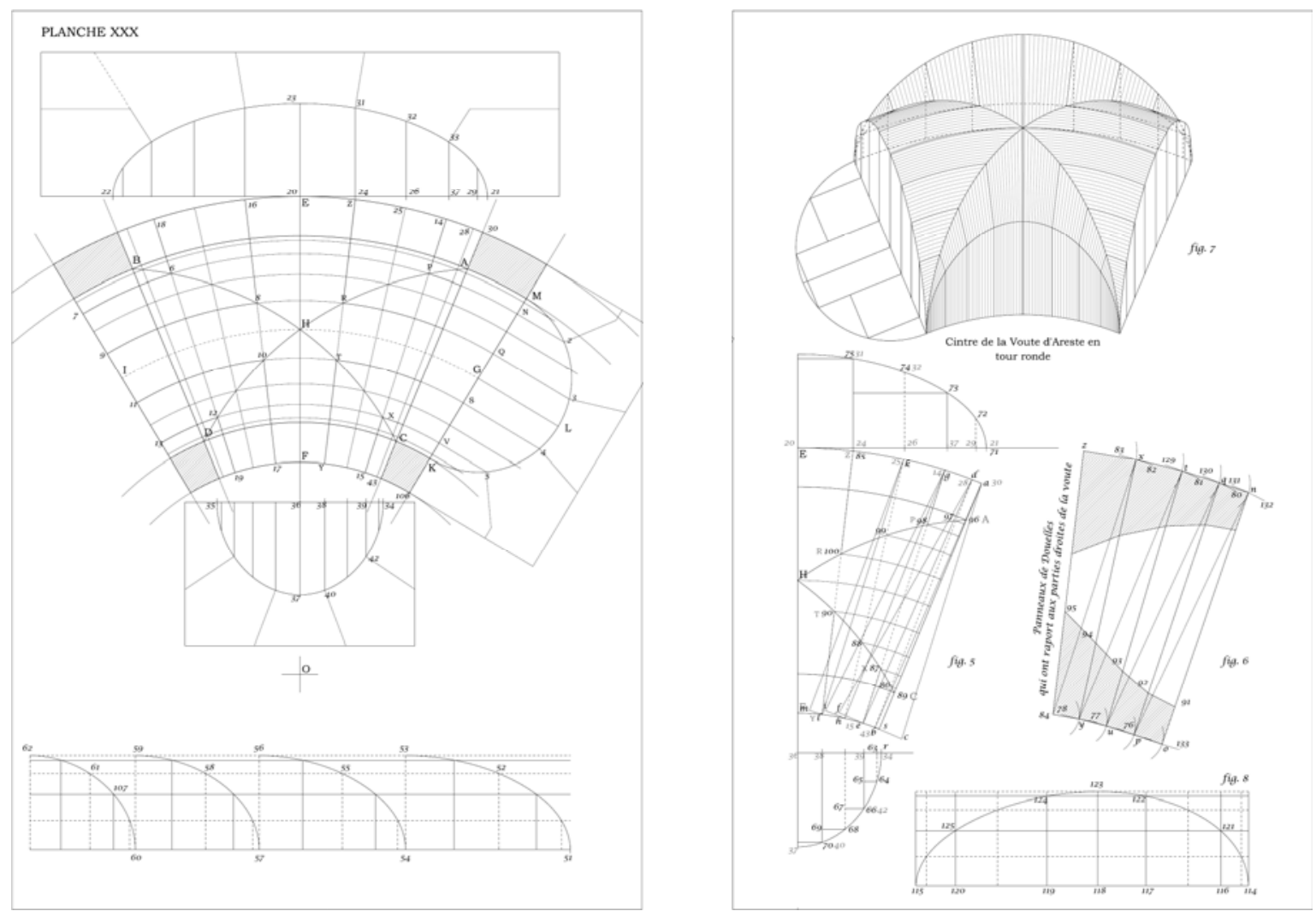

Figura I. «Voûte d’arête en tour ronde» según se describe en el tratado de J.-B. de La Rue (1728)

Como parte del trabajo, se buscaron ejemplos construidos de esta bóveda con el fin de compararlos con el trazado teórico. Aunque se buscaron ejemplos construidos no sólo en cantería, sino también en albañilería, la búsqueda fue poco fructífera ya que apenas aportó tres ejemplos:

- una bóveda en la galería de la Villa Giulia en Roma, obra de Jacopo Barozzi da Vignola (s. XVI), realizada en albañilería y por lo tanto sin posibilidad de compararla con el trazado de cantería (figura II); 


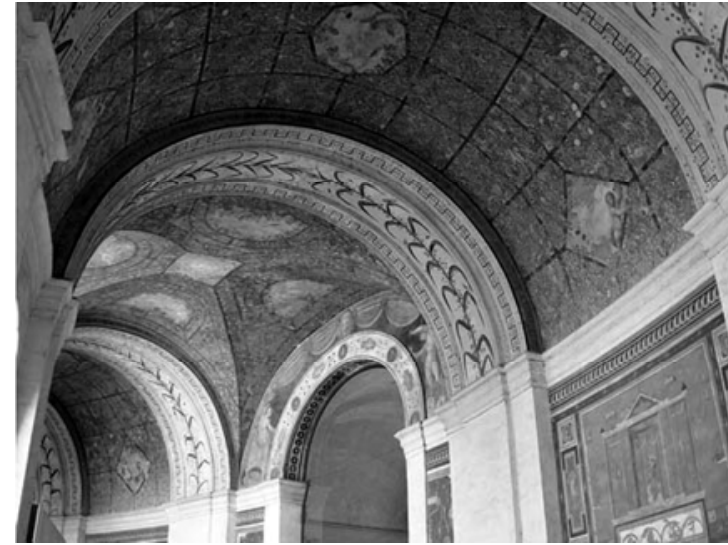

Figura II. Villa Giulia en Roma (fotografía de Farm4 en Flickr.com)

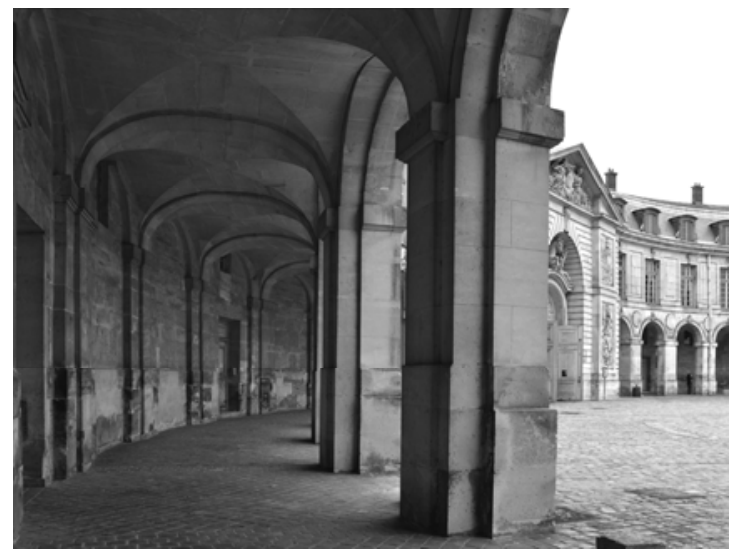

Figura IV. Grande Écurie de Versailles (Francia)

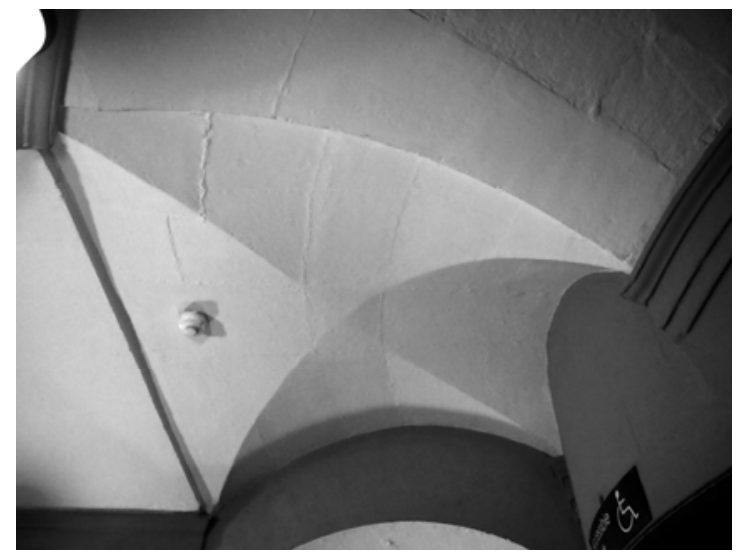

Figura VI. Catedral de Saint Paul en Londres (Reino Unido) (fotografía de Enrique Rabasa Díaz)

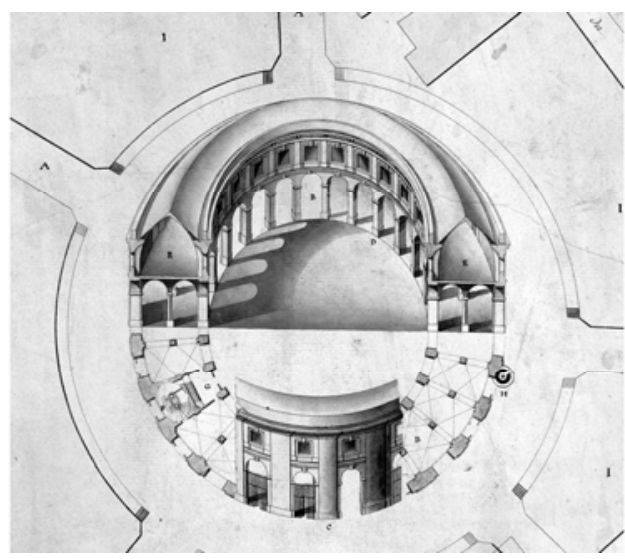

Figura III . Halle aux Blés de París (Francia). Dibujo de Nicolas Le Camus de Mézières (www.verge.com)

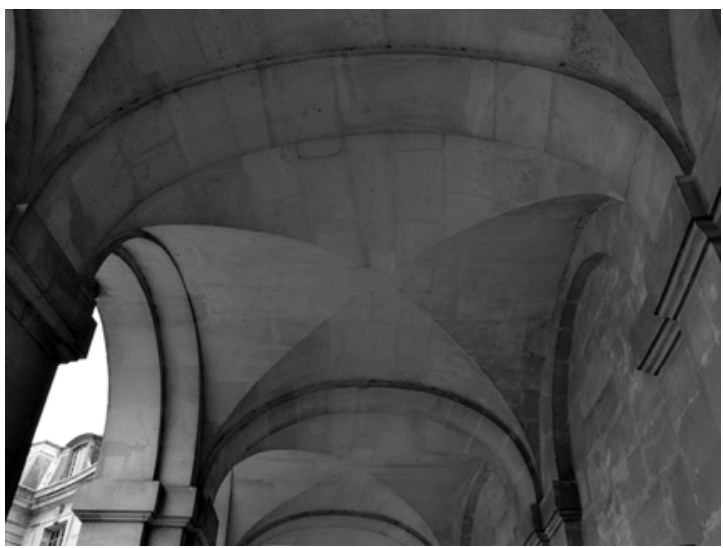

Figura V. Grande Écurie de Versailles (Francia)

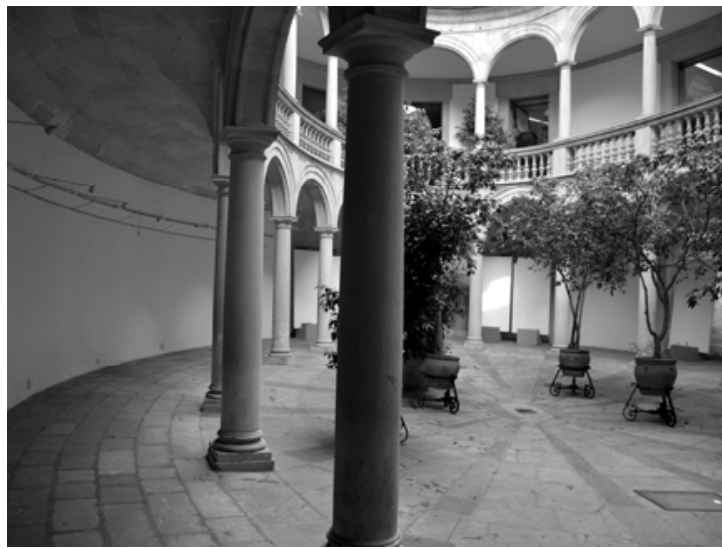

Figura VII. Claustro de San Antonio en Palma de Mallorca (España) 
- las bóvedas de la Halle aux Blés de París - actual Bourse de commerce de París-. obra de Nicolas Le Camus de Mézières, (s. XVIII), destruidas a finales del siglo XIX (figura III); $\mathrm{y}$

- las bóvedas del patio de acceso a la Grande Écurie de Versalles, obra de Jules Hardouin-Mansart (s. XVII), que es precisamente la bóveda que J.-B. de La Rue pone como ejemplo de este trazado, y por lo tanto no aportaba ninguna novedad (figuras IV y V). ${ }^{1}$

Esta situación nos llamó la atención por tres motivos. En primer lugar porque dicha bóveda queda recogida en todos los tratados de cantería y estereotomía desde el s. XVIII, dando lugar a profundas, y profusas, disquisiciones sobre su geometría correcta.

En segundo lugar, porque no se trata de una bóveda que responda a un problema no planteado; esta bóveda permite abrir huecos en un espacio de planta anular, problema que ha estado presente en toda la historia de la arquitectura desde época romana. El recurso compositivo de disponer un espacio central rodeado por una galería desde la que se accede es recurrente en la historia de la arquitectura, como ejemplifican las girolas de las catedrales románicas y góticas, pero el problema de su abovedamiento se ha resuelto sistemáticamente con otras soluciones distintas a la bóveda estudiada.

Por último, porque no se es una solución «innecesariamente complicada» ${ }^{2}$; el diseño y la labra no son inmediatos, pero la solución propuesta en los tratados es más sencilla que otros ejemplos de estereotomía que sí se han construido, como la Vis de San Gil (SANJuRJo Álvarez 2009, 238-243) o la cúpula en Vuelta de Capazo (RABASA DÍAZ 2013b, 12-13).

Lo que sí pudimos comprobar a medida que revisábamos ejemplos de corredores anulares (girolas, edificios de planta central con estructura de doble casco, ${ }^{3}$ claustros, patios...) es que las

1 Durante el desarrollo de la investigación encontramos dos ejemplos más de este tipo de bóveda, una bóveda rebajada en los sótanos de la catedral de Saint Paul en Londres, de finales del s. XVII (figura VI) y una sucesión de medias bóvedas de arista en el claustro de la iglesia de San Antonio en Palma de Mallorca (figura VII), fechado en 1729 (LUCENA et al. 1997).

2 Tomado de Enrique RABASA DíAZ (2009b).

3 Richard Krautheimer emplea la expresión «estructura de doble casco» para referirse a edificios donde un núcleo central -casco interior- es rodeado por deambulatorios y tribunas que constituyen el segundo 


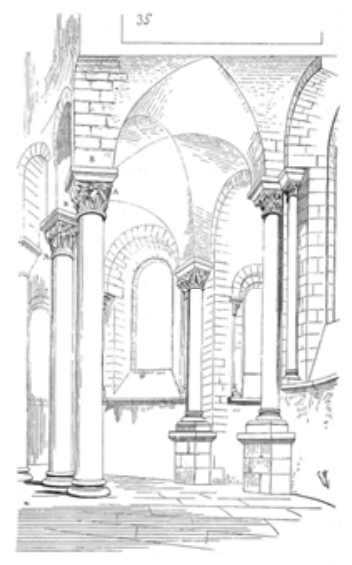

soluciones propuestas en cada momento de la historia han sido muy variadas, respondiendo al sistema constructivo disponible en cada momento, unas veces con propuestas más ingeniosas y otras con resultados más toscos, pero siempre condicionado por las posibilidades que ofrecía cada sistema constructivo.

Eugène-Emmanuel Viollet-le-Duc, se enfrentó a este mismo problema en su teoría sobre la construcción gótica desarrollada en el Dictionnaire raisonné de l'architecture française du XIe au XVIe siècle. En el artículo «Voûte» (VIOLLET-LE-DuC 1854-1868, 9: 465550) aborda el estudio del espacio de la girola y la bóveda que lo cubre empleándolo como pretexto para explicar la evolución desde la bóveda romana hasta la bóveda de crucería gótica francesa del siglo XIII. ${ }^{4}$ Viollet-le-Duc no afirma que el problema del abovedamiento de la girola forzara el desarrollo de la bóveda de crucería gótica, pero le sirve como hilo conductor de su discurso. Para Viollet-le-Duc, una de las innegables ventajas del sistema de bóveda gótica es su capacidad de adaptación a cualquier forma en planta, ejemplificada en el espacio de la girola, lo que habría contribuido a su éxito.

El análisis de las posibilidades que un determinado tipo de de bóveda brinda para resolver el abovedamiento de los espacios de planta irregular, trascendiendo el problema de la planta anular, es lo que ha dado lugar a esta investigación.
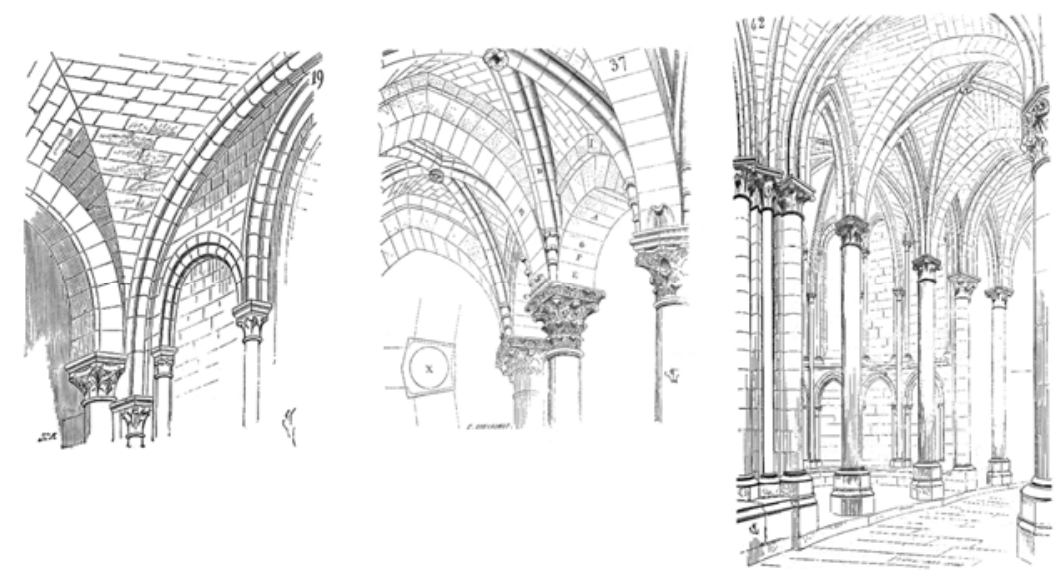

Figura VIII. Ejemplos de girolas dibujados por E-E. Viollet-le-Duc en el Dictionnaire raisonné (18541868) (http://fr.wikisource.org)

casco (KRAUTHEIMER [1965] 2011, 92). Como ejemplos podemos señalar San Lorenzo de Milán o San Vital de Rávena.

4 Este artículo complementa el de «Construction. Voûtes» (VIOLLET-LEDuC 1854-1868, 4: 62-126), donde también recoge algunos ejemplos de bóvedas en girolas. 


\section{Índice de capítulos}

\section{Introducción}

PRIMERA PARTE: FORMA Y DEFORMACIÓN EN ARQUITECTURA ABOVEDADA

2. Intuiciones

3. El problema de la deformación

4. Primera aproximación: «El compromiso con el difícil conjunto»

5. Segunda aproximación: Apuntes para una teoría de las bóvedas no canónicas

SEGUNDA PARTE: BÓVEDAS NO CANÓNICAS EN ESPAÑA, SIGLOS XVI-XVIII

6. Planteamiento

7. Bóvedas de crucería no canónicas

8. Bóvedas baídas no canónicas

9. Bóvedas de arista no canónicas

10. Conclusiones

APÉNDICE: Propuesta metodológica

REFERENCIAS

Rosa Senent Domínguez

Escuela Técnica Superior de Arquitectura. Universidad Politécnica de Madrid 



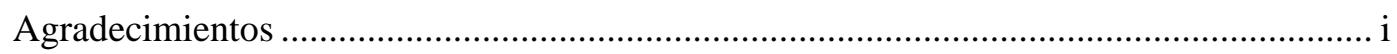

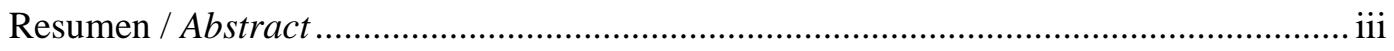

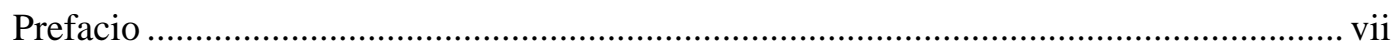

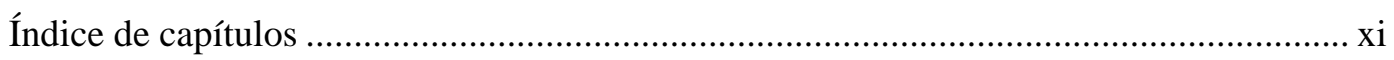

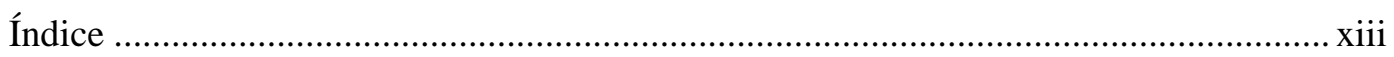

Origen de las imágenes y abreviaturas................................................................... xix

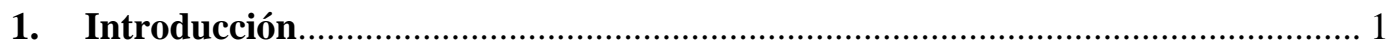

1.1 Las bóvedas no canónicas: una definición provisional ................................. 3

1.2 Estado del arte. La construcción de la bóveda ............................................. 7

La cuestión de la girola ............................................................................... 9

La adaptabilidad de la bóveda de crucería .......................................................... 13

Las capillas cuadradas: bóvedas baída y de arista .......................................... 14

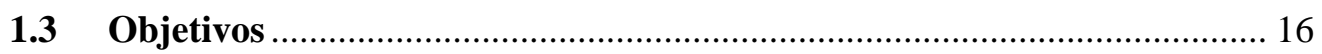

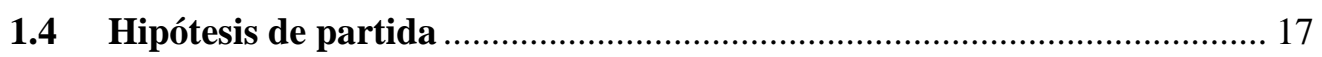

1.5 Estructura de la tesis y propuesta metodológica..................................... 19

Estructura de la tesis ...................................................................................... 19

Las capillas cuadradas como objeto de estudio ............................................. 20

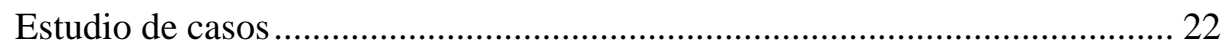

Límites espaciales y temporales................................................................. 23

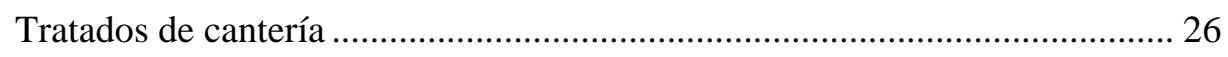

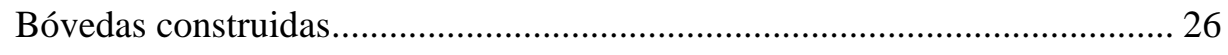

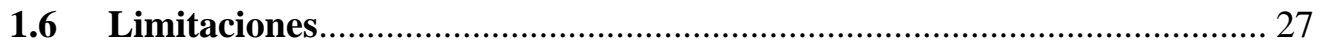

Bóvedas no canónicas - Bóvedas irregulares - Bóvedas deformadas ............. 30

PRIMERA PARTE: FORMA Y DEFORMACIÓN EN ARQUITECTURA ABOVEDADA ................... 35

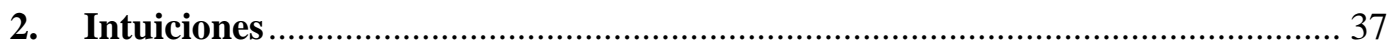

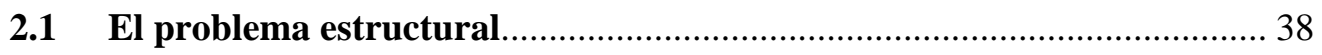

2.2 Bóveda y superficie .............................................................................. 41 


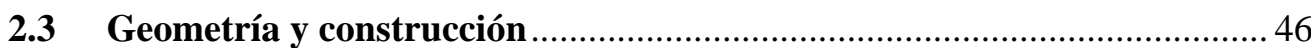

2.4 La cuestión de las bóvedas no canónicas ........................................................ 48

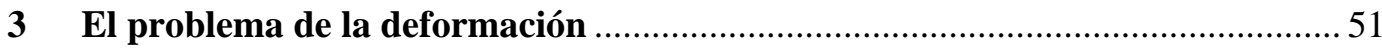

3.1. Deformación y contradicción …………………………………………..... 53

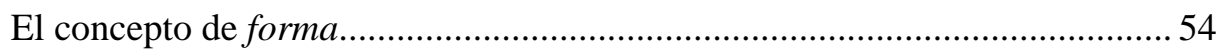

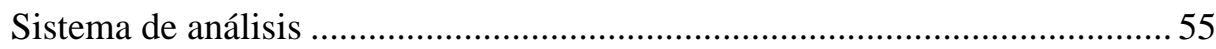

La noción de deformación ................................................................................. 57

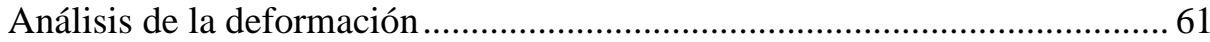

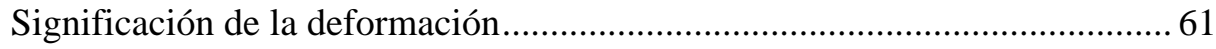

3.2. Deformación en arquitectura abovedada. Fundamentos ............................ 65

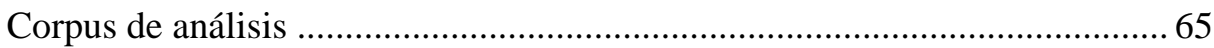

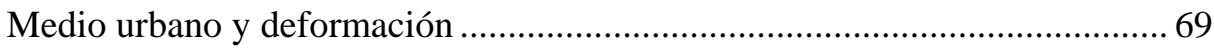

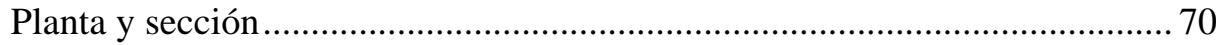

Proyección horizontal. Limitaciones ................................................................ 73

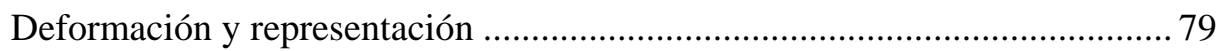

Deformación y percepción. Grados de deformación.......................................... 83

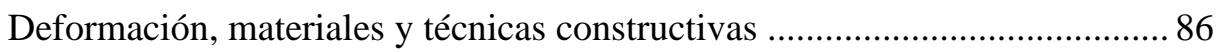

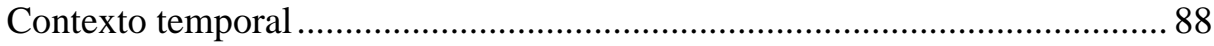

3.3. Origen, planteamiento y resultado ……………........................................... 91

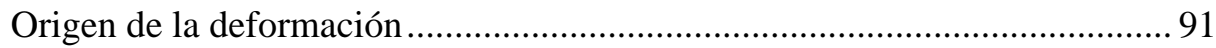

Causas formales de la deformación................................................................ 102

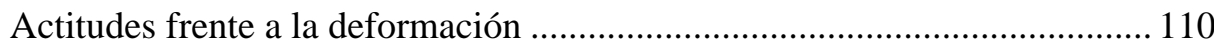

Modalidades de resolución de la deformación................................................ 115

3.4. Niveles de análisis ................................................................................... 121

Primera aproximación: análisis a nivel de conjunto....................................... 122

Segunda aproximación: análisis a nivel de bóveda ........................................ 128

4. Primera aproximación: «El compromiso con el difícil conjunto»...................... 133

4.1. La voûte en tour ronde ................................................................................ 137

Antecedentes. Arquitectura romana y paleocristiana ...................................... 141 
El planteamiento del problema. Bóvedas románicas en España

(siglos XI y XII)

La solución al problema. La bóveda de crucería gótica

(siglos XII-XIV).

La alternativa tardogótica. La bóveda de crucería de

múltiples nervios (siglos XV y XVI).

La solución moderna. Bóvedas clasicistas (siglos XVI y XVII) ………….... 150

La respuesta especulativa (siglo XVIII) ........................................................ 158

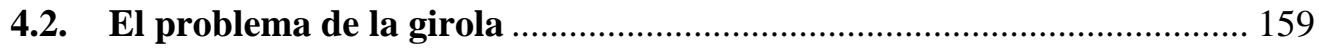

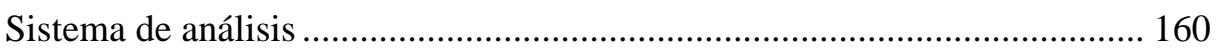

Base de datos de girolas. Catalogación ............................................................ 165

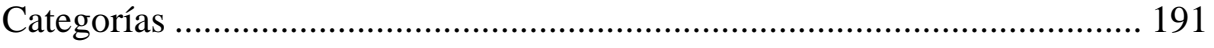

Modalidades de resolución de la deformación............................................... 201

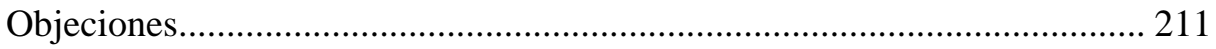

4.3. Girolas en manuscritos y tratados ........................................................... 213

El Carnet de Villard de Honnecourt .............................................................. 215

El Musterbuch de Hans Hammer .................................................................. 217

El manuscrito de Rodrigo Gil de Hontañón-Simón García ............................ 219

El manuscrito de Hernán Ruiz el Joven ........................................................ 223

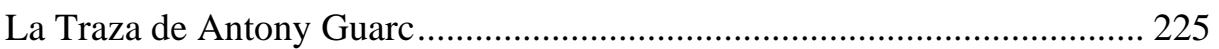

Traza de una girola en la Catedral de Cuenca................................................ 226

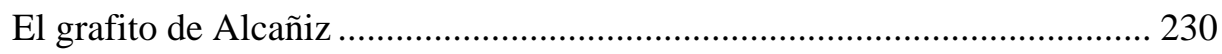

4.4. «La irregularidad inherente al orden»................................................... 231

\section{Segunda aproximación:}

Apuntes para una teoría de las bóvedas no canónicas 239

5.1. Las bóvedas no canónicas. El punto de vista de los tratados .................. 242

Los manuscritos y tratados de cantería de los siglos XVI al XVIII............... 243

Bóvedas no canónicas en manuscritos y tratados ........................................ 249

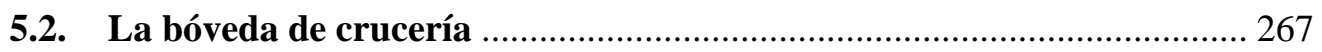

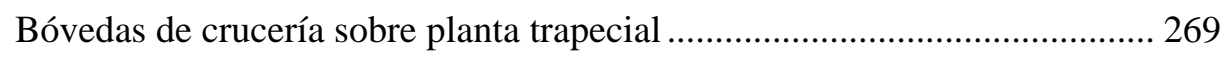

Bóvedas de crucería con apoyos asimétricos .................................................. 289 
Bóvedas de crucería de nervios asimétricos................................................... 299

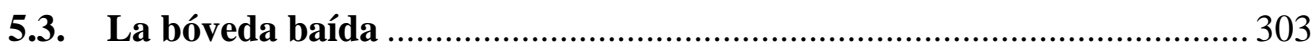

La bóveda baída construida. El problema de la esfera ...................................... 305

La bóveda baída en la tratadística ................................................................... 308

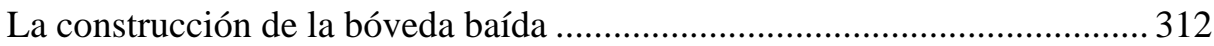

Despiece e irregularidad. La bóveda de la iglesia de Saint-Médard

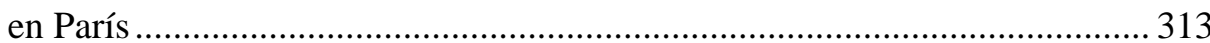

Una reflexión sobre el origen de la bóveda baída ............................................ 319

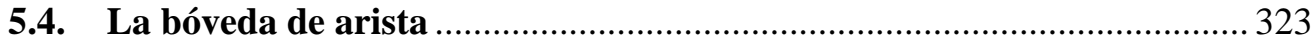

La bóveda de arista de planta rectangular y la cuestión del luneto ................ 323

La bóveda de arista y los lunetos en la tratadística ........................................ 326

La construcción de la bóveda de arista........................................................... 334

La iglesia de Saint-Jacques-du-Haut-Pas en París ........................................... 335

5.5 Declaración sobre las bóvedas no canónicas................................................ 341

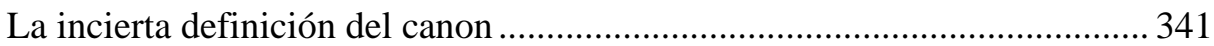

El punto de vista de los tratados..................................................................... 344

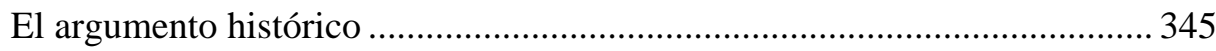

Bóvedas canónicas y no canónicas................................................................... 348

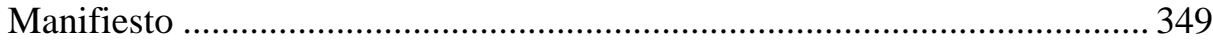

SEGUNDA PARTE: BÓVEDAS NO CANÓNICAS EN ESPAÑA, SIGLOS XVI-XVIII................. 351

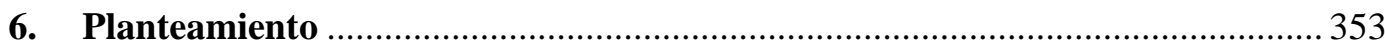

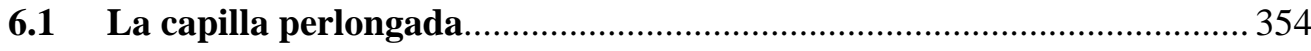

6.2 Las capillas irregulares: el rombo igual y el rombo desigual................... 356

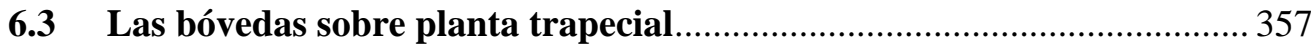

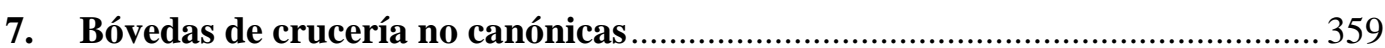

7.1. La bóveda de crucería con nervaduras asimétricas .................................... 363

El diseño de la bóveda de crucería de nervios asimétricos ............................. 377

La construcción geométrica de la forma de la bóveda .................................... 387

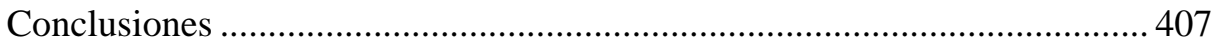


7.2. Las bóvedas trapeciales de la girola de la Catedral de Segovia 409

El diseño de la girola de la Catedral de Segovia

El trazado de las bóvedas de la girola de la Catedral de Segovia 416

La construcción geométrica de la forma de la bóveda 420

Conclusiones 424

8. Bóvedas baídas no canónicas

8.1. Las bóvedas irregulares del tratado de Vandelvira:

bóvedas baídas sobre rombo y romboide. 431

Título C «Capilla desigual por hiladas cuadradas».... 433

Título CXXXX «Del rombo igual» 435

Título CXXXXI. «El rombo desigual» 439

Análisis de los trazados. La adaptación del canon. 443

Una apostilla sobre el último dibujo 447

Conclusiones 450

8.2. Las bóvedas trapeciales de la girola de la Catedral de Málaga 451

La construcción de la Catedral de Málaga 452

Las bóvedas de la Catedral de Málaga 458

La construcción geométrica de la forma de la bóveda..... 464

Conclusiones 468

8.3. Las bóvedas trapeciales de la girola de la catedral de Granada 471

La cabecera de la Catedral de Granada 472

Las bóvedas de la girola de la Catedral de Granada 477

La construcción geométrica de la forma de la bóveda 483

Elementos góticos y renacentistas en las bóvedas de la girola de la

Catedral de Granada. 489

Conclusiones 491

9. Bóvedas de arista no canónicas 493

9.1. La bóveda de arista sobre planta rectangular 497

El modelo teórico: bóvedas de arista rectangulares en manus. y tratados

La bóveda de arista sobre planta rectangular en el manuscrito de Gelabert . 499 
El modelo construido: bóvedas de arista sobre planta rectangular

en Palma de Mallorca (siglos XVI-XVIII)..................................................... 503

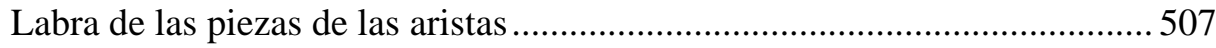

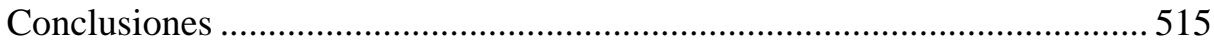

9.2. La solución dieciochesca al problema de la girola:

la bóveda de arista sobre planta anular ................................................. 517

La construcción geométrica de la voûte d'arête en tour ronde ....................... 518

La voûte d'arête en tour ronde en el tratado de J.-B. de La Rue ................... 523

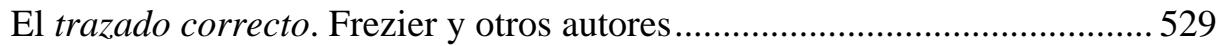

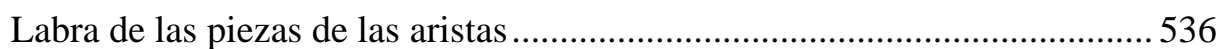

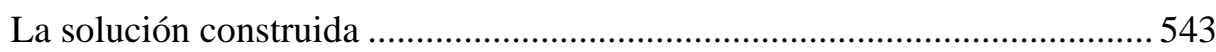

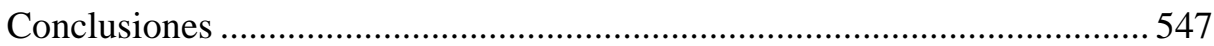

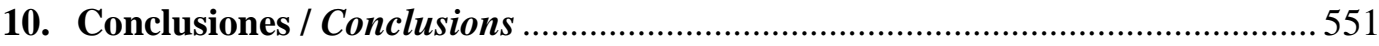

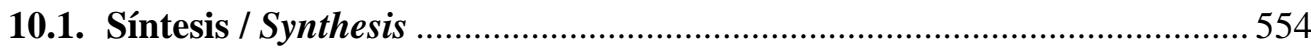

Forma y deformación en arquitectura abovedada /

Form and deformation in vaulted Architecture ............................................... 555

Bóvedas no canónicas en España, siglos XVI-XVIII

Non canonical vaults in Spain, 16th-18th centuries....................................... 560

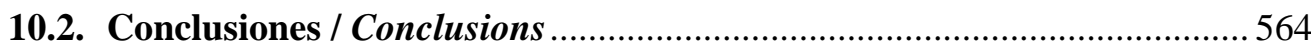

10.3. Futuras líneas de investigación / Future research topics ............................ 575

10.4. Forma y geometría / Form and geometry ..................................................... 581

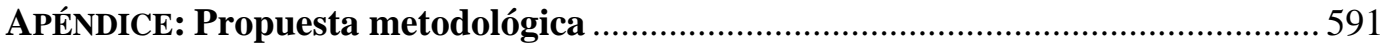

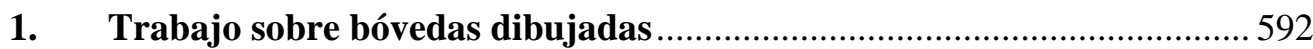

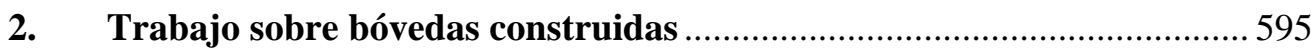

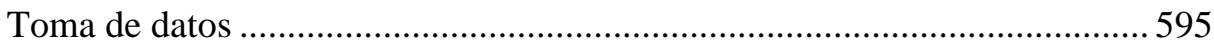

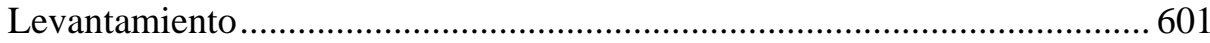

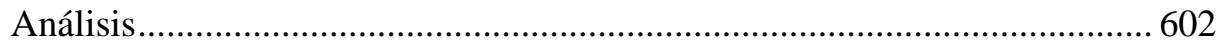

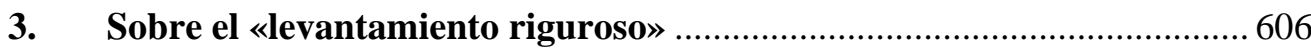

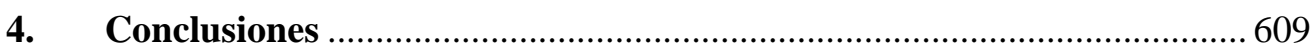

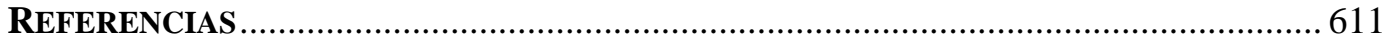




\section{Origen de las imágenes y abreviaturas}

Las imágenes -esquemas, dibujos y fotografías- recogidas en este documento son propiedad de la autora, salvo en aquellos casos en los que se indica expresamente lo contrario.

Se indica el origen de aquellas figuras tomadas de otros autores, empleando el sistema autor-año siempre que ha sido posible. Se indica también la fuente de la imagen digital, en aquellos casos en los que la digitalización no ha sido realizada por la autora.

- BibETSAM - Biblioteca de la Universidad Politécnica de Madrid: http://biblioteca.aq.upm.es/

- BNE - Biblioteca Nacional de España - Biblioteca Digital Hispánica: http://www.bne.es/es/Catalogos/BibliotecaDigitalHispanica/Inicio/index.html

- BnF - Bibliothèque nationale de France: http://www.bnf.fr/fr/acc/x.accueil.html

- CESR - Centre d'Études Supérieures de la Renaissance de la Université de Tours Architectura: architecture, textes et images XVIe-XVIIe siècles (bajo la dirección de Frédérique Lemerle et Yves Pauwels): http://architectura.cesr.univ-tours.fr/

- DigiUPM - Colección Digital de la Universidad Politécnica de Madrid: http://cdp.upm.es/R?RN=628582139

- Gallica - Colección Digital de la Bibliothèque nationale de France (BnF): http://gallica.bnf.fr/

- Google Books: https://books.google.es/

- Google Maps: https://www.google.es/maps

- Gotik-Romanik (página web creada por Dr.-Ing. Heinz Theuerkauf, Munich): http://www.gotik-romanik.de/

- Internet Archive: https://archive.org/

- IPCE - Instituto de Patrimonio Cultural de España (Ministerio de Educación, Cultura y Deporte) - Planoteca: http://ipce.mcu.es/documentacion/archivo/fondos.html

- RAE - Real Academia Española de la lengua: ${ }^{1}$ http://www.rae.es/

- SEHC - Sociedad Española de Historia de la Construcción: http://www.sedhc.es/

- Wikipedia.org: https://www.wikipedia.org/ Las imágenes forman parte de: Wikipedia Commons (https://commons.wikimedia.org/)

- Dehio-Bezold Wikipedia.org: Algunas de las plantas utilizadas se han tomado del libro de G. G. DeHIO y G. von Bezold (1884-1898) digitalizadas por Wikipedia en: https://commons.wikimedia.org/wiki/Category:Images_from_Die_kirchliche_Baukunst_des_A bendlandes_by_Dehio_and_Bezold

- Wikisource.fr: https://fr.wikisource.org/wiki/Wikisource:Accueil Las imágenes del Carnet de Villard de Honnecourt (c. 1225-1235) y del Dictionnaire raisonné de E.-E. VIOLLET-LE-DUC (1854-1868) se han tomado de Wikisource.

En algunos casos, estas imágenes podrían no estar ya disponibles.

1 En general se ha consultado la 22 edición del Diccionario de la lengua española (2011), consulta que se ha realizado a través de internet: http://lema.rae.es/drae/ 



\section{Introducción}

De la Architectura Recta, no solo en los siglos passados, sino tambien en este nuestro, con acierto y curiosidad han escrito differentes autores, perficionando y adornando, y donde parecio necessario, corrigiendo las Ideas de Palacios, y Templos, que en diez libros Vitruvio Pollion nos dibuxo. He los seguido en mucho, en el Tratado precedente. Entro ahora escribir de la Obliqua, sin tener nadie, a quien pueda siguir, o imitar. En obra muchas cosas he visto bien labradas, y en ellas las Leyes de la Architectura Obliqua bien executadas; he visto tambien en Reales Edificios muchos yerros; porque como no hay ningun libro, que trate de Architectura Obliqua, (...)

(CARAMUEL 1678 [1984], Tomo 2, Tratado VI:1) 



\subsection{Las bóvedas no canónicas: una definición provisional}

Definitions are a time-honored way of opening any book (SHODEK y BECHTHOLD [1980] 2008, 3).

Al iniciar la investigación el título de la tesis hacía referencia a las bóvedas sobre planta irregular. Sin embargo el término irregular se mostró pronto poco preciso, inadecuado al concepto que queríamos manejar.

¿Cuándo podemos decir que una bóveda cubre una planta irregular? Un polígono regular es aquél 'cuyos lados y ángulos son iguales entre sí', ${ }^{1}$ sin embargo resulta evidente que una bóveda de arista enfrentada, por ejemplo, a una planta pentagonal, por muy regular que ésta sea, en un problema nada regular - 'ajustado y conforme a regla'-. En cambio, las bóvedas sobre planta rectangular, ya sean de crucería, de arista o baídas, son relativamente frecuentes, ¿podemos clasificarlas como irregulares simplemente porque, en sentido estricto, un rectángulo es un polígono irregular?
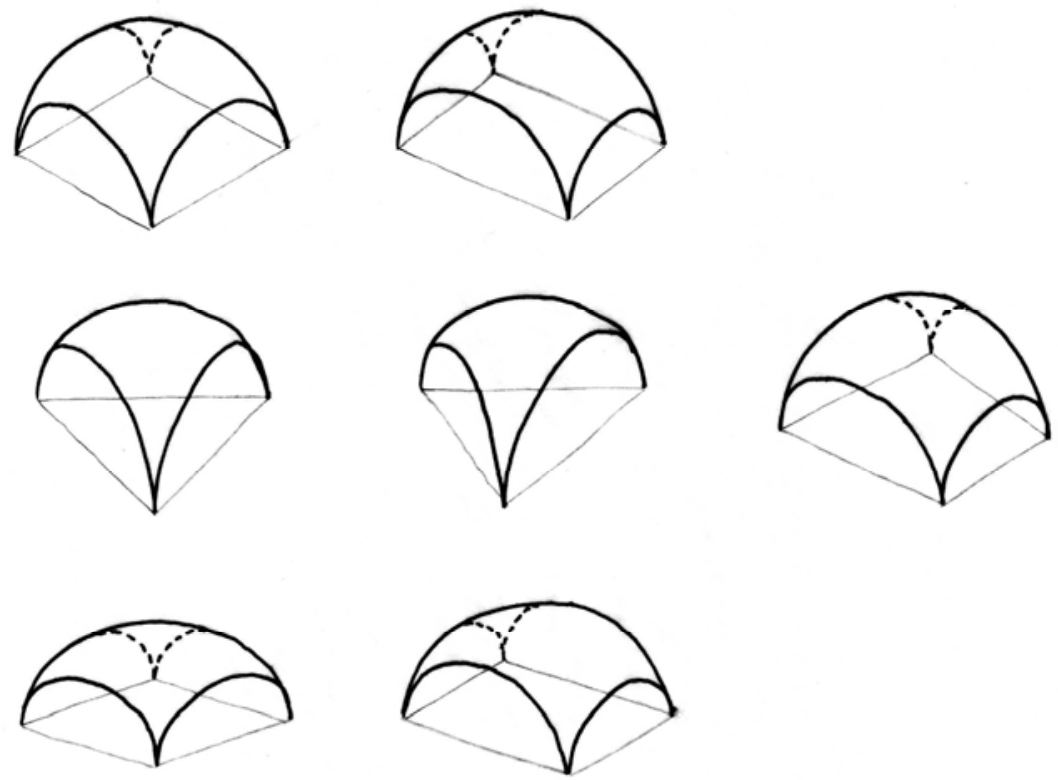

Figura 1.1. Bóvedas baídas en el manuscrito de Vandelvira: cuadrada, perlongada, sobre triángulo igual, sobre triángulo desigual, cuadrado desigual, rombo igual y rombo desigual

Encontramos alguna pista sobre este asunto en el Libro de Traças de Cortes de Piedra de Cantería de Alonso de Vandelvira (1575-1591). En el primer capítulo habla de algunos conceptos y

1 Las definiciones entrecomilladas en este apartado están tomadas de la $22^{\mathrm{a}}$ edición del Diccionario de la Lengua Española de la Real Academia Española (RAE) (http://www.rae.es/). 
construcciones geométricas (figura 1.3) y define las figuras regulares como aquellas que quedan inscritas en una circunferencia:

[regulares] Dicen a las que son contingentes a un círculo que les describe/suscribe dentro o fuera con los ángulos o esquinas de sus lados.

(VANDELVIRA [1575-1591] 1977, 1: 42, fol. 5r).

Irregulares serían, por el contrario, aquellas que no quedan inscritas en una circunferencia:

que no son contenidas o contingentes a un círculo con todos sus ángulos.

(VANDELVIRA [1575-1591] 1977, 1: 42-43, fol. 5r).

De este modo el cuadrado y el rectángulo serían figuras regulares, del mismo modo que todos los tipos de triángulo; un trapecio podría ser regular mientras que el rombo y el romboide nunca serían figuras regulares (figura 1.2).
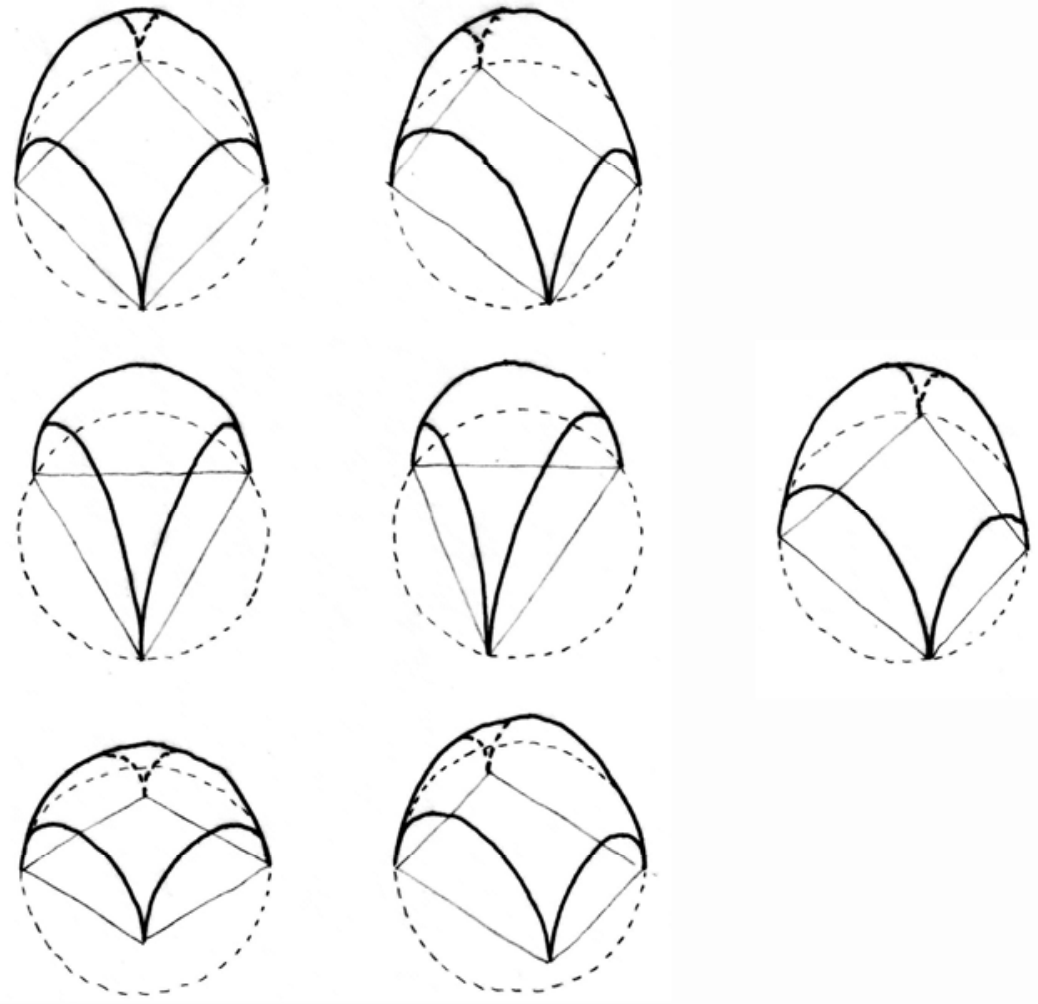

Figura 1.2. Bóvedas sobre figuras regulares e irregulares, según Vandelvira

Para referirse a aquellas figuras cuyos lados no son 'iguales entre sí', Vandelvira habla de una «figura desigual»: 
otras trapieça/trapecios que llamamos cuadrángulo desigual (...).

Trapieça/Trapecio o cuadrángulo desigual, que llamamos los canteros, quiere decir una figura desproporcionada de la orden de las otras porque es figura de cuatro lados y otros tantos ángulos desiguales.

(VANDELVIRA [1575-1591] 1977, 1: 43-44, fol. 5v)

El porqué de este modo de diferenciar entre las figuras en regulares e irregulares, tan distinta de la que empelamos hoy en día, la encontramos en la parte dedicada a bóvedas del tratado.

Dice Vandelvira: «Y así digo que toda capilla regular es cerrada en esfera recta, ya sea redonda ya sea cuadrada, aunque en diferentes cortes» (VANDELVIRA [1575-1591] 1977, 1: 163, fol. 123v), es decir, con una superficie esférica. Si una superficie esférica la cortamos por planos verticales -correspondiendo con los lados de la figura regularobtenemos lo que se tradicionalmente se conoce como bóveda baída, «capilla en vuelta redonda o capilla baída» (VANDELVIRA [15751591] 1977, 1: 127, fol. 81v).

Podemos comprobar cómo Vandelvira, tras una brevísima referencia a la bóveda de arista, erige la parte de su tratado dedicado a bóvedas sobre la bóveda baída, de la que ofrece 16 variantes. ${ }^{2}$ Para Vandelvira, una figura es regular precisamente cuando se puede cubrir con una bóveda baída, requisito que cumplen todas las figuras que quedan inscritas en una circunferencia y que él define como regulares. Por este motivo, en el tratado de Vandelvira encontramos, dentro de las bóvedas regulares, la bóveda cuadrada, con todas sus variantes, la bóveda rectangular, todas las bóvedas triangulares e incluso una curiosa bóveda trapezoidal recogida en el título 100, la «Capilla desigual por hiladas cuadradas» (VANDELVIRA [1575-1591] 1977, 1: 132, fol. 85v) (figura 1.4).

La definición de Vandelvira es extremadamente interesante porque liga los conceptos geométricos a las posibilidades del sistema constructivo con el que trabaja. Regular e irregular dejan de ser dos conceptos geométricos abstractos para convertirse en dos conceptos ligados a la construcción.

2 Si a las capillas cuadradas sumamos la bóveda de crucería, las bóvedas por cruceros, las capillas artesonadas y la «capilla cruzada», que no son sino bóvedas baídas con nervios (BRAVO 2011), el número de bóvedas baídas en el tratado de Alonso de Vandelvira sube a 33; a las que sumaremos las seis bóvedas irregulares al final de tratado (cfr. capítulo 8, apartado 8.1). 


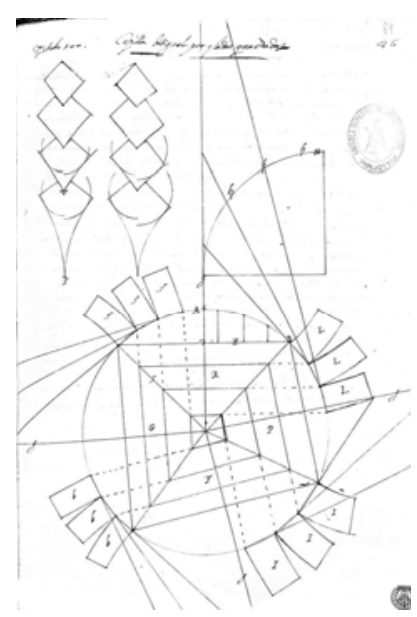

Figura 1.4. Título 100 «Capilla desigual por hiladas rectas»

(VANDELVIRA 1575-1591, fol. 85v)

(fuente: DigiUPM)
Conviene hacer dos puntualizaciones antes de abandonar -sólo de momento- el tratado de Vandelvira. En primer lugar, entre los 141 títulos de su tratado (de los que 68 están dedicados a bóvedas), no aparece ninguna bóveda sobre planta pentagonal. Más allá del cuadrado, el rectángulo y el triángulo, aparecerán los ochavos y las veneras, pero no pentágonos. Sin duda, el problema de una bóveda sobre planta pentagonal, ${ }^{3}$ por muy regular que esta sea según su definición, seguía siendo un problema poco frecuente como para dedicarle un capítulo en exclusiva. ${ }^{4}$

En segundo lugar, Vandelvira hace esta definición de bóveda regular porque está trabajando con bóvedas baídas. No podríamos esperar la misma situación si el sistema constructivo de referencia hubiera sido otro, como por ejemplo la bóveda de arista.

Volviendo al problema de partida, era necesario buscar un concepto que ligara la cuestión geométrica al sistema constructivo empleado, a ser posible a cualquier sistema y no limitado a uno concreto como en el caso de Vandelvira.

Si aceptamos, al menos a nivel teórico, que cada tipo de bóveda está pensada para resolver una determinada planta, éste sería el canon o 'modelo de características perfectas'. Una bóveda canónica sería aquella 'que se ajusta exactamente a las características de un canon', resolviendo el problema para el cual ha sido ideada. En cambio, una bóveda no canónica sería una bóveda que se adapta a una forma diferente a aquella para la que fue inicialmente concebida.

¿Cuáles son las bóvedas canónicas y las bóvedas no canónicas? La respuesta no es general, como intuimos gracias a Vandelvira, ya que depende del tipo de bóveda. Tomando por ejemplo la bóveda de arista, pensada para resolver una planta cuadrada, al construir una bóveda de arista sobre planta rectangular surgen varios problemas de carácter geométrico que deben ser resueltos para poder ejecutarla; una bóveda de arista de planta rectangular es por tanto una bóveda no canónica. Por el contrario, la bóveda de crucería gótica sobre planta rectangular es una forma canónica, ya que la bóveda de crucería gótica

3 Sí aparecerán bóvedas pentagonales en tratados posteriores (cfr. capítulo 5, apartado 5.1).

4 El Título 100, con su «Capilla desigual por hiladas rectas» (VANDELVIRA [1575-1591] 1977, 1: 132, fol. 85v), ejemplificaba cualquier tipo de bóveda sobre figura regular, sin necesidad de entrar en más detalles (figura 1.3). 
vino, precisamente, a resolver el problema de adaptación de la bóveda de arista a la planta rectangular. ${ }^{5}$

\subsection{Estado del arte. La construcción de la bóveda ${ }^{6}$}

By construction I mean the geometrical construction of a particular form of vault ${ }^{7}$

(FRANKL 1962, 43)

Dentro del campo de la Historia de la Construcción las bóvedas históricas son abordadas desde dos perspectivas distintas: su comportamiento mecánico, dentro del ámbito más general de la mecánica de fábricas, y su construcción; este último relacionado con la definición geométrica de su forma y las de las piezas que las construyen. Esta última, tradicionalmente denominada cortes de piedra, cantería o montea, ${ }^{8}$ es lo que se conoce desde finales del siglo XVIII como estereotomía. ${ }^{9}$

El interés por la construcción de bóvedas de piedra se inició en la segunda mitad del siglo pasado con trabajos como los de Fernando Chueca Goitia (1951), Geneviève Barbé-Coquelin DE LISLE (1977), Jean-Marie PÉROUSE DE MonTClos (1982), Antonio BoneT CORREA (1989) y Javier GóMEZ MARTínEZ (1998). Estos trabajos pusieron de manifiesto la importancia de la estereotomía en la historia de la arquitectura francesa y española.

A partir de los años ochenta comenzaron las investigaciones directamente relacionadas con la construcción de la forma de la bóveda y los problemas geométricos que en ella intervienen, con

5 La bóveda de crucería tardogótica sobre planta rectangular plantea, en cambio, nuevos problemas por la multiplicación en el número de nervios y claves, y por el empleo de mecanismos de control de la volumetría (LóPEz Mozo et al. 2015).

$6 \quad$ Se incluyen aquí las referencias a otros autores que han abordado el análisis de alguna bóveda no canónica -aunque no la llamaran así-. No se incluyen las publicaciones de la autora realizadas durante el desarrollo de la tesis y que avanzan algunos de los resultados aquí expuestos.

7 «Por construcción entiendo la construcción geométrica de una forma concreta de bóveda» (FRANKL [1962] 2002, 77).

8 «Trait», «Art du trait» 0 «Coupe des pierres» en francés.

9 Como señala Enrique Rabasa, el término estereotomía es un neologismo griego que se empezó a emplear al querer «mostrar la disciplina como organización autónoma y articulada», una «voluntad de cientifismo que terminará por convertir a la disciplina en especialidad de los profesores de geometría» (RABASA DíAZ 2000, 239). 
estudios generalistas como los de Enrique RABASA DÍAZ en España (2000) y Jöel SAKAROVITCH en Francia (1997); trabajos monográficos sobre tratados, como los de José Carlos Palacios GonZALO del tratado de Vandelvira (1990) y José CALVO LÓPEZ del tratado de Ginés Martínez de Aranda (1999); trabajos monográficos sobre edificios concretos, como los de Ana LÓPEz Mozo sobre las bóvedas de piedra de El Escorial (2009) y Rosa Ana GUERRA PESTONIT sobre el Colegio de Nuestra Señora de la Antigua de Monforte de Lemos (2012); trabajos sobre determinados autores como los de Soraya GeniN sobre João de Castilho (2014) y Carmen Pérez de los Ríos sobre GUILLÉM SAGRERA (2016); trabajos sobre problemas concretos, como los de Rafael MARTín TALAVERANO sobre bóvedas rebajadas (2014), Francisco Pinto PUERTO sobre cúpulas (1998), Alberto SANJURJO ÁLVAREZ sobre escaleras de caracol (2009) y Miguel TAín GUZMÁN sobre monteas en Galicia (2003). ${ }^{10}$

Las bases generales de la disciplina está ya establecidas y las investigaciones que se están llevando a cabo en la actualidad continúan las líneas de investigación antes indicadas, desde dos líneas de trabajo distintas:

- El análisis de arquetipos teóricos recogidos en los tratados, y posterior su comparación con ejemplos construidos.

- El análisis de casos construidos, relacionándolos, en la medida de lo posible, con los modelos recogidos en los tratados.

En algunos de estos estudios encontramos ya problemas asociados a bóvedas irregulares, resueltas de una manera distinta a la inicialmente esperada. Sin embargo, el estudio de estas bóvedas es tratado de manera individual, como excepciones o casos aislados, no habiendo sido abordado de manera sistemática un estudio de las bóvedas irregulares. Cuando la bóveda construida se aparta del modelo y no responde a las reglas inicialmente previstas es tratada como un caso aislado, fruto de una adaptación particular a unas condiciones de contorno diferentes de las reflejadas en la teoría.

10 En este apartado se citan tan sólo las obras más representativas de cada uno de los autores. Para una relación más completa puede consultarse en la bibliografía las obras de los autores aquí citados. 
La cuestión de la girola

Como señalábamos en el prefacio, el problema de la girola fue abordado por Eugène-Emmanuel Viollet-le-Duc en su Dictionnaire raisonné de l'architecture française du XIe au XVIe siècle en los capítulos «Construction. Voûtes» $\mathrm{y}$ «Voûte», donde realiza una breve revisión histórica de la evolución del abovedamiento de las girolas francesas entre los siglos XI y XII (figura 1.5). El desarrollo de este tipo de espacios le sirve como hilo conductor para explicar la evolución desde la bóveda de arista románica hasta la bóveda de crucería gótica. ${ }^{11}$ Viollet-le-Duc no afirma que el problema de la girola fuera el que motivara la aparición de la bóveda de crucería, pero sí defiende que la capacidad de adaptación de la bóveda de crucería gótica a cualquier espacio en planta fue uno de los factores que contribuyó a su éxito (figura 1.6).

El análisis de Viollet-le-Duc no supone un estudio sistemático de todas las girolas construidas, ni siquiera las francesas, sino que se basa en una selección de ejemplos significativos construidos entre los siglos XI y XII que le sirven para mostrar la evolución desde la bóveda anular con penetraciones románica hasta la bóveda de crucería gótica del siglo XII. Viollet-le-Duc dibuja dos historias paralelas, una en el artículo «Construction. Voûtes» ${ }^{12}$ y otra en el artículo «Voûte», ${ }^{13}$ siguiendo un orden presuntamente cronológico. Sin embargo no debemos caer en la trampa de creer que este un orden cronológico es el real. Las historias que dibuja Viollet-le-Duc muestran una evolución del sistema de abovedamiento, ejemplificado en una serie de edificios; independientemente de los problemas para datar algunas de estas obras, los ejemplos están tan próximos en el tiempo que las

11 Como ya es sabido (Abraham [1933] 1934, 101), buena parte de las teorías expuestas por Eugène-Emmanuel Viollet-le-Duc en el Dictionnaire ya habían sido desarrolladas previamente en una serie de artículos publicados en la revista Annales archéologiques entre $1844 \mathrm{y}$ 1847 (VIOLLET-LE-DUC 1844-1847). Sin embargo, en estos artículos no se aborda el problema de la girola.

12 Clermont Ferrand (Basilique Notre-Dame-du-Port), Saint-Nectaire (Église de Saint-Nectaire), Issoire (Abbatiale Saint-Austremoine), SaintSavin-sur-Gartempe (Abbaye de Saint-Savin), Langres (Cathédrale Saint-Mammès), Reims (Basilique Saint-Rémi), Châlons-enChampagne (antes Châlons-sur-Marne; Collégiale Nôtre-Dame-enVaux), París (Cathédrale Notre-Dame), Saint-Leu-d'Esserent (Église prieurale Saint-Nicolas) (VIOLLET-LE-DUC 1854-1868, 4:67-84).

13 Clermont Ferrand (Basilique Notre-Dame-du-Port), Poissy (Collégiale Notre-Dame), Brioude (Basilique Saint-Julien), Saint-Denis (Basilique de Saint-Denis), París (Cathédrale Notre-Dame), Senlis (Cathédrale Notre-Dame) (VIOLLET-LE-DuC 1854-1868, 9:489-517).
DICTIONNAIRE RAISONNE

L'ARCHITECTURE

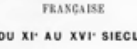

VIOLLET-LE-DUC

E. VIOLLET-LE-
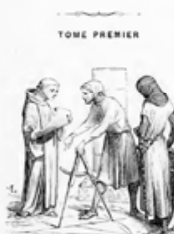

PA. MOREL If C

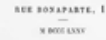

Figura 1.5. Portada del Dictionnaire Raisonné

(VIOLLET-LE-DuC 18441847

(http://wikisource.fr)

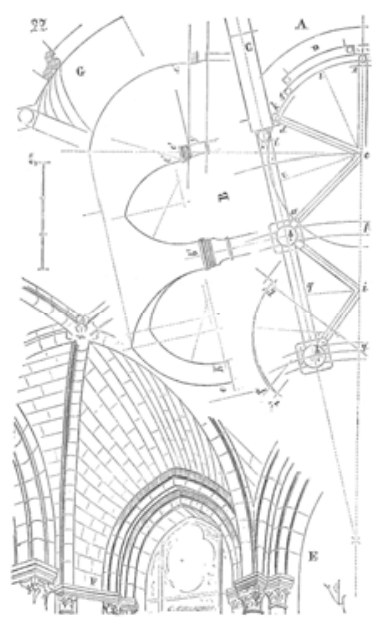

Figura 1.6. Análisis de la bóveda de la girola de la abadía de Saint-Denis (Francia) según E.-E. VIOLLET-LE-DUC (18441847, 9:504)

(http://wikisource.fr) 


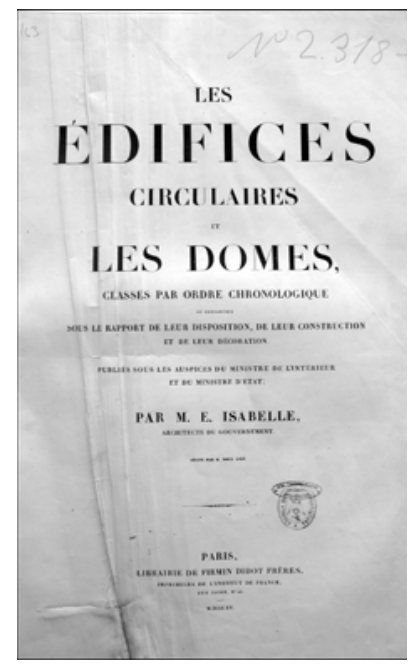

Figura 1.7. C.-E. Isabelle (1855) (BibETSAM)

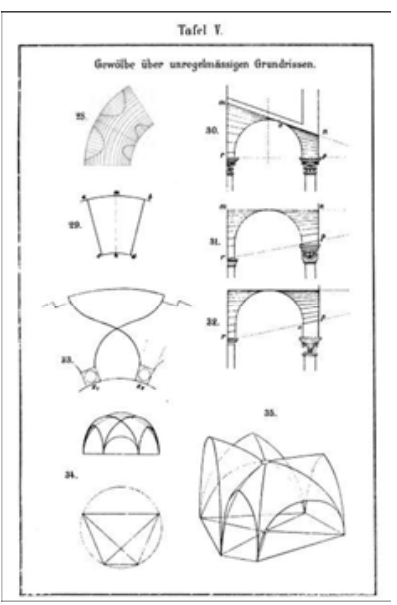

Figura 1.8. Lámina 5 del libro de UngewitterMohrman (1890, Tafel V) (http://archive.org)

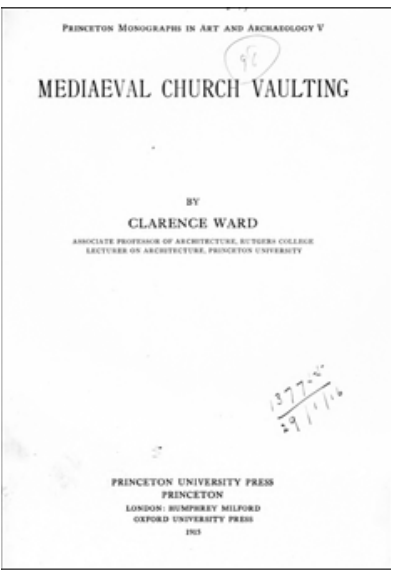

Figura 1.9. C. Ward (1915) (http://archive.org) innovaciones incorporadas en una obra de una gran ciudad no tienen porqué haber llegado a un pueblo de provincias.

Estos artículos destacan porque en ellos no sólo se estudian los aspectos relacionados con la construcción general de la bóveda, sino también aspectos de detalle, en particular el diseño de los apoyos, y la interacción de las bóvedas con el resto de elementos de edificio, como galerías superiores, capillas radiales y contrafuertes. Viollet-le-Duc es consciente de que la modificación de cualquiera de los elementos del edificio afecta al resto.

El problema del abovedamiento del deambulatorio no es exclusivo de las girolas, también lo encontramos en edificios de planta central con estructura en doble casco. Un curioso libro de mediados del siglo XIX titulado Les édifices circulaires et les dômes (figura 1.7) dibuja una colección de edificios de planta central, algunos de ellos rodeados de galerías y constituye la primera aproximación sistemática a este tipo de edificios (ISABELLE 1855). ${ }^{14}$

Aunque en el Lehrbuch der Gotischen Konstruktionen G. Ungewitter habla específicamente de las bóvedas sobre planta trapecial de las girolas (UNGEWITTER [1859] 1890, 15-18) (figura 1.8), ${ }^{15}$ es Auguste Choisy el primero en dedicarle un apartado a las «Voûtes des galeries tournantes» dentro de su Histoire de l'Architecture (CHOISY 1899, 2:289-292). Por su parte, Arthur Kingsley Porter también trata el problema de la «rib vault on a curved plan» en su Medieval Architecture. Its Origins and Development, a partir del ejemplo de la iglesia de Morienval (PORTER 1909, 2:69-75).

Clarence Ward es el primero en dedicarle un capítulo completo al problema de las «ambulatory vaults» en su Mediaeval Church Vaulting (figura 1.9), donde realiza un completo recorrido por las bóvedas de las girolas, desde los primeros ejemplos romanos hasta ejemplos tardogóticos alemanes del siglo XV (WARD 1915, 158-184) (figura 1.10).

14 Existen otros trabajos que abordan el problema de los edificios de planta central, como el de Eduardo Carazo (1994) sobre arquitecturas centralizadas en Castilla y León. Sin embargo estos trabajos se suelen centrar en el problema de la planta central, sin que exista un estudio sistemático del problema de los edificios de planta central con estructura en doble casco, al margen de los numerosos ejemplos reflejados en el libro de Richard Krautheimer sobre arquitectura paleocristiana y bizantina (KRAUTHEIMER [1965] 2011).

15 Según Paul Frankl los comentarios sobre los problemas de las aristas de intersección se deben a Mohrman (FRANKL [1960] 1961: 538). 

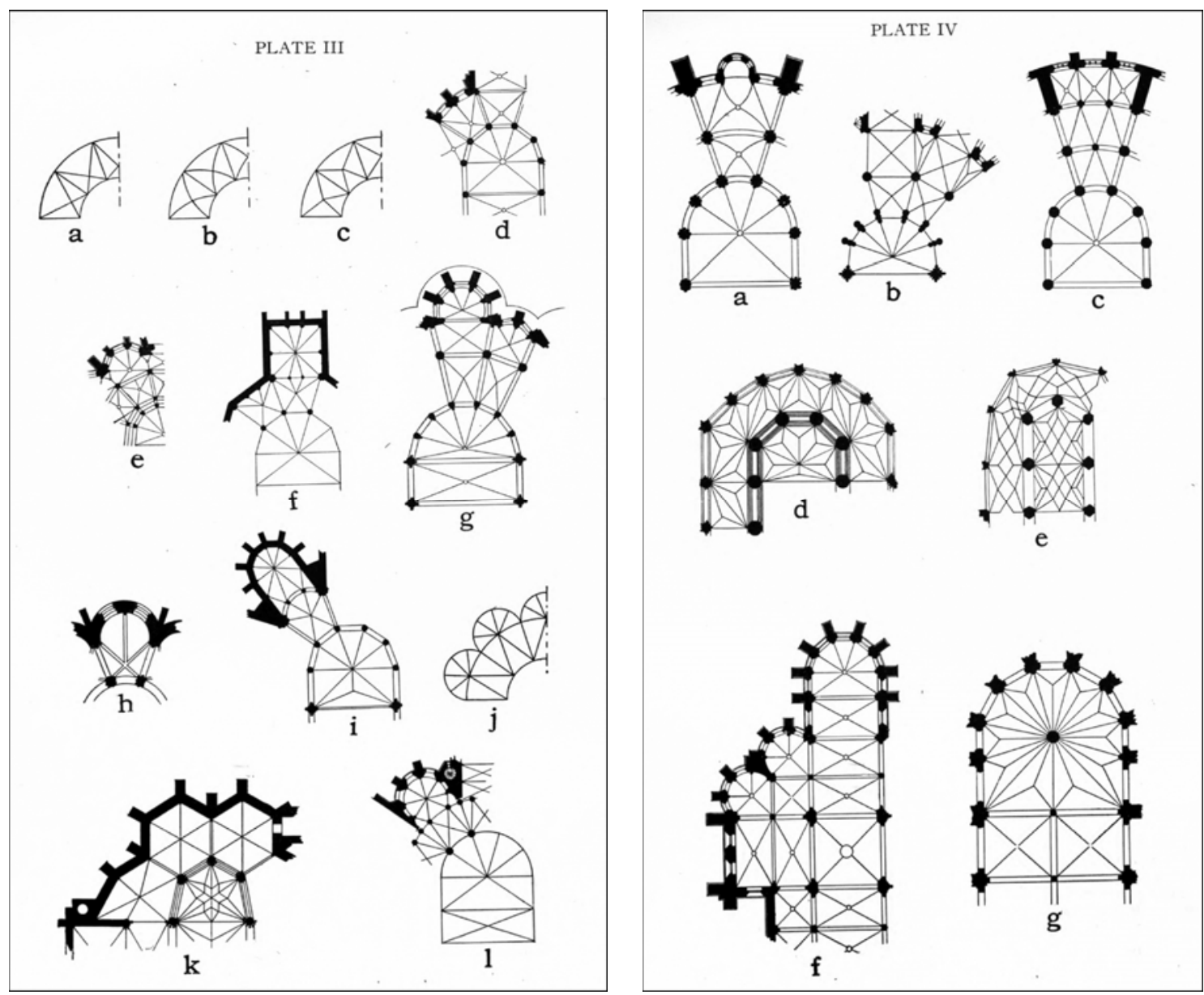

Figura 1.10. Láminas de Clarence Ward dedicadas a las «ambulatory vaults» (WARD 1915, 167 y 179) (http:// archive.org)

Estas referencias, las más reciente de hace un siglo, constituyen los únicos trabajos que analizan el problema del abovedamiento de la girola de manera global, a través del estudio y la comparación de una serie de casos más o menos numeroso.

Suele ser frecuente la referencia al problema de la bóveda del deambulatorio al hablar de la girola de la Catedral de Toledo. En Toledo el maestro evita construir bóvedas de planta trapecial subdividiendo el espacio en tramos cuadrados y triangulares, tal y como explican G. E. Street en su libro de 1865 (STREET [1926] 2015, 264). Resulta cuanto menos paradójico que los incisos sobre bóvedas de planta trapecial que encontramos sean, precisamente, al hablar de un ejemplo donde se evita usar bóvedas de planta trapecial.

Otros autores posteriores harán breves referencias al problema de la bóveda del deambulatorio, sin que en ningún caso podamos hablar de un estudio sistemático de las mismas. Podemos destacar el libro de Henri J. W. Thunnissen sobre bóvedas donde aborda 


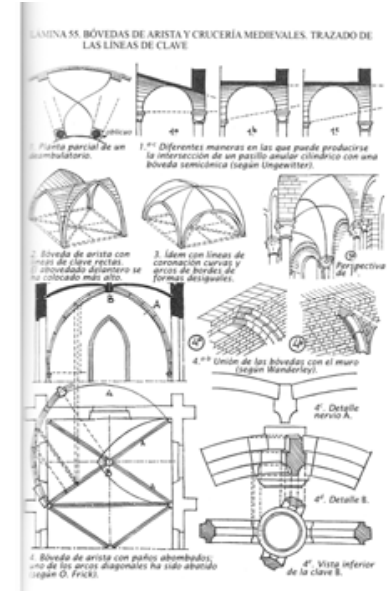

Figura 1.11. Lámina 55 del libro de Thunnissen ([1950] 2012, 167)

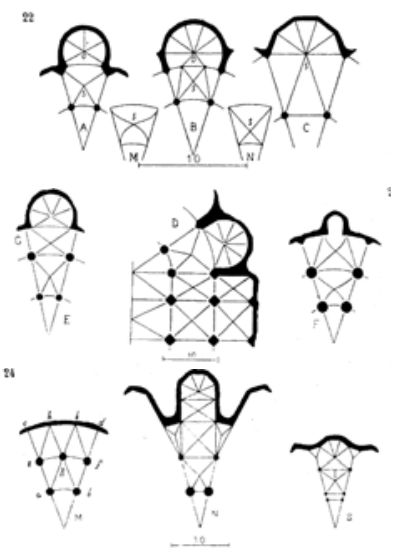

Figura 1.12. Dibujos de bóvedas en girolas según $\mathrm{A}$. Choisy (1989, 2:290, 291 y 292)

(www.augustechoisy2009.net)

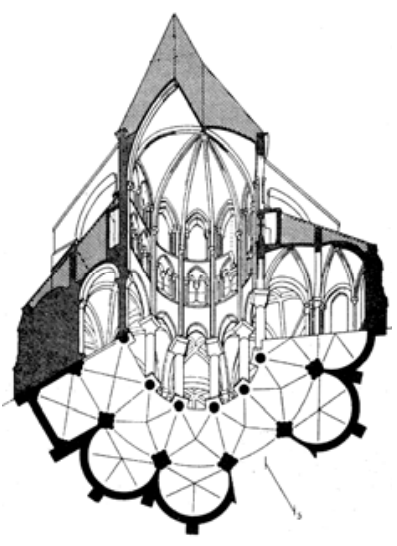

Figura 1.13. Girola de Saint-Germain des Près según A. Choisy (1989, 2:474)

(www.augustechoisy2009.net) específicamente el problema de las bóvedas de los deambulatorios (THUNNISSEN [1950] 2012, 178-182) pero centrándose en los problemas teóricos de la intersección (figura 1.10), que relaciona con la bóveda de arista de planta anular y el conoide de Wallis (cfr. capítulo 9, apartado 9.2). Aunque dibuja varios ejemplos, tanto de edificios de planta central con estructura en doble casco (THUNNISSEN [1950] 2012, 91, 93 y 116) como de girolas (THUNNISSEN [1950] 2012, 166 y 177), no los desarrolla ni plantea un análisis sistemático.

En general, los ejemplos estudiados se refieren únicamente a bóvedas de crucería, con alguna mención a bóvedas románicas anteriores. En ningún caso se estudian las alternativas de deambulatorio planteadas por la arquitectura renacentista y clasicista. El único texto donde se analiza brevemente el problema del abovedamiento de la girola, con ejemplos no sólo góticos, es el libro de Earl E. Rosenthal sobre la Catedral de Granada (España) (ROSENTHAL 1961).

El problema de adaptación de la bóveda a la planta trapecial de los tramos de un deambulatorio exige no sólo la deformación de la planta sino también de la sección. Dicho de otro modo, una vez se ha deformado la planta, la volumetría no es inmediata, sino que exige una toma de decisiones. Curiosamente, de todos los autores anteriores tan sólo Viollet-le-Duc (figura 1.6), Ungewitter-Mohrman (figura 1.8) y Thunnissen (figura 1.11) incluyen dibujos de la volumetría de la bóveda. Choisy (figura 1.12) y Ward (figura 1.10) se limitan a dibujos en planta, ${ }^{16}$ aunque este último incluye fotografías que ilustran el problema. Por su parte Porter, además del dibujo en planta y las fotografías, completa la explicación con un alzado esquemático de la bóveda de la girola de Morienval (Francia).

Encontramos algunos trabajos recientes que analizan bóvedas concretas en deambulatorios o espacios de planta anular. Concretamente los de Jos TomLOW (1989 y 1999) sobre las bóvedas del Castillo de Bellver en Palma de Mallorca (España) y el de José Calvo López, Miguel Ángel Alonso Rodríguez, Enrique Rabasa Díaz y Ana López Mozo sobre las bóvedas de la girola de la Catedral de Murcia (España) (CALVo LóPEZ et al. 2005). Completa este panorama un reciente trabajo de Isabel Antolín Cano sobre las bóvedas dieciochescas de la Catedral de Cadiz (España), de planta cuadrada (ANTOLÍn CANO 2013), y el de Soraya Genin sobre la bóveda del

16 Choisy dibuja, con su característica perspectiva caballera de planta vista desde abajo, algunos deambulatorios en apartados posteriores (CHOISY 1899, 2:228, 230, 449, 474 y 476) (figura 1.13). 
deambulatorio del Monasterio de Santa Maria da Vitória en Batalha (Portugal) (GENIN 2014 298-302). ${ }^{17}$

\section{La adaptabilidad de la bóveda de crucería}

Uno de los primeros hechos que se pone de relevancia al estudiar la bóveda de crucería es su flexibilidad para adaptarse a plantas irregulares. Casi todos los autores clásicos (s. XIX - prin. s. XX) señalaron esta capacidad de adaptación como una de las ventajas de dicho sistema constructivo.

Sin embargo, aunque el número de bóvedas de crucería irregulares es notable, no encontramos muchos estudios sobre bóvedas irregulares de crucería: ${ }^{18}$

Entre los trabajos sobre bóvedas de crucería de planta irregular hay que señalar el informe realizado por Santiago Huerta Fernández y Ana López Mozo sobre el cimborrio de la iglesia de San Juan de los Reyes en Toledo (HuERTA y LóPEz 2005), el Informe de Santiago Huerta Fernández sobre la bóveda de antigua la cocina del Castillo de Bellver en Palma de Mallorca (HuERTA 2008), la comunicación de Rafael Martín Talaverano sobre las bóvedas rebajadas de la iglesia de Santa Ana en Annaberg-Buchholz (MARTín 2011), los trabajos de Paula Fuentes González sobre las bóvedas de arcos cruzados de los cimborrios de las Catedrales de Zaragoza y Teruel (FuENTES 2013), la comunicación de David Wendland, María Aranda Alonso y Alexander Kobe sobre una bóveda en el Albrechsburg en Meissen (WENDLAND et al. 2014) y Soraya Genin sobre la bóveda del acceso a la sacristía en el Monasterio de Alcobaça (GENIN 2014, 293-297) (figura 1.14). ${ }^{19}$

17 No se trata de una girola al uso, sino una girola rectificada (cfr. capítulo 4, apartado 4.2). La bóveda realiza la transición entre el ábside semicircular y el perímetro de trazado ortogonal, permitiendo el acceso a las Capellas Imperfeitas, de planta centralizada. Al margen del análisis de la bóveda, todo el conjunto merece ser analizado desde la perspectiva de la deformación en arquitectura abovedada (cfr. capítulo 3, apartado 3.3 y capítulo 4, apartado 4.4).

18 Toda bóveda construida presenta irregularidades; nos referimos a aquellos casos en los que la deformación de la planta se convierte en un factor de diseño (cfr. capítulo1, apartado 1.6).

19 Tal y como ya señaló Viollet-le-Duc, la bóveda que cubre un ábside semicircular plantea algunos problemas por su asimetría transversal (VIOLLET-LE-DuC [1854-1868] 1996, 94-96), por lo que también deberíamos incluirlas dentro del grupo de las no canónicas. Soraya Genin ha estudiado algunas en su Tesis Doctoral (GENIN 2014, 221-224, 227-230). 
Merece especial atención el artículo de Miguel Ángel Alonso y José Calvo sobre una clave de bóveda de la iglesia de Santa Catalina de Valencia (ALONSO y CALVO 2007). En este trabajo se reconstruye la planta y la volumetría de una bóveda romboidal desaparecida a partir del análisis pormenorizado de una única clave encontrada, poniéndolo en relación con la bóveda de crucería sobre rombo igual al final del manuscrito de Vandelvira (cfr. capítulo 8, apartado 8.1).

Como se explicará más adelante (cfr. capítulo 5, apartado 5.2), la irregularidad del perímetro no constituye el único caso de bóveda de crucería no canónica. Una bóveda de crucería con nervios asimétricos como la del claustro de la catedral de Segovia (PALACIOS 2009 y PALACIOS 2010) (cfr. capítulo 7, apartado 7.1) o una irregularidad en la disposición de los apoyos también conduce a soluciones anómalas. Las bóvedas con apoyos asimétricos se hicieron relativamente frecuentes en el tardogótico centroeuropeo, pero tan sólo encontramos una referencia en el libro de Danuta Hanulanka (1971). ${ }^{20}$

\section{Las capillas cuadradas: bóvedas baída y de arista}

Más adelante se justificará esta afirmación (cfr. capítulo 5, apartado 5.3 y 5.4) pero, de momento y aunque parezca una simplificación rotunda que entraría en contradicción con lo dicho al comienzo de esta tesis, vamos a considerar que las bóvedas baída y de arista canónicas son las de planta cuadrada -las capillas cuadradas de las que habla Vandelvira-; el resto de bóvedas, incluidas las rectangulares, forman parte del grupo de las bóvedas no canónicas.

La baída es otro tipo de bóveda que goza de cierto prestigio por de su adaptabilidad a espacios de planta distinta a la cuadrada, tal y como ha señalado Ana López Mozo (LóPEz Mozo 2009,140; LóPEZ Mozo et al. 2011, 744); si bien el número de ejemplos de este tipo de bóvedas no es tan amplio como en el caso de bóvedas de crucería. Los trabajos sobre bóvedas baídas construidas de planta no cuadrada han sido realizados por Ana López Mozo sobre la bóveda rectangular de la cocina de El Escorial (LÓPEZ Mozo 2009, 343-350), Miguel Ángel Alonso y José Calvo sobre las bóvedas rectangulares de la iglesia de Navamorcuende en Toledo (ALONSO y CALVo 2011), Ana María Bravo Bernal sobre la bóveda rectangular de El Sagrario de la Catedral de Sevilla (BRAvo Bernal 2011), Pau Natividad Vivó y

20 El texto está en polaco, por lo que sólo podemos hacer una referencia genérica a su contenido. 
José Calvo López sobre una bóveda en el campanario de la iglesia del Salvador de Caravaca de la Cruz (NATIVIDAD Vivó y CALVo LóPEZ 2011), Pau Natividad Vivó y Ricardo García Baño sobre la bóveda pentagonal de la sacristía de la Colegiata de Huéscar (NATIVIDAD VIVÓ y GARCÍA BAÑO 2013).

Desde el punto de vista teórico, el problema de la bóveda baída de planta rectangular en el manuscrito de Vandelvira ha sido estudiado por José Carlos Palacios GonZalo (1990, 260-263 y 268-271) y Pau NATIVIDAD ViVÓ (2012). ${ }^{21}$

Un caso particular de bóveda baída lo constituyen las bóvedas por cruceros (figura 1.15). Los trabajos sobre bóvedas por cruceros de planta distinta a la cuadrada has sido realizados por Sandra Cynthia Bravo Guerrero sobre los distintos tipos de bóvedas por cruceros (BRAVO GUERRERO 2011) y sobre las bóvedas rectangulares de la Catedral de San Ildefonso en Mérida, Yucatán (Bravo Guerreo 2013). También hay que señalar el trabajo de Pau Natividad Vivó y José Calvo López sobre la bóveda de planta rectangular por cruceros de El Salvador de Caravaca (NATIVIDAD VIVÓ y CALVo LóPEZ 2012).

A medio camino entre la bóveda de crucería y la bóveda de arista, hay que señalar el trabajo de Pau Natividad Vivó y José Calvo López sobre la bóveda aristada esviada de las Torres de Quart en Valencia (NATIVIDAD y CALVO 2010).

En el campo de las bóvedas de arista, la bóveda del ayuntamiento de Arles constituye no sólo un «chef-d'œuvre» de la estereotomía francesa (PÉROSUSE 1983), sino un ejemplo de bóveda de arista de planta irregular resuelta de manera original (TAMBORERO y SAKAROVITCH 2003; TAMBORERO 2009).

También destaca los trabajos de Santiago Huerta y Enrique Rabasa sobre las bóvedas de arista rectangulares del claustro de Sant Bonaventura de Llucmajor (HUERTA FERNÁNDEZ y RABASA DÍAZ 2006), de José Calvo López sobre las bóvedas de arista rectangulares peraltadas del Hospital de Marina en Cartagena (CALVO LÓPEZ 2007, 171-173), de Rosa Ana Guerra Pestonit sobre las bóvedas rectangulares del claustro del Colegio de Monforte de Lemos (GuerRA 2012, 305-344) y de Pau Natividad Vivó, José Calvo López y Gaspar Muñoz Cosme sobre las bóvedas esviadas de las Torres de

21 José Carlos Palacios también ha analizado algunas de las bóvedas baídas de planta triangular en el manuscrito de Vandelvira (PALACIOS GONZALO 1990 272-277). 
Quart en Valencia (NATIVIDAD VIVÓ y CALVO LÓPEZ 2010; NATIVIDAD VIVÓ 2011; NATIVIDAD VIVÓ et al. 2012);

Más recientes son las bóvedas de arista de planta irregular del ayuntamiento de Brooklyn, estudiadas por Benjamín IBARRA SEVILLA (2015).

\subsection{Objetivos}

In ogni secolo, filosofi e artisti hanno fornito definizioni del bello; grazie alle loro testimonianze è così possibile ricostruire una storia delle idee estetiche attraverso i tempi.

Diversamente è accaduto col brutto. Il più delle volte si è definito il brutto in opposizione al bello ma a esso non sono state quasi mai dedicate trattazioni distese, bensì accenni parentetici e marginali

(ECO 2007, incipit)

Esta investigación surge de una pregunta: ¿qué sucede cuando una bóveda se adapta a una planta distinta de aquella para la que ha sido concebida? O, dicho de otro modo, ¿qué sucede en arquitectura abovedada cuando el perímetro se deforma?

Inicialmente esta pregunta se planteó para el abovedamiento de los deambulatorios, como caso particular de adaptación a unas condiciones de contorno distintas de las inicialmente previstas. El propósito de la investigación era analizar las bóvedas sobre deambulatorios, estudiando qué problemas esboza el abovedamiento de estos espacios y las distintas maneras de resolverlo en función del sistema constructivo elegido. Al tratarse de un espacio arquitectónico presente a lo largo de toda la historia de la arquitectura, que ha experimentado un proceso continuo de prueba y error, su análisis permitiría comparar las distintas soluciones a un mismo problema dadas a lo largo de la historia.

Sin embargo el problema del abovedamiento de los deambulatorios sólo puede ser entendido como parte de un argumento mayor: el de las bóvedas deformadas. Para poder entender cómo una bóveda se deforma para adaptarse a la forma trapecial de los tramos de un deambulatorio, previamente es necesario haber entendido la manera en que la bóveda se deforma para adecuarse a otros perímetros más sencillos.

La teoría general sobre construcción geométrica de la forma de la bóveda sobre el caso de las formas canónicas, no deformadas, ya se ha llevado a cabo. Cuando la bóveda construida se aparta del modelo y no responde a las reglas inicialmente previstas es tratada como un 
caso aislado, fruto de una adaptación particular a unas condiciones de contorno diferentes de las reflejadas en la teoría; la bóveda deformada es tratada como una excepción. ${ }^{22}$ :

El objetivo de esta tesis es ir un paso más allá en el análisis de esas bóvedas anormales, buscando las reglas comunes que subyacen en la adaptación a unas condiciones de contorno distintas de las inicialmente esperadas; y hasta qué punto los principios establecidos en los modelos teóricos siguen siendo válidos.

En 2004 Umberto Eco publicó su Storia della belleza, tres años más tarde publicó su contrapunto, la Storia della bruttezza. Imitando la idea de Umberto Eco, el objetivo de esta tesis es sentar las bases para una historia de la fealdad de bóvedas.

\subsection{Hipótesis de partida}

I like complexity and contradiction in architecture ${ }^{23}$ (VENTURI [1966] 2002, 16)

El interés por el estudio de las formas deformadas en arquitectura no se debe a esa preferencia que Venturi pregonaba por la «arquitectura equivocada» (VENTURI [1966] 1995, 25), sino al hecho de haber constatado que algunas de las conclusiones a las que se ha llegado en el estudio de las bóvedas históricas se debe a que dichos estudios se han realizado casi exclusivamente sobre formas canónicas, no deformadas. Esta aproximación se ha mostrado insuficiente a la hora de analizar muchos ejemplos construidos.

Partimos de la hipótesis de que el estudio de las formas deformadas puede aportar información complementaria a lo que ya sabemos sobre construcción de bóvedas históricas, llegando a poner en cuestión algunas de las afirmaciones que actualmente se dan por ciertas.

En el caso de las bóvedas canónicas es habitual encontrar que es posible llegar al mismo resultado por diferentes caminos; ante una solución construida es difícil discernir el camino efectivamente seguido y esto puede dar lugar a equivocaciones. Sin embargo, cuando

22 Si bien la excepción resulta ser más frecuente de lo inicialmente esperado, ya que las bóvedas construidas responden a unas condiciones específicas que exigen, en la mayoría de los casos, una adaptación de la teoría.

23 «Me gusta la complejidad y la contradicción en arquitectura» (VENTURI [1966] 1995, 25). 
la bóveda se aparta del canon las decisiones tomadas se ponen de manifiesto ya que un camino distinto implica un resultado distinto.

Las virtudes y los defectos de un sistema constructivo se ponen de manifiesto cuando se ven obligados a enfrentarse a un problema distinto de aquel para el que fueron concebidos; los elementos esenciales se mantienen, pero se desechan los accesorios. En aquellos casos en los que la bóveda se aparta del canon y se ve obligada a deformar su planta, es cuando aparecen en juego estrategias distintas de las inicialmente esperadas.

Tal y como sugiere Viollet-le-Duc, dicha adaptación puede implicar la evolución hacia un sistema constructivo distinto:

Malgré les difficultés que soulevait la construction des voûtes d'un collatéral pourtournant un sanctuaire reposant sur des colonnes, en partant de la donnée romaine ou byzantine, il est à croire que l'on tenait fort à cette disposition du plan, car les architectes occidentaux ne cessèrent de chercher la solution de ce problème depuis le commencement du XIIe siècle jusqu'à ce qu'ils l'aient résolu d'une manière complète à la fin de ce siècle. Il faut reconnaître même que cette longue suite d'essais ne contribua pas médiocrement à développer le système d'où procède la voûte d'arête du XIIIe siècle; système excellent, puisqu'il permet toutes les combinaisons imaginables en n’employant toujours qu'un même procédé.

(VIOLLET-LE-DUC 1854-1868, 9:489)

La investigación sobre las bóvedas anómalas puede aportar información adicional sobre el origen y la evolución de determinados sistemas constructivos.

Además, el estudio de las bóvedas no convencionales puede aportar información complementaria que aclare algunas cuestiones todavía no resueltas, quizá porque sólo se ha estudiado en bóvedas canónicas. 


\subsection{Estructura de la tesis y propuesta metodológica}

L'uscita è una sola, ma puoi sbagliare. Hai bisogno di un filo d'Arianna per non perderti (ECO [1983] 2000, 525)

Estructura de la tesis

La tesis se estructura en dos partes: en la primera parte se analizan los conceptos de forma y deformación en el contexto de la arquitectura abovedada con objeto de sentar las bases para una teoría de las bóvedas no canónicas. En la segunda parte se analizan tres tipos de bóveda desde la perspectiva de las bóvedas no canónicas: la bóveda de arista, la bóveda de crucería y la bóveda baída, a partir de un estudio de casos de bóvedas en España entre los siglos XVI y XVIII.

Si bien se consideró esta estructura como la más adecuada para la tesis, yendo de lo general a lo particular, la investigación no siguió este orden lineal, ya que el estudio de casos es el que ha permitido sentar las bases para una teoría de las bóvedas no canónicas.

Tras un primer capítulo con la introducción, la primera parte de la tesis, «Forma y deformación en arquitectura abovedada» se divide en cuatro capítulos -numerados de 2 al 5-. En primer lugar -capítulo 2- se recogen una serie de ideas que han orientado esta investigación. A continuación -capítulo 3- se analiza el concepto de deformación en arquitectura abovedada tomando como punto de partida el sistema propuesto por Borie, Micheloni y Pinon ([1978] 1984) y tomando en consideración las peculiaridades del objeto de estudio. Se proponen dos niveles de análisis de la deformación en arquitectura abovedada: análisis a nivel de conjunto y análisis a nivel de bóveda. El primer nivel de análisis, basado en el sistema propuesto por Borie, Micheloni y Pinon, se desarrolla en el capítulo 4, donde se lleva a cabo una aproximación a la deformación en arquitectura abovedada desde el conjunto del edificio a partir de un análisis en planta.

El segundo nivel de análisis se desarrolla en el capítulo 5, donde se realiza una primera aproximación al problema de la deformación de la bóveda, centrado ya en tres tipos constructivos: la bóveda de crucería, la bóveda baída y la bóveda de arista. Esta aproximación se realiza desde un primer análisis de la planta y en una reflexión sobre los problemas derivados de la sección.

En la segunda parte de la tesis «Bóvedas no canónicas en España, siglos XVI al XVIII», se analizan los problemas asociados a la construcción de la sección en un estudio de casos de los tres tipos antes señalados y para una serie de problemas concretos. 
De nuevo esta segunda parte se divide en cuatro capítulos numerados del 6 al 9-. En el primero -capítulo 6- se exponen las circunstancias comunes de los tres problemas a analizar: la planta rectangular, la planta esviada y la planta trapecial. A continuación se analizan estos tres problemas para cada tipo de bóveda: bóveda de crucería -capítulo 7-, bóveda baída -capítulo 8- y bóveda de arista capítulo 9-.

Podría decirse que la primera parte de la tesis pretende responder, o iniciar la respuesta, a las preguntas:

- ¿ ¿Qué? / ¿Qué caracteriza las bóvedas no canónicas?

- ¿ ¿Por qué? / ¿Por qué se construyen bóvedas no canónicas?

- ¿Dónde? y ¿Cuándo? / ¿Dónde y cuándo encontramos bóvedas no canónicas?

Mientras que la segunda parte se centra en el ¿Cómo? -¿Cómo se resuelven las bóvedas no canónicas?-, aplicado a tres tipos concretos de bóvedas.

El último capítulo de la tesis -capítulo 10- recoge las conclusiones de ambas partes y propone futuras líneas de investigación derivadas del trabajo desarrollado. El capítulo concluye con una reflexión sobre el uso de los conceptos de forma y geometría, inevitablemente ligados al análisis de bóvedas históricas

\section{Las capillas cuadradas como objeto de estudio}

Tomando como punto de partida el problema del deambulatorio, y ante la evidente necesidad de acotar el objeto de estudio, esta investigación se ha centrado en tres tipos de bóveda: la bóveda de arista, la bóveda de crucería y la bóveda baída. Los motivos que justifican esta decisión son tres.

En primer lugar porque son tres bóvedas funcionalmente relacionadas ya que las tres se apoyan sobre arcos en su perímetro, ${ }^{24}$

24 Por este motivo Vandelvira agrupa las bóvedas de arista y baída bajo del denominador común de capillas cuadradas, porque ambas responden a un mismo problema aunque se basen en criterios formales distintos, la bóveda de arista basada en la bóveda de cañón y la bóveda baída basada en la cúpula. La bóveda de crucería de Vandelvira es «un casquete perfectamente esférico sobre el cual se sujeta una nervadura de tipo ojival» (PALACIOS GONZALO [1990] 2003, 290), una bóveda baída, es decir, otra capilla cuadrada. 
ya sean arcos formeros sobre un muro o arcos perpiaños sobre apoyos puntuales.

En segundo lugar, aunque relacionada con el anterior, porque son los tres tipos de bóveda empleadas en el abovedamiento de los deambulatorios. $^{25}$
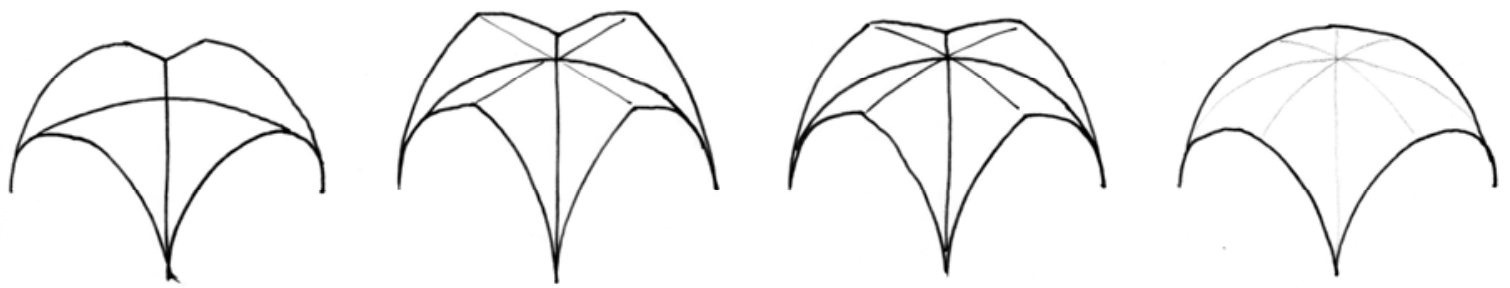

Figura 1.16. Bóvedas de arista, de crucería y baída.

Por último, al menos a nivel teórico, es posible establecer una relación en la evolución entre los tres tipos de bóveda basada en una hipotética evolución histórica (figura 1.16). Según explica E.-E. Viollet-le-Duc la bóveda de crucería surge a partir de la bóveda de arista debido, entre otros motivos, por los problemas de adaptación a la planta rectangular (VIOLLET-LE-DUC 1854-1868, 4:14-37). La definición previa de las líneas de intersección por medio de arcos de circunferencia, semicirculares para los ojivos y apuntados para formeros y perpiaños, no sólo simplificó la construcción geométrica de la forma de la bóveda sino que además permitió evitar el uso de aristas de curvatura variable.

Por su parte, el desarrollo de la bóveda de crucería se caracterizó por la multiplicación del número de nervios que darán lugar a distintas volumetrías caracterizadas por la forma de la sección o rampante: rampante llano, rampante redondo, etc. (PALACIOS 2009, 117-120) Uno de los tipos de bóveda de crucería tardogótica en España es el denominado rampante con la vuelta de la diagonal, que emplea para el rampante el mismo arco que para el nervio ojivo haciendo que los arcos del perímetro dejen de ser apuntados; su forma es un preludio de la bóveda baída (cfr. capítulo 5, apartado 5.3). ${ }^{26}$

25 La girola de la catedral de Málaga parece una excepción, ya que parece cubierto con un casquete pseudo-esférico sobre pechinas, pero, como se ha visto tras su análisis, se trata en realidad de bóvedas baídas como las empleadas en el resto de la catedral (cfr. capítulo 8, apartado 8.2).

26 Esta especulación no debe tomarse al pie de la letra como un proceso lineal que explicaría el origen de la bóveda baída; se trata de una reflexión sobre la relación formal entre tres tipos de bóveda aparentemente dispares. 
A pesar de establecer esta relación diacrónica entre los tres tipos de bóveda, la segunda parte de la tesis no sigue esta estructura ya que en el período de tiempo estudiado, la bóveda de arista es la última en extenderse. Los tratados del siglo XVI, en especial el de Vandelvira, muestran gran profusión de bóvedas baídas y tan sólo dos ejemplos de bóvedas de arista; por el contrario, los tratados del siglo XVIII parecen haber olvidado la bóveda baída y centran sus explicaciones en la bóveda de arista y sus variantes.

Si bien el punto de partida son las bóvedas de cantería en las que el despiece se hace evidente al intradós, las bóvedas analizadas son de fábrica, tanto de cantería como de albañilería. ${ }^{27}$ De todas formas, al centrar el análisis en el intradós el material pierde importancia y las conclusiones son de aplicación, con muchos matices, a otros materiales.

\section{Estudio de casos}

El estudio de casos se ha fundamentado en dos líneas de investigación, la primera sobre soluciones teóricas de bóvedas propuestas en los manuscritos y tratados de cantería, y la segunda sobre bóvedas efectivamente construidas.

La idea inicial era establecer una comparación entre teoría y práctica, confrontando el grado de relación entre ambas. Sin embargo este doble análisis sólo se pudo llevar a cabo en contadas ocasiones (cfr. capítulo 9, apartado 9.1). Constatamos que las bóvedas no convencionales reflejadas en los tratados eran pocas y apenas se habían llevado a la práctica, mientras que las soluciones construidas no respondían a modelos teóricos propuestos, manifestando un divorcio entre teoría y práctica.

El estudio de casos inicialmente propuesto abarcaba todas las posibles situaciones de bóvedas no convencionales para los tres tipos propuestos: bóveda de crucería, bóveda baída y bóveda de arista. Sin embargo, una revisión del estudio de casos reveló una primera distinción entre casos insustanciales, resueltos de manera trivial y que no aportaban ninguna novedad significativa, frente a otros problemas de mayor contenido. En la primera parte de la tesis (cfr. capítulo 5, apartado 5.1) se expone la casuística de las bóvedas no canónicas,

27 El problema de las bóvedas de albañilería construidas sin cimbra constituyen un caso de estudio de extraordinario interés pero que queda fuera de los límites de esta investigación (cfr. capítulo 1, apartado 1.6 y capítulo 10, apartado 10.3). 
mientras que el análisis recogido en la segunda parte de la tesis se centra en algunos de estos problemas interesantes.

En principio la búsqueda de ejemplos construidos se ha centrado en arquitectura religiosa, ${ }^{28}$ entendiendo como tal los lugares de culto y sus dependencias anexas -como los claustros-, por tres motivos:

- Es el tipo de espacios donde encontramos deambulatorios, ya sea en edificios de planta basilical con girola ya sea en edificios de planta central de doble casco. Aunque el problema del deambulatorio se hace extensivo a otros espacios de planta anular, como patios, el número de ejemplos es mucho más reducido.

- Es relativamente sencillo encontrar amplia documentación sobre este tipo de arquitecturas, lo que en un principio facilitó la búsqueda de ejemplos.

- Frente a otros tipos arquitectónicos, es frecuente que los espacios de culto estén abovedados, situación más excepcional si nos referimos a otras arquitecturas. Señalar también que en este tipo de espacios la complejidad de las bóvedas se incrementa, cosa que no sucede en otras arquitecturas donde los ejemplos manejados son sencillos.

Sin embargo, la elección de este corpus de análisis condicionará algunas de las conclusiones de la investigación, en particular las relativas a la primera parte de la tesis (cfr. capítulo 3, apartado 3.2).

\section{Límites espaciales y temporales}

La investigación fija los límites temporales para el estudio de casos recogido en la segunda parte de la tesis entre los siglos XVI y XVIII. Durante la Edad Media abundan las irregularidades en arquitectura, sin embargo esto no se traduce en un aumento de la complejidad de las bóvedas, siendo las propias tolerancias del sistema constructivo las que asumen las irregularidades. En arquitectura clásica en cambio, es más difícil encontrar irregularidades, pero éstas se resuelven de manera consciente.

28 Tan sólo se han analizado algunos ejemplos de bóvedas construidas en edificios no religiosos. Cabe destacar las bóvedas de arista de planta rectangular construidas en Palma de Mallorca (cfr. capítulo 9, apartado 9.1). 


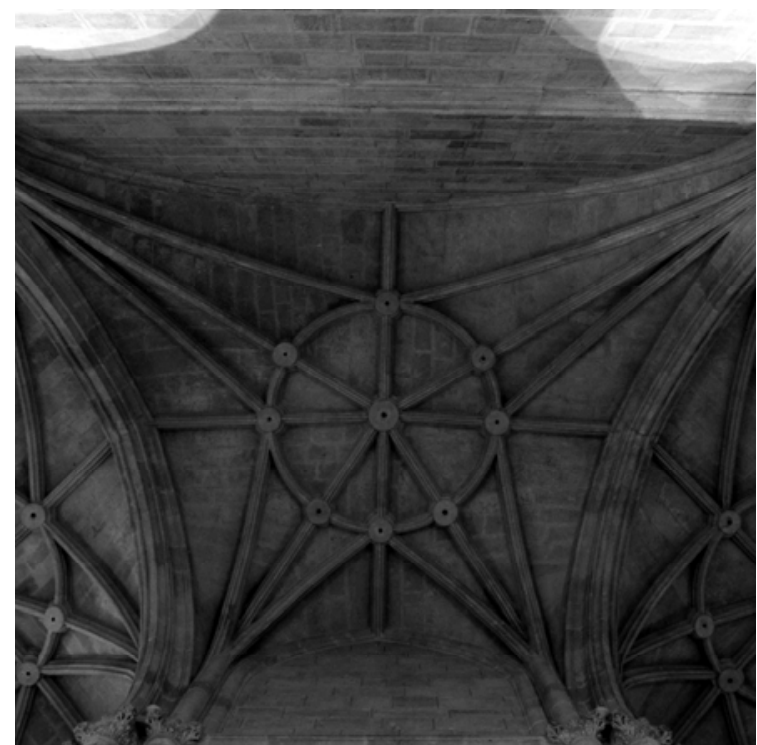

Figura 1.17. Bóveda de la girola de la Catedral de Almería

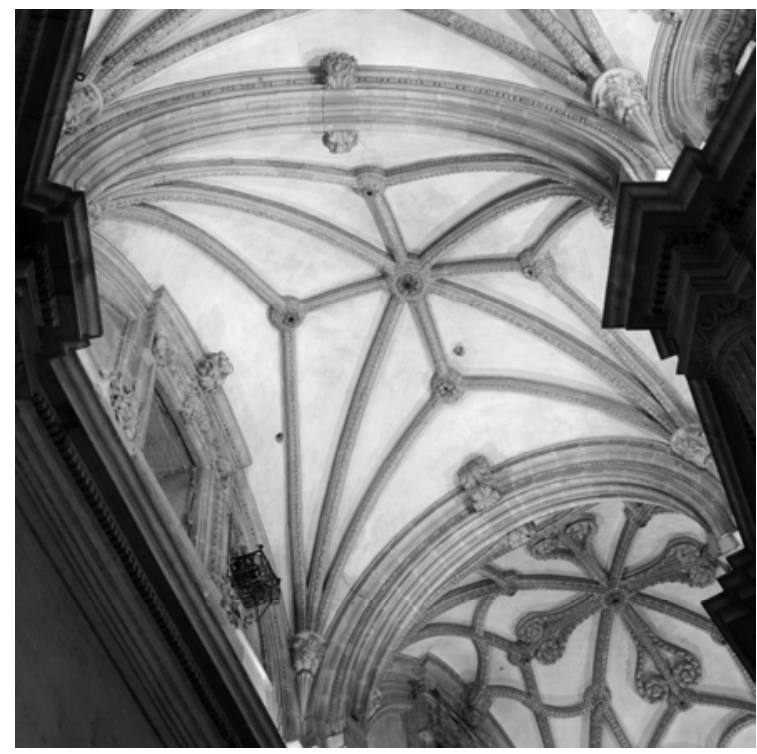

Figura 1.19. Bóveda de la girola de la Catedral de Guadix (Granada)

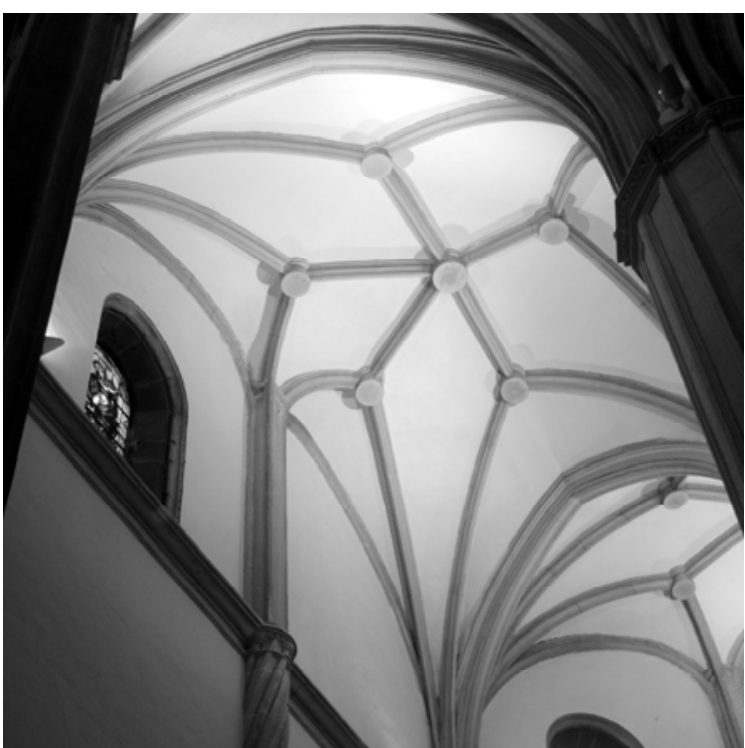

Figura 1.18. Bóveda de la girola de la colegiata de Baza (Granada)

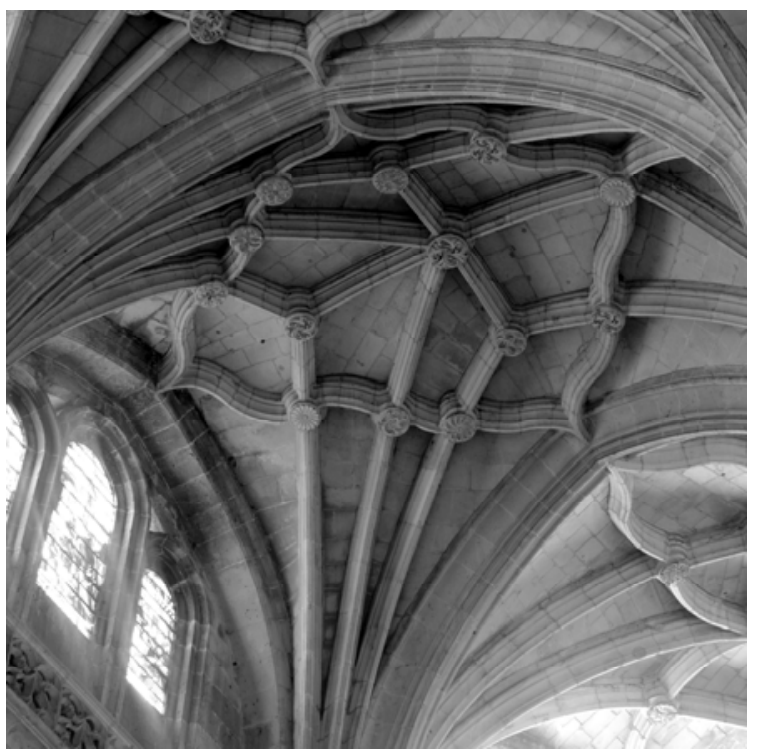

Figura 1.20. Bóveda de la girola de la Catedral de Segovia

Antes del siglo XVI aunque abundan las bóvedas irregulares, éstas no suelen presentar soluciones de especial interés; si nos fijamos en el espacio de la girola, éste se suele resolver por medio de una bóveda de crucería sencilla. ${ }^{29}$ Señalaba Chueca Goitia el interés por

29 Sí aparecen soluciones compositivas originales, como la empleada en la girola de la Catedral de Notre-Dame de París (Francia). Los aspectos compositivos de la girola se desarrollan en el capítulo 4 (apartado 4.2). 
analizar las bóvedas tardogóticas -él no emplea este términoespañolas de los siglos XV y XVI. Es cierto que en el campo de las bóvedas normales de crucería encontramos ya en el siglo XV en España ejemplos cuya complejidad los aleja de la simple croisée d'ogives. ${ }^{30}$ Sin embargo, esta complejidad tarda más en trasladarse al ámbito de deambulatorio, quizá por su dificultad intrínseca. Las primeras bóvedas de crucería complejas en deambulatorios españoles las encontramos en las catedrales de Almería, Baza, Guadix y Segovia, de mediados del siglo XVI (figuras 1.17, 1.18, 1.19 y 1.20 respectivamente). ${ }^{31}$

En el otro extremo, a partir del siglo XIX se generaliza el uso de los nuevos materiales, cambiando radicalmente el panorama edificatorio. Precisamente es durante los siglos XVI, XVII y XVIII cuando la edificación de bóvedas tardogóticas en España, resultado de la evolución de la bóveda de crucería clásica, dará lugar a ingeniosas soluciones que no sólo conviven con bóvedas baídas y de arista, sino que establecen una relación entre dos formas aparentemente distintas de concebir las construcción geométrica de la forma de la bóveda.

En cuanto a los límites geográficos, la investigación se ha centrado en las bóvedas construidas en España por motivos de accesibilidad. Sin embargo, la influencia francesa en la los tratados españoles e cantería hizo imprescindible ampliar el contexto geográfico a los tratados de estereotomía franceses, que se complementó con la búsqueda y el análisis de algunas bóvedas construidas en Francia.

En la primera parte de la tesis los límites geográficos y temporales son más laxos. Por una parte el fenómeno de la deformación en arquitectura abovedada en España no puede entenderse sino como parte del contexto europeo en el que se inscribe. Por otra parte, era necesario hilvanar una primera aproximación a la historia de la deformación en arquitectura abovedada, que contextualizara los ejemplos recogidos en la segunda parte de la tesis.

Sin embargo se ha evitado conscientemente delinear una cronología de los ejemplos que se estudian en la primera parte de la

El problema de la bóveda de crucería sencilla de planta trapecial se aborda en el capítulo 5 (apartado 5.2).

30 Con la excepción de la bóveda de la girola de Notre-Dame de París (Francia). En España destaca por su singularidad la bóveda de la girola de la Catedral de Palencia.

31 Ejemplos como los recogidos por José Carlos PALACiOs GONZALO en su libro de 2009. 
tesis, no sólo por la dificultad que entrañan, sino por el convencimiento en su irrelevancia.

\section{Tratados de cantería}

Complementariamente, esta horquilla temporal coincide con la de la base teórica con la que comparar las soluciones construidas, ya que los primeros manuscritos que encontramos en España están fechados en el siglo XVI. ${ }^{32}$ El límite temporal superior lo marca la publicación en 1799 de la Géométrie Descriptive de Gaspar Monge, que supuso un cambio de paradigma en los textos sobre cantería.

Como ya se ha señalado, el análisis de bóvedas no canónicas se ha centrado en los tratados de estereotomía y cantería españoles y franceses de los siglos XVI al XVIII. Para el caso de las bóvedas de crucería, se han consultado los dibujos tardo-medievales conservados en Europa Central, de los siglos XV y XVI.

En general, el trabajo sobre manuscritos y tratados se ha realizado a partir de copias digitales, de facsímiles o de ediciones críticas. Sólo en aquellos casos en los que no disponía de dicha copia se ha trabajado con la copia original. ${ }^{33}$

\section{Bóvedas construidas}

El análisis de las bóvedas construidas se ha llevado a cabo a partir de un levantamiento tridimensional de las mismas. La toma de datos para los levantamientos se ha realizado bien por medio de una estación total equipada con distanciómetro láser -Leika Flex Line TS2-, o por medio de fotogrametría digital de imágenes cruzadas -Photomodeler Scanner-. En el análisis pormenorizado de casos se detallan los medios empleados en cada caso.

En el Anexo A se describe con más detalle el procedimiento seguido tanto para la toma de datos, como para el posterior análisis de las bóvedas, especificando las hipótesis que se han manejado y avanzando una propuesta metodológica para el análisis de las soluciones construidas.

32 El tratado de Philibert de L'Orme, primer tratado francés con construcciones de cantería, también es del siglo XVI.

33 En la bibliografía se indica la copia consultada en cada caso. 


\subsection{Limitaciones}

Many debates have their origin in a false premise, in stating the wrong question

(HUERTA FERNÁNDEZ 2009, 843)

Esta tesis habla de bóvedas deformadas y lo primero que conviene aclarar es que hablamos de deformación desde el punto de vista de la morfología; no se estudian los fenómenos de deformación estructural.

El origen de esta tesis está en una cuestión de adaptación de la forma: la deformación desde el punto de vista de la morfología, y se centra únicamente en los aspectos relacionados con la construcción geométrica de la forma de la bóveda. Se han dejado fuera de la tesis otros muchos aspectos de interés en el análisis de bóvedas históricas comportamiento estructural, proceso de ejecución, materiales, cimbras y herramientas auxiliares, fuentes documentales, problemas históricos, etcétera- por dos motivos:

En primer lugar porque creemos que la cuestión planteada es la primera que debe ser respondida; cuando una bóveda se deforma plantea, en primer lugar, un problema morfológico. La complejidad que no la contradicción- de este problema es suficiente como para justificar por sí sola la investigación, sin necesidad de añadirle otras cuestiones en un intento por enriquecer la pregunta.

En segundo lugar porque tratar de responder a muchas preguntas desviaría la atención sobre la pregunta inicialmente formulada.

Sin obviar cierto grado de provocación al pretender «que el proceso de formalización de la arquitectura plantease problemas específicos e irreductibles» (BORIE et al. [1978] 2008, 15).

El objeto de estudio es un tema muy amplio y para hacer viable la investigación ha sido necesario acotar el estudio de casos a tres tipos de bóveda, dentro de un ámbito geográfico concreto y en un período concreto. Por este motivo, la base teórica recogida en la primera parte de la tesis no puede, ni pretende, cerrar una teoría sobre las bóvedas no canónicas sino tan sólo sentar las bases para posteriores investigaciones.

Las bóvedas estudiadas se analizan desde una deformación de la planta. No se analizan bóvedas con anomalías en sección, como pueden ser bóvedas con arranques a distinta altura como las empleadas para sustentar escaleras. Un ejemplo de esto último es la bóveda de arista anular y rampante, que a los problemas de la bóveda de arista anular suma los de la Vis de Saint-Giles. Se conserva un 
magnífico ejemplo de esta bóveda en la escalier du fer-à-cheval del palacio de Fontainebleau (figura 1.21) (obra de Philibert de L'Orme, reconstruida en 1632 por Jean Androuet du Cerceau), relacionada con la realizada por Philibert de L'Orme en el Château d'Anet, hoy desaparecida.
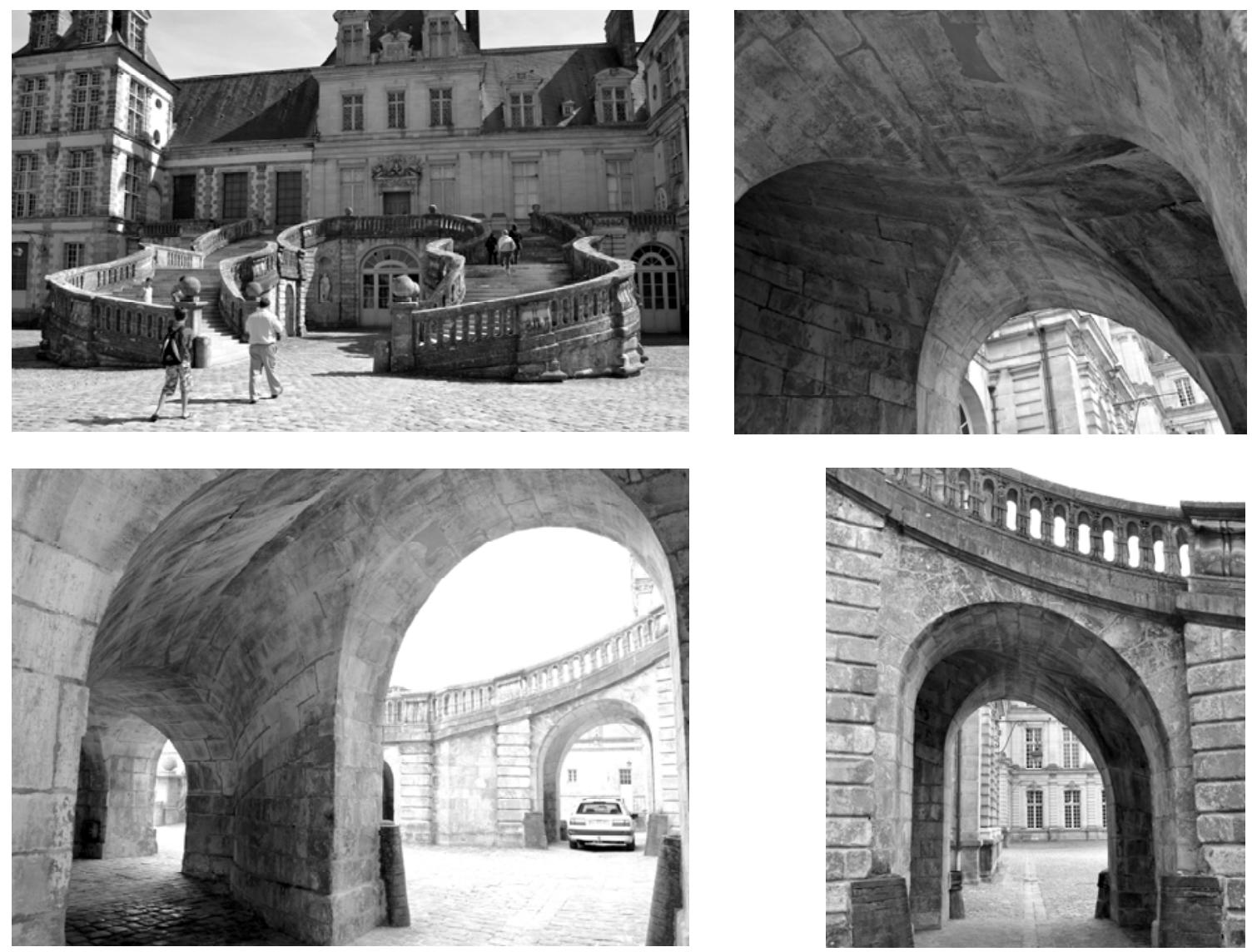

Figura 1.21. Bóveda de arista anular y rampante, escalier du fer-à-cheval de Fontainebleau

Han quedado expresamente fuera de esta investigación la bóveda de cañón, con sus numerosas variantes recogidas en los tratados dentro de los capítulos dedicados a arcos, decendas, troneras, y capialzados, por ser un objeto de estudio cuya envergadura exige una investigación en exclusiva que en buena medida ya ha sido llevada a cabo (PALACIOS GonZALO 1990; SAKAROVITCH 1997; Gordo MuRILlO 1997; RABASA DÍAZ 2000; CALVO LÓPEZ 1999).

También quedan fuera las bóvedas cuyo arranque, en lugar de situarse sobre arcos perimetrales, lo hace a nivel sobre un muro: cúpulas y bóvedas esquifadas, con sus dos variantes: las veneras y los ochavos. Las cúpulas constituyen un caso de estudio de gran envergadura, con los ejemplos singulares de las grandes cúpulas barrocas de Bernini, Borromini y Guarini entre otros. Por su parte, las 
conclusiones sobre la bóveda de arista son en buena medida de aplicación a la bóveda esquifada.

Una bóveda no es una superficie geométrica sin espesor, sino que es un elemento constructivo dotado de canto. Sin embargo, en esta investigación el análisis de la forma de la bóveda se ha centrado en la superficie de intradós de la bóveda. No se han medido los espesores de las bóvedas analizadas -tampoco se han visitados los bajocubiertas $^{34}$ - y las únicas apreciaciones que tienen en cuenta el espesor de la bóveda se refieren a problemas de cantería, como los reflejados al analizar las bóvedas de arista de planta rectangular y anular (cfr. capítulo 9, apartados 9.1 y 9.2).

Aunque las bóvedas analizadas son de fábrica, tanto cantería como albañilería, el análisis centrado en el intradós relativiza la importancia del material y las conclusiones pueden ser de aplicación, en parte, a otros materiales.

No se ha analizado el problema concreto de las bóvedas de ladrillo construidas sin cimbra, donde cobran gran importancia los mecanismos de control geométrico de la forma durante la ejecución material -guías, cuerdas, cintreles, barras etcétera-. Dentro de esto podríamos destacar las bóvedas bizantinas, las bóvedas tabicadas y las bóvedas extremeñas de rosca de ladrillo. El problema de las bóvedas de ladrillo realizadas sin cimbra constituye un objeto de estudio de envergadura, que arrojaría sin duda interesantes resultados y que merece atención propia.

Es necesario advertir que, tal y como se ha señalado, la mayor parte de ejemplos analizados se refieren a arquitectura religiosa, lo que ofrece una visión sesgada del fenómeno de la deformación en arquitectura abovedada recogido en la primera parte de la tesis (cfr. capítulo 3, apartado 3.2).

No se han investigado los aspectos históricos relacionados con cada una de las bóvedas estudiadas o sus artífices. En este campo nos hemos limitado a la información ya publicada para los aspectos generales relacionados con cada una de las bóvedas.

La búsqueda de bóvedas en España ha pretendido ser exhaustiva en lo que a bóvedas sobre deambulatorios se refiere. Sin

34 La visita al bajocubierta permite, en muchos casos, obtener información sobre la construcción geométrica de la forma de la bóveda, como de hecho ha sucedido con la visita al bajocubierta de las bóvedas de la girola de la Catedral de Granada (cfr. capítulo 8, apartado 8.3). Sin embargo, esta visita no siempre ha sido posible. 
embargo, para otros casos de bóvedas, el hecho de estar localizadas en muchas ocasiones en espacios de transición o de servicio, de acceso restringido y sin documentación, hace imposible una relación exhaustiva. La tesis incluye algunas bóvedas francesas, en este caso los ejemplos recogidos se incluyen para ilustrar algunas cuestiones y no constituyen un listado.

En un primer momento se planteó la posible difusión de las bóvedas en deambulatorios en las colonias de ultramar; sin embargo, tras un primer sondeo, hemos comprobado que el modelo de catedral exportado a América fue el de la Catedral de Sevilla, de cabecera recta y por lo tanto sin tramos trapezoidales o irregulares. De nuevo esta búsqueda no ha sido exhaustiva por lo que no puede descartarse la existencia de este tipo de bóvedas.

Bóvedas no canónicas - Bóvedas irregulares - Bóvedas deformadas

Podemos plantearnos la conveniencia de sustituir la expresión bóvedas no canónicas, por la expresión bóveda irregular, sin duda más sencilla y que en principio apunta menos dudas, al no requerir explicaciones adicionales. Sin embargo, vamos a ver cómo la expresión bóveda irregular, formula más problemas que soluciones.

En primer lugar, hay que advertir que la expresión bóveda irregular carece de sentido, una bóveda no es regular o irregular, una bóveda se asienta sobre un perímetro regular o irregular, ${ }^{35}$ pero la bóveda en sí no es regular o irregular.

¿Podríamos hablar entonces de bóvedas sobre planta irregular? Ya se ha señalado al comienzo de este capítulo lo desafortunado de vincular la regularidad de una bóveda a la regularidad de su planta. Por un lado, al margen del cuadrado, no son frecuentes las bóvedas sobre polígonos regulares; ${ }^{36}$ por otro lado, las bóvedas de planta rectangular sí son relativamente frecuentes, aunque, en este caso, el rectángulo no sea un polígono regular.

Veremos también numerosos ejemplos de bóvedas que, pese a asentarse sobre planta cuadrada, presentan anomalías por decisiones sobre la sección -aún situando todos sus apoyos a la misma altura-.

35 Lo que plantearía una duda adicional, una bóveda que se asienta sobre un polígono regular, pero cuyos apoyos están situados a distinta altura, ¿es de planta regular o irregular?

36 Exceptuando, quizá, las bóvedas de planta octogonal y semioctogonal u ochavos. 
La irregularidad de la planta no es el único caso de bóveda no convencional.

Por último, conviene tener presente que casi todas -por no decir todas- las bóvedas construidas presentan un cierto grado de irregularidad por su adaptación a las condiciones de contorno reales; todas las bóvedas construidas son irregulares. Esta tesis se refiere a aquellas bóvedas en las que la irregularidad se convierte en un factor de diseño. ${ }^{37}$

Sí resulta más acertada la expresión bóveda deformada aunque, de nuevo, es imprescindible matizarlo ya que, en Arquitectura, muchos tienden a confinar el uso de la palabra deformación al análisis de estructuras. ${ }^{38}$

Según el diccionario de la Real Academia Española de la Lengua, deformación es 'acción y efecto de deformar', siendo deformar 'hacer que algo pierda su forma regular o natural'. Cualquier alteración de la forma es una deformación. Una acción estructural no es la única capaz de provocar una deformación. ${ }^{39}$ También hay

37 Lo que no necesariamente tiene que ver con lo forzado de la deformación. Es indiscutible que una bóveda con una planta visiblemente irregular plantea un problema, tal y como sucede en los tramos trapeciales de las girolas. Sin embargo, una pequeña irregularidad -sólo perceptible tras un levantamiento topográficopuede constituir un condicionante de diseño, tal y como sucede en la bóveda sobre el crucero de la iglesia de San Juan de los Reyes en Toledo, analizada por Santiago Huerta Fernández y Ana López Mozo. En este caso, la elección de una bóveda por arcos cruzadas podría estar relacionada con las irregularidades de la planta (HUERTA FERNÁNDEZ y LÓPEZ MOZO, 2005).

38 Lo que seguramente sea calificable de deformación profesional.

39 Si nos centramos en el análisis de estructuras, cuando hablamos de una estructura deformada debemos tener presente que lo que verdaderamente percibimos -y cuantificamos- son movimientos: flechas, desplomes, etc. El movimiento de la estructura -de un punto de la estructura- es resultado de la suma de dos componentes: el movimiento de sólido rígido y la integral -suma diferencial- de las deformaciones. El movimiento de sólido rígido se descompone en traslación sobre los tres ejes de coordenadas y giro alrededor de los tres ejes. La deformación se descompone en deformación longitudinal y deformación angular -distorsión-, de nuevo respecto a los tres ejes de coordenadas.

Las deformaciones a su vez se clasifican en dos tipos: directas e indirectas. Las directas tienen su origen en fuerzas aplicadas sobre la estructura, que provocan esfuerzos que a su vez provocan deformaciones. Las indirectas o impuestas tienen su origen en incrementos de temperatura, errores de ejecución, asientos, etc. Estos fenómenos pueden provocar esfuerzos y deformaciones, sin que exista una relación directa entre ambos. Por ejemplo, un incremento de 
deformaciones perspectivas y anamorfismos -deformaciones producidas por procedimientos ópticos o matemáticos-; en geometría hablamos de las transformaciones geométricas: algunas pueden implican deformaciones -transformaciones afines y proyectivas- y otras no -traslación, simetría, giro, semejanzas.$-^{40}$

Desde el punto de vista de nuestra investigación, la expresión bóveda deformada tiene una ventaja añadida frente a bóveda irregular. Mientras que es posible definir la palabra irregular sin necesidad de referirla a la palabra regular, las expresiones bóveda deformada y bóveda no canónica implican la existencia de una forma previa, no deformada, un canon. La existencia de esa forma previa -no necesariamente materializada, pero sí conformada como modelo-, es una de las hipótesis sobre las que se asienta esta investigación. ${ }^{41}$

En cualquier caso, no debemos olvidar que todas las bóvedas construidas presentan movimientos -descenso de la clave, desplomes y aperturas de los apoyos, deformación de cimbras, etcétera-. Algunos autores ya han apuntado procedimientos que permiten tener en cuenta estos movimientos a la hora de analizar la construcción geométrica de la forma de una bóveda (LÓPEz Mozo 2009; HuERTA FernÁNDEZ

temperatura en una estructura isostática provocará deformaciones, pero no esfuerzos; un incremento de temperatura en una estructura hiperestática provocará esfuerzos -precisamente provocados por impedir los movimientos-. Una fuerza no es la única acción capaz de provocar una deformación.

En cualquier caso, si hacemos la hipótesis de sólido rígido, como suele ser habitual en estructuras de fábrica, las deformaciones son nulas y los movimientos de la estructura se deben, únicamente a movimientos de sólido rígido. Desde el punto de vista del análisis de estructuras, un arco de dovelas no puede deformarse, aunque sí moverse: «Las dovelas no pueden deslizar ni deformarse en sí mismas, pero pueden rotar alrededor de los puntos de contacto entre una y otra (...)» (HEYMAN [1995] 1999, 19). Podemos afirmar que, en sentido estricto, la expresión bóveda deformada no tiene sentido desde el punto de vista del análisis de estructuras históricas de fábrica.

40 Aunque de nuevo deberíamos matizarlo. Un cambio de escala -una homotecia- ¿es una deformación? No es este el lugar de discutirlo, aunque podríamos estar tentados. No vamos a plantear un estudio de la deformación desde un punto de vista puramente geométrico matemático-.

41 Parece que en una tesitura similar, ante la necesidad de dar un nombre a unas bóvedas que se salían de lo convencional, Robert Willis acuñó la expresión «crazy vaults» para referirse a las bóvedas con trazado de nervios asimétrico del Coro de San Hugo de la catedral de Lincoln (FRANKL 1953, 97) (cfr. capítulo5, apartado 5.2). 
2012b; Guerra Pestonit 2014, RABAsa DíAz et al. 2012a), sin embargo esto no es siempre posible.

El objetivo de esta tesis es explicar la construcción geométrica de la forma de las bóvedas y debemos ser conscientes de que tratar de llegar a conclusiones sobre la geometría original proyectada de un elemento construido hace varios siglos, sujeto a todo tipo de vicisitudes, puede resultar muy arriesgado. En el Anexo A se detallan algunas de las consideraciones que se han tenido en cuenta en el análisis de ejemplos construidos.

He was acquainted with the normal vault form, and because these vaults in Lincoln cathedral deviate from the norm, he called them crazy. Whether they are normal or abnormal, let us understand they particular form.

(FRANKL 1953, 97) 

PRIMERA PARTE.

\section{FORMA Y DEFORMACIÓN EN ARQUITECTURA ABOVEDADA}

Malgré les difficultés que soulevait la construction des voûtes d'un collatéral pourtournant un sanctuaire reposant sur des colonnes, en partant de la donnée romaine ou byzantine, il est à croire que l'on tenait fort à cette disposition du plan, car les architectes occidentaux ne cessèrent de chercher la solution de ce problème depuis le commencement du XIIe siècle jusqu'à ce qu'ils l'aient résolu d'une manière complète à la fin de ce siècle. Il faut reconnaître même que cette longue suite d'essais ne contribua pas médiocrement à développer le système d'où procède la voûte d'arête du XIIIe siècle; système excellent, puisqu'il permet toutes les combinaisons imaginables en n’employant toujours qu'un même procédé.

(VIOLLET-LE-DUC 1854-1868, 9 :489) 



\section{Intuiciones}

(...) ¿Sólo la intuición puede apartar esa duda? -Si ella es una voz interior -¿Cómo sé cómo debo seguirla?

¿Y cómo sé que no me descamina?

Pues, si puede encaminarse rectamente, también puede descaminarse.

((La intuición como excusa innecesaria)) (WITTGENSTEIN Investigaciones filosóficas §213) ${ }^{1}$

En el análisis de bóvedas históricas encontramos tres ideas muy extendidas que, aunque generalmente aceptadas, no dejan de ser engañosas. Estas tres ideas son: la primacía del problema estructural, la identificación entre las nociones de bóveda y superficie, y la escisión entre los conceptos de geometría y construcción. La intuición de la falsedad de estas tres ideas -y de la limitación que suponen- ha orientado el desarrollo de esta tesis.

1 (WITTGENSTEIN [1953] 2012, 209). 


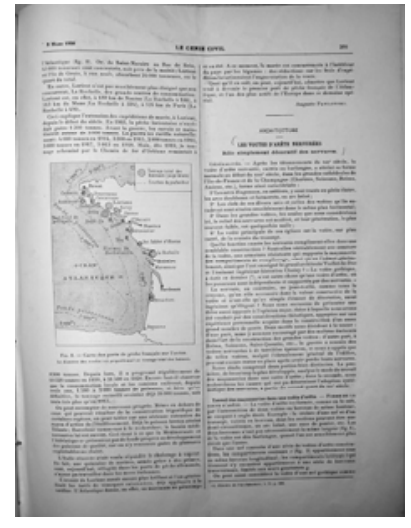

Figura 2.1. Primera página del artículo de V. Sabouret «Les voutes d'arête nervurées. Rôle simplement décoratif des nervures» (SABOURET 1928, 205)

\subsection{El problema estructural}

Las obras no se construyen para que resistan. Se construyen para alguna otra finalidad o función que lleva, como consecuencia esencial, el que la construcción mantenga su forma y condiciones a lo largo del tiempo. Su resistencia es una condición fundamental; pero, no es la finalidad única, ni siquiera la finalidad primaria (TORROJA MiRET [1957] 1996, 2).

Es indiscutible que construir una bóveda es un problema estructural de primer orden, más si pensamos que la fábrica es un material que no resiste tracciones. Salvar un vano con un material que no es capaz de resistir tracciones -y por lo tanto flexiones- es una proeza de la humanidad que todavía hoy nos maravilla. También es indiscutible que a la hora de intervenir en un edificio histórico el problema estructural cobra importancia ya que intervenir en el equilibrio de fuerzas no deja de ser arriesgado; temerario si no se comprende.

Como ya han señalado Jacques Heyman y Santiago Huerta, el problema estructural de las fábricas es un problema de estabilidad que los maestros constructores resolvieron gracias al uso de reglas proporcionales y modelos a escala con las que construyeron edificios que han llegado hasta nuestros días. Estos procedimientos, alejados de los planteamientos de resistencia actuales, les permitieron construir edificios que todavía hoy nos sorprenden. Gracias a los trabajos de Jacques Heyman (1995) y Santiago Huerta ([1990] 2004) sabemos que dichos métodos, basados en el uso de proporciones válidas (HUERTA [1190] 2004, 518) responden con acierto a los problemas de estabilidad que estas estructuras plantearon.

Sin embargo, aunque cada una de estas obras fuera una «hazaña de la ingeniería estructural» (HEYMAN [1995] 1999, 3), esto no quiere decir que el problema estructural fuera el único al que se enfrentaron, ni siquiera el más importante.

Los edificios que construimos en la actualidad suelen tener una estructura diferenciada, ${ }^{2}$ es decir, un elemento concreto del edificio la estructura- asume el cumplimiento de las exigencias estructurales del edificio. Esto, junto con una indudable necesidad de optimización y ajuste de costes, ha hecho que el problema estructural cobre gran importancia. Sin embargo, la necesidad de resolver un problema estructural no puede llevarnos a pensar que la finalidad del edificio es

2 No todos los edificios que se construyen en la actualidad tienen estructura diferenciada, aunque sí la mayoría. 
que resista, es una condición necesaria, pero no el objetivo: «Las obras no se construyen para que resistan» (TORROJA [1957] 1996, 2).

En edificios históricos es raro encontrar estructura diferenciada; ${ }^{3}$ lo normal es que un mismo elemento resuelva a la vez muchos problemas, entre ellos el estructural. El problema estructural tiene entonces una importancia relativa, no es el único -ni siquiera el principal- factor de diseño.

Los maestros constructores manejaban estructuras que sabían que funcionaban y, a lo sumo, las cambiaban de escala. La cúpula de Santa Maria del Fiori en Florencia de Brunelleschi no se paralizó sólo porque fuera un problema construir una bóveda de $41 \mathrm{~m}$ de luz; el problema fundamental radicaba en la imposibilidad de hacerlo sin cimbra (KING [2000] 2005, 38).

Si ante un edificio histórico tratamos de explicar todos y cada uno de sus elementos desde el punto de vista estructural encontraremos que cuando un elemento no queda justificado estructuralmente, pasa a ser considerado como «meramente decorativo» (SABOURET 1928, 205) y como tal, inútil desde el punto de vista de la construcción (figura 2.1).

El muro de una catedral resuelve, con mejor o peor fortuna, un problema higrotérmico, al ser el encargado de separar el ambiente interior del exterior. Sin embargo, a nadie -espero- se le ocurriría justificar el muro de doble hoja medieval (VIOLLET-LE-DuC 18541868 9:12) desde un punto de vista higrotérmico. ${ }^{4}$

Podemos analizar estructuras históricas de fábrica, empleando la teoría del análisis límite, en casos de restauraciones (HUERTA FERNÁNDEZ y LÓPEZ MOZO 2005, 2), especialmente en casos de cambios de uso, "para estudiar la estabilidad (...) ante las nuevas cargas» (HUERTA FERNÁNDEZ y RABASA DÍAZ 2006, 1); también para comprobar aquellos elementos «cuya estabilidad ofrece a priori más dudas» (GUERRA PESTONIT 2012, 87) y poder «interpretar de forma racional las deformaciones» (GUERRA PESTONIT 2012, 87).

El análisis estructural también puede mostrarnos cómo algunos elementos aparentemente estructurales, como las 126 barras de hierro

3 Quizá se pueda poner el ejemplo de los arbotantes góticos como ejemplo de estructura histórica diferenciada.

4 Justificar, que no analizar. El muro puede ser analizado -si su heterogeniedad en sección y en alzado lo permite- pero no parece razonable tratar de justificar que los maestros constructores medievales hicieran una doble hoja pensando en su comportamiento higrotérmico. 
que unen la cúpula interior de la Basílica de la Virgen de los Desamparados en Valencia con la cúpula exterior, no tienen en la actualidad una función estructural. Aunque parezca que la cúpula interior está colgada de la exterior, en realidad estas barras tuvieron su utilidad durante la construcción -como control geométrico de la forma y para evitar problemas de pandeo e inestabilidad- y hoy son un «testimonio del proceso constructivo» (HUERTA FERNÁNDEZ 2012b, 381-382).

En otros casos, como el diseño de la cáscara que cierra las bóvedas tardogóticas con nervios de doble curvatura Schlingrippengewölbe-, todavía no han sido explicado y el análisis estructural de las mismas puede aportar datos sobre dicho diseño (WENDLAND 2012, 356).

Sin embargo no debemos perder de vista lo relativo del problema estructural. «Por otro lado hay que tener en cuenta que el enfoque teórico [desde el análisis estructural], al tiempo que conduce a conclusiones válidas e interesantes, arrojará muy poca luz sobre las racionalizaciones del arquitecto medieval» (HEYMAN, 1968 [1995], 83).

Un ejemplo de la excesiva importancia que en muchas ocasiones se le da al problema estructural lo encontramos en la famosa polémica decimonónica sobre la «verdadera función de los nervios» en una bóveda gótica. El debate focalizado en la presunta utilidad estructural de las nervaduras ha quedado obsoleto gracias a los trabajos de Jacques Heyman en los años 60 del siglo pasado (HUERTA FERNÁNDEZ 2009). A pesar de ello, todavía hoy cuando un autor analiza una bóveda gótica parece obligado a responder a la pregunta de si el nervio es estructural o meramente decorativo; no parece existir una alternativa. Un nervio que no resuelva -o contribuya a resolverun problema estructural es considerado ornamental: ${ }^{5}$ «las ligaduras o cualquier configuración más compleja de nervios, aplicadas a la superficie continua del casco de la bóveda, tienen una función estrictamente ornamental» (HEYMAN [1983] 1995, 272).

5 También se emplea los términos «decorativo» (SABOURET 1928, 205) o «formal» (FUENTES GonZÁLEZ 2014, 9). Éste último podría ser correcto, pero merece la pena detenerse en la acepción del término. En efecto una de las funciones de la nervadura es la construcción geométrica de la forma de la bóveda, y por lo tanto su función es formal -configuración-. Se discutirá a continuación pero formal, por oposición a constructivo (FUENTES GonZÁLEZ 2014, 169) es una acepción del término que lo banaliza. 


\subsection{Bóveda y superficie}

La geometría analítica es mucho más potente que la gráfica y, sin embargo, ningún objeto complejo se ha generado a través de la misma. Todas las formas han partido de intuiciones gráficas y a partir de representaciones claras, mientras que la geometría analítica ha intervenido en un segundo plano para el ajuste de formas.

(ESCRIG PALLARÉS 2005, 11)

A finales del s. XVIII Gaspard Monge impartió sus famosas Leçons données aux Écoles Normales (MONGE 1799) donde sentó las bases de la Geometría Descriptiva (figura 2.2). El objetivo de esta nueva disciplina era el de proveer a los estudiantes de la École Polytechnique con una teoría geométrica que justificara los procedimientos gráficos empleados en las distintas ramas de la ingeniería. Las bases de esta ciencia se encuentran en el arte del corte de piedra, también denominado cantería o montea, desarrollada por maestros canteros a partir de la Edad Media y plasmada en los manuscritos y tratados de cantería de los siglos XVI, XVII y XVIII.

Una de las pretensiones de la Geometría Descriptiva era perfeccionar la técnica de la edificación a través de una racionalización de sus medios, alejada del oscurantismo de los talleres medievales. Sin embargo, este intento de racionalización llevo a un distanciamiento entre teoría y práctica que todavía persiste en la actualidad (SAKAROVITCH 1998, RABASA DíAZ 2000).

Herederos de los métodos de la Geometría Descriptiva, en la actualidad el estudio de bóvedas históricas se plantea desde la geometría de superficies, asimilando la bóveda a su superficie de intradós y aplicándole los mismos procedimientos empleados en el estudio de superficies. Esta manera de entender las bóvedas, que podría tener validez para la edificación actual, se ha revelado poco funcional al referirse a las bóvedas históricas (LóPEz Mozo et al. 2011).

En la actualidad nos encontramos con dos situaciones aparentemente enfrentadas, la primera lleva a una reducción de posibilidades, la segunda a una multiplicación de posibilidades. Pese a su aparente disparidad, ambas surgen de la desafortunada aplicación del análisis de superficies al estudio de bóvedas históricas.

La primera equipara la bóveda con la superficie de intradós y exige a la bóveda que se acomode a la rígida definición según los tipos superficie. De esta manera una trompa es una «bóveda cónica» (TOSCA [1707-1715] 1727, 182; RABASA DÍAZ 2000, 367; PALACIOS GONZALO [1990] 2003, 25), una bóveda de cañón es una «bóveda

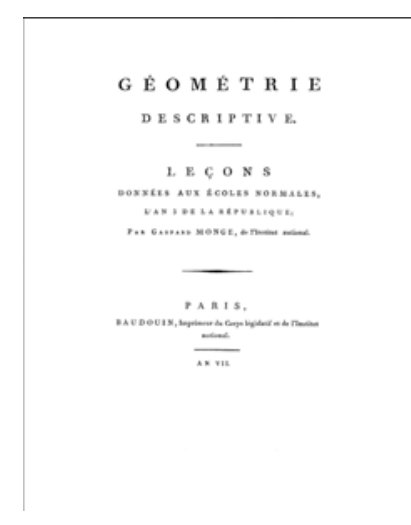

Figura 2.2. La Géométrie descriptive de Gaspard Monge (MONGE [1989] 1799) (fuente: Gallica) 


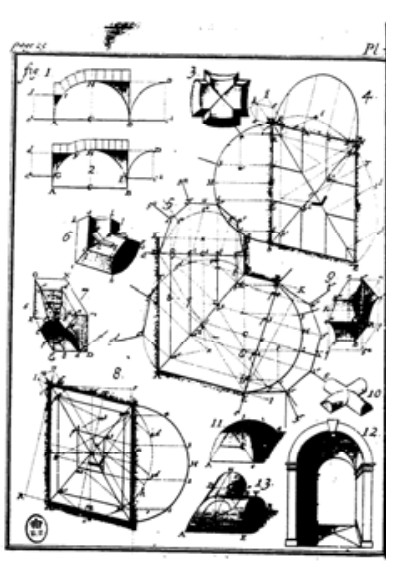

Figura 2.3. Bóvedas de arista según Frezier (17371739, Pl. 70)

(fuente: Gallica) cilíndrica» (TOSCA [1707-1715] 1727, 95; PALACIOS GONZALO [1990] 2003, 63), una cúpula es una «bóveda semiesférica» (TOSCA [1707-1715] 1727, 252; RABASA DÍAZ 2000, 362), una bóveda baída es «una semiesfera cortada por cuatro planos verticales» (TOSCA [1707-1715] 1727, 218; CHUECA GoITIA 1951, 130; PALACIOS GONZALO [1990] 2003, 255; HUERTA FERNÁNDEZ [1990] 2004, 482), las bóvedas de arista son «intersecciones de superficies cilíndricas» (EsCRIG PAllarés y PÉREZ VALCÁRCEL 2004, 156) o la «intersección de dos cañones cilíndricos» (TosCA [1707-1715] 1727, 201).

Cuando una bóveda no se ajusta a la superficie de referencia se le antepone el prefijo "pseudo» y se la incluye en el campo de las excepciones. El problema es que el número de excepciones resulta ser mayor que el esperado.

En el segundo caso se analizan todas las situaciones posibles desde el análisis de superficies. Por ejemplo, en el caso de la bóveda de arista, explica Benito Bails (figura 2.3) ${ }^{6}$

«Quando dos cañones seguidos se encuentran y cortan, se originan diferentes bóvedas, según el modo con que se cruzan, siendo las principales la bóveda que llamamos por arista, y la que llamamos en rincón de claustro» (BAILS 1796, 475).

Esta aproximación la encontramos también en el libro de Henri J.W Thunnissen, quien a la hora de abordar el capítulo dedicado a la «Geometría» de bóvedas explica las distintas superficies cilíndricas, cónicas, de revolución, de traslación y la «cuña de Wallis» -conoide(THUNNISSEN [1950] 2012, 10-18), para a continuación analizar las distintas posibilidades de intersecciones.

El equiparar bóveda y superficie lleva a creer que es posible concebir cualquier tipo de bóveda, afirmación que se derrumba al constatar que las bóvedas que la humanidad ha construido durante siglos no son todas, sino sólo unas cuantas, materializadas a medida que se hicieron necesarias y ligadas, en buena medida, a las posibilidades de cada sistema constructivo.

Esta segunda aproximación estaría relacionada con el empleo de la «geometría analítica» tal y como la explica Félix Escrig Pallarés: «Los métodos analíticos se basan en las inmensas posibilidades que

$6 \quad$ El tratado de Benito Bails se basa en el del francés Amédée-François Frezier (1737-1739), a quien realmente debemos esta forma de explicar la bóveda de arista (FREZIER 1737-1739, 3:4 y ss.) 
las expresiones matemáticas tienen para definir espacios (...)» (ESCRIG PALLARÉS 2005, 5). ${ }^{7}$

La segunda aproximación es especialmente perversa. Ya que la infinita variedad de bóvedas hipotéticas puede hacernos creer que las bóvedas construidas, aunque representen un número reducido dentro de la multiplicación de posibilidades, están consideradas. No es así, tal y como ejemplifica el problema de la bóveda del deambulatorio y la bóveda de arista de planta anular (cfr. capítulo 9, apartado 9.2). Al referirse al problema del deambulatorio señala Thunnissen:

Cuando se sitúa un pasillo o un deambulatorio, con o sin capillas adyacentes, como en la mayoría de las catedrales románicas o góticas, se originan problemas excepcionales. Es especialmente difícil dar una buena solución a las bóvedas (...). Los vanos son en forma de trapecio de manera que tiene lugar la intersección entre un semicono y un semicilindro que da lugar a líneas de intersección que en planta son líneas curvas. (THUNNISSEN [1950] 2012, 178-180).

A continuación realiza un repaso entre algunas posibilidades a la hora de controlar la geometría, que dibuja en la lámina 55 (THUNNISSEN [1950] 2012, 178-180) (figura 1.11). ${ }^{8}$ Finalmente añade:

No obstante, se habría llegado antes a un buen resultado si, en lugar de un cono, que termina en un punto, se hubiera tomado otro cuerpo que en lugar de en un punto terminara en una línea recta, esto es, la cuña de Wallis. Sin embargo ésta comenzó a usarse en la práctica mucho más tarde. (THUNNISSEN [1950] 2012, 180)

Finalmente explica cómo los constructores medievales simplificaron las cosas haciendo que «las proyecciones de los arcos diagonales en planta fueran líneas rectas» (THUNNISSEN [1950] 2012, 180).

La aproximación es insuficiente y no explica en absoluto el problema. En primer lugar las tres posibilidades de intersección que detalla, a las que dedica media página, sólo se relacionan con algunos

7 Frente a la «geometría analítica», F. Escrig habla de la «geometría gráfica» de la que explica «Los métodos gráficos son aquellos que establecen relaciones entre formas complejas, en mayor o menor grado, a partir de formas sencillas, normalmente líneas de curvatura sencilla, rectas o arcos de círculo» (ESCRIG PALLARÉS 2005,5).

8 Tomado de UngewitTER-Mohrman (1890, Tafel V). Ver figura 1.8. 


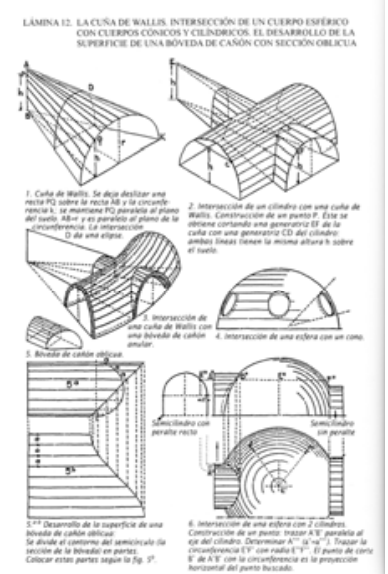

Figura 2.4. Cuña de Wallis según Thunnissen ([1950] 2012, 30) de los primeros deambulatorios románicos. Al no dar ejemplos reales la aproximación parece bastante teórica pero, en cualquier caso, sólo explicaría un reducidísimo número de ejemplos.

En segundo lugar, la «cuña de Wallis» (figura 2.4) -a la que dedica un párrafo-, tal y como veremos, hace su aparición en los tratados de estereotomía del siglo XVIII relacionada con la «bóveda de arista anular» ${ }^{9}$ pero no es apenas empleada en la práctica (cfr. capítulo 9, apartado 9.2). Por último, la sencilla explicación de la bóveda de crucería gótica aplicada al deambulatorio -a la que dedica un párrafo-, no hace justicia a la variedad de soluciones adoptadas (cfr. capítulo 5, apartado 5.2).

Señala Félix Escrig Pallarés que «[los métodos analíticos] son más poderosos que los gráficos puesto que son más genéricos» (ESCRIG PALLARÉS 2005, 5), pero sin embargo:

la geometría analítica se ha encerrado en el mundo paramétrico, que excluye formas no parametrizables. Así hay formas complejas que pueden generarse con un número corto de parámetros mientras que necesita infinitos para una forma sencilla.

Por ejemplo, es incapaz de definir coherentemente la Espiral de Durero, basada en la serie de Fibonaci (...). (ESCRIG PALLARÉS 2005, 6)

Frente a ambas situaciones, un modelo rígido con un número limitado de posibilidades que deja fuera la realidad construida, o un número infinito de posibilidades incapaz de explicar los ejemplos construidos, podemos contraponer el tratado de León Battista Alberti.

L. B. Alberti (1485) divide los tipos de bóveda en tres: fornix, cámera y recta sphérica (ALBERTI 1485, Liber III, giiii): ${ }^{10}$ Fornix para la bóveda de cañón, recta sperica para la cúpula y cámera para las bóvedas de arista y baída; esta última también denominada cimborrio a vela (ALBERTI 1582, 86-87). ${ }^{11}$ Esta sencilla división

9 En ningún texto de los siglos XVIII y XIX se hace referencia a la «cuña de Wallis» 0 «conoide de Wallis».

10 En italiano: «I modi delle volte sono questi, amezza botte, a spigoli, \& a cupola ronde» (ALBERTI 1550, Libro III, Cap. XIII: 89 §17-18).

11 «Testudinem tum quidem in medio relinquet: quam nos turgidi veli similitudine auleam nûncupabimus» (ALBERTI 1485, Liber III, giiii).

En italiano: «ella lascerà alhora una volta net mezo, la qual' noi a similitudine d'un velo gonfiato chiameremo una cupola a vela» (AlberTi 1550, Libro III, Cap. XIII: 89 §40-41). 
llama la atención por su simplicidad, especialmente si la comparamos con textos actuales, donde los tipos de bóveda se dividen y subdividen hasta crear una auténtica taxonomía, una 'ordenación jerarquizada y sistemática ${ }^{12}$ de todos los tipos posibles de bóvedas.

Estas clasificaciones, quizá útiles para algunas cosas, acaban por intoxicar la disciplina. Parece que el primer objetivo en el análisis de bóvedas históricas sea el de clasificarla en función de la superficie de intradós -pese a la dudosa utilidad de este objetivo-, empleando criterios estrictos basados en la geometría de superficies; cuando esto no es posible, siempre es posible crear una nueva clase.

Entre ambos extremos, la simplificación de Alberti y la taxonomía de bóvedas, posiblemente la virtud esté en el punto medio. Sin embargo, cuando una situación se ha convertido en extrema es conveniente enfrentarla con su opuesta. En el capítulo 5 de la tesis se plantea una alternativa abierta en la manera de entender la forma de la bóveda, que se complementa con una reflexión (cfr. capítulo 10, apartado 10.4) sobre el uso de los términos forma y geometría en la raíz del problema.

Si bien no es incorrecto utilizar el término superficie para referirse al intradós de una bóveda, para evitar la asimilación directa entre los términos bóveda y superficie, a lo largo de la tesis vamos a hablar simplemente de intradós de una bóveda, evitando emplear la palabra superficie; reservando esta última para aquellas explicaciones sobre geometría.

$12 \quad 22^{\mathrm{a}}$ edición del Diccionario de la Lengua Española de la Real Academia Española (RAE) (consulta a través de internet: http://www.rae.es/recursos/diccionarios/drae) 


\subsection{Geometría y construcción}

Au surplus, il serait illusoire d'attribuer à toutes les voûtes byzantines un tracé géométrique rigoureusement défini, et dans plus d'un cas l'irrégularité de forme que présentent les panneaux des voûtes montre que les Byzantins se sont contentés d'un cimbelot pour tracer

l'arêtier, se fiant pour régler la courbure des surfaces au sentiment des formes qui est inné chez les populations de race grecque. ${ }^{13}$

(CHOISY 1883, 57)

La independencia entre los procesos geométricos de diseño y la construcción puede llevar a pensar en la geometría como algo abstracto, decidido a priori sobre el papel y separada de la realidad constructiva. La geometría como un juego separado de la construcción -que es algo más serio.

La palabra construcción como 'acción y efecto de construir' se refiere a todo el proceso de edificación, sin embargo tendemos a asimilarlo a los medios materiales empleados -materiales, sistemas constructivos y medios auxiliares-. Por contrapartida, la geometría formaría parte de los procesos de diseño previos, independientes de la puesta en obra posterior.

La geometría es una parte más del proceso constructivo y es inseparable de éste. No sólo interviene en el proceso previo de diseño, con una decisión consciente sobre la forma del elemento a construir. También interviene durante la puesta en obra, a través de los mecanismos auxiliares empleados. La forma final de una bóveda es el resultado de decisiones a priori tomadas durante la fase de diseño, pero también de otras derivadas del proceso de puesta en obra y de los mecanismos empleados. ${ }^{14}$

El séptimo aforismo estructural de Javier Rui-Wamba Martija comienza: «No se debe calcular una estructura que no se sepa dibujar» (RUI-WAMBA MARTIJA 1998, 39). Cualquier estructura debe poder ser dibujada, no sólo a priori sobre el papel, también debe poder ser

13 «Por lo demás sería ilusorio atribuir a todas las bóvedas bizantinas un trazado geométrico rigurosamente definido. En más de un caso, la irregularidad de forma que presentan los paños de las bóvedas muestra que los bizantinos se limitan a emplear un cintrel para trazar la arista. Para resolver la curvatura de las superficies, se fían de un sentido de las formas innato en los pueblos de raza griega». (CHOISY 1997, 57-58), traducción de Francisco Javier Girón Sierra y Gema López Manzanares.

14 Un ejemplo claro de la influencia de los mecanismos de control de la geometría durante la construcción lo constituyen las bóvedas bizantinas construidas sin cimbra descritas por Auguste Choisy (CHOISY [1883] 1997). 
dibujada durante la puesta en obra a través del empleo de medios auxiliares -cimbras- y de control de la forma -cuerdas, cintreles-. La generalización en el uso de los nuevos materiales de construcción desde mediados del siglo XIX y la aparición de las nuevas herramientas de dibujo asistido por ordenador -y su coordinación con los procesos de fabricación asistida por ordenador, CAD-CAM, y de cálculo por elementos finitos, FEM- han llevado a una libertad formal que nos puede hacer perder de vista que estas herramientas son muy modernas. ${ }^{15}$

Durante siglos las limitaciones técnicas de la representación gráfica, durante las fases de diseño ${ }^{16}$ y puesta en obra, han influido directamente en las posibilidades formales. Sólo se podía construir aquello que se podía dibujar y por lo tanto la geometría, como control de la forma, era parte indisoluble del proceso constructivo.

Un ejemplo lo encontramos en las bóvedas con nervios de doble curvatura -Schlingrippengewölbe-. La aparente complejidad geométrica de los mismos se lograba con unas sencillas herramientas de diseño (BURCHER 1979; WENDLAND y VENTAS-SIERRA 2013) que permitían la labra de las dovelas y su puesta en obra, dando lugar a bóvedas con «un grado de sofisticación extraordinario» (PALACIOS GONZALO 2009, 55).

Si al analizar edificio histórico separamos los procesos geométricos de los constructivos nos lleva, en el mejor de los casos, a duplicar información. En el peor de los caso, a banalizar el problema.

A lo largo de esta tesis se emplea el término construcción en el sentido que le da Paul Frankl en su libro sobre arquitectura gótica: "por construcción entiendo la construcción geométrica de una forma concreta de bóveda» (FRANKL [1962] 2002, 77). Este empleo de la palabra construcción también está en relación con el título de la

15 La tesis doctoral de Juan Rey Rey profundiza en la barrera que supuso durante siglos las limitaciones en el tratamiento de las formas, no sólo en las herramientas de cálculo estructural, sino también en el campo de la representación gráfica (REY REY 2013).

16 Cuando hablamos de diseño no está limitado al actual sistema de representación por doble proyección ortogonal -diédrico- de planta, alzado y sección. La representación en planta sí era necesaria, pero el sistema de alzado y sección no es el único capaz de controlar la volumetría de la bóveda. Los sistemas que encontramos en los manuscritos tardomedievales basados en la planta y la elevación independiente de los arcos -que no alzado- permiten un control de la geometría de la bóveda más eficaz que el sistema de planta sección (RABAsA DíAz 2000, 121-130).

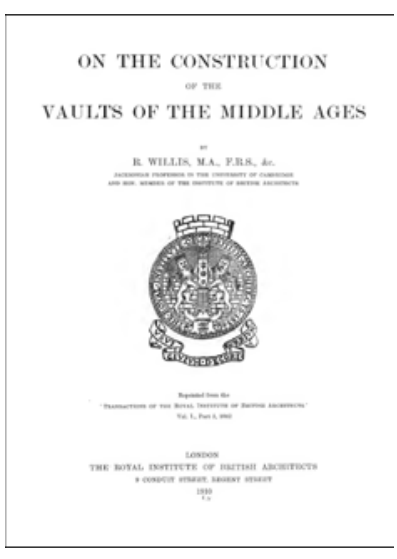

Figura 2.5. «On the construction of the vaults of the Middle Ages» (WILLIS [1842] 1910)

(fuente: http://archive.org) 
memoria de Robert Willis, "On the construction of the vaults of the Middle Ages» (WILLIS [1842] 1910) (figura 2.5):

Por ello no he dicho nada respecto a los principios mecánicos, y me he limitado a aspectos relacionados con la forma y disposición. Creo, a partir del examen de las obras de los arquitectos de la Edad Media, que estos aspectos tienen una influencia infinitamente más grande sobre sus estructuras que las relaciones de los empujes, entonces muy poco comprendidas, y sobre las que cometieron errores manifiestos y, en algunos casos, fatales.

(WILLIS [1842] 2012, 101) $^{17}$

\subsection{La cuestión de las bóvedas no canónicas}

El estudio de las bóvedas no canónicas pone de manifiesto la falsedad de las tres ideas que señalábamos al principio de este capítulo: la primacía del problema estructural, la identificación entre las nociones de bóveda y superficie, y la escisión entre los conceptos de geometría y construcción; y las limitaciones que estas ideas implican.

En el artículo «Voûte» del Dictionnaire raisonné de l'architecture française du XIe au XVIe siècle E.-E. Viollet-le-Duc explica cómo los problemas ocasionados por la bóveda anular de los deambulatorios surgen, en primer lugar, de la necesidad de adaptación a una planta distinta de aquella para la que había sido concebida. Los problemas estructurales pasan a segundo término, a pesar del interés que tenían para su autor, y que tanta literatura han generado (HUERTA FERNÁNDEZ 2009; TARRÍO ALONSO 2009).

Cuando Viollet-le-Duc analiza la evolución del problema del deambulatorio a través de una serie de ejemplos, no lo hace desde el enfoque estructural, sino desde el enfoque de construcción geométrica del conjunto y de los elementos de detalle, aunque también hable de la estructura. La bóveda gótica resuelve el problema no por su mayor fiabilidad estructural, sino por su flexibilidad para adaptarse a un perímetro distinto del inicialmente concebido. La geometría se vuelve una parte indispensable del proceso constructivo.

17 «Thus I have said nothing respecting mechanical principles, and have confined myself to form and arrangement. But it appears to me, from examination of the works of the Middle Age architects, that the later considerations had an infinitely greater influence upon their structures than the relations of pressure, then very little understood, and about which they made manifest and sometimes fatal errors (...)» (WILLIS [1842] 1910, 46). 
Curiosamente la potencia de esta idea fue recalcada por uno de los más feroces detractores de las tesis de Viollet-le-Duc. Pol Abraham (figura 2.6) acusa a Viollet-le-Duc y sus seguidores de olvidar que el hecho de que algo no sea estructural no quiere decir que no sea constructivo:

Pero del hecho de que la bóveda de crucería ya no sea "estructural”, en el sentido de la escuela de Viollet-leDuc, no debería afirmarse, por una reacción demasiado simplista, que sea indiferente al arte de la construcción. ${ }^{18}$

(АВRAHAM 1934, 58)

Para a continuación resaltar la utilidad de la nervadura gótica como método geométrico para simplificar el trazado de intersecciones:

La comodidad de trazar las bóvedas por penetraciones es un hecho de capital importancia que da una explicación mucho más satisfactoria del éxito universal de las bóvedas nervadas que la hipótesis caduca de su función portante» ${ }^{19}$

(ABRAHAM 1934, 60).

El análisis de las bóvedas no canónicas también pone de manifiesto lo erróneo de abordar el estudio de las bóvedas históricas desde un análisis de superficies. La necesidad de adaptarse a un perímetro distinto deforma también la volumetría de la bóveda. Esta deformación del intradós podría analizarse desde la geometría de superficies, pero dicho análisis no sería coherente con la bóveda ni con el contexto en que fue levantada. Los maestros constructores no manejaban la geometría de superficies pero fueron capaces de resolver bóvedas extremadamente complejas.

Tan sólo a finales del siglo XVIII, anticipando la Geometría Descriptiva de Monge, encontramos ejemplos donde la geometría de superficies cobra importancia, conduciendo a un divorcio entre teoría y práctica donde los medios se confunden con el fin. (cfr. capítulo 9, apartado 9.2).

18 Traducción propia, en el original: «Mais, de ce que la croisée d’ogives n'est plus «structurale», au sens de l'école de Viollet-le-Duc, il ne faudrait pas, par une réaction trop simpliste, affirmer qu'elle est indifférente à l'art de bâtir» (ABRAHAM 1934, 58).

19 Traducción propia, en el original: «La commodité de tracer les voûtes pénétrantes est un fait d'importance capitale donnant une explication bien plus satisfaisante du succès universel des voûtes nervurées que l'hypothèse périmée de leur fonction portante» (ABRAHAM 1934, 60).

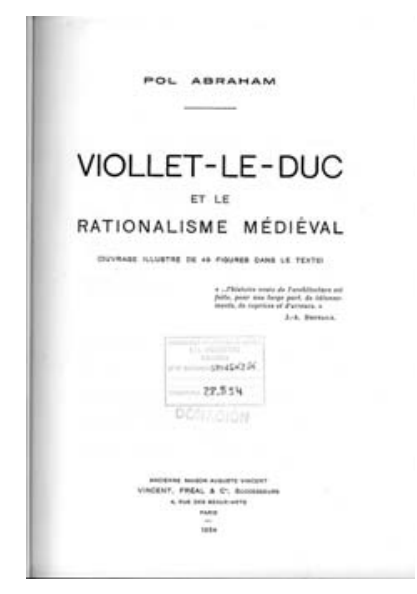

Figura 2.6. Viollet-le-Duc et le rationalisme médiéval (ABRAHAM 1934) 



\section{El problema de la deformación}

Mies refers to a need to «create order out of the desperate confusion of our time.» But Kahn has said «by order I do not mean orderliness.» Should we not resist bemoaning confusion? Should we not look for meaning in the complexities and contradictions of our times and acknowledge the limitations of systems? These, I think, are the two justifications for breaking order: the recognition of variety and confusion inside and outside, in program and environment, indeed, at all levels of experience; and the ultimate limitation of all orders composed by man. When circumstances defy order, order should bend or break: anomalies and uncertainties give validity to architecture1

(VENTURI [1966] 2002, 41)

1 Mies se refiere a la necesidad de «crear un orden de la extrema confusión de nuestra época». Pero Kahn ha dicho que «por orden no quiero decir regularidad». ¿ No deberíamos resistirnos a los que deploran la confusión? ¿No deberíamos buscar significados a las complejidades y contradicciones de nuestra época y reconocer las limitaciones de los sistemas? Estas, creo, son las dos justificaciones para destruir el orden: el reconocimiento de la variedad y la confusión en el interior y exterior, en el programa y el medio ambiente, y en todos los niveles de la experiencia; y la limitación característica de todos los órdenes hechos por el hombre. Cuando las circunstancias retan al orden, el orden debería doblarse o romperse: las anomalías y las incertidumbres dan validez a la arquitectura.

Traducción de Antón Aguirregoitia Arechavaleta y Eduardo Felipe Alonso (VENTURI [1966] 1995, 64). 

En ciertas circunstancias la regularidad no es ni deseable ni adecuada, y son las formas deformadas las que constituyen la solución geométrica más adecuada a un problema dado

(BORIE et al. [1978] 2008, 16).

En este capítulo se analiza el concepto de deformación en arquitectura abovedada tomando como punto de partida el libro de Alain Borie, Pierre Micheloni y Pierre Pinon, Forma y deformación de los objetos arquitectónicos y urbanos $^{2}$ pero teniendo en consideración las peculiaridades del objeto de estudio. En primer lugar se hace una síntesis crítica del método propuesto por estos autores. A continuación se exponen las peculiaridades de la arquitectura abovedada como objeto de estudio, que matizan algunos de las afirmaciones de Borie et al. Posteriormente se realiza una primera aproximación a la deformación en arquitectura abovedada enfocada al origen de la deformación, las actitudes frente a la misma y la formalización de la deformación. Por último se proponen dos niveles de análisis ${ }^{3}$ de la deformación en arquitectura abovedada.

\title{
3.1 Deformación y contradicción
}

\author{
Podemos suponer entonces que en origen \\ de cada forma deformada hay una contradicción, \\ un obstáculo en el desarrollo natural de su formalización
}

(BORIE et al. [1978] 2008, 55).

A continuación se sintetiza el método de análisis formulado por Borie et al., como fundamento del método de análisis de la deformación en arquitectura abovedada propuesto en esta tesis. Hemos realizado una aproximación crítica a este texto, que es el único que propone un análisis de la arquitectura desde la perspectiva de la deformación. Sin

2 La primera edición del libro se publica en 1978, editada por el Centre d’Études et de Recherches Architecturales de París; la segunda edición es de 1984, editada por la École Nationale Supérieure des Beaux Arts de París, y reeditada en 2006 por la editorial Éditions Parenthèses de Marsella. La única edición en castellano es de 2008, de la editorial Reverté de Barcelona. He trabajado sobre la edición francesa de 1984 y la edición castellana de 2008.

3 No deben confundirse los niveles de análisis, que se explican al final de este capítulo (cfr. apartado 4), con los niveles constitutivos, expresión empleada por Borie, Micheloni y Pinon para designar «conjuntos de elementos homogéneos entre sí que poseen una estructura propia» (BORIE et al. [1978] 2008, 37 y 91-96). 
embargo, data de finales de los años setenta del siglo pasado y no ha sido revisado desde entonces. ${ }^{4}$

\section{El concepto de forma}

El concepto de deformación va íntimamente ligado al de forma. De todas las acepciones y actitudes frente a este concepto, nos interesa la forma tal y como lo manejan estos autores. La forma arquitectónica es entendida como una doble estructuración de la materia y el espacio: «un cierto estado de equilibrio entre la estructuración del espacio y de la materia» (BORIE et al. [1978] 2008, 31).

Esta acepción de la forma permite su análisis directo, en sí mismo, no vinculada a otros fenómenos (BORIE et al. [1978] 2008, 21$31)$.

A partir de ahí, el proyecto arquitectónico o «técnica arquitectónica», es la triple adaptación recíproca de las formas y su contexto (humano y físico) (figura 3.1):

- Adaptación de las formas a su 'contenido' [contexto humano], el 'programa'.

- Adaptación de las formas a su 'contexto' [contexto físico], el 'contexto'.

- Adaptación interna de las formas, los 'modelos formales' (coherencia entre la estructuración del espacio y la estructuración de la materia).

(BORIE et al. [1978] 2008, 32).

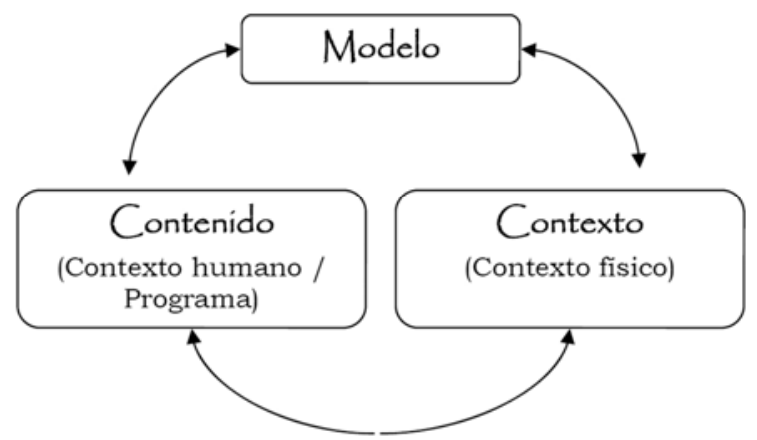

Figura 3.1. Triple adaptación recíproca de las formas y su contexto

4 El vocabulario empleado en este apartado es el empleado en la traducción al castellano del libro (BORIE et al. [1978] 2008). 


\section{Sistema de análisis}

El sistema de análisis de las formas propuesto por estos autores tiene un doble objetivo. Por un lado será el sistema de análisis el que permita definir el concepto de deformación. Por otra parte, el sistema de análisis de las formas será el empleado en el análisis de las deformaciones.

Se proponen dos sistemas de análisis, ambos basados en un desglose del objeto de estudio: ${ }^{5}$

- Primer sistema: desglose en elementos constitutivos.

- Segundo sistema: desglose en niveles constitutivos.

\section{Desglose en elementos constitutivos}

El sistema de análisis por desglose en elementos constitutivos se basa en el método denominado 'análisis estructural' por Christian NorbergSchulz en su libro Intenciones en arquitectura (NOBERG-SCHULZ [1967] 1998, 66). La forma se descompone primero en 'elementos' y luego en 'relaciones' (BORIE et al. [1978] 2008, 36-51) (figura 3.2).

Conviene advertir que, aunque estos autores hablan de «elementos lineales, planos y volumétricos» (BORIE et al. [1978] 2008, 36), el análisis se va a centrar en la representación en planta, donde los elementos son realmente percibidos como puntuales, lineales y planos. ${ }^{6}$

\section{Desglose en niveles constitutivos}

Los niveles constitutivos son «conjuntos de elementos homogéneos entre sí que poseen una estructura propia», distinguiéndose entre el nivel material -estructuración de la materia- y el nivel espacial estructuración del espacio- (BORIE et al. [1978] 2008, 36-37 y 91-96) (figura 3.3).

$5 \quad$ El sistema de análisis es el mismo para las formas arquitectónicas y para las formas urbanas, aunque difieren los niveles constitutivos empleados. Para nuestra investigación, tal sólo nos interesa el análisis de las formas arquitectónicas.

6 Los únicos ejemplos analizados donde se pone de manifiesto la volumetría se encuentran en las páginas 46 y 47. 
Elementos

Elementos lineales

Elementos planimétricos

Elementos volumétricos

\section{Relaciones}

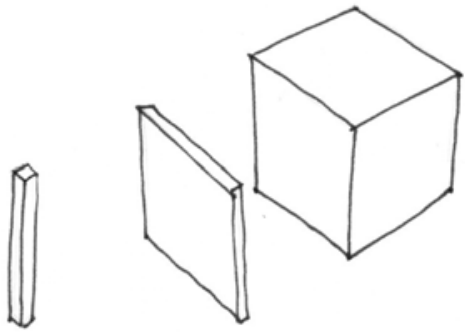

Posicionamiento

Alejamiento Proximidad Unión Inclusión

Obediencia

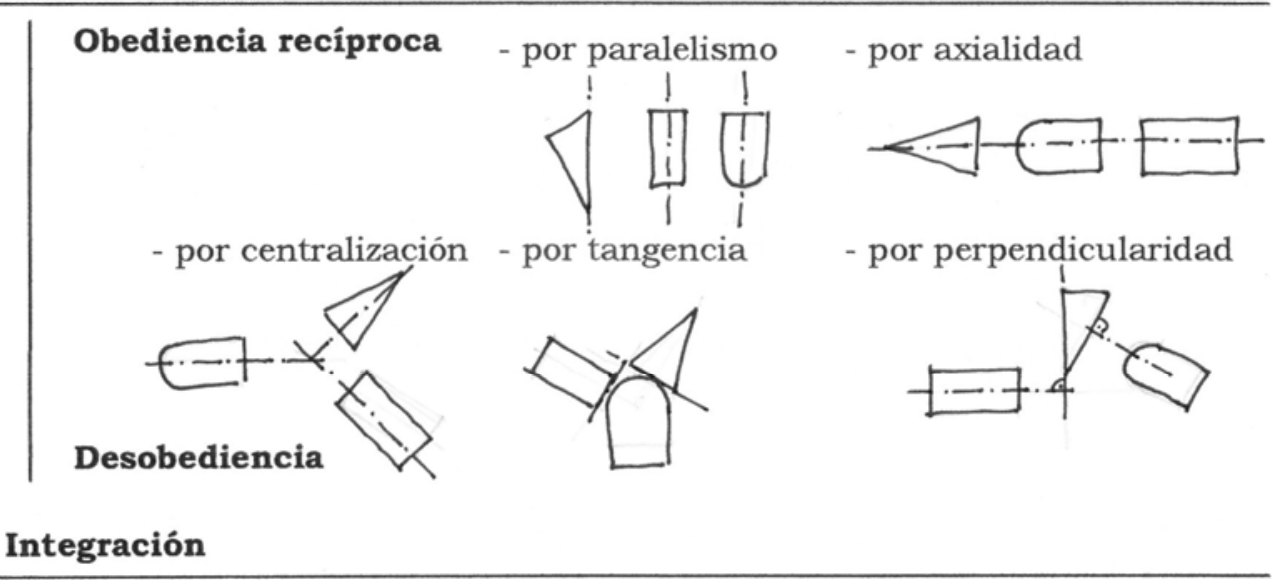

\section{| Integración}

- por repetición

- por subordinación - por unificación

$\square \square \square \square$

$\square \square \square \square$

No integración

- yuxtaposición
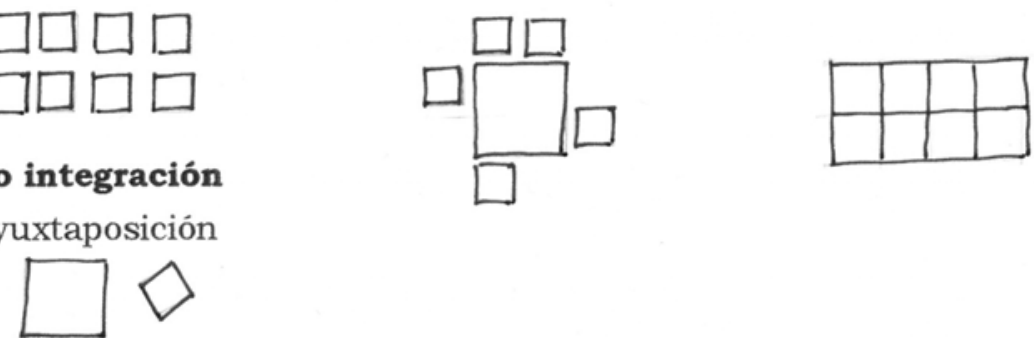

\section{Transformaciones (modalidades de relación)}

Integridad - Desobediencia Deformación-Reobediencia Articulación
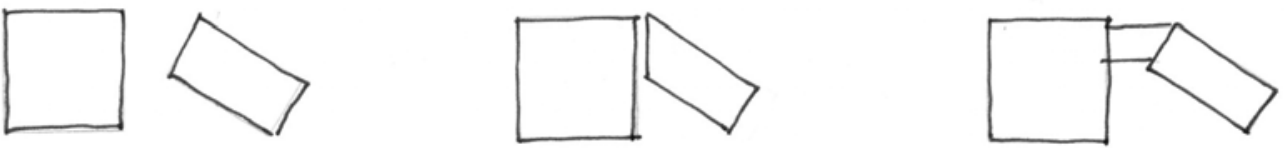

Figura 3.2. Análisis por desglose en elementos constitutivos 


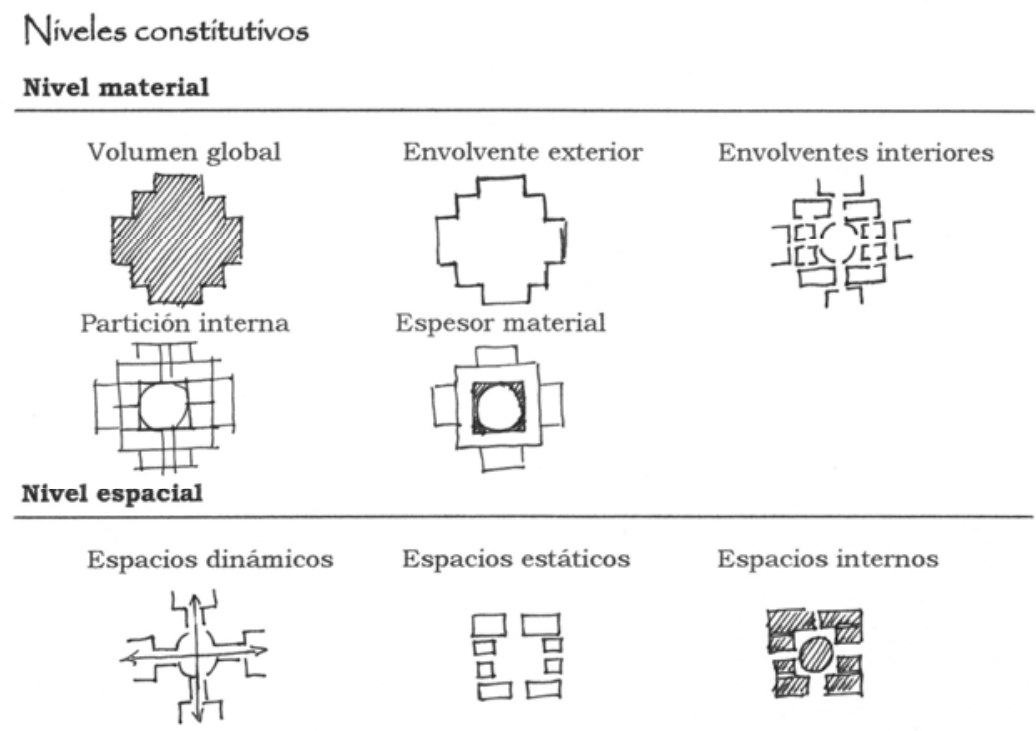

Figura 3.3. Niveles constitutivos

La noción de deformación

«Una deformación es aquella acción que modifica una forma real o virtual» (BORIE et al. [1978] 2008, 86).

Del sistema de análisis anterior se pone de manifiesto que la deformación aparece como una de las modalidades de relación, como alternativa a la integridad y la articulación, y exige unas condiciones formales de posicionamiento y desobediencia -0 de geometrías incompatibles-.

Veíamos que la técnica arquitectónica es la triple adaptación recíproca de las formas y su contexto -humano y físico-. Una deformación aparece como consecuencia de una contradicción, un desequilibrio, entre los datos del programa, el contexto y el modelo formal (figura 3.4):

- Contradicción entre datos de un programa.

- Contradicción entre los datos del programa y el contexto.

- Contradicción entre los datos del programa y el modelo formal.

- Contradicción entre el modelo formal y el contexto.

- Contradicción entre dos datos del contexto;

- Contradicción entre dos modelos formales. 


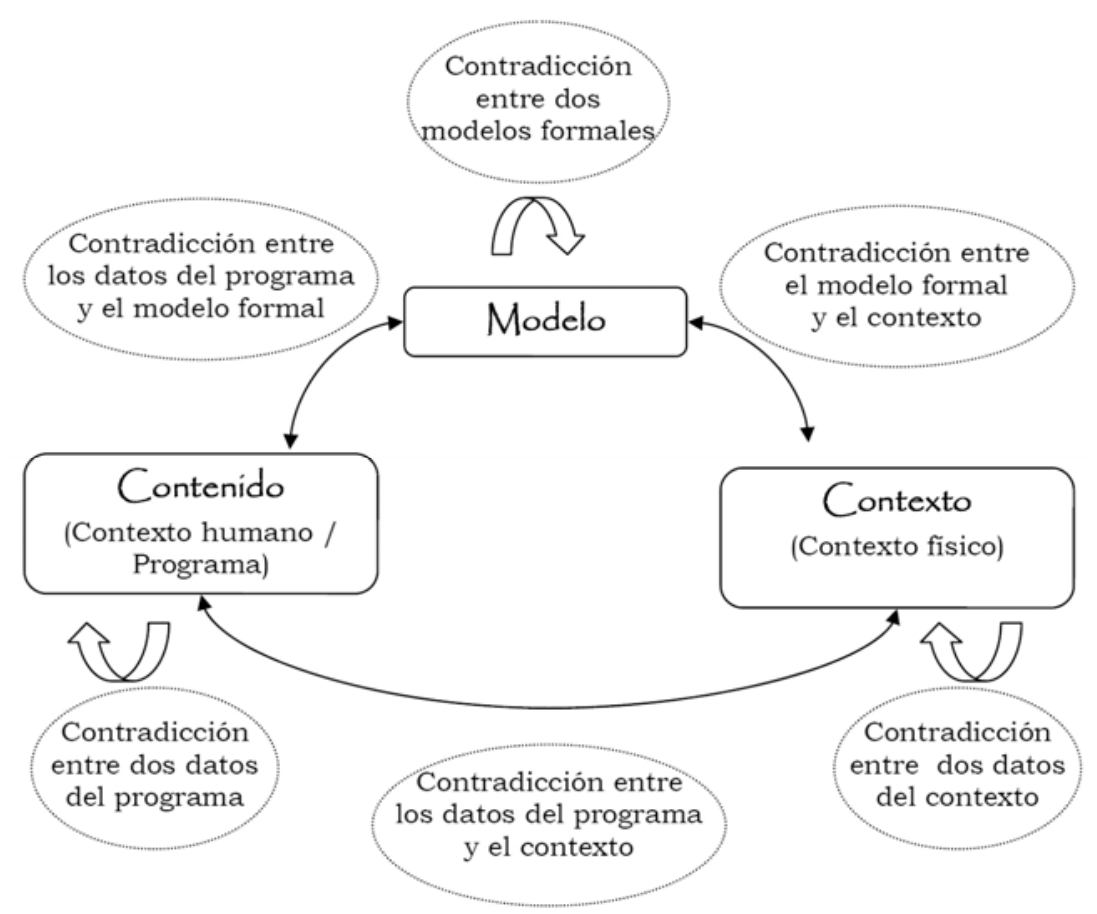

Figura 3.4. La contradicción como origen de la deformación

La contradicción, no resuelta a su nivel, desciende al de las formas dando lugar a la deformación.

De lo anterior se distinguen dos tipos de contradicciones, y por lo tanto dos tipos de deformaciones (figura 3.5):

- Las obligadas, que se sufren, y que provienen de una incompatibilidad entre los datos del programa y/o del contexto.

- Las deliberadas, que se quieren, y que responden a voluntades formales. Estas últimas, a su vez, se pueden distinguir entre:

- Las que deforman para conservar o restablecer un orden estético (estilísticas).

- Las que deforman para singularizar (semióticas).

Como veremos, la distinción entre deformaciones obligadas y deliberadas, vinculando las primeras a «los datos del programa y del contexto físico» (BORIE et al. [1978] 2008, 59), y las segundas a una contradicción entre modelos formales no es clara.

Además, la contradicción debe ser asumida por un solo elemento a nivel formal, lo que se denomina «la doble obediencia» (BorIE et al. [1978] 2008, 55). 


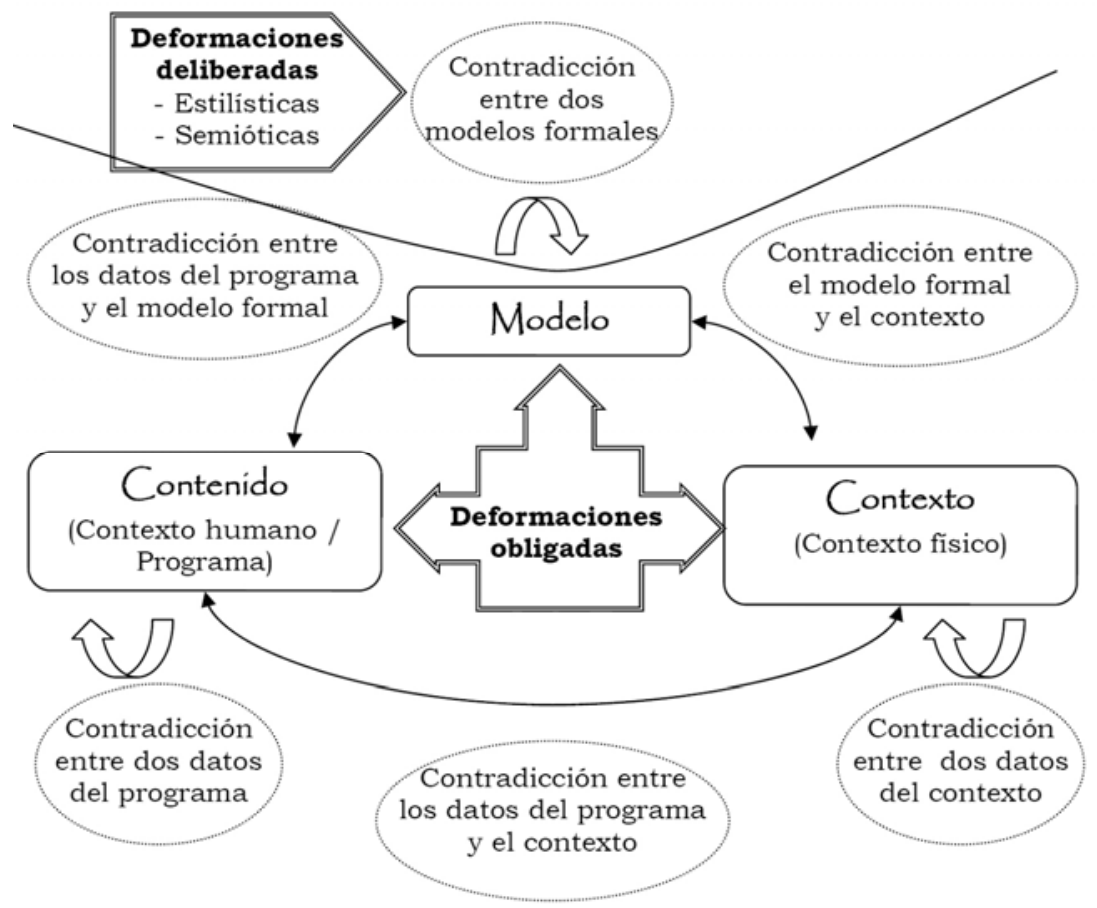

Figura 3.5. Distinción entre deformaciones obligadas y deformaciones deliberadas

$\mathrm{Al}$ revisar las posibles causas -formales- de posicionamiento y desobediencia éstas pueden agruparse en un número limitado de categorías:

- Relaciones estático-dinámicas, entre espacios estáticos y espacios de circulación, donde la deformación puede ser asumida por uno u otro.

- Inclusión de geometrías incompatibles (p. ej. circular y ortogonal), o de un orden geométrico y otro orgánico.

- Desajuste axial entre dos ejes que no son ni paralelos ni perpendiculares. $^{7}$

Por último hay que advertir que no toda contradicción se traduce en deformación; «una yuxtaposición de dos formas desobedientes, incluso con gran contigüidad, no constituye una deformación» (BORIE et al. [1978] 2008, 82). Por este motivo para que una deformación pueda ser reconocida como tal es necesario que se cumplan tres criterios:

- Que exista una forma inicial, ya que «hablar de deforma no tiene sentido más que si existe una forma inicial de la que pueda provenir».

7 Para un sistema geométrico ortogonal. 


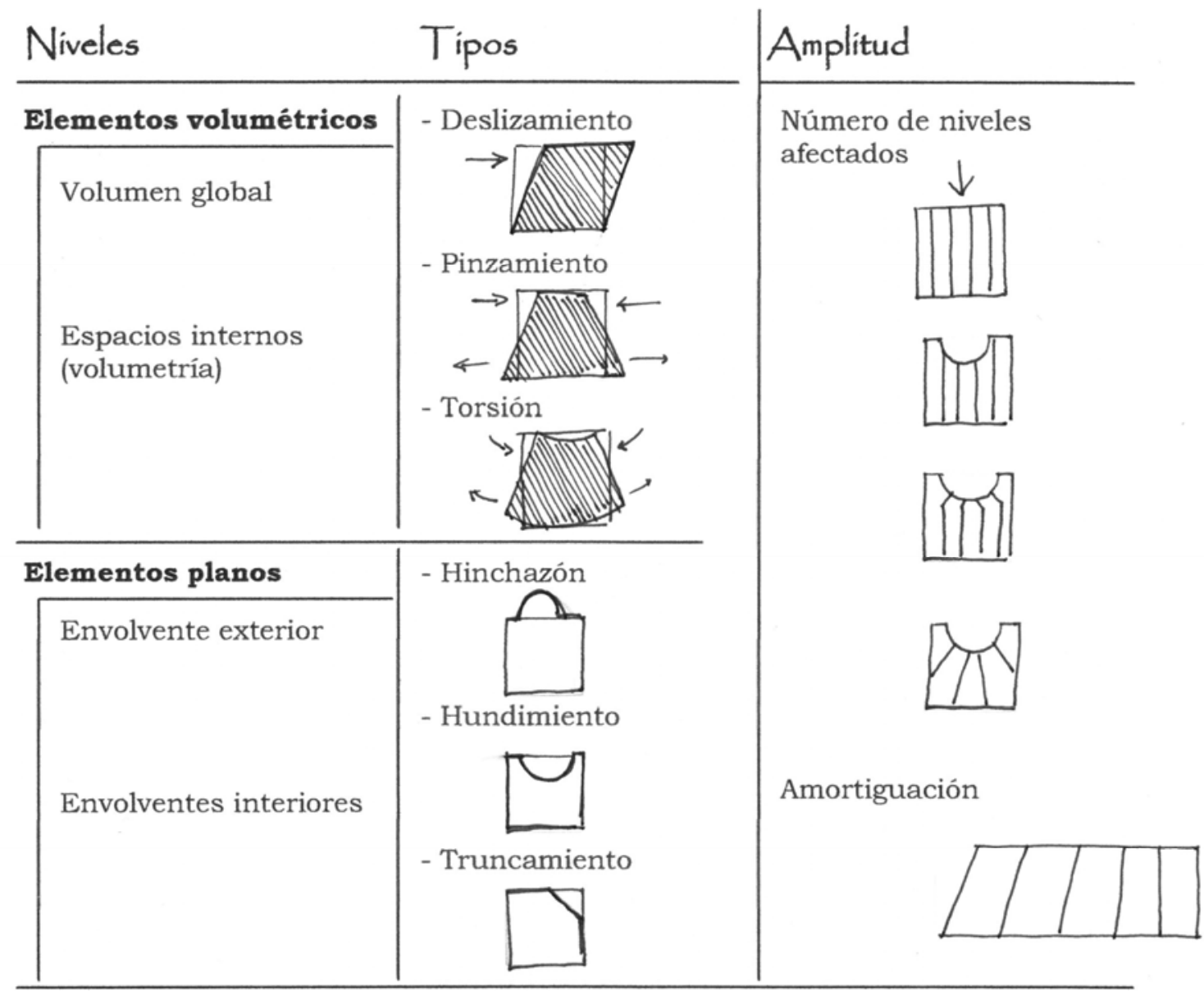

Elementos lineales

Partición interna

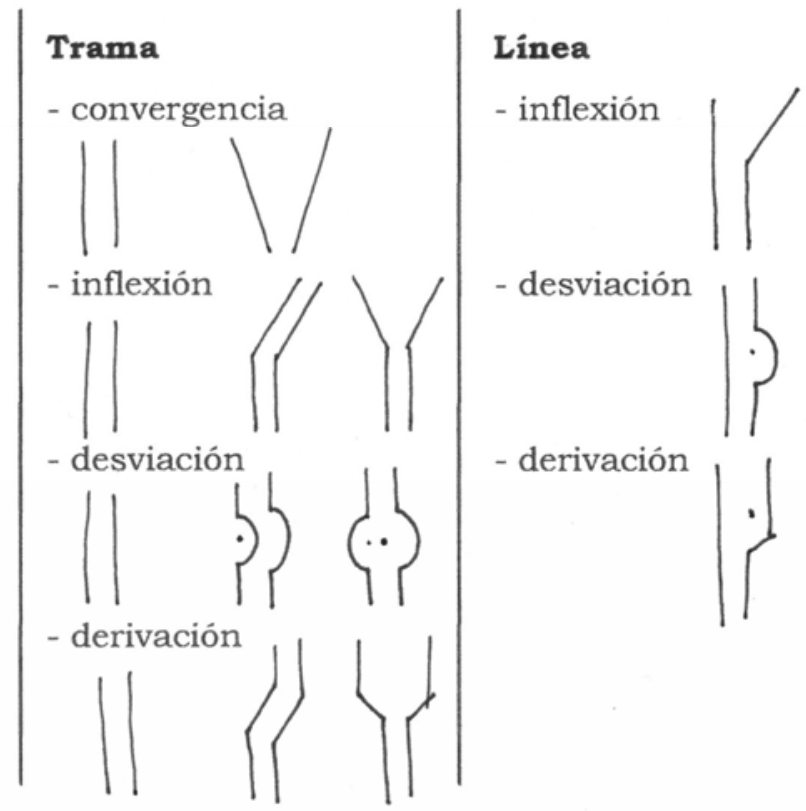

Figura 3.6. Análisis de la deformación 
- «Esta forma inicial debe poder ser reconocida en la deforma». ${ }^{8}$

- La causa de la deformación «debe ser conocida y/o perceptible».

(BORIE et al. [1978] 2008, 82)

\section{Análisis de la deformación}

Identificada una deformación, el sistema de análisis se basa en tres preguntas (figura 3.6):

- «¿Cuál es la parte de la forma sobre la que se aplica la deformación?; (...) ¿cuál es el nivel constitutivo que está implicado?».

- «¿De qué modo se deforma el elemento?, ¿cuáles son los tipos posibles de deformación de un elemento o un sistema geométrico arquitectónico?».

- «¿Cuál es el grado de repercusión de la deformación dentro de la forma dada?, ¿cuál es la amplitud de la deformación?»

(BORIE et al. [1978] 2008, 89-91)

Hay que tener presente que la causa de la deformación ${ }^{9}$ no determina el nivel de aplicación ni el tipo de deformación, y éstos, a su vez, no condicionan la amplitud de la deformación (BORIE et al. [1978] 2008, 99). Además, los niveles constitutivos son a priori independientes unos de otros.

Sí que existe, en cambio, una relación entre los niveles de aplicación y los tipos de deformación posible, aunque esta relación no es unívoca; un mismo nivel puede adoptar distintos tipos de deformación.

En el fenómeno de la deformación no es determinista, lo que implica responder a cada una de las cuestiones por separado para poder analizar la significación de la deformación.

\section{Significación de la deformación}

La significación de la deformación se basa en un doble análisis, el del significante y el del significado.

8 La cursiva es de los autores.

$9 \quad$ En realidad se refieren al origen de la deformación -la contradicción entre modelo, contexto y programa-, no a las causas formales. 
El significante analiza el nivel o niveles a los que se aplica la deformación, el tipo y la amplitud, respondiendo a las preguntas planteadas en el apartado anterior.

El nivel sobre el que se aplica la deformación suele ser el considerado secundario, reflejando la jerarquía entre los distintos niveles. Sin embargo, en algunos casos de deformaciones deliberadas, el nivel deformado es aquel que se quiere destacar.

Una misma contradicción puede dar lugar a distintos tipos de deformación. El tipo de deformación depende del tipo de nivel afectado -volumen, envolvente o trama-. Hay tipos de deformación que son más perceptibles que otros -p.ej. un hundimiento es más perceptible que un deslizamiento (BORIE et al. [1978] 2008, 78) - por lo que el tipo de deformación es reflejo de la actitud frente a la misma. El grado de deformación, su intensidad, es también significativo.

Por último, la amplitud, el número de niveles afectados por la deformación, expresa la fuerza de la deformación frente a la receptividad del elemento deformado. Es raro que la deformación se limite a un único nivel, por lo que la primera dificultad que surge en el análisis es identificar el nivel inicialmente afectado -que estará en relación con la causa de la deformación-. Teóricamente, «la amplitud de la deformación depende ante todo del grado de coherencia interna de las formas» (BORIE et al. [1978] 2008, 99).

Identificada la causa de la deformación, el análisis comienza con la identificación del nivel inicialmente afectado y del tipo de deformación que presenta. A continuación se estudia si hay otros niveles afectados y los tipos de deformación, valorándose la intensidad de la deformación -en un nivel- y la amplitud de la misma -entre unos niveles y otros-. La amplitud de la deformación va ligada a otro fenómeno, el de la amortiguación, que implica un reajuste progresivo e los niveles implicados que atenúa la deformación (BORIE et al. [1978] 2008, 99).

Por su parte, el significado analiza las actitudes ante la deformación, las causas y su efecto.

Las tres actitudes posibles ante la deformación son:

- Rechazo.

- Aceptación.

- Voluntad. 
En los dos primeros casos hablamos de contradicciones obligadas, que se sufren; en el tercer caso hablamos de una contradicción deliberada, que se busca.

Las causas ${ }^{10}$ tienen que ver con la voluntad. En los casos de rechazo de la deformación encontramos una voluntad de conservar la integridad de la forma a cualquier precio. En los casos de aceptación de la deformación, éstas se producen gracias a la flexibilidad del modelo arquitectónico. Por último, en los casos de deformación voluntaria, ésta es buscada, bien por su efecto plástico o para denotar la intención del proyectista.

En cuanto a los efectos, éstos tienen que ver con la modalidad de resolución, que van desde la desintegración del modelo arquitectónico hasta el empelo de soluciones específicas.

(BORIE et al. [1978] 2008, 104-118)

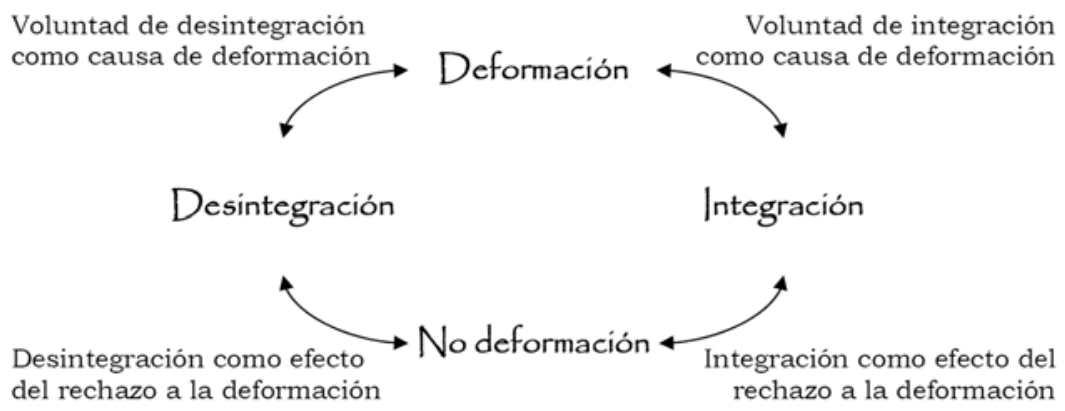

Figura 3.7. Relación integración-deformación

10 No las causas formales, que se han explicado antes, sino las causas como motivos, 'causa o razón que mueve para algo'. 



\subsection{Deformación en arquitectura abovedada. Fundamentos}

Le premier résultat de cette innovation fut d'obliger les constructeurs à composer leurs édifices en commençant par les voûtes, et, par conséquent, de ne plus rien livrer au hasard

(VIOLLET-LE-DUC 1854-1868, 4:44)

El sistema de análisis propuesto por Borie, Micheloni y Pinon, resumido en el apartado anterior, es el marco teórico de referencia para analizar el fenómeno de la deformación. Sin embargo, las peculiaridades del objeto de estudio -la arquitectura abovedadahacen imprescindibles ciertas matizaciones.

\section{Corpus de análisis}

A menudo nos sorprende el aspecto transhistórico de nuestra obra, que mezcla alegremente ejemplos arquitectónicos tomados de todas las fuentes y de todas las épocas.

(BORIE et al. [1978] 208, 17)

La investigación se centra en el campo de la deformación en arquitectura abovedada, pero ha sido necesario acotar el objeto de estudio, restringiendo los tipos de ejemplos a analizar. Nos hemos centrado en arquitectura religiosa occidental y, más concretamente, en el edificio del templo -la iglesia-, aunque haremos referencia al conjunto -monástico o catedralicio- al que pertenece.

Los motivos que justifican esta decisión son los siguientes:

- Es un tipo de arquitectura habitualmente abovedado.

No toda la arquitectura histórica es abovedada; construir una bóveda exigía un coste que sólo podía ser asumido por determinados estamentos. Uno de los objetivos que justificaban el empleo de una bóveda frente a una cubierta de madera más económica, era aumentar la solidez y durabilidad de la edificación frente al fuego -iglesias- o frente a potenciales ataques -castillos-.

- Los ejemplos más innovadores de bóvedas los encontramos, por lo general, en arquitectura religiosa, que constituyen la edificación singular e icónica de la época.

Podríamos decir que los edificios religiosos constituyeron la vanguardia de la edificación durante muchos siglos, actuando como auténticos laboratorios de edificación. En estos edificios es habitual encontrar ejemplos innovadores de 


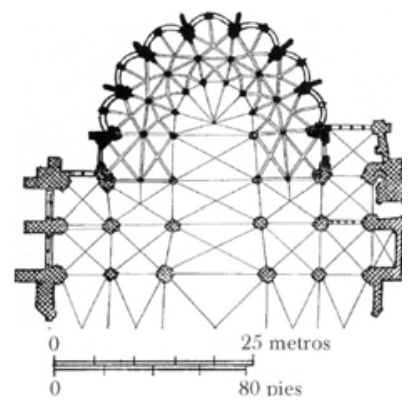

Figura 3.8. Cabecera de la basílica de Saint-Denis (Francia)

(FRANKL [1962] 2002, 105) bóvedas (PALACiOS GONZALO 2009). En la arquitectura civil, en cambio, los ejemplos son más escasos y podríamos decir que menos interesantes. ${ }^{11}$

- Es un tipo de arquitectura que ha llegado hasta nosotros en unas condiciones parecidas a cómo fueron concebidas.

No sólo se trata de una arquitectura hecha para perdurar, además ha continuado en uso hasta nuestros días lo que suele ser garantía de conservación. ${ }^{12}$ Por añadidura, el tipo de uso al que estaban destinadas ha exigido pocas alteraciones a lo largo de la historia. ${ }^{13}$

Por contraposición, una peculiaridad a tener en cuenta es que estos edificios normalmente se han construido a lo largo de períodos dilatados de tiempo, con cambios sobre el proyecto inicial, ampliaciones, reconstrucciones, etc. Estos fenómenos suelen dar lugar a deformaciones por cambios en el proyecto, como el ensanchamiento de la crujía de la Basílica de Saint-Denis (Francia) (figura 3.8) en la unión del presbiterio y el transepto; o por la incorporación de nuevos elementos, como en la girola de la Catedral de Cuenca (figuras 3.9 y 3.10 ).

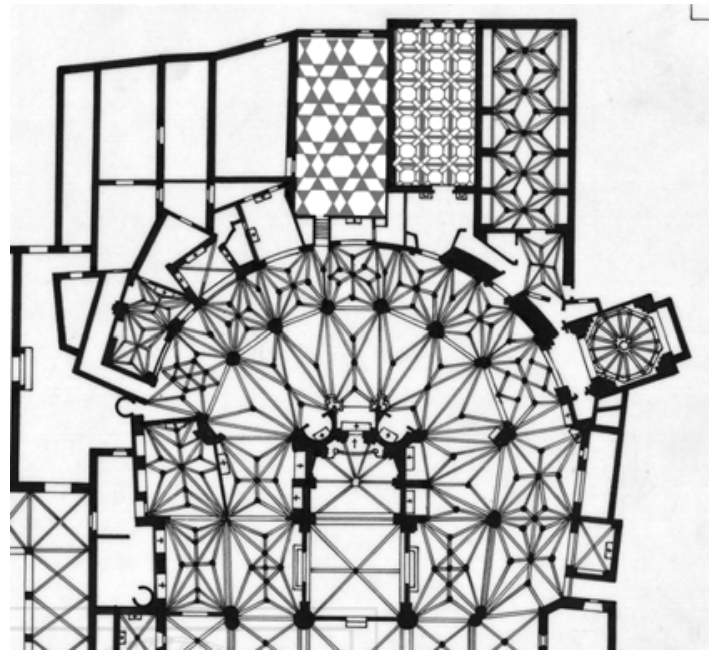

Figura 3.10. Cabecera actual de la Catedral de Cuenca (fuente: IPCE)

11 Con notables excepciones, como las lonjas de Palma de Mallorca y Valencia.

12 Como excepción debemos señalar que algunas situaciones, como las desamortizaciones liberales del siglo XIX en España, condujeron a la desaparición de parte de este patrimonio.

13 No así en el caso de las edificaciones anexas. 
La edificación dilatada a lo largo del tiempo puede no ser el origen de la deformación, pero influir en el modo de resolverla; no es lo mismo que la irregularidad de la parcela se asuma en el proyecto inicial, a que se resuelva en ampliaciones posteriores.

- Suele ser sencillo encontrar documentación.

Normalmente no es difícil encontrar documentación -en especial plantas- de este tipo de arquitecturas -con las salvedades que señalaremos más adelante-, lo que permite tener un corpus de análisis bastante amplio sobre el problema de la deformación para esta primera parte de la tesis. No sucede lo mismo con los conjuntos monásticos o catedralicios donde la documentación, aunque sigue siendo copiosa, no es tan abundante.

Sin embargo, el hecho de centrar el corpus de análisis en las iglesias condiciona las conclusiones a las que podemos llegar, que no serán cómodamente extrapolables al conjunto de la arquitectura abovedada. Conviene advertir además que no toda la arquitectura abovedada responde a los mismos tipos de abovedamiento; la arquitectura oriental se basa en sistemas de cúpulas, con unas reglas compositivas distintas de las capillas cuadradas empleadas en la arquitectura occidental, en la que se centra esta investigación. ${ }^{14}$

Una de las limitaciones se refiere a la relación con el medio urbano, que será abordada en el apartado siguiente. La segunda limitación se refiere la jerarquía entre modelos formales.

En la arquitectura religiosa encontramos modelos formales poderosos -iglesias-, donde es más difícil admitir una deformación por el apego que se produce tanto al modelo geométrico como al modelo funcional. Es habitual que las anomalías se trasladen a las edificaciones anexas -conjunto monástico o catedralicio- donde prima el modelo funcional frente al formal. «En una forma arquitectónica (...), lo más sujeto a deformación es la parte de la forma que no es una 'copia', es decir, que no se considera proveniente de un modelo» (BORIE et al. [1978] 2008, 86). Por este motivo no es infrecuente que las deformaciones se trasladen, cuando es posible, a las edificaciones anexas antes que a los elementos esenciales. La abadía de Fountains en Inglaterra es un ejemplo de esta jerarquización (figura 3.11).

14 La arquitectura occidental también emplea cúpulas, pero normalmente restringidas a ciertas partes del edificio. 
Un ejemplo extremo de esto lo constituye en conjunto monástico de Mont-Saint-Michel en Francia, donde, pese a las dificultades del contexto, el templo es casi regular; ${ }^{15}$ son las edificaciones anexas las que asumen la irregularidad, que se produce no sólo en planta sino también en sección (figura 3.12).
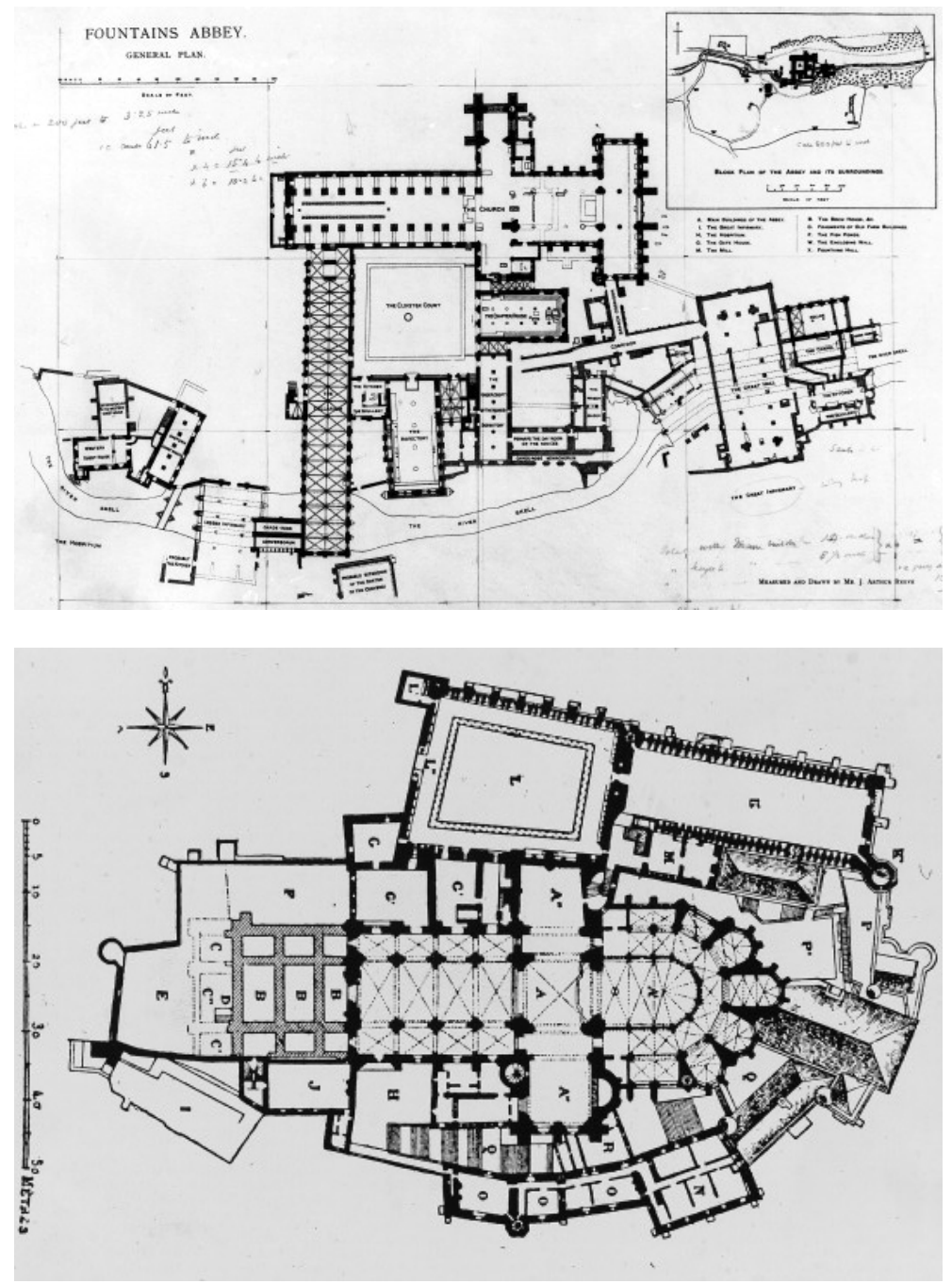

Figura 3.11. Planta de la abadía de Fountains (Reino Unido) de J. Arthur Reeve, Courtauld Institute of Art (fuente: Gotik-Romanik)
Figura 3.12. Planta de la abadía de Mont-Saint-Michel (Francia), Courtauld Institute of Art (fuente: Gotik-Romanik)

La arquitectura se basa en el uso de modelos, siendo significativo en su análisis, no sólo el uso que hace de los mismos, sino la posibilidad «de que éstos puedan ser modificados y la manera en que se les modifica» (BORIE et al. [1978] 2008, 104).

15 El transepto norte es un trapecio rectángulo ya que el muro norte sigue la alineación del claustro. El transepto sur está ligeramente esviado. 


\section{Medio urbano y deformación}

En cierta medida se puede hablar pues de una subordinación de la arquitectura a la morfología urbana.

(BORIE et al. [1978] 2008, 77)

Esta tesis se centra en la deformación en arquitectura abovedada, independientemente del conflicto con el medio urbano del que surge; para el estudio previo de dicho conflicto remitimos al libro de Borie et al. Sin embargo, de nuevo condicionado por la elección del corpus de análisis, hay algunas consideraciones de la relación entre edificación religiosa y medio urbano que es necesario tener en cuenta.

Estos autores ya señalaron la importancia del medio urbano ya que «los objetos arquitectónicos no pueden separarse de su contexto físico», y habiendo constatado que «la deformación aparece precisamente en la unión de estos dos ámbitos (arquitectónico y urbano), bien porque lo urbano deforme lo arquitectónico, bien porque, menos frecuentemente, lo arquitectónico deforme lo urbano» (BORIE et al. [1978] 2008, 104-118).

Sin embargo la subordinación de lo arquitectónico a lo urbano no es tan fuerte en el caso de la arquitectura religiosa. Por un lado la arquitectura religiosa por lo general disponía de los medios para expropiar terreno, y librarse, al menos en parte, de los condicionantes del parcelario y el viario. El ejemplo de la Catedral de Segovia es paradigmático en este sentido: pese a estar situada en el medio de un casco urbano ya consolidado cuando se construyó en el siglo XVI, su planta se impone con rotundidad (fig. 3.13). No obstante encontramos excepciones a esta situación como en Saint-Aspais de Melun (Francia) (figs. 3.38 y 3.39) o la catedral de Bautzen (Alemania) (fig. 3.14). ${ }^{16}$

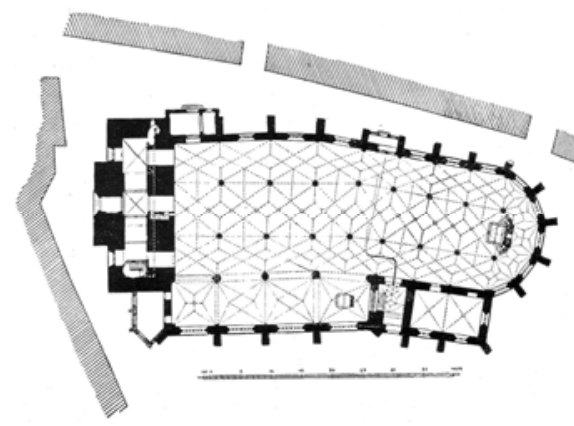

Figura 3.14. Catedral de Bautzen (Alemania), según planta de Rauda (1825) (fuente: Wikipedia.org)

16 No pretende esta tesis profundizar en estas consideraciones de tipo histórico, sociológico, económico; tan sólo constatamos que el número de deformaciones que podemos encontrar en arquitectura religiosa es menor que en la arquitectura civil de ese mismo período. 


\section{Planta y sección}

En lo relativo a los fenómenos de deformación, rápidamente nos hemos dado cuenta de que la representación en planta (la proyección horizontal) era la que mejor revelaba el fenómeno, al ser pocas las deformaciones compositivas que aparecían en la representación vertical, debido a la influencia de las limitaciones constructivas. $\quad$ (BORIE et al. [1978] 2008, 36)

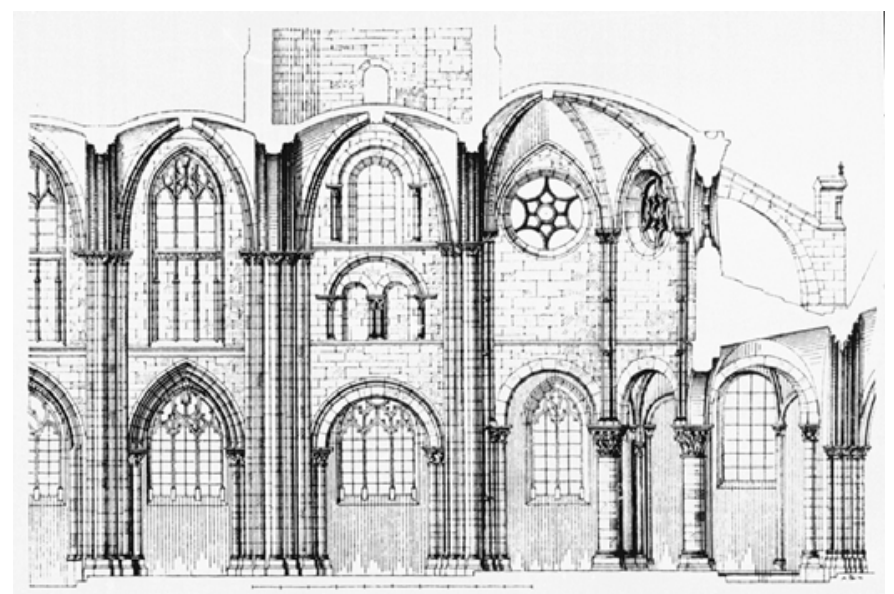

Figura 3.15. Sección de la cabecera de la Colegiata de Poissy (Francia) según Dehio-Bezold (fuente: Gotik-Romanik)

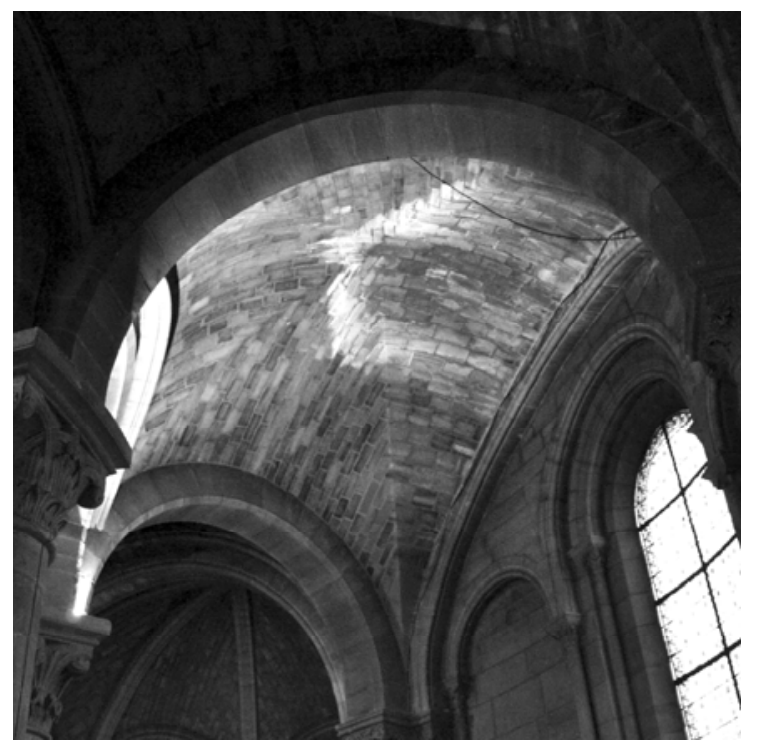

Figura 3.17. Detalle de la bóveda de la girola de la Colegiata de Poissy (Francia)

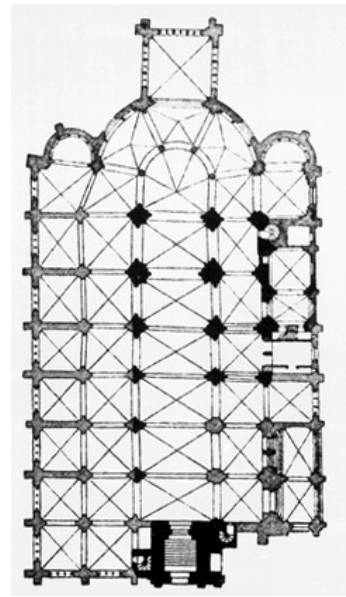

Figura 3.16. Planta de la Colegiata de Poissy (Francia) según Dehio-Bezold (fuente: Gotik-Romanik)

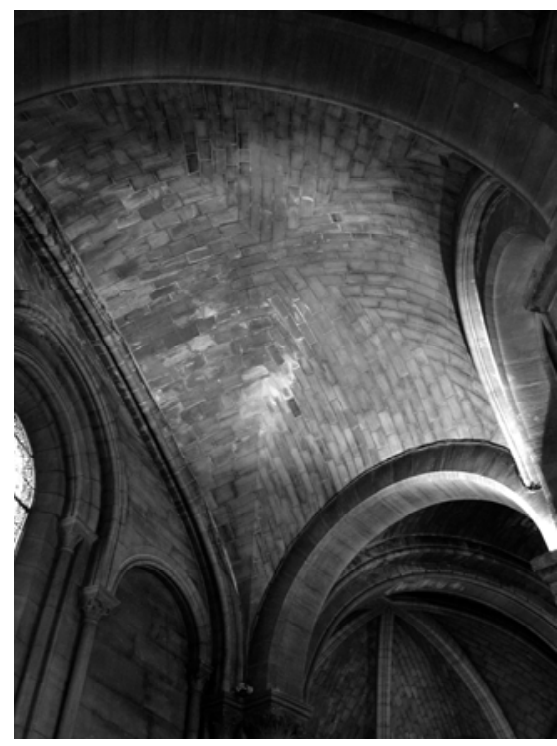

Figura 3.18. Detalle de la bóveda de la girola de la Colegiata de Poissy (Francia)

Por este motivo, Borie et al. centran su análisis en la representación en planta, que les permitirá además «la comparación de 
gran número de ejemplos» (BORIE et al. [1978] 2008, 17). Ya hemos señalado además que quedan fuera del objeto de estudio de esta tesis los problemas de deformación de bóvedas en sección (cfr. capítulo 1, apartado 1.4).

Sin embargo, el análisis del fenómeno de la deformación en arquitectura religiosa abovedada exige una consideración de los problemas derivados de la sección que hacen que el análisis en proyección horizontal, aunque sirva como punto de partida, no sea suficiente. Los motivos son tres:

- En primer lugar porque una bóveda es un objeto tridimensional y una deformación de la planta implica una deformación de la sección que no es inmediata, ni sencilla, tal y como ejemplifican las bóvedas de la girola de la Colegiata de Poissy (Francia) (figuras 3.15, 3.16, 3.17 y 3.18). De todas formas, una primera aproximación a través de la planta sigue siendo válida como punto de partida, pero debe ser completada con un análisis en sección que implica la materialización de la bóveda. Sobre los aspectos relacionados con la volumetría se profundiza en el capítulo 5 y en la segunda parte de la tesis.

- En segundo lugar, porque algunos condicionantes surgen de problemas derivados de la sección. El abovedamiento de un deambulatorio puede venir condicionado por la presencia de galerías superiores, tal y como señala Viollet-le-Duc (VIOLLET-LE-DuC 1854-1868, 9: 489). O por la necesidad de apoyar la estructura de cubierta condiciona la altura relativa de una bóveda y sus arcos perimetrales (VIOLLETLE-DUC 1854-1868, 9: 510).

- En tercer lugar porque, al contrario que la mayor parte de la arquitectura civil, aunque la planta de un templo se desarrolle en su mayor parte sobre un plano, sin embargo no suele tener una sección constante, siendo frecuentes los cambios de altura de unas naves a otras. Esta realidad no deja constancia en la planta y sin embargo influye en el análisis, ya que un cambio en la altura de las bóvedas independiza o relaciona dos elementos (cfr. capítulo 3, apartado 3.4).

Por otra parte, tal y como se explicará en el subapartado «Deformación y percepción», los cambios de altura pueden ocultar la percepción de la deformación, fenómeno que no es ostensible en la planta. 
También hay que añadir otra peculiaridad del objeto de estudio: el hecho de que, independientemente de la sección, los problemas de deformación de una bóveda no están sólo asociados a una deformación en planta: algunas bóvedas deformadas responden a un perímetro regular donde en apariencia no hay deformación (cfr. capítulo 5, apartado 5.2). Un perímetro regular pero con asimetría de apoyos plantea un problema de deformación de la bóveda; al contrario que el ejemplo recogido por Borie et al., donde este «solape de geometrías compatibles» no provoca una «deformación real» (BORIE et al. [1978] 2008, 61) (figura 3.19). Es más, aunque tanto la forma del perímetro como la disposición de apoyos sean regulares, encontramos ejemplos de bóvedas deformadas por el diseño asimétrico de su nervadura (cfr. capítulo5, apartado 5.2 y capítulo 7, apartado 7.1).

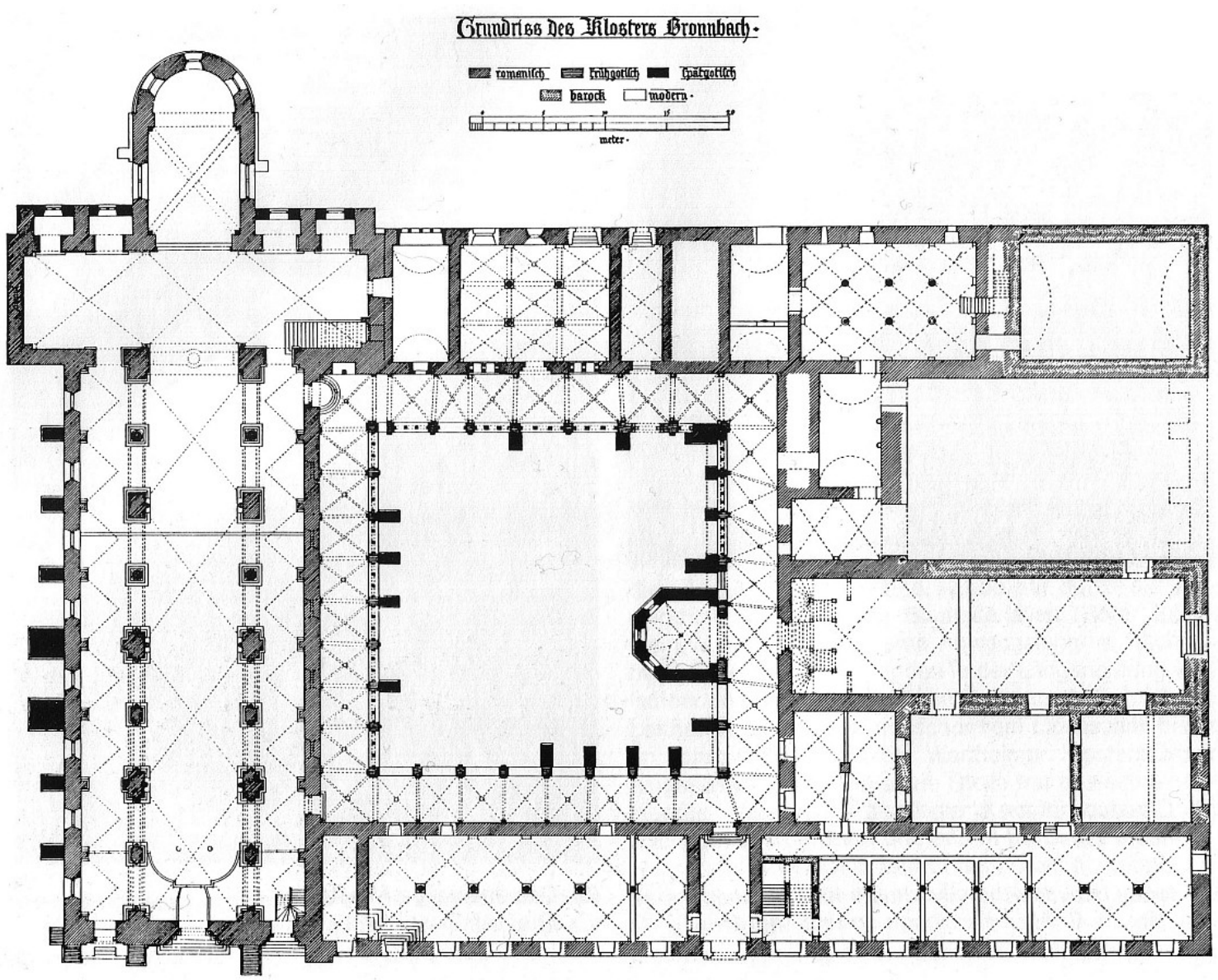

Figura 3.19. Planta de la Iglesia abacial de Bronnbach (Alemania) (fuente: Wikipedia.org)

Por último hay que advertir que, aunque abunda la documentación sobre templos, en especial plantas, es frecuente encontrar errores -en especial en la zona de la girola-, tal y como vemos en los distintos dibujos -incluso maquetas- de la Catedral de Málaga (cfr. capítulo 8, apartado 8.2). 


\section{Proyección horizontal. Limitaciones}

A pesar de lo dicho anteriormente, el uso de la proyección horizontal -la planta- sigue siendo el mejor modo de abordar un primer análisis de los problemas de deformación, si bien es necesario completarlo con una intuición de la sección.

Bruno Zevi ha señalado e insistido en la imposibilidad de representar completamente el espacio arquitectónico a través de un solo dibujo -ni siquiera de la combinación de varios dibujos y fotografías- (ZEVI [1948] 1998, 34), a pesar de lo cual «la planta es todavía el único medio que nos permite juzgar el organismo entero de una obra arquitectónica» (ZEVI [1948] 1998, 34).

A la hora de analizar el fenómeno de la deformación en arquitectura abovedada a través de la planta encontramos dos limitaciones. La primera, y fundamental, es que en las plantas convencionales «no se expresa la jerarquía de alturas de cada uno de los distintos vacíos» (ZEVI [1948] 1998, 41) (figura 3.20).

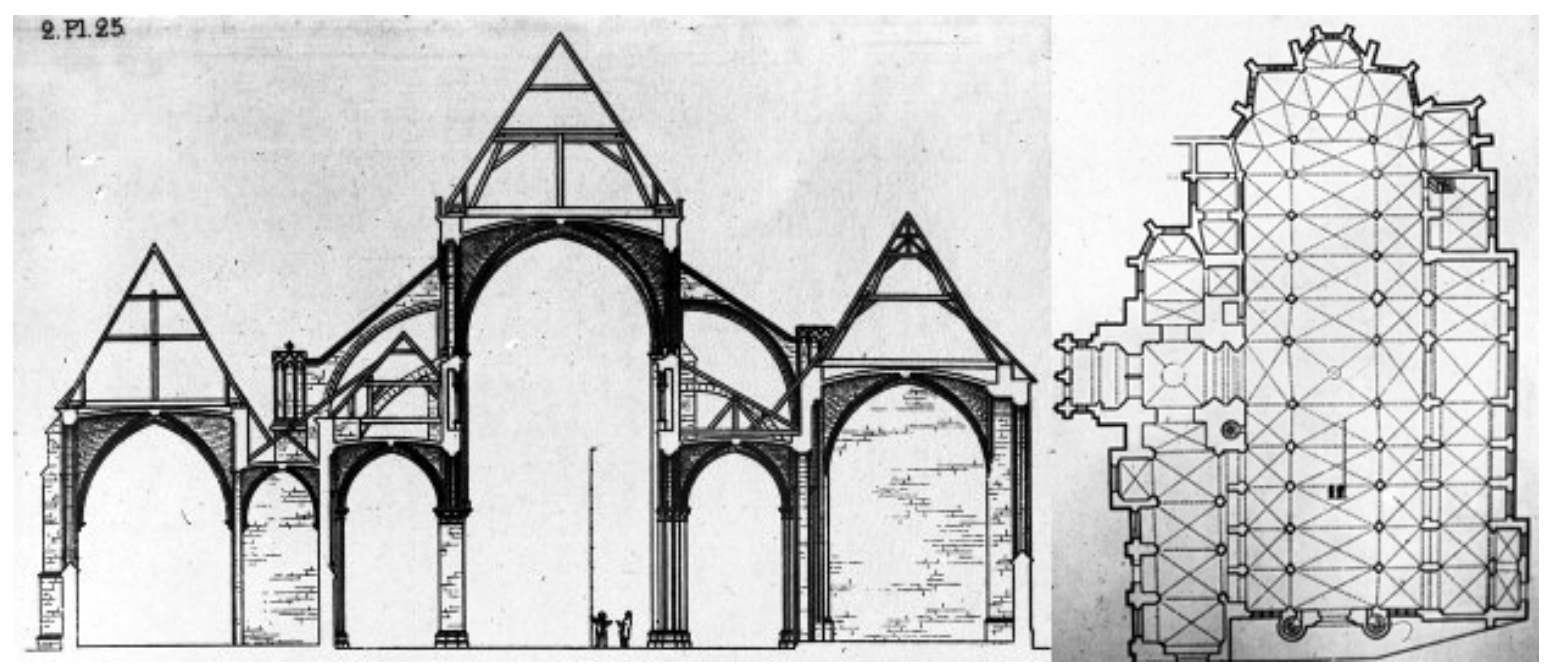

Figura 3.20. Sección y planta de la iglesia de Nuestra Señora de Brujas -Onze-Lieve-Vrouwekerk- (Bélgica) (Courtauld Institute of Art) (fuente: Gotik-Romanik)

La segunda limitación evidente de la planta es que ésta no puede reflejar satisfactoriamente la forma de la bóveda -ni siquiera el tipo de bóveda empleada-. En los casos de bóvedas nervadas o de arista, sí que hay una primera intuición a través del trazado de los nervios y las aristas, ${ }^{17}$ que debería ser a trazos o puntos para indicar

17 Aunque en muchas ocasiones se confundan ambos tipos de bóveda, en particular cuando la escala del dibujo hace que sólo se dibujen los ejes de los nervios. Los casos más confusos los encontramos cuando en el dibujo de la planta de un mismo edificio, se alterna el dibujo de nervios y de aristas empleando el mismo código gráfico. 


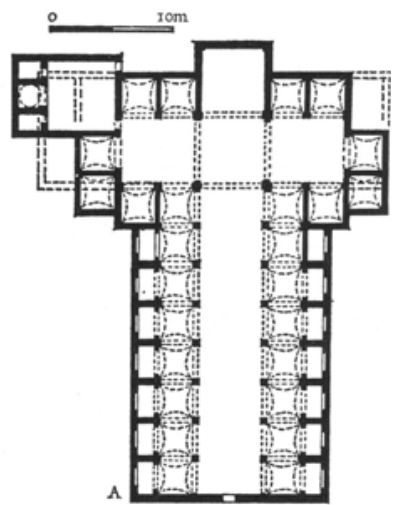

Figura 3.21. Planta de la iglesia de San Lorenzo de Florencia (Italia) (HEYDENREICH y LOTZ [1974] 1999, 22)

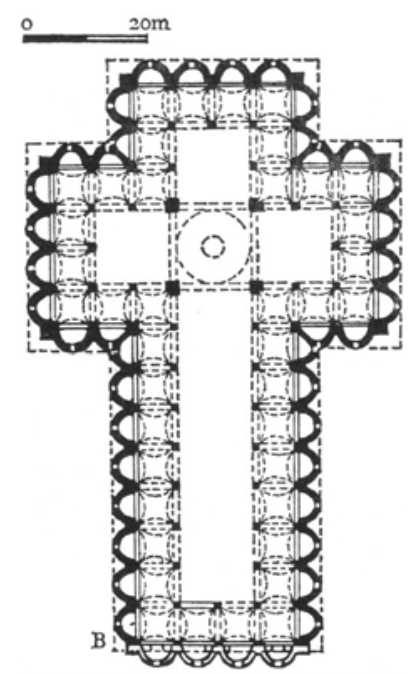

Figura 3.22. Planta de la iglesia del Santo Spirito de Florencia (Italia)

(HEYDENREICH y LOTZ

[1974] 1999, 22)

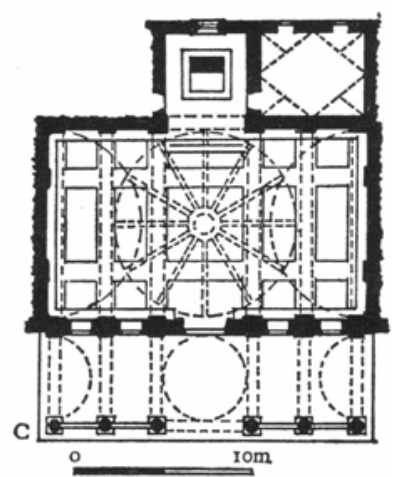

Figura 3.23. Planta de la Capilla Pazzi de Florencia (Italia)

(HEYDENREICH y LOTZ

[1974] 1999, 22) que estas líneas representan algo que sucede por encima del plano de proyección. En los casos de bóvedas baídas se han hecho algunos intentos como en las plantas de las iglesias de San Lorenzo y el Santo Spirito recogidas en manual de Cátedra sobre arquitectura italiana del Renacimiento por (HEYDENREICH y LOTZ [1974] 1999, 22), pero resultan confusas (figuras 3.21 y 3.22). ${ }^{18}$

Esta limitación de la proyección horizontal sólo puede completarse con un dibujo de la sección. El análisis de la deformación en arquitectura abovedada a partir de la planta exige tomar en consideración la sección, aunque ésta no quede reflejada en el dibujo.

Conviene insistir en la primera limitación, ya que puede ser solventada recurriendo a dibujos de planta específicos como los empleados por Bruno Zevi (ZEVI [1948] 1998, 39). Tengamos en cuenta las siguientes consideraciones:

- En primer lugar, es imprescindible tomar en consideración los cambios de altura de las bóvedas -no sólo por su importancia en el análisis, sino también por su importancia en la percepción de la deformación-. No es lo mismo dos bóvedas separadas por un arco perpiaño, que una bóveda que se apoya sobre un muro por medio de un arco formero, en el que se abre un arco inferior sobre el que apoya una segunda bóveda. Esta distinción se puede hacer por medio del sombreado de la planta, empleando distintos sombreados en función del nivel al que se sitúen las bóvedas. ${ }^{19}$

- Relacionado con el anterior, la necesidad de distinguir entre un muro que apoya sobre un arco - o una arquería- y un arco perpiaño -o una sucesión de arcos perpiaños-, ambos reflejados en planta por la sucesión de soportes. Esto sólo puede significarse con el empleo de distintos grosores de línea.

Lo mismo sucede con bóvedas de cañón. Como ejemplo podemos señalar la planta recogida por Borie et al. de la Mezquita y madrasa de Hunat Hatun -en el libro aparece escrito «Huang Hatun»- del siglo XIII, en Kayseri (Turquía) (BORIE et al [1978] 2008, 61), o la de la Capilla Pazzi de Florencia, donde se mezclan las líneas de trazos que indican la sección de la bóveda de cañón con la línea de trazos de la proyección de la cúpula central (HEYDENREICH y LOTZ [1974] 1999, 22) (figura 3.23).

19 Este tipo de dibujos sólo tienen sentido para el análisis y su demostración 
- También es preciso distinguir entre arista, nervios y arcos perpiaños. La distinción entre aristas y nervios es sencilla si, en el caso de los segundos, se dibuja su espesor -posible a partir de cierta escala-.$^{20}$ En el caso de la distinción entre arco perpiaño y nervio, ésta sólo queda reflejada por el distinto grosor de unos y otros. ${ }^{21}$

Todas estas matizaciones no serán necesarias siempre, sino que van en función del estadio de análisis en que nos encontremos. Sí son forzosas para el análisis de la deformación en arquitectura abovedada que proponemos en el capítulo 4 de la tesis, como paso previo al análisis de la deformación de bóvedas. Sin embargo también hay que advertir que no son suficientes para el análisis de bóvedas deformadas, donde el trabajo en sección es ineludible.

Evidentemente, estos criterios no agotan todas las posibilidades, tan sólo hemos indicado aquellos que hemos encontrado necesarios a la hora de analizar el problema de la deformación en arquitectura abovedada. Por ejemplo, en un trazado complejo de nervios de una bóveda de crucería tardogótica, en ocasiones no queda claro si un punto en el perímetro es un apoyo o una clave, como sucede en los laterales de la bóveda de la Capilla de La Antigua en la Catedral de Sevilla (MARTín TALAVERANO et al. 2012, 86-87) (figs. 3.24 y 3.25).

Por contrapartida, nos encontramos también con bóvedas que se apoyan sobre un muro que descansa sobre un arco, normalmente debido a fases constructivas sucesivas distintas. En este tipo de bóvedas, como las de la girola de la antigua Catedral de SaintTrophime de Arlés, el apoyo no se manifiesta en la planta lo que dificulta su análisis (figuras 3.26 y 3.27).

Debemos ser conscientes además de que intentar explicar todo el edificio a través de un único dibujo implica dejar algunas incompletas y que las características concretas de un edificio pueden hacer aconsejable otras medidas.

20 Otra distinción sería entre nervios sobre los que apoya directamente la plementería, de aquellos nervios sobre los que se levanta un murete que separa el nervio de la plementería (MARTín TALAVERANO 2011; WENDLAND et al. 2014).

21 Desde el punto de vista de la construcción geométrica de la forma de la bóveda, independientemente de su función estructural, la diferencia entre los nervios y los arcos perpiaños es que estos últimos contribuyen a independizar -o no-bóvedas adyacentes, lo que normalmente queda reflejado en su grosor. Otra cuestión es la insustancial distinción que algunos autores hacen entre los distintos tipos de nervios. 


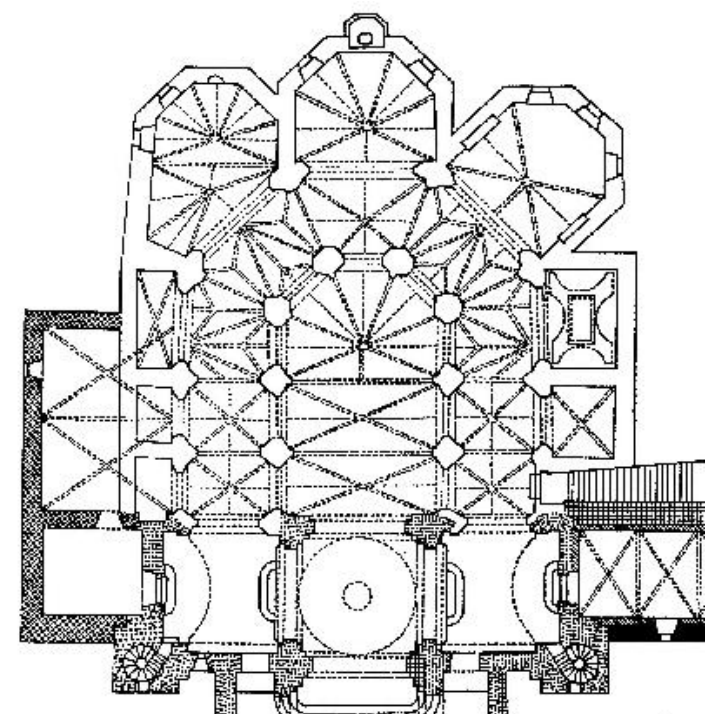

Figura 3.26. Planta de la cabecera de la antigua Catedral de Saint-Trophime d'Arles (Francia) (www.romanes.com) (fuente: Gotik-Romanik)

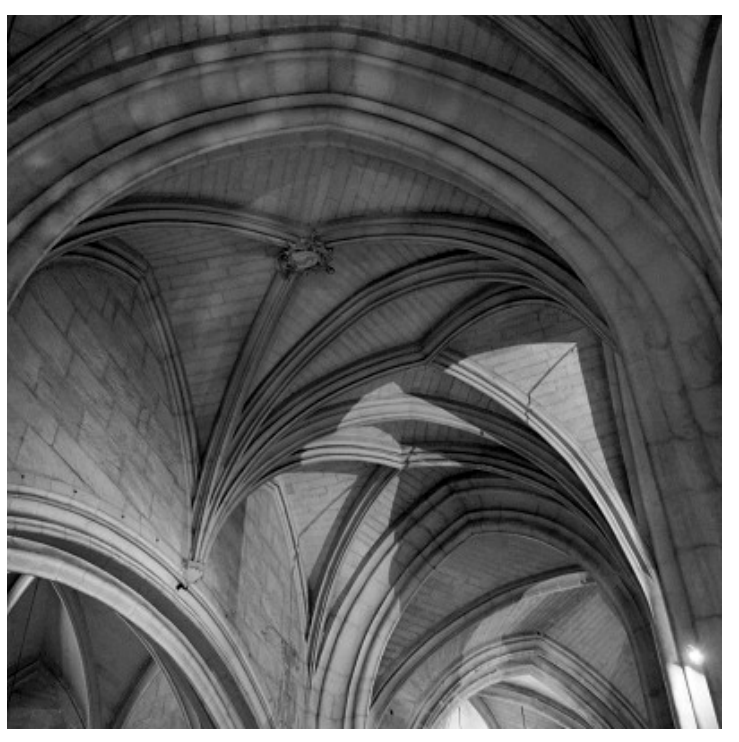

Figura 3.27. Detalle de la bóveda sobre la girola de la antigua Catedral de Saint-Trophime d'Arles (Francia)

(fuente: Gotik-Romanik)

Podemos ilustrar algunos de los problemas que acabamos de señalar con la bóveda de crucería de la sacristía de la Catedral de Perpignan, construida entre 1433 y 1447 por el arquitecto mallorquín Guillém Sagrera. ${ }^{22}$ La sacristía está situada al sureste de la catedral, aprovechando un espacio residual entre el ábside, la capilla de «la Magrana» y el claustro; unas edificaciones de servicio cierran el extremo este del recinto. Se trata de un espacio de perímetro fuertemente irregular fuertemente marcado por la presencia de los contrafuertes del ábside.

Guillém Sagrera resolvió el abovedamiento de la sacristía empleando una solución de pilar central sobre el que apoya una bóveda de crucería de nervadura sencilla. La destreza de su autor no sólo queda reflejada en la maestría con la que resuelve la bóveda, sino en la manera de resolver los apoyos que nacen, a excepción de uno, ${ }^{23}$ directamente del muro sin intermediación de ménsulas o pilares.

Disponemos de tres dibujos de la planta de la sacristía. Los dos primeros se encuentran en la monografía de Gabriel Alomar sobre

22 No hay documentos que prueben que Guillém Sagrera es el autor de la bóveda de la sacristía. Pierre Ponsich (1953) atribuyó la autoría al arquitecto mallorquín en base a los detalles constructivos. La tesis doctoral de Carmen Pérez de los Ríos sin duda contribuirá a arrojar luz sobre esta cuestión (PÉREZ DE LOS RÍOS 2016).

23 (SENENT-DOMínGUEZ et al 2012). 
Guillém Sagrera: un dibujo de la planta completa de la catedral con la sacristía (AlOMAR 1970, 97) y un dibujo de detalle de la sacristía (AlOMAR 1970, 103) (figuras 3.28 y 3.29). El tercero es un dibujo de Besse de 1957 (1957) (figura 3.30).

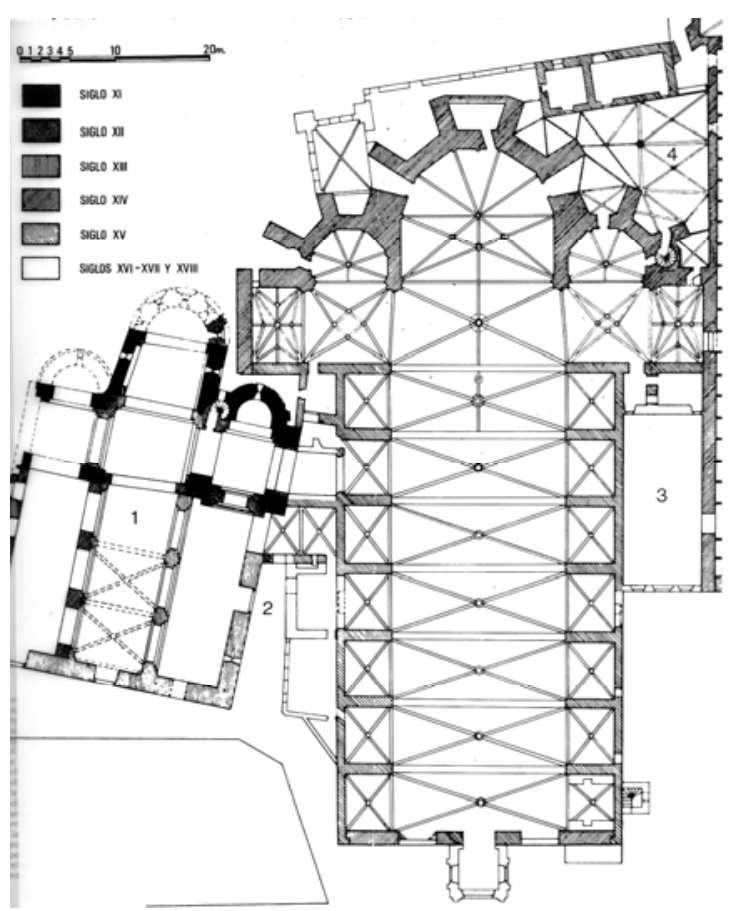

Figura 3.28. Planta de la Catedral de Perpignan publicada por Gabriel ALOMAR $(1970,97)$

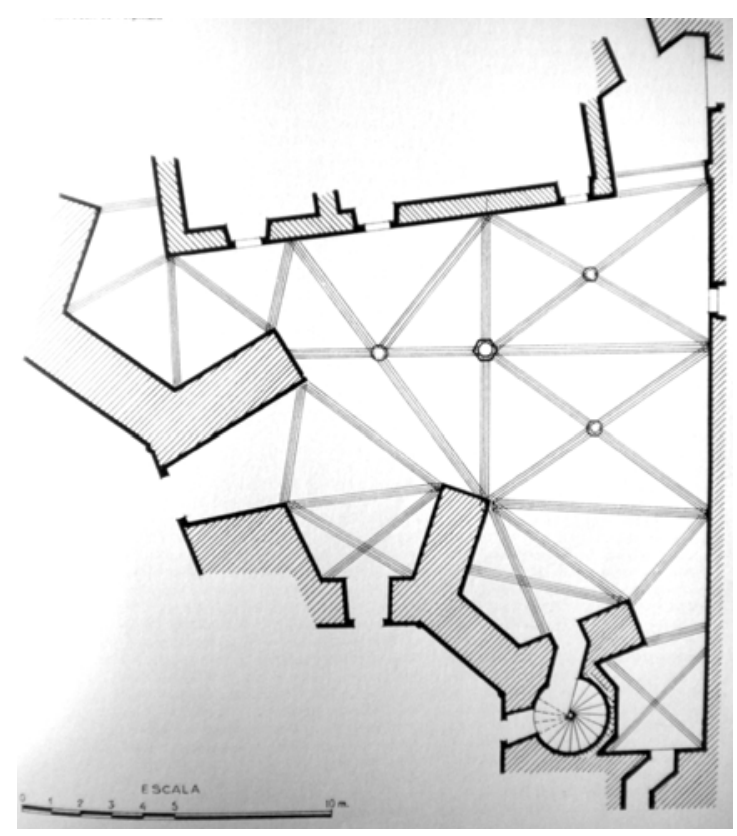

Figura 3.29. Planta de la sacristía de la Catedral de Perpignan publicada por G. AlomAR $(1970,103)$

En los tres dibujos la bóveda se presenta como un galimatías de nervios sobre un perímetro fuertemente irregular, sin límites precisos. Esta imagen no se corresponde con la que percibimos al visitar la sacristía; la sala sigue siendo irregular pero no es tan compleja como se presenta en los dibujos (figura 3.31).

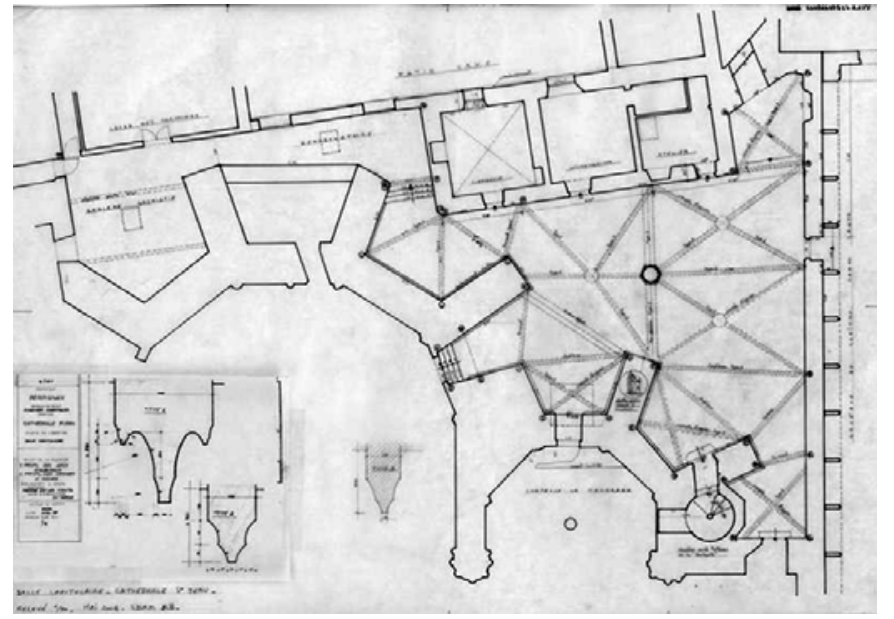

Figura 3.30. Planta de BESSE (1957) de la Sacristía de la Catedral de Perpignan (Médiathèque de l'Architecture et du Patrimoine) 
En primer lugar el perímetro de la bóveda no se corresponde con el recinto, ya que los espacios entre contrafuertes se encuentras abovedados a una altura por debajo de la de la bóveda principal. Lo mismo sucede con la galería que rodea el ábside, y dos espacios residuales en los extremos.

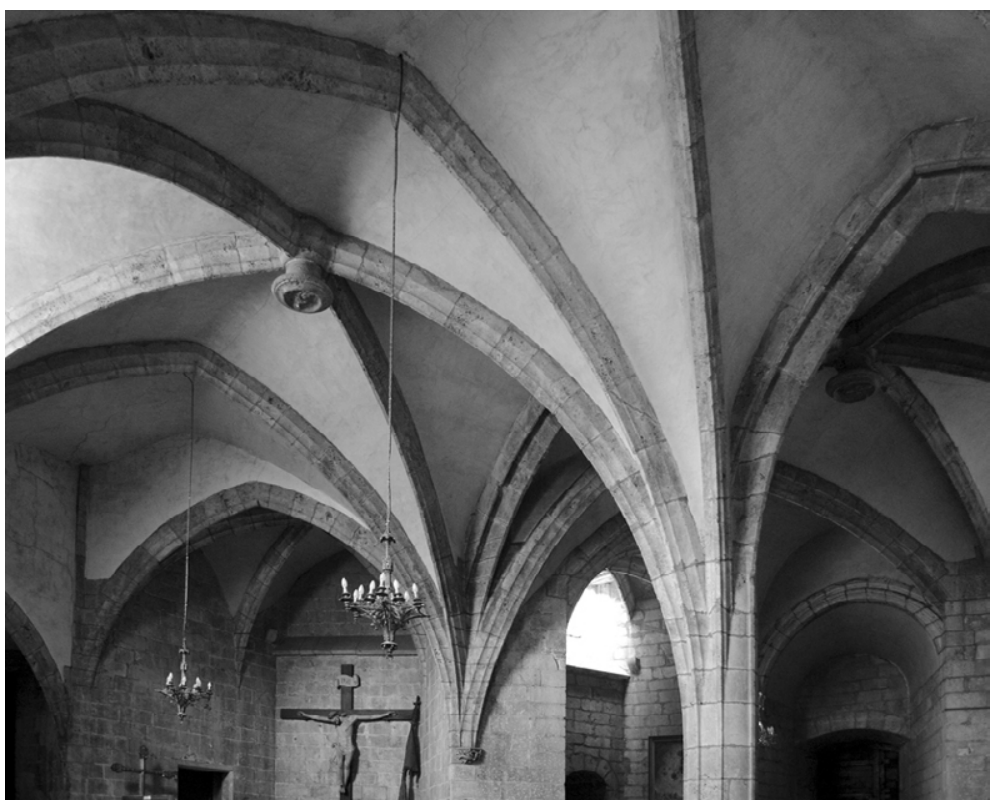

Figura 3.31. Sacristía de la Catedral de Perpignan (fotografía de Carmen Pérez de los Ríos)

Teniendo esto en consideración, el caótico perímetro de la bóveda pasa a ser el de un octógono fuertemente irregular. Sigue siendo complejo, pero no tanto como aparece en los dibujos antes citados.

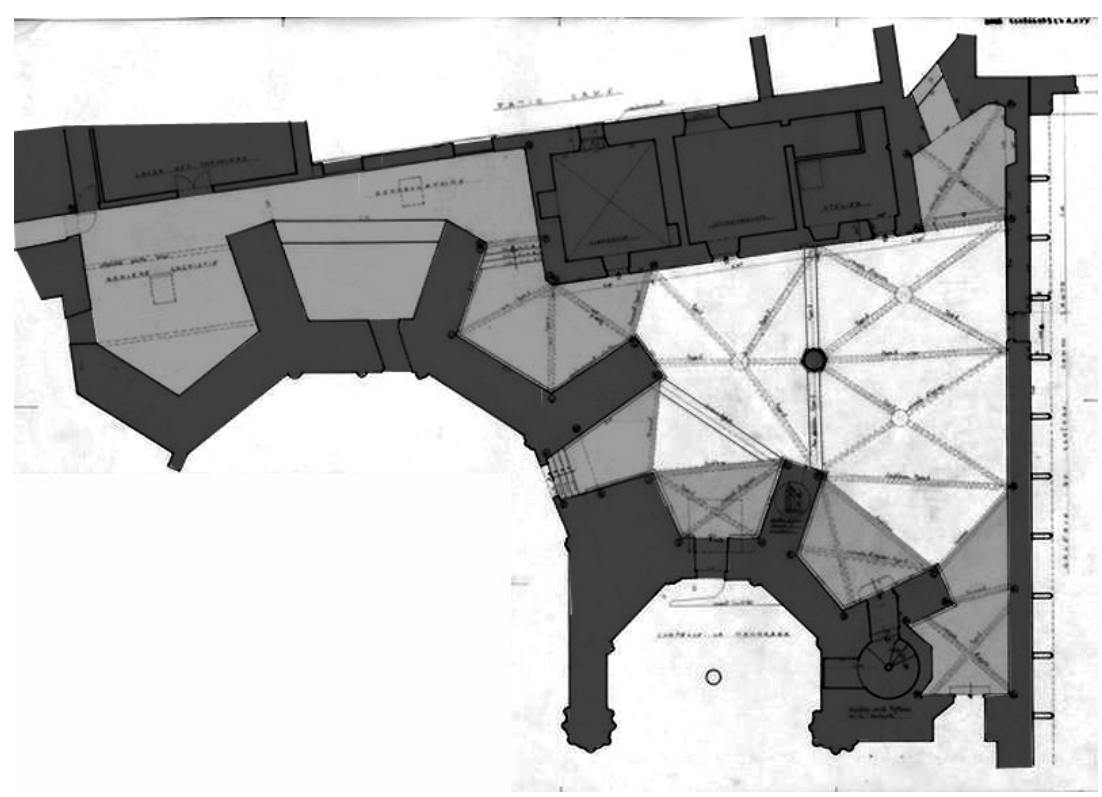

Figura 3.32. Planta de la Sacristía de la Catedral de Perpignan, elaborada a partir de la planta de Besse (fig. 3.30) 
En segundo lugar, de los arcos/nervios que aparecen en el dibujo, dos son potentes arcos apuntados que dividen el espacio de la sacristía en dos. Éstos sí quedan reflejados en el dibujo de Besse pero no en el de Alomar, simplemente por su grosor. Un tercer arco apuntado, une dos contrafuertes no adyacentes, independizando dos sectores de la bóveda. Este arco marca una cierta continuidad con la línea de cierre de los contrafuertes.

Empleando un sombreado para distinguir las cotas de las distintas bóvedas, reflejando en planta el grosor de los distintos arcos y nervios y empleando grosores de línea para distinguir los cambios de plano, obtenemos un dibujo más claro. Evidentemente hay muchos aspectos que no quedan reflejados en la planta, como la complejidad de los apoyos, con nervios que arrancan a distinta altura, pero facilita el análisis (figura 3.32).

En cualquier caso, no debemos olvidar que una planta así dibujada está encaminada a un tipo de análisis concreto, aunque resulta «insuficiente por sí misma» (ZEVI [1948] 1998, 43).

\section{Deformación y representación}

Borie et al. abordan tres puntos en la relación entre deformación y representación, que tienen que ver con la representación durante la fase de proyecto (BORIE et al. [1978] 2008, 78-81):

- «La deformación sin representación gráfica».

- «La representación como obstáculo para la deformación».

- «Las deformaciones específicas de la representación».

«La primera constatación es que las arquitecturas sin arquitecto -por tanto no dibujadas previamente- son muy flexibles a nivel de la adaptación de sus formas a su medio» (BORIE et al. [1978] 2008, 78). Esta afirmación carece de interés para nuestro trabajo, ya que todas las arquitecturas aquí consideradas son arquitecturas con arquitecto. Sí conviene en cambio hacer algunas consideraciones sobre los otros dos puntos.

«A partir del momento en que se concede al dibujo una importancia preponderante, incluso en detrimento del objeto construido, toda desobediencia o imprecisión natural podrá considerarse insoportable, puesto que es contraria al orden formal en que se dibuja» (BORIE et al. [1978] 2008, 79). Por un lado es cierto que a partir del Renacimiento, cuando el dibujo cobra importancia como fin en sí mismo, el número de deformaciones que encontramos 
es menor, o por lo menos se resuelven de manera más consciente. Un buen ejemplo lo constituye el forro exterior de la Basílica de Vicenza (Italia), donde el forro exterior de Andrea Palladio debe adaptarse a las numerosas irregularidades del edificio preexistente (figura 3.33).

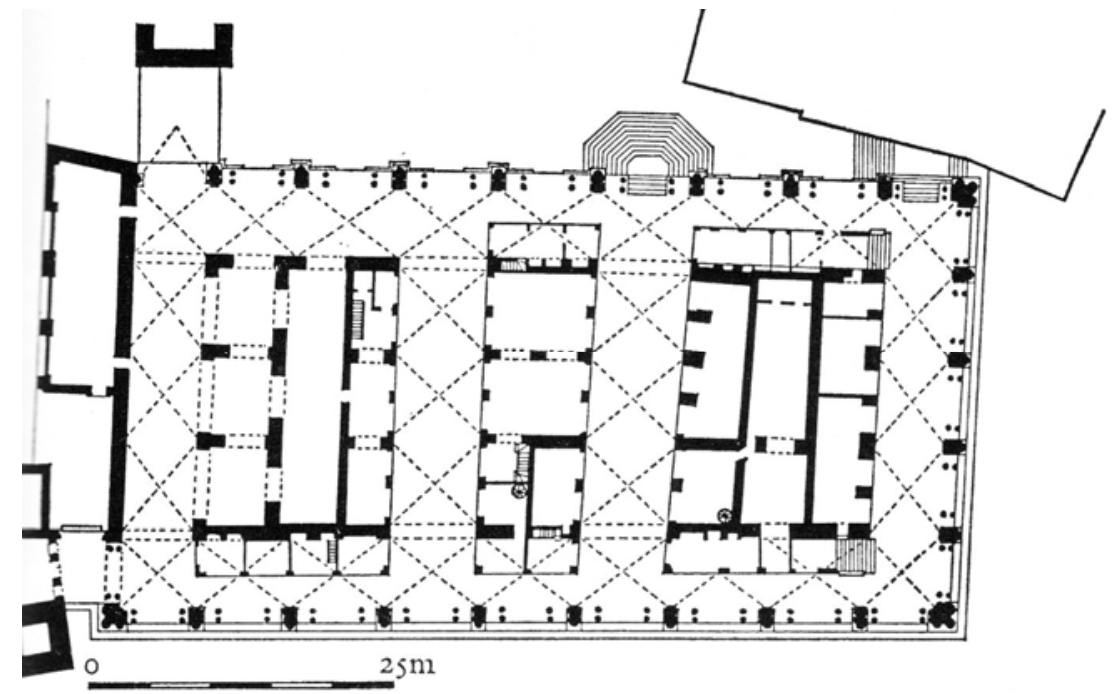

Figura 3.33. Planta de la Basilica Palladiana de Vicenza, cuyo forro exterior es obra de Andrea Palladio (HEYDENREICH y LoTz [1974] 1999, 493)

Sin embargo, la visión sinóptica que da el dibujo y que es obstáculo para la deformación, permite a su vez nuevas formas de resolver la contradicción por medio de deformaciones específicas como son las articulaciones circulares -rotondas, hemiciclos...- y la repetición por simetría. En el caso de la arquitectura abovedada encontramos una circunstancia curiosa. A partir del Renacimiento comienzan a proliferar los proyectos donde se recurre al elemento circular -como los patios de Sebastiano Serlio o los proyectos neoclásicos de Jean-Nicolas-Louis Durand ([1760-1834] 1795-, sin embargo el número de ejemplos de bóvedas sobre planta anular se reduce drásticamente, bien porque no se abovede -como en el atrio del Altes Museum de Berlín- o bien porque finalmente no se construyan plantas anulares, tal y como sucedió con el proyecto de Bramante para el claustro de San Pietro in Montorio en Roma (Italia) (cfr. capítulo 4, apartado 4.1).

Todas estas reflexiones se refieren al dibujo de proyecto, sin embargo conviene hacer algunas consideraciones sobre el dibujo de levantamiento, el del objeto ya construido. Borie et al. hablan del dibujo como obstáculo para la deformación, «si de simple medio compositivo pasa a ser un fin en sí misma» (BORIE et al. [1978] 2008, 80), esta situación se da también a la hora de representar un edificio ya construido. 


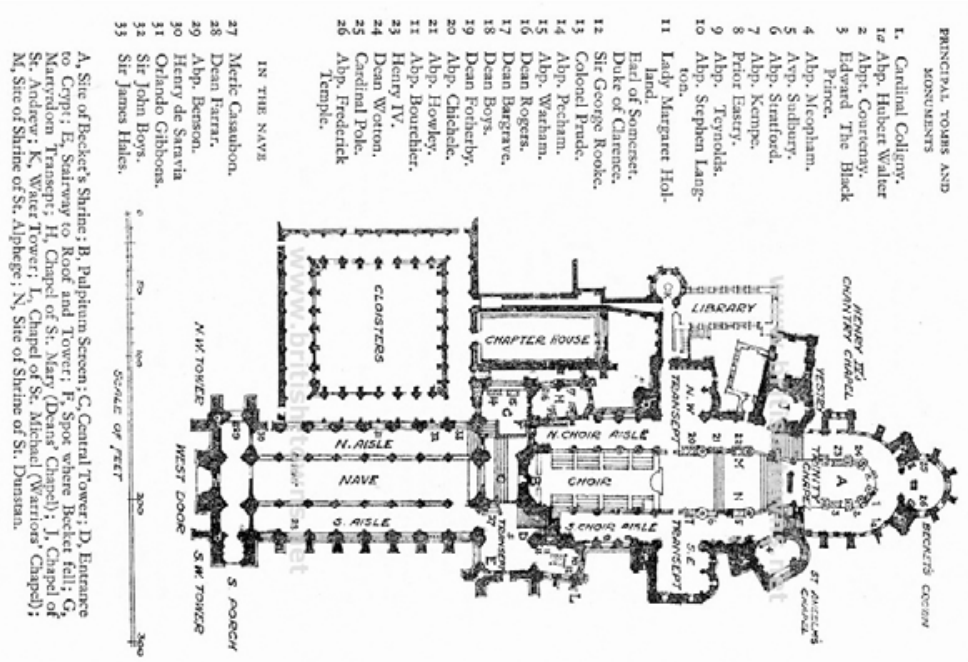

Figura 3.34. Planta de 1950 de la Catedral de Canterbury (Reino Unido)

(http://www.british-towns.net)

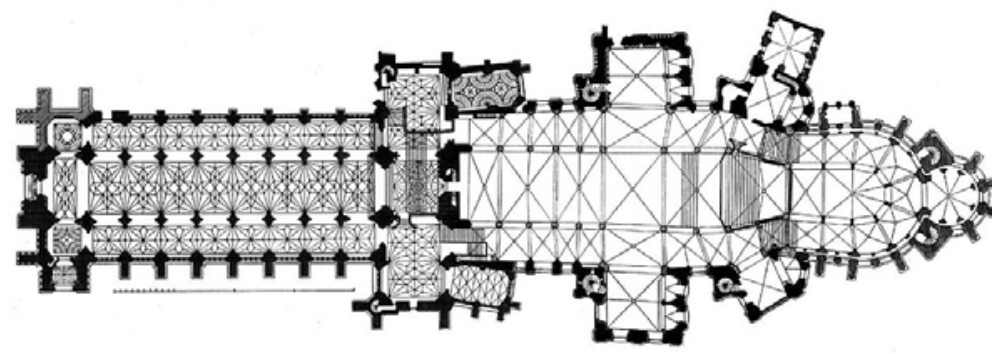

Figura 3.35. Planta de la Catedral de Canterbury (Reino Unido) según Dehio-Bezold (fuente: Gotik-Romanik)

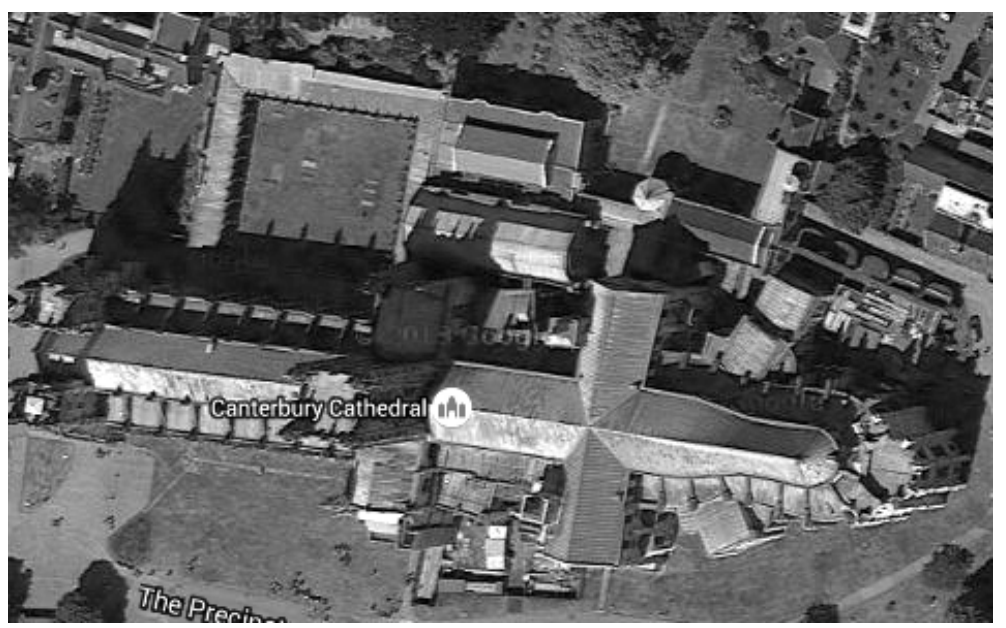

Figura 3.36. Fotografía aérea de la Catedral de Canterbury (Reino Unido)

(Google Maps, consultada el 2 de septiembre de 2015)

Abordar un estudio de la deformación en arquitectura abovedada es difícil en parte por la documentación disponible. Borie et al. ya señalaban la dificultad de encontrar documentación de determinados edificios deformados ya que «los estudios tipológicos (...) han dejado en la sombra todo lo que era aberrante o meramente inclasificable» (BORIE et al. [1978] 2008, 181-182). En el caso de la arquitectura religiosa, suele haber bastante documentación sobre los templos, pero no así sobre las edificaciones anexas donde se suelen relegar las deformaciones siempre que es posible. 
Pero además es posible detectar en general cierta repugnancia a la hora de dibujar deformaciones. Es evidente que la representación o no de una deformación va a depender de la escala, ${ }^{24}$ pero hay ejemplos en los que la deformación a una determinada escala ya sería evidente y sin embargo se oculta. El dibujo se regulariza en lo que podríamos considerar una mentira piadosa. En realidad no podemos hablar de un error del dibujo -al menos no en todos los casos-, ya que dicho dibujo puede estar orientado a explicar otra cosa; ${ }^{25}$ el error está en tomar el dibujo para otros fines.

Podemos señalar por ejemplo un dibujo de ca. 1951 de la Catedral de Canterbury (figura 3.34). La catedral y el conjunto catedralicio se encuentran muy deformados, sin embargo el dibujo oculta la deformación del claustro, el transepto y la nave primitiva (figura 3.35 y 3.36) ${ }^{26}$ Debemos tener presente que la finalidad de este dibujo es la de situar las tumbas y monumentos, por lo que el error no estaría en el dibujo sino en tomarlo para otros fines. ${ }^{27}$

A cambio encontramos otros curiosos ejemplos en los que el edificio aparece deformado en una publicación, pero es un problema de la copia utilizada para su reproducción. El dibujo de la cabecera de la Catedral de San Vito de Praga en el libro de Paul Frankl ([1962] 2002, 302) es un buen ejemplo (figura 3.37).

Abordar el estudio de la deformación a través del análisis del espacio de la girola tiene la ventaja de que no es un tipo de deformación que se oculte. Sin embargo es normal encontrar errores manifiestos en el dibujo de las bóvedas de la girola -extensible en muchas ocasiones a otras partes del edificio- como es la confusión entre nervios y aristas o los errores de trazado. Por ejemplo, dibujar en línea recta intersecciones que son en realidad curvas alabeadas, como

24 Lo que nos advierte a la hora de aumentar la escala de un dibujo sin haber tomado nuevos datos.

25 Se trataría de un «levantamiento topológico» según la expresión utilizada por José Luis de Miguel en la prelectura de tesis de Rosa Ana Guerra Pestonit.

26 El dibujo no puede ocultar la irregularidad de las capillas de St. Mary (Deans' Chapel) y de St. Michael (Warriors' Chapel) ya que no caben de otra manera.

27 Los láminas de Juan Gómez son particularmente confusos ya que en algunos casos sí dibuja deformación, como en la iglesia de San Vicenzo in Prato de Milán (Italia), la Basílica de San Bassiano en Lodi Vecchio (Italia) y Vèzelay (Francia) y en otros no la dibuja, como en la Catedral de Ávila (GómEZ y GONZÁLEZ DE LA BUELGA 2003, 291, 311, 367, 369 respectivamente). 
las de la girola de Notre-Dame-Du-Port dibujadas por Juan Gómez y Gz. de la Buelga (2003, 321). ${ }^{28}$

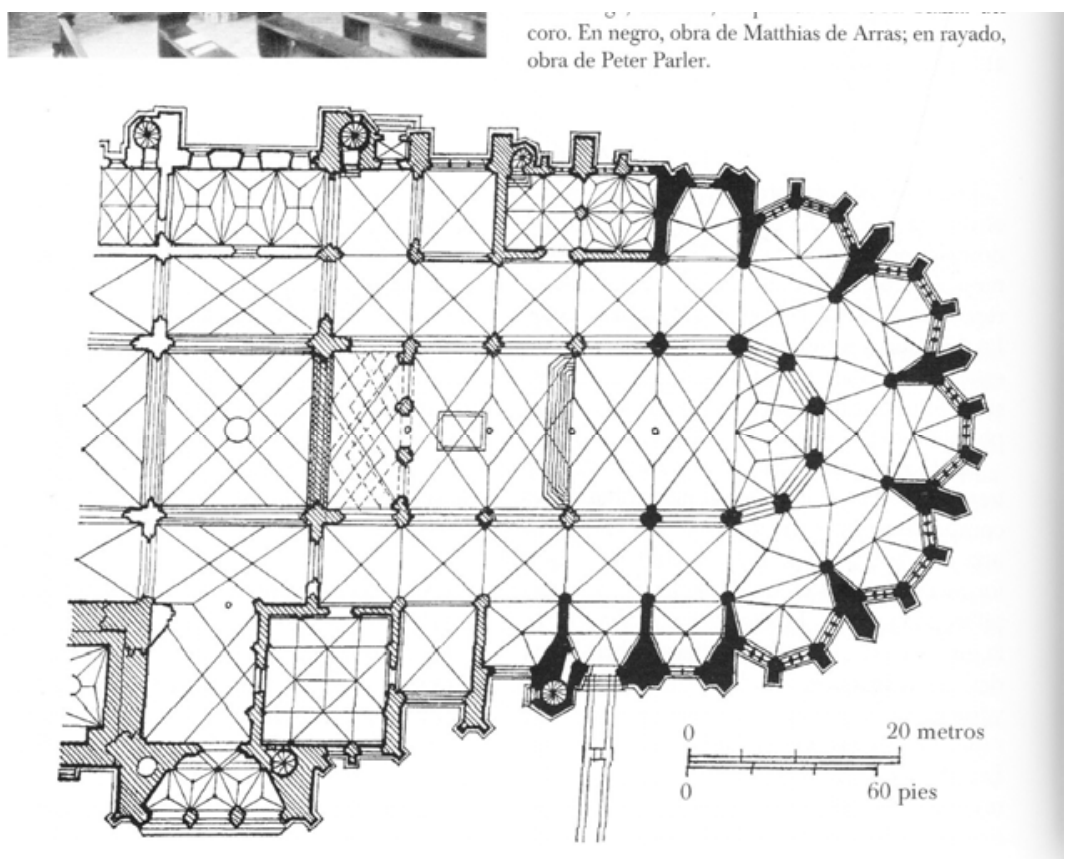

Figura 3.37. Planta de la Catedral de San Vito de Praga (República Checa) publicada por Paul FRANKL ([1962] 2002, 302)

En este sentido resulta llamativa la alegría con que muchos autores se apresuran a dibujar las aristas / nervaduras de la iglesia de la abadía de Jumièges (Francia), pese a no disponer de datos de su trazado real al encontrarse destruida.

Lo que se combina con otros errores en la documentación adicional -cuando existe- como en las secciones de la Catedral de Málaga (cfr. capítulo 8, apartado 8.2).

\section{Deformación y percepción. Grados de deformación}

A menudo la percepción asimila las formas a sus modelos ideales y/o memorizados.

(BORIE et al. [1978] 2008,78)

Esto hace que en muchos casos la deformación no se perciba. Esto es de especial importancia en bóvedas donde el fenómeno de la deformación se sitúa a una altura sobre la vista que hace que éstas no se perciban con claridad.

28 En especial si tenemos en cuenta que en los dibujos de Sainte-Foi de Conques y Santiago de Compostela sí se dibuja la curva sinuosa, seguramente errónea pero al menos orientativa de lo que sucede en la realidad (GómEZ Y Gz. DE LA BUELGA 2003, 324 y 325). 
El caso de la iglesia de Saint-Aspais de Melun es especialmente llamativo ya que, pese a la muy notable irregularidad de la planta (figura 3.38), ésta no se percibe al entrar en la iglesia (figura 3.39). ${ }^{29}$ Esta falta de percepción de la deformación se ve motivada, entre otras cosas, por la regularidad de la nave central, situada a mayor altura que las laterales. Este ejemplo pone en relación los fenómenos de percepción de la deformación con lo expuesto en el apartado anterior sobre la necesidad de tener en cuenta la sección. ${ }^{30}$

Otro ejemplo llamativo, y en cierto modo contrapuesto a lo anterior, lo constituyen las bóvedas de la girola de la Catedral de Granada. Estas bóvedas tienen planta ligeramente trapecial. En una primera aproximación al interior del edificio, esta deformación no es clara -se aproxima la bóveda al modelo cuadrado ideal- pero sí resulta evidente cuando se observan las bóvedas desde abajo. Sin embargo, una fotografía cenital no pone de manifiesto la forma trapecial de las bóvedas ya que el fenómeno tiende a atribuirse a la deformación perspectiva de la fotografía, que no parece cenital.

En el caso de la Catedral de Granada, resulta llamativa la interpretación errónea que Earl E. Rosenthal (1961) realiza del dibujo de la planta de la girola de Manuel Gómez Moreno ([1941] 1983). Gómez Moreno dibuja la planta de las bóvedas ligeramente trapecial, tal y como sucede en la realidad, pero Rosenthal no lo ve y afirma como «Siloé avoided the extreme trapezoidal shapes usually employed in the ambulatory of the Gothic chevet» (ROSENTAL 1961, 77).

Podemos señalar un problema añadido en el análisis de la deformación y es la necesidad de visitar el edificio, tal y como pone de manifiesto el caso de la girola de la Catedral de Granada. Somos conscientes por lo tanto de las objeciones que pueden surgir a esta primera parte de la tesis, donde la mayoría de los edificios señalados no han sido visitados.

Otro aspecto relacionado con la percepción tiene que ver con los grados de deformación que señalábamos en la Introducción. Podríamos decir que toda bóveda es irregular ya que responde a unas condiciones de contorno específicas, y la arquitectura trabaja con unas tolerancias de fabricación, más marcadas en el caso de arquitecturas

29 Otros factores, como puede ser la iluminación de la nave central frente a las laterales, pueden contribuir a lograr este efecto.

30 En el transcurso de la investigación no ha sido posible visitar la iglesia por encontrarse cerrada por remodelación. Esta apreciación se basa en lo observado en las fotografías disponibles en internet y por lo tanto está sujeta a revisión. 
históricas. Sin embargo esta tesis se centra en aquellas bóvedas en las que la deformación de su perímetro se convierte en un factor de diseño.
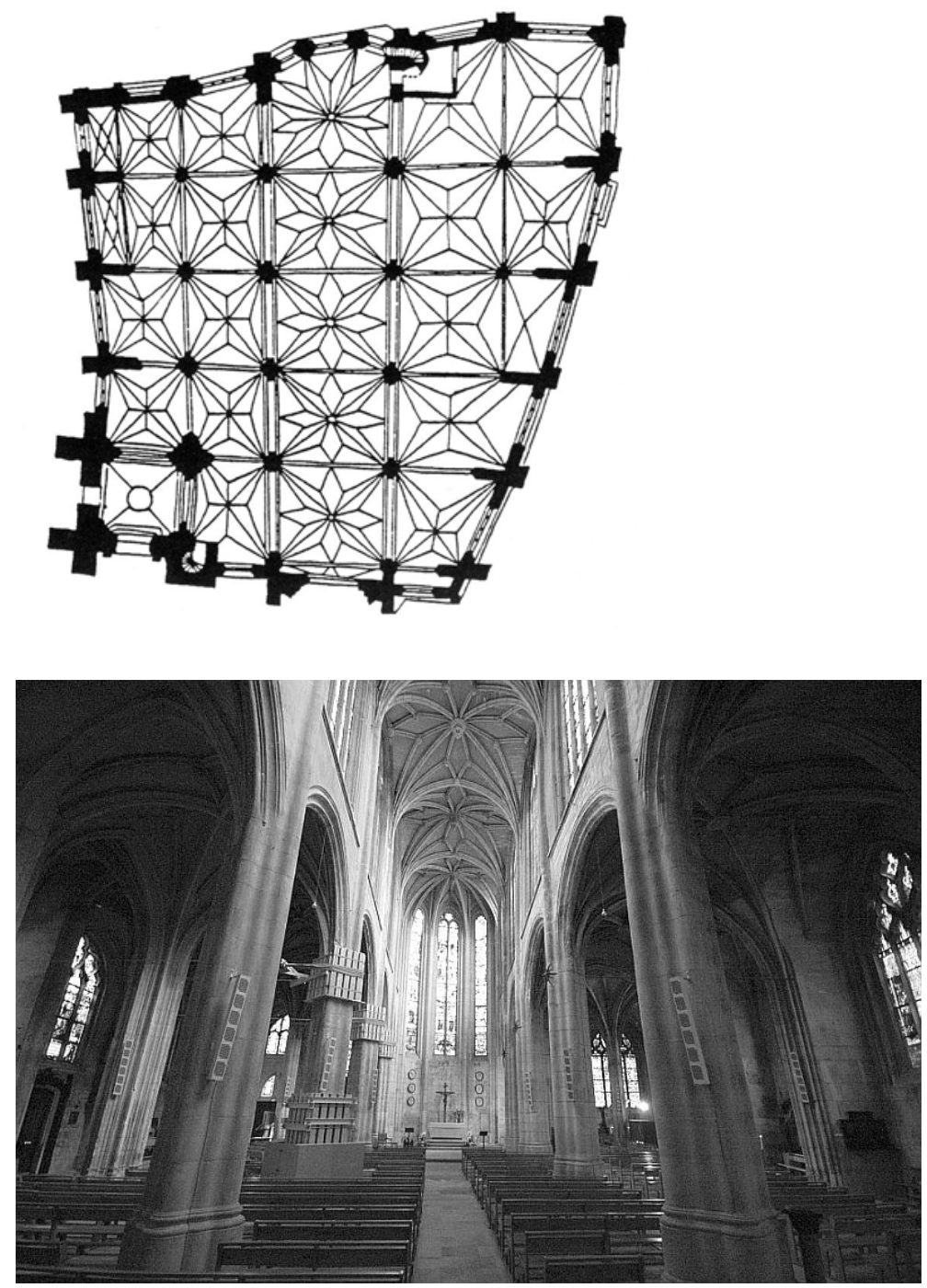

Figura 3.38. Planta de la iglesia de Saint-Aspais de Melun (Francia)

(BORIE et al. [1978] 2008, 114)
Figura 3.39.Fotografía del interior de la iglesia de SaintAspais de Melun (Francia) (fotografía de Patrick Raymond) (fuente: Gotik-Romanik)

Podríamos distinguir entre:

- Irregularidades patentes que actúan como factor condicionante del diseño. Este tipo de irregularidades las encontramos en las bóvedas trapeciales de las girolas.

- Irregularidades latentes que sólo se ponen de manifiesto tras un levantamiento.

En la mayoría de los casos podríamos llegar a firmar que el primer tipo de irregularidad tiene que ver con bóvedas no canónicas, donde la irregularidad es un factor de diseño; mientras que las segundas son irregularidades asumidas por el propio sistema constructivo. Sin 
embargo, valorar en qué casos la irregularidad se convierte en un factor de diseño no es tan sencillo.

En primer lugar hay que tener en cuenta el sistema constructivo empleado. Las bóvedas de albañilería son más tolerantes con las deformaciones, que las bóvedas de cantería. Incluso dentro de la cantería, es preciso distinguir entre una cantería con juntas gruesas como la románica, capaz de asumir más irregularidades que la estereotomía clásica francesa, de juntas finas.

Valorar el segundo tipo de irregularidades es más difícil. En algunos casos la irregularidad es asumida por las propias tolerancias del sistema constructivo mientras que en otros casos podemos aventurar el empleo de un determinado sistema constructivo para ocultar una irregularidad que sin embargo sólo parece ponerse de manifiesto en el levantamiento.

Un ejemplo de esto lo encontramos en la bóveda sobre el crucero de la iglesia de San Juan de los Reyes en Toledo, analizada por Santiago Huerta Fernández y Ana López Mozo. En este caso, la elección de una bóveda por arcos cruzadas podría estar relacionada con las irregularidades de la planta (HUERTA FERNÁNDEZ y LÓPEZ Mozo, 2005).

Por contrapartida, también encontramos casos en los que existe una voluntad de poner de manifiesto cualquier irregularidad, por pequeña que esta sea, como ejemplifican las bóvedas de las naves laterales de la iglesia de Saint-Jacques-du-Haut-Pas en París (cfr. capítulo 5, apartado 5.4).

\section{Deformación, materiales y técnicas constructivas}

El empleo de ciertos materiales o técnicas constructivas puede influir en las posibilidades de deformación de los edificios y, eventualmente, en los tipos de deformaciones a los cuales se ha recurrido.

(BORIE et al. [1978] 2008, 81)

Al iniciar la investigación partimos de la hipótesis de que la deformación, en arquitectura abovedada, plantea un problema de índole constructivo. Esta hipótesis se ha visto confirmada a medida que avanzamos en la investigación.

La arquitectura ofrece una alternativa inmediata frente a la deformación de la bóveda, y es la de no abovedar recurriendo a otra técnica constructiva. Como ejemplo podemos señalar la iglesia de San Francisco de Morella (Castellón), cubierta con una estructura de madera sobre arcos diafragma (ZARAGOZÁ CATALÁN 2000, 38). Otras 
alternativas a la bóveda son la cubierta de madera ${ }^{31} \mathrm{y}$, en caso de querer apoyar un piso, el forjado de madera.

La arquitectura abovedada presenta otra alternativa adicional: recurrir al espesor de los muros para absorber pequeñas diferencias: «las arquitecturas de masa (piedra, ladrillo, etcétera) pueden soportar puntualmente las deformaciones utilizando para ello el espesor de los muros» (BoRIE et al. [1978] 2008, 36). «Igualmente, el espesor de los muros, al dispersar los espacios, facilita que la amplitud de una deformación se limite a un solo espacio o a un solo nivel» (BORIE et al. [1978] 2008, 99).

En efecto este ha sido uno de los recursos a los que ha recurrido con frecuencia la arquitectura abovedada, aunque no es posible emplearlo siempre. Constatamos que es un ejemplo frecuente en las iglesias barrocas, para independizar la planta del exterior; como ejemplo podemos señalar las iglesias de Sant'Ivo alla Sapienza y San Carlo alle Quattro Fontane en Roma (Italia), obras de Francesco Borromini; y la iglesia de San Lorenzo de Turín (Italia), de Guarino Guarini (figura 3.40).

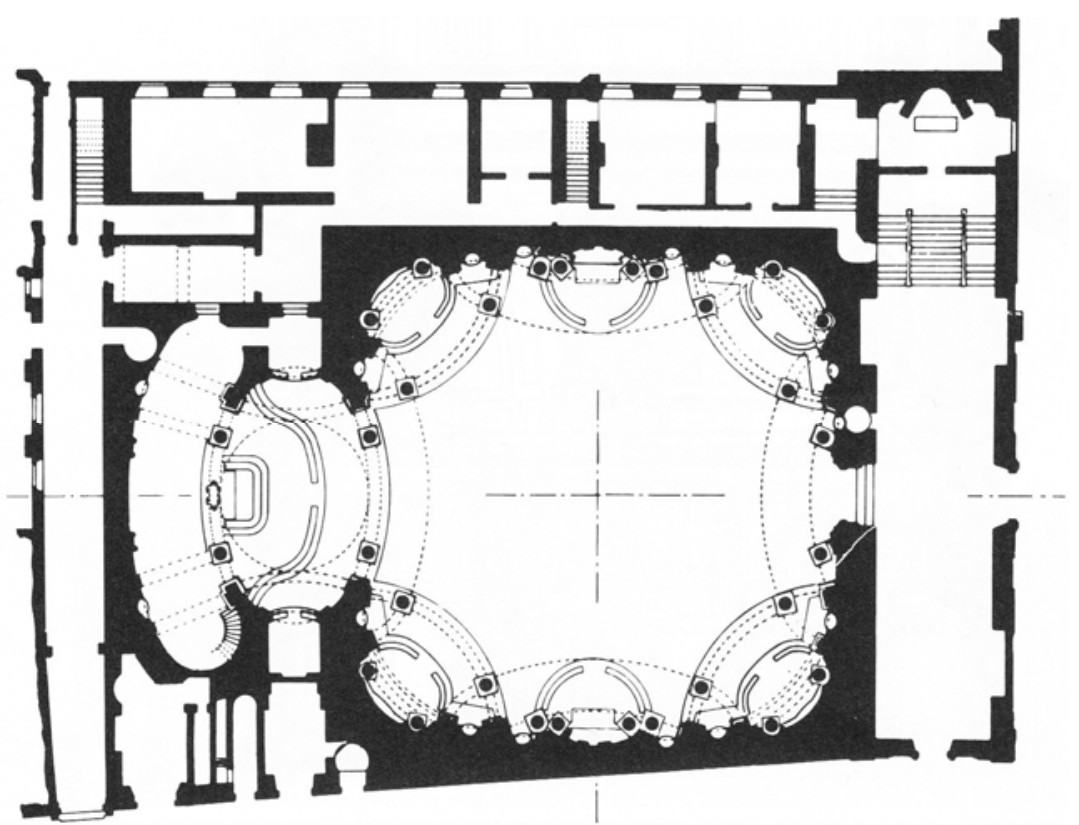

Figura 3.40. Planta de la iglesia de San Lorenzo en Turín (Italia)

(FLETCHER [1896] 2008, 914)

31 Una cubierta de madera sobre una planta deformada no está exenta de dificultad, como atestiguan las cubiertas construidas sobre las girolas y donde no es infrecuente encontrar problemas de filtraciones. Sin embargo, esta técnica constructiva queda fuera del ámbito de estudio de esta investigación. 
En la iglesia de Santa María della Pace en Roma el espesor del muro no sólo permite compaginar el trazado octogonal de la iglesia con el claustro, ${ }^{32}$ también independiza el interior de la iglesia de la orientación de la via della Pace (figura 3.83).

Aunque «desde la perspectiva de la deformación, la independencia con respecto a la escala es evidente en la medida en que la deformación es la resolución concreta de una situación puramente compositiva» (BORIE et al. [1978] 2008,89). Sin embargo, las cualidades de las formas relacionadas los problemas constructivos sí «que están ligadas a una escala en particular» (BORIE et al. [1978] 2008, 89). Un espacio deformado de unas ciertas dimensiones plantea un problema constructivo; en cambio, para una misma forma a mucha menor escala el problema se puede resolver casi de cualquier manera (figura 3.41).

\section{Contexto temporal}

Comparando libremente formas similares tomadas de contextos diferentes, hemos observado que con el transcurso del tiempo se vuelven a encontrar de modo idéntico los mismos tipos de dificultades geométricas, aún cuando sean asumidas y tratadas de modo diferente por los arquitectos. (...) la geometría tiene exigencias específicas y reglas totalmente independientes de las circunstancias y del entorno cultural en que se encuentre.

(BORIE et al. [2006] 2008, 17)

Al igual que Borie et al., en la primera parte de la tesis vamos a comparar ejemplos de muy diversas épocas y esto no puede plantear dudas acerca de la conveniencia o no de trazar cronologías como la que expone Viollet-le-Duc en su Dictionnaire (cfr. Prefacio). Sin embargo estas cronologías provocan más dudas que certezas. En primer lugar por las dudas en la datación no sólo del edificio, sino de determinados elementos dentro del edificio; teniendo en mente además posibles reconstrucciones. En segundo lugar porque el hecho de que una innovación haga aparición en dos lugares distintos en dos momentos distintos -en especial si no hay mucha separación temporal entre ambos- no implica que exista relación entre ellas, sino que es posible haber llegado a la misma solución por dos caminos distintos.

32 El trazado octogonal de la cabecera facilita el enlace con el claustro de Bramante, cuya orientación responde a la via Arco della Pace. Sin embargo el ángulo que forman no es exacto, lo que se resuelve con el espesor del muro. 


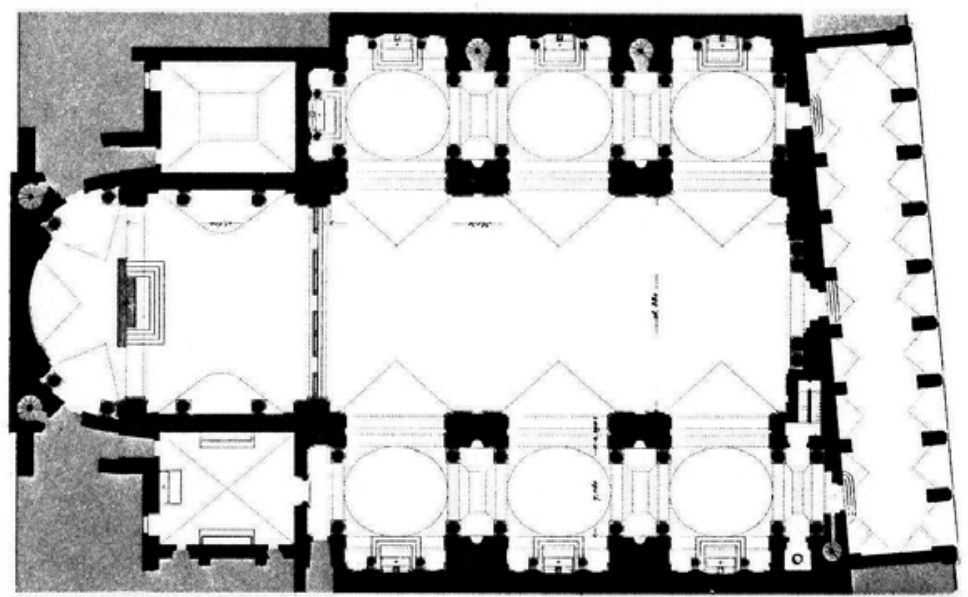

Figura 3.41. Planta de la Iglesia SS. Apostoli en Roma (Italia) (LETAROUILLY [1860] 1982, 167)

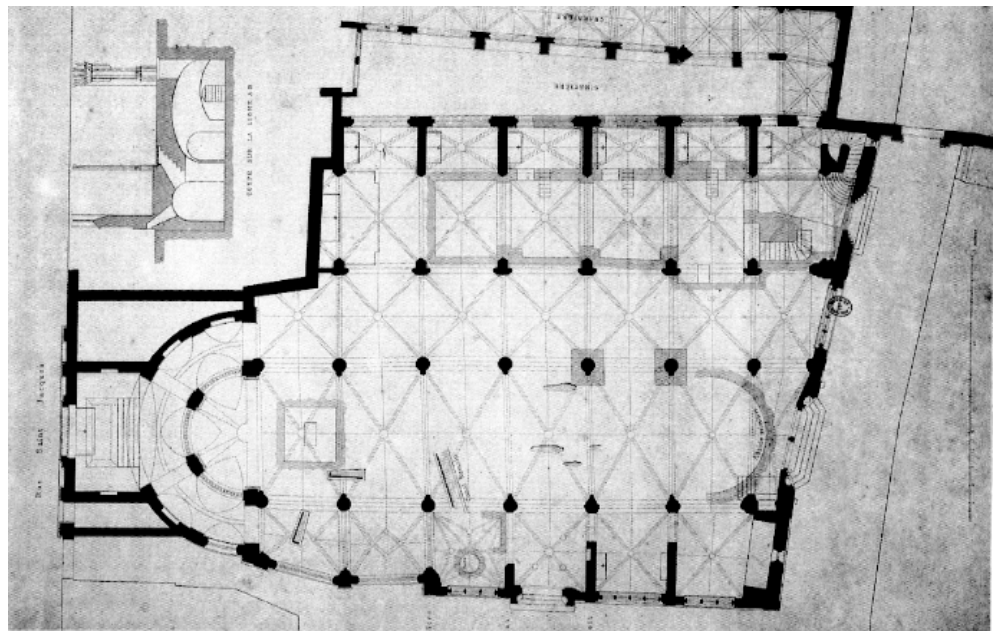

Figura 3.42. Panta de la desaparecida iglesia de Saint Benoit en París (Francia) (Bos 2003, 140)

Cuando vemos que el ejemplo de resolver el abovedamiento de un espacio de planta anular por medio de una subdivisión en cuadrados y triángulos, como en el paradigmático ejemplo de la girola de la Catedral de Toledo (s. XIII) (figura 3.43), lo encontramos cinco siglos antes en la Capilla Palatina de Aquisgrán (fin. s. VIII) (figura 3.44), esta precedencia no es suficiente para establecer una relación de causa-efecto entre ambas, ya que podemos suponer que es posible llegar a dicha solución por un proceso relativamente sencillo de subdivisión del problema en partes.

Sí se ha trazado una cronología de las bóvedas de nervios asimétricos recogidas en la segunda parte de la tesis (cfr. capítulo 7, apartado 7.1) -con todas las limitaciones y dudas que veremosporque nos encontramos con un elemento cuyo trazado extremadamente singular nos habla de una copia consciente al menos del trazado en planta. Evidentemente esta hipótesis es discutible pero, como veremos, se trata de un trazado original al que no parece posible llegar por la mera multiplicación de nervios. 


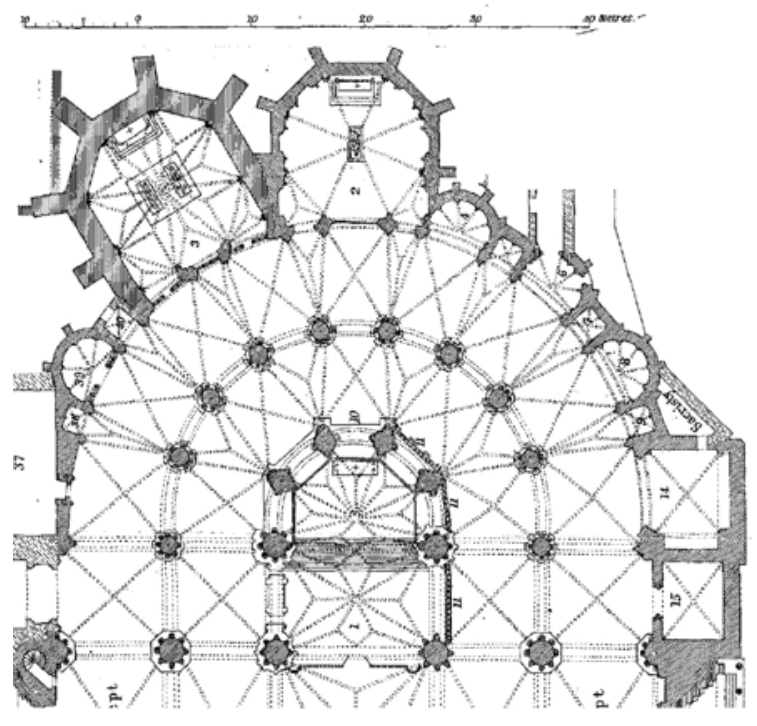

Figura 3.43. Cabecera de la Catedral de Toledo (STREET 1929)

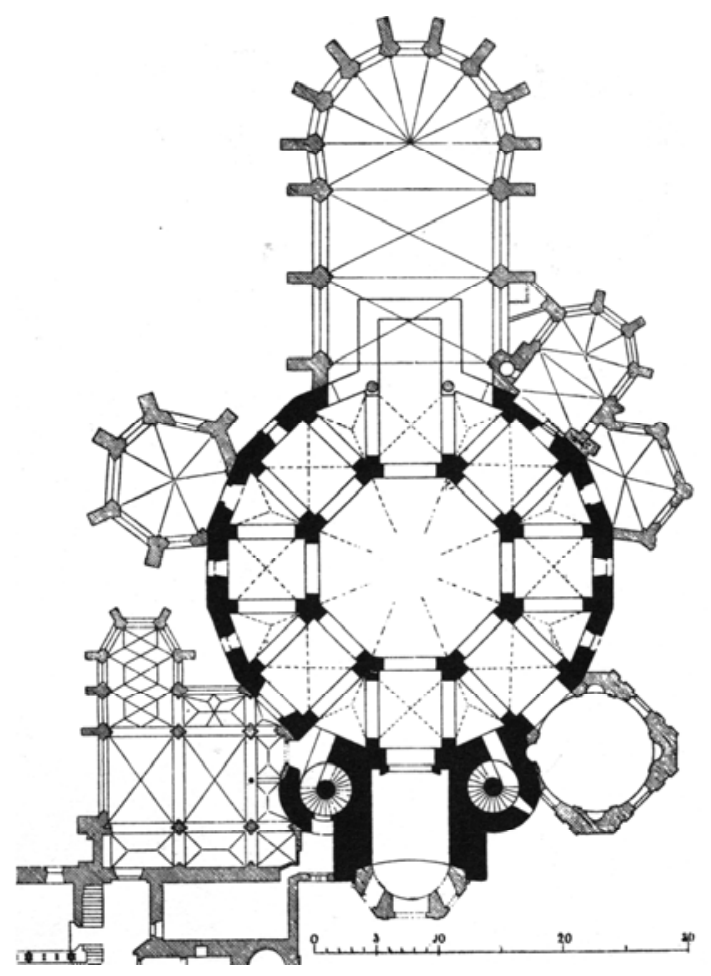

Figura 3.44. Capilla Palatina de Aquisgrán (Alemania) según Dehio-Bezold (fuente: Wikipedia.org)

Creemos, por lo tanto, que en efecto es lícito mezclar ejemplos de muy diversas épocas a la hora de analizar el fenómeno de la deformación.

Sin embargo es conveniente señalar dos salvedades. La primera se refiere a las reflexiones sobre la deformación en arquitectura que tienen que ver con las distintas épocas. Se dice que «en la arquitectura clásica, las deformaciones se reservan para los espacios secundarios; en la arquitectura medieval, por el contrario, repercuten sobre el conjunto del objeto» (BORIE et al. [1978] 2008, 104). Esto tiene en parte que ver con lo ya señalado sobre «Deformación y representación», pero también con la relación que se establece en cada época con los modelos arquitectónicos y el modo en que éstos admiten ser modificados.

La segunda se refiere a la evolución de los sistemas constructivos. Decíamos que las posibilidades de un sistema constructivo facilitan o dificultan la deformación, evidentemente esto no es independiente de la época en la que se construyeron. Sin embargo es posible abordar ambas cuestiones sin necesidad de establecer una cronología exacta y precisa de cada uno de los elementos. 


\subsection{Origen, planteamiento y resultado}

Observemos la planta de una ciudad cualquiera; en ella se destacan tres tipos de líneas: la línea recta, la línea sinuosa y, por último, la línea curva. (POËTE [1920] 1997, 63)

Esta primera aproximación a la deformación en arquitectura abovedada está enfocada en tres aspectos:

- El origen de la deformación y las causas formales que la provocan.

- Las actitudes frente a la deformación y las razones que motivan dichas actitudes, que influyen en la manera de resolverlas.

- La formalización de la deformación.

\section{Origen de la deformación}

Borie, Micheloni y Pinon distinguen entre el origen de la deformación, que está en un conflicto no resuelto, y las causas formales de la deformación.

No es la intención de esta tesis profundizar en el origen de la deformación. Aunque nuestro interés se centra en las causas formales de la deformación, que emergen de un análisis puramente formal, vamos a hacer un breve repaso sobre el origen de la deformación. Hay que tener presente que las circunstancias efectivas que dan lugar a la contradicción sólo pueden conocerse tras un análisis en profundidad de cada uno de los edificios.

Veíamos que el origen de la deformación está en una contradicción entre el -los- modelo arquitectónico, los datos del programa y el contexto físico. En el campo de la arquitectura abovedada podemos señalar además las posibilidades del sistema constructivo empleado, como cuarto factor en discordia.

\section{$\underline{\text { Contradicción entre el modelo formal y el contexto físico }}$}

En arquitectura religiosa uno los orígenes más frecuentes de deformación lo encontramos en una contradicción entre el modelo formal y el contexto físico, ya sea el medio rural o el urbano. El edificio obligado a adaptarse al medio urbano -parcelario y viario-, como ya hemos visto en la iglesia de Saint-Aspais de Melun (Francia) (figuras 3.38 y 3.39) o la Catedral de Bautzen (Alemania) (figura 
3.14), o a la topografía, como en la abadía de Saint-Martin du Canigou (Francia) (figura 3.45).

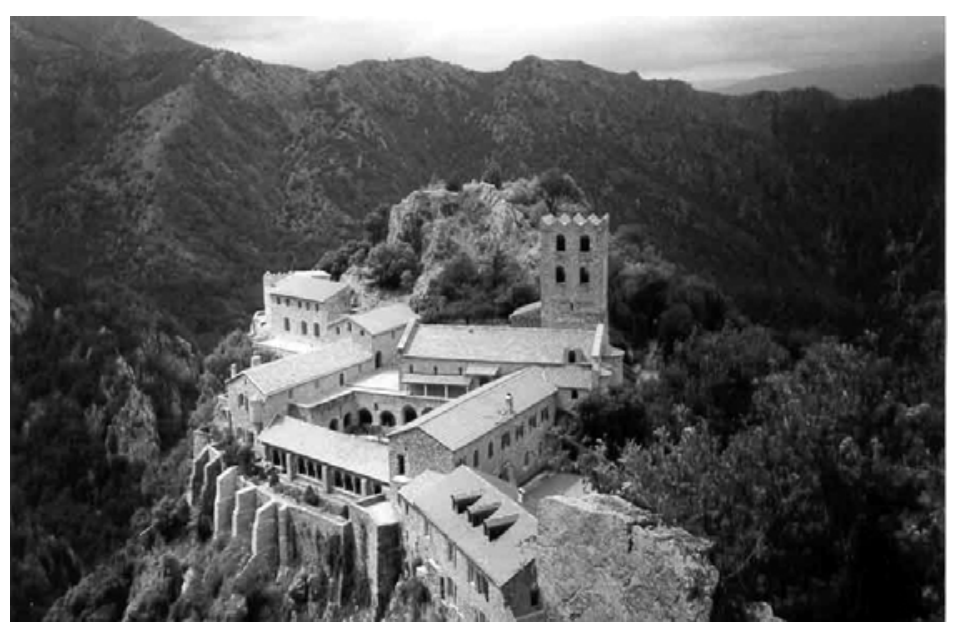

Figura 3.45. Abadía de saint-Martin du Canigou (Francia) (fotografía de Alain107 en Flick) (fuente: Gotik-Romanik)

El viario suele representar un condicionante mayor que el parcelario. En las iglesias parisinas de Saint-Germain-l'Auxerrois (figura 3.46) y Saint-Leu-Saint-Giles (figura 3.47) la cabecera se deforma, achatándose para no invadir la calle posterior -la rue de l'Arbre Sec en el primer caso, la antigua rue Salle-au-Comte ${ }^{33}$ en el segundo-.

Los problemas de la topografía pueden ser parcialmente solventados a costa de una fuerte inversión económica, como intuimos en la abadía de San Francisco de Asís (Italia).

\section{Contradicción entre el contexto físico y los datos del programa}

Como ejemplo de contradicción entre el contexto físico y los datos del programa encontramos el ya señalado por Borie et al. de la necesidad de orientación de las iglesias dentro del tejido urbano (BORIE et al. [1978] 2008, 57).

La intervención de Juan Caramuel Lobkowitz en la Catedral de Vigevano surge de la necesidad de disimular la distinta orientación entre la Piazza Ducale -con orientación NO SE- y el Duomo, orientado hacia el Este. Si bien la contradicción surge de la distinta orientación entre la plaza y la iglesia, la intervención estaría orientada a restablecer el orden estético.

33 En la actualidad la trasera de la iglesia de Saint-Leu-Saint-Giles da al Boulevard Sébastopol del plan Haussmann. 


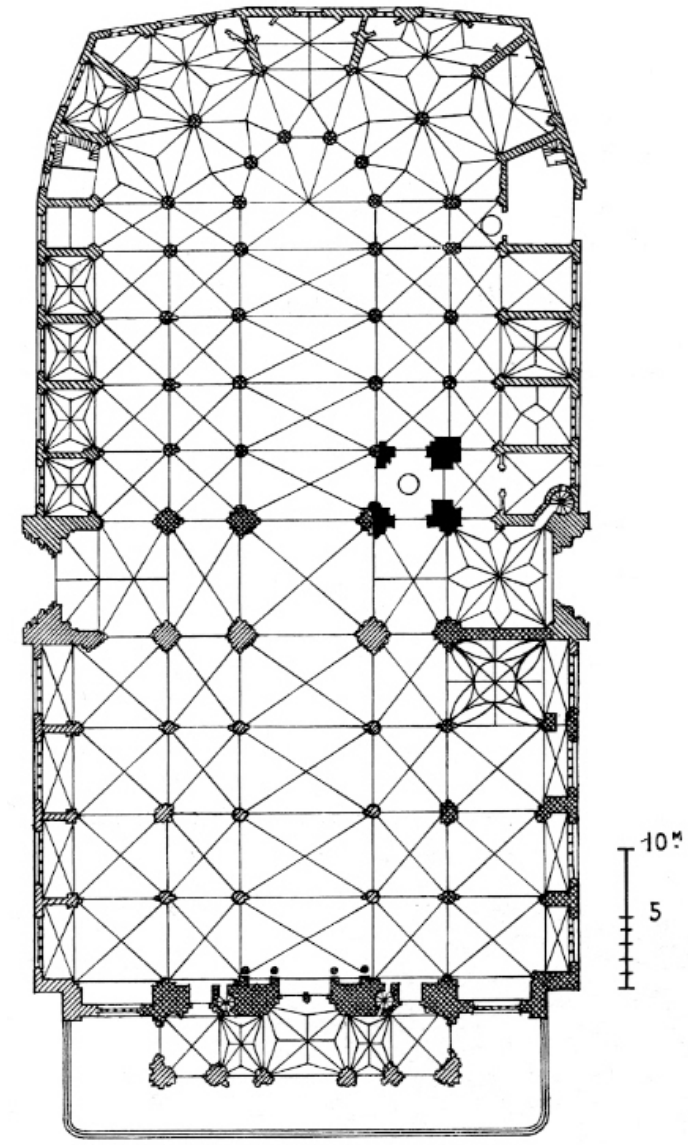

Figura 3.46 Iglesia de Saint-Germain-l’Auxerrois en París (Francia) (Bos 2003, 167)

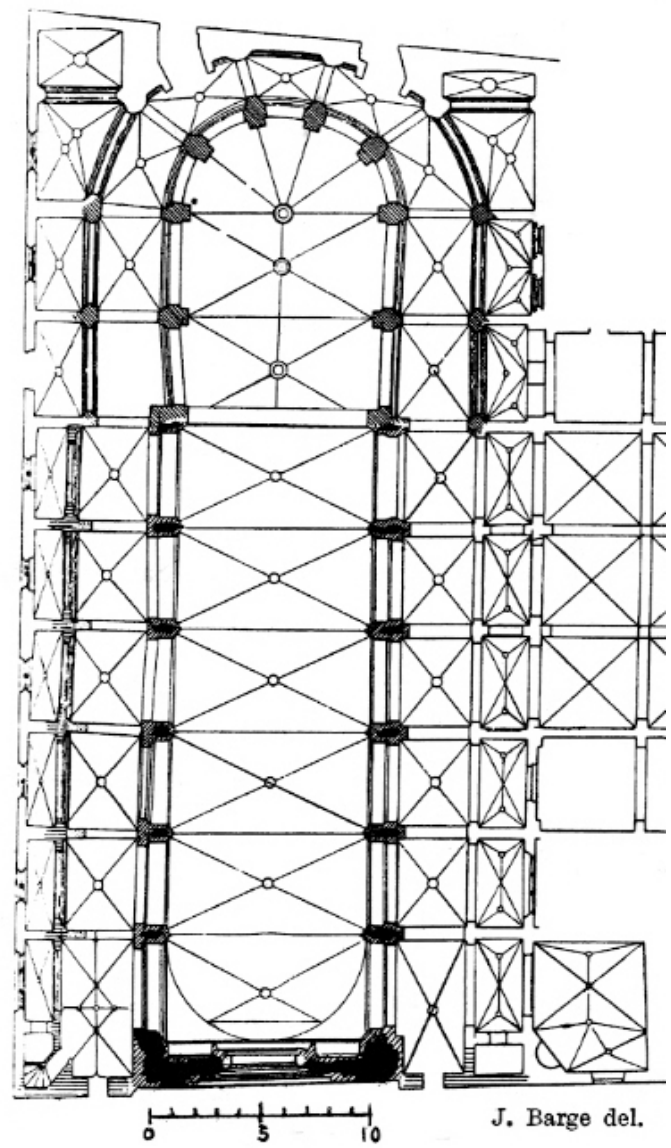

Figura 3.47 Iglesia de Saint-Leu-Saint-Giles en París (Francia) (Bos 2003, 223)

En el caso de monasterios, es frecuente encontrar contradicciones entre los datos del programa y el contexto. Si pensamos en la planta del monasterio de San Galo (ANÓNIMO, s. IX) como el reflejo del programa de un monasterio y lo comparamos con las plantas de monasterios construidos, encontraremos diferencias provocadas, en la mayoría de los casos, por la necesidad de adecuarlo al contexto físico concreto -topografía, ríos, etcétera. ${ }^{34}$

Uno de los ejemplos más habituales es la posición del claustro, que en principio debería situarse a la derecha del templo -es decir, al sur del templo, si éste está orientado hacia el Este como es habitual-, de manera que el templo no proyecte sombra sobre el claustro. Sin embargo encontramos numerosos ejemplos de monasterios donde el claustro se sitúa al norte del templo: Monasterio de Batalha (Portugal),

34 Nos referimos principalmente a las edificaciones en torno al claustro. El resto de dependencias del monasterio admiten mayor flexibilidad. 
Catedral de Canterbury (Reino Unido) (figura 3.36), Melrose Abbey (Reino Unido), Mont-Saint-Michel (Francia) (figura 3.12), Santa María de Huerta (Soria), Sherborne Abbey (Reino Unido), Abadía de Thoronet (Francia), o en otra posición: Monasterio de Asís (Italia). ${ }^{35}$

\section{Contradicción entre dos datos del contexto físico}

Pese a que ya señalábamos que estas arquitecturas solían disponer de los medios económicos para solventar las dificultades del parcelario, también encontramos casos de contradicción entre dos datos del contexto físico: el parcelario y el viario. Un ejemplo lo encontramos en la iglesia de San Marcos de Madrid, en el que la iglesia se intenta orientar según la calle de San Leonardo (San Leandro en el plano de 1831), provocando alteraciones en las dependencias anexas que deben dar respuesta a la distinta orientación de la parcela (figura 3.48).

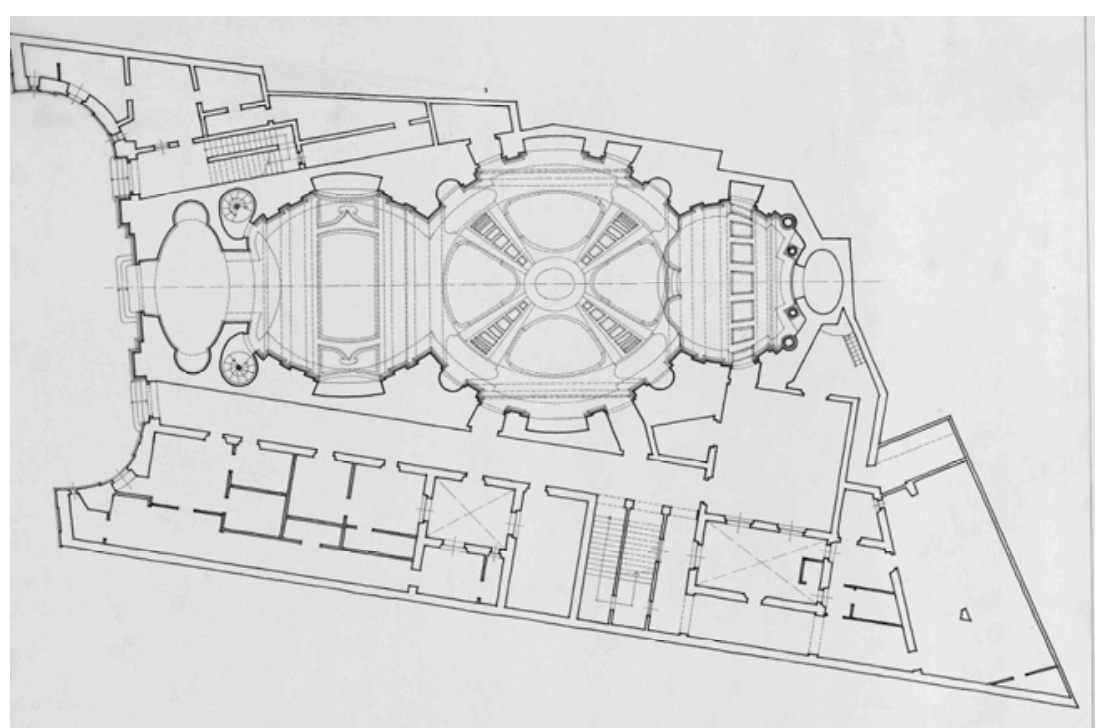

Figura 3.48 Iglesia de San Marcos en Madrid (fuente: IPCE)

Dos fenómenos frecuentes en este tipo de arquitecturas son el aprovechamiento de estructuras preexistentes, y las distintas fases de construcción. En estos casos podríamos considerar que la estructura ya construida pasa a ser parte del contexto físico -aunque posteriormente forme parte del conjunto final- y como tal puede entrar en contradicción con otros datos del contexto, con datos del programa o con el modelo formal. Para valorar este tipo de situaciones es

35 En este caso la basílica se orienta hacia el Oeste, seguramente motivado por los condicionantes topográficos; el claustro se sitúa por encima del ábside. 
necesario tener presente la historia del edificio y las distintas fases de proyecto y edificación por las que ha pasado.

Esto lo observamos en el aprovechamiento de espacios residuales como la Sacristía de la Catedral de Perpignan (Francia), donde el perímetro de la sacristía viene condicionado por la existencia de la cabecera de la iglesia, el claustro y unas dependencias al este (figura 3.28). En la pequeña iglesia de Greifensee (Suiza) la el perímetro en forma de cuarto de círculo de la iglesia viene impuesto por el aprovechamiento de la muralla (figuras 3.49, 3.50, 3.51)..

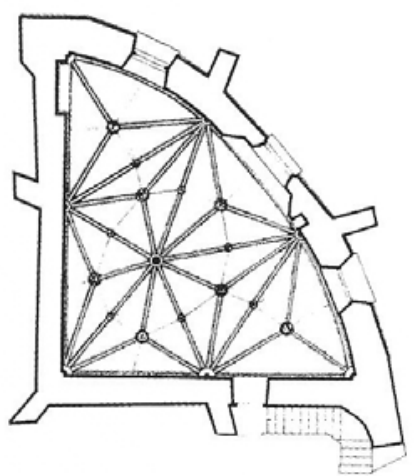

Figura 3.49. Iglesia de Greifensee (Suiza) (RIESTRA [2004] 2007, 205)
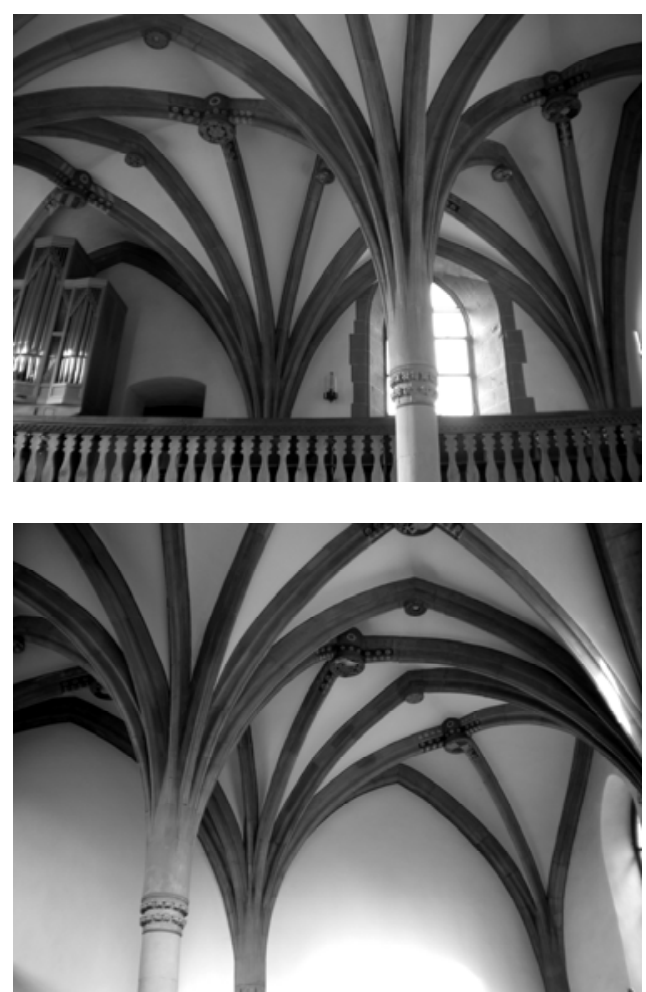

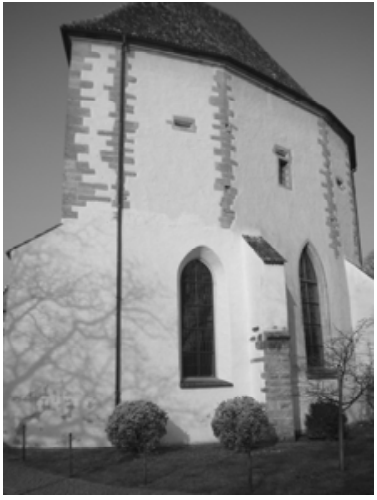

Figura 3.50. Exterior de la iglesia de Greifensee (Suiza)
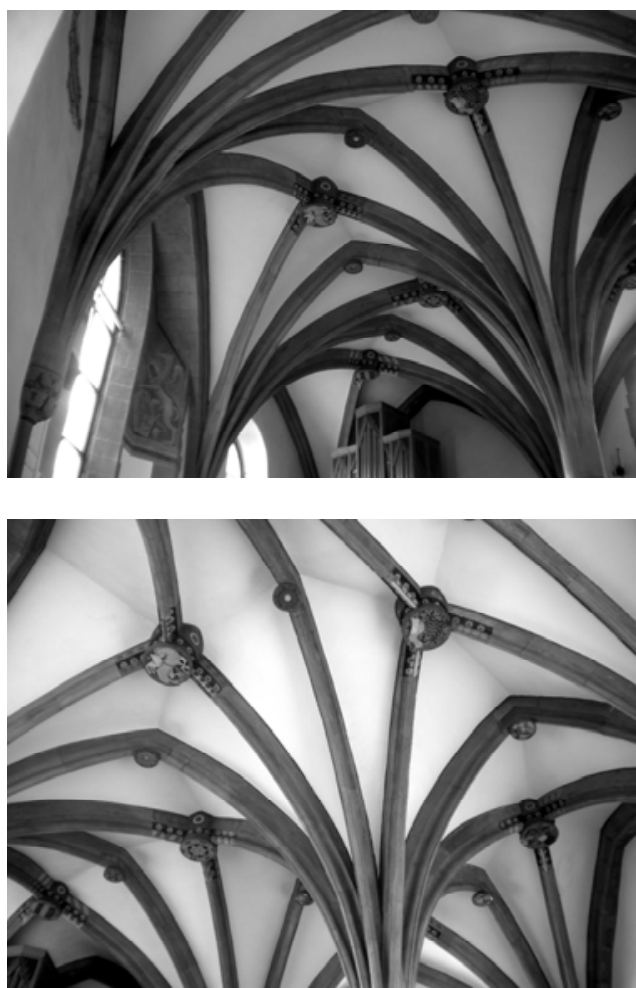

Figura 3.51. Vistas del interior de la iglesia de Greifensee (Suiza) 


\section{Contradicción entre dos modelos formales}

La cuestión de la girola se analizará en profundidad en el capítulo siguiente (cfr. capítulo4, apartado 4.4). Desde una perspectiva histórica la girola puede ser explicada por la necesidad de establecer una circulación en torno al ábside; ${ }^{36}$ hablaríamos entonces de una contradicción entre un modelo -la planta basilical con ábside semicircular- y un dato del programa -la circulación-. Sin embargo también es posible verlo como la contradicción entre dos modelos formales distintos -la planta basilical de una iglesia y la planta central de doble casco de un martiria-. Como veremos más adelante, la cabecera semicircular de los templos -con o sin girola- también es origen de contradicciones.

Otra contradicción entre dos modelos formales la encontramos en las Salas Capitulares inglesas de planta central. El perímetro octogonal regular $^{37}$ de la Sala Capitular entra en conflicto con la ortogonalidad del resto del conjunto. Sin embargo no suele dar lugar a deformaciones (figura 3.52).

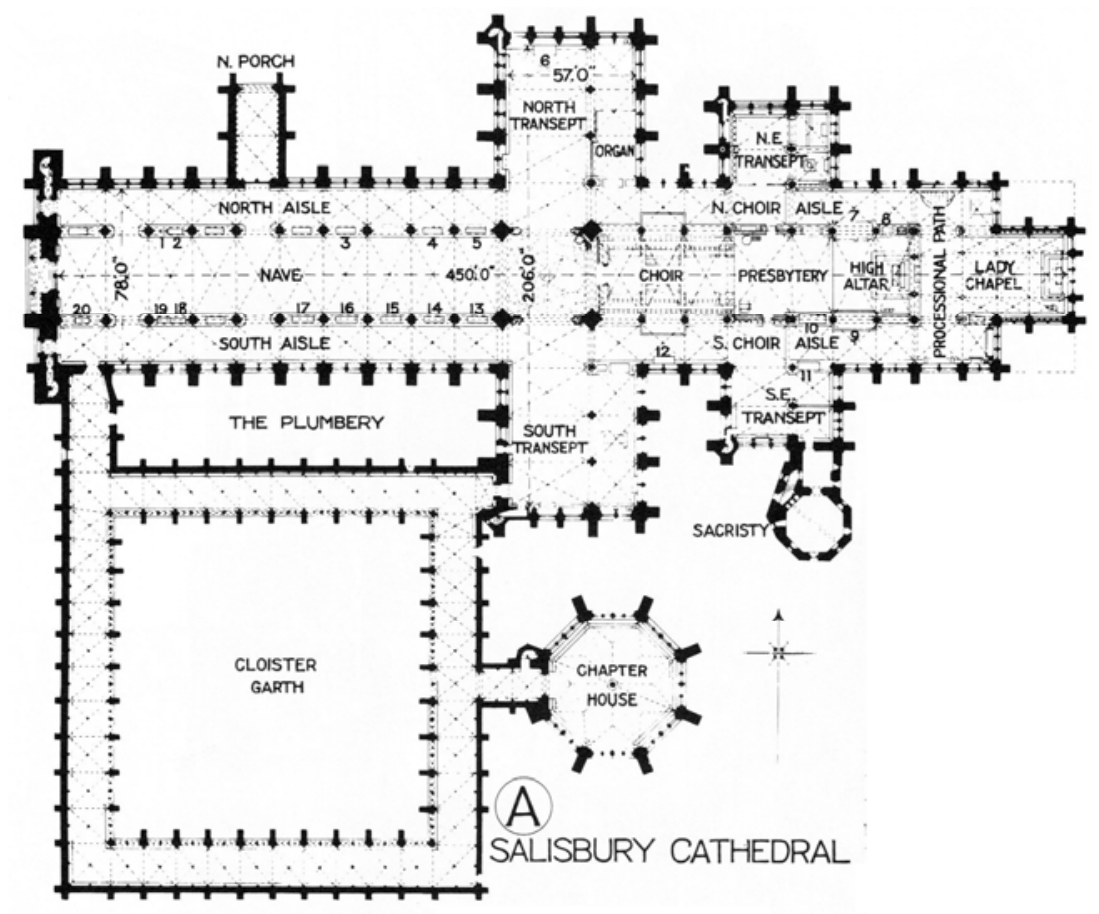

Figura 3.52. Catedral de Salisbury (Reino Unido) (FLETCHER [1896] 2008, 440)

36 Empleado para procesiones en el interior de la iglesia.

37 Como excepción podemos señalar la sala capitular de la abadía de Westminster y la catedral de Lichfield, cuyo perímetro es un octógono irregular. 
En arquitectura religiosa es raro encontrar ejemplos de contradicción entre dos datos de un programa o entre el modelo formal y el programa, ya que el modelo formal ha ido incorporando las necesidades del programa.

\section{Casos de contradicción con el sistema constructivo}

En arquitectura abovedada el sistema constructivo entra a formar parte de la ecuación modelo-programa-contexto pudiendo dar lugar a contradicción. Hemos visto la interrelación entre el modelo formal y los condicionantes del sistema constructivo que señalaba Viollet-le-

Duc al abordar la cuestión del abovedamiento de los deambulatorios:

La cabecera de las iglesias se complica con la girola, pues la estructura de ésta exige grandes habilidades constructivas.

(LAMPÉREZ ROMEA 1908-1909, 1:435)

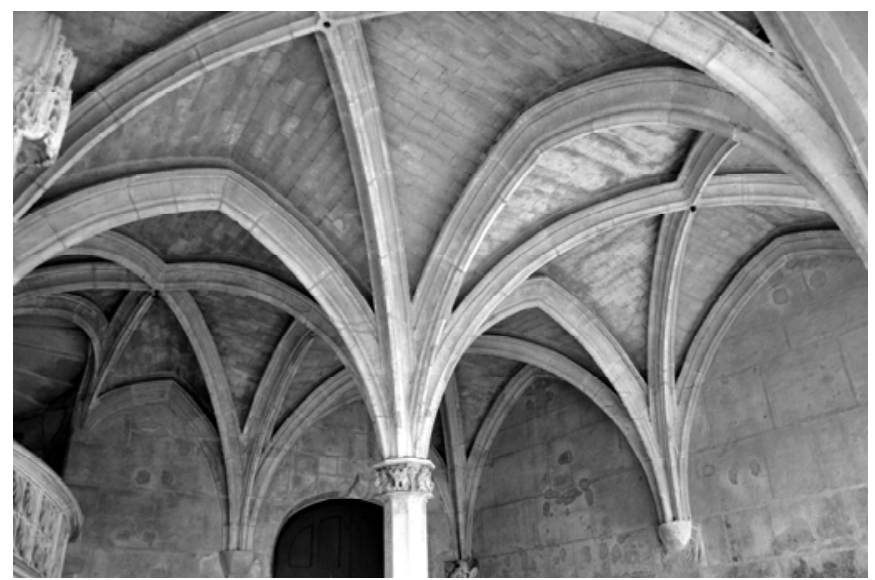

Figura 3.53. Pórtico bajo la capilla del Hôtel de Cluny (París)

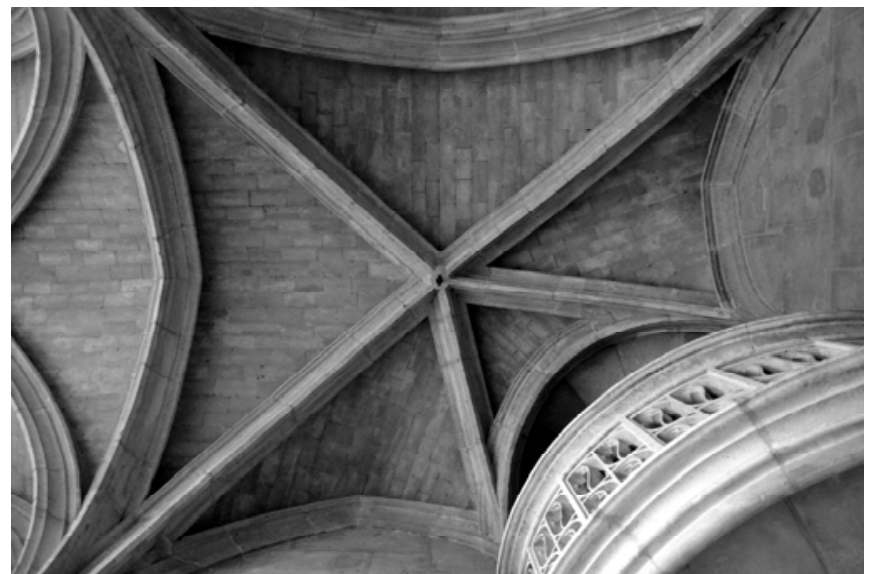

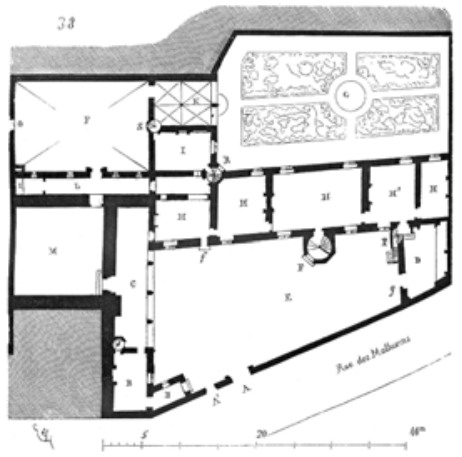

Figura 3.54 Hôtel de Cluny (París) (VIOLLET-Le-DuC 1854-1868, 6:286)

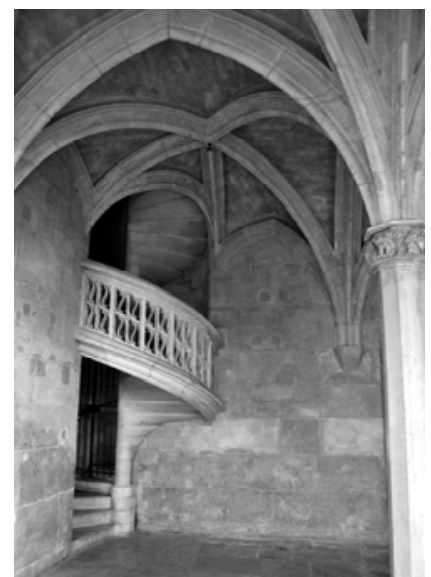

Figura 3.55. Detalle de la bóveda que da paso a la escalera 
No es el único caso. Según $\mathrm{M}^{\mathrm{a}}$ Luz Rokiski Lázaro, la iglesia de San Andrés en Cuenca tardó en abovedarse por la forma de trapecio de su planta:

Alviz y Arnani levantaron los muros del edificio pero no lo llegaron a cerrar. A un arquitecto como Alviz, que estaba acostumbrado a manejar soluciones góticas, cubrir un edificio con los tramos asimétricos indudablemente le planteaba un problema de muy difícil solución. (ROKISKI LÁZARO 1995, 107)

Una contradicción entre el sistema constructivo y los datos del programa lo encontramos en las bóvedas de los sotocoros, obligadas a rebajarse para situar el coro sobre ellas (López Mozo 2009, 360-365; Martín Talaverano 2014) Otro ejemplo lo encontramos en la bóveda bajo la capilla del Hôtel de Cluny en París (Francia), donde la bóveda, inicialmente de planta cuadrada, se deforma para alojar una escalera (figuras 3.53, 3.54 y 3.55).

Como ejemplo de contradicción entre el sistema constructivo y el contexto podemos señalar la bóveda del crucero de la Catedral de Córdoba, cuyas dimensiones vienen impuestas por el ritmo de pilares de la mezquita, lo que obliga a recurrir a una bóveda de planta oval de una proporción determinada (RABASA DíAZ 2000, 288-289).

\section{Deformaciones perspectivas}

Decíamos en la Introducción que dejábamos fuera de esta tesis las deformaciones perspectivas, tan frecuentes en la arquitectura a partir del Renacimiento. Sin embargo conviene hacer un pequeño inciso.

Hay muchos casos donde no es posible conocer el origen de la deformación, como sucede en la iglesia románica de Santa María del Mercado en León (figura 3.56), con planta en forma de «ataud». Por la época en que fue construida, no parece inmediato atribuir esta irregularidad a una «deformación perspectiva», tal y como, sin embargo explica Vicente Lampérez. La convergencia aparente de los muros se corregiría haciéndolos divergentes (LAMPÉREZ ROMEA 1908-1909, 1:89). Frente a este ejemplo, la deformación perspectiva tendería a alargar el templo, en la capilla de Samos (Galicia), San Pedro de Roda (Gerona) (figura 3.57), Santa María de Estíbaliz (Älava) y San Martín de Sarroca (Barcelona) (LAMPÉREz RoMEA 1908-1909, 1:89).

Este tipo de efectos podría explicar también el empleo de tramos de longitud variable (LAMPÉREZ ROMEA 1908-1909, 1:90). 
Seguramente habrá en otros monumentos españoles más casos de estas curiosas deformaciones, aunque no se conozcan ó no hayan sido notados. Los que quedan estudiados no pueden atribuirse a defectos de replanteo, pues la regularidad y simetría que presentan alejan esa idea. Son casos elocuentes de saber y de la ingeniosidad de aquellos maestros, inconscientes herederos de los que en el Panteón apelaron a artificios no menos sutiles para corregir los efectos visuales.

(LAMPÉREZ ROMEA 1908-1909, 1:90)

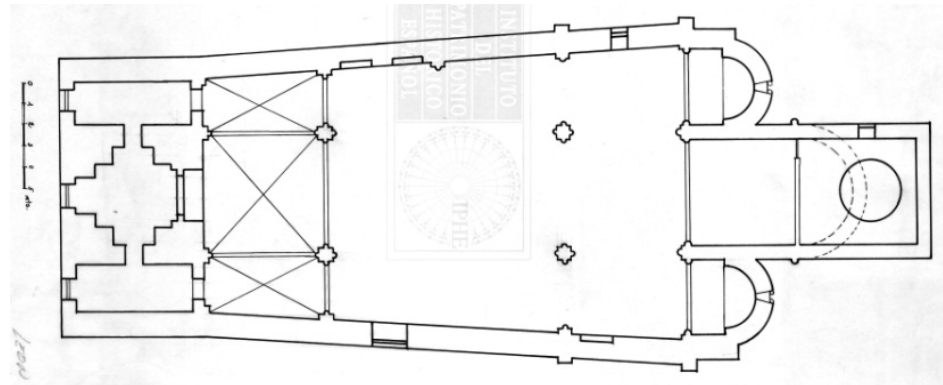

Figura 3.56. Iglesia de Santa María del Mercado (León)

(fuente: IPCE)

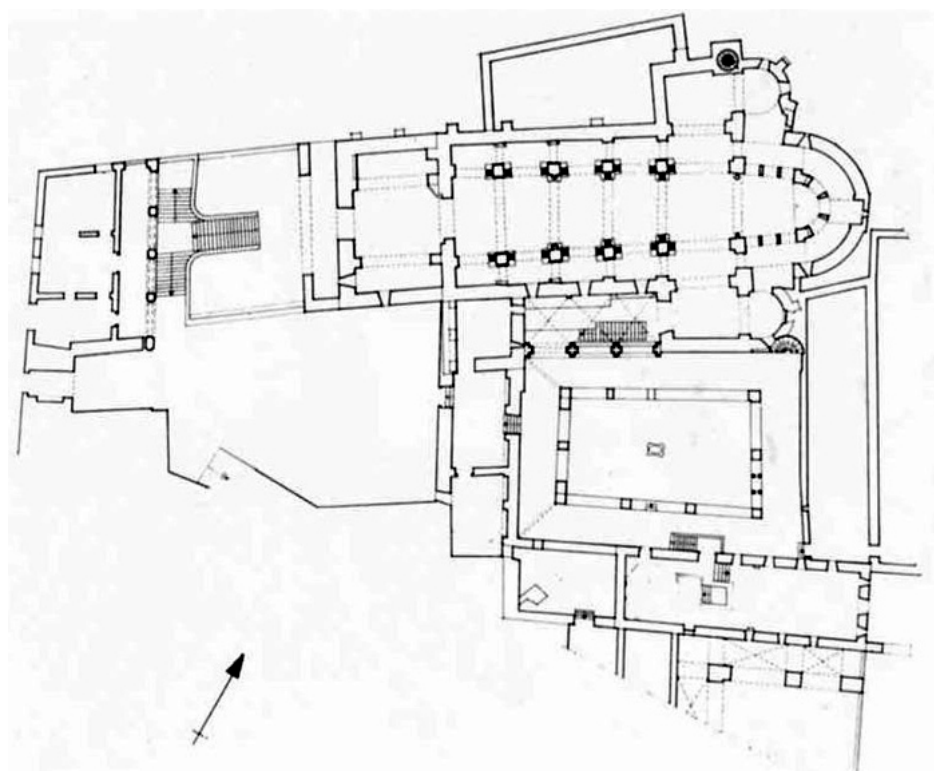

Figura 3.57. Iglesia de San Pedro de Roda (Gerona)

(http://www.enciclopedia.cat)

Incertidumbres en el análisis del origen de la deformación

Decíamos en el primer apartado de este capítulo, al exponer el sistema de análisis propuesto por Borie et al., cómo la distinción entre deformaciones obligadas y deliberadas, vinculando esta distinción al origen de la deformación, no es clara

En primer lugar cabe preguntarse hasta qué punto es ineludible, en un análisis centrado en la forma, detenerse a estudiar el origen de la deformación. 
En segundo lugar, tal y como señalan estos autores, «no siempre es fácil determinar por qué se crea una cadena de deformaciones» (BORIE et al. [1978] 2008, 99). En algunos casos es difícil, en otros es imposible.

Como acabamos de ver en los ejemplos señalados, para conocer el origen de la deformación es necesario conocer el contexto físico en el que se construyó, lo que implica tener información no sólo sobre la topografía, el parcelario y el viario originales, sino también sobre las distintas fases constructivas. También es necesario conocer las necesidades planteadas en el programa y los distintos proyectos planteados. Todos estos aspectos sólo son posibles en un análisis en profundidad de cada uno de los ejemplos analizados, ${ }^{38}$ lo que resulta imposible para los objetivos y limitaciones planteados en esta primera parte de la tesis.

En algunos casos el origen de la deformación sólo puede ser atribuido a un error de replanteo. En la Seo de Zaragoza la bóveda del cimborrio está esviada, sin que en apariencia existan condicionantes que lo provoquen. En cambio, el ligero esviaje del crucero de la iglesia de San Juan de los Reyes en Toledo parece responder a la cimentación preexistente (HUERTA FERNÁNDEZ y LÓPEZ MOZO, 2005).

En tercer lugar, en ocasiones una deformación no es vinculable a una contradicción. La disposición de la planta plantea una deformación sin que exista una contradicción que explique el origen de dicha deformación. Estaríamos ante deformaciones voluntarias, pero que no surgen de una contradicción con los modelos formales, sino como simple voluntad de singularizar. Un ejemplo de esto último lo constituye la Sacristía de la Sacra Capilla de El Salvador de Úbeda (Jaén), obra de Andrés de Vandelvira. La oblicuidad de la sacristía respecto al resto del templo sólo parece explicarse por una voluntad de alarde (figura 3.58):

Mientras Andrés de Vandelvira sitúa la sacristía de la iglesia de San salvador, en Úbeda, de una manera extrañamente torcida, que exige más esfuerzo de geometría que de construcción o estabilidad, y que se diría pensada sólo para forzar su acceso por un rincón y adaptar un paso abovedado alas oblicuidades que resultan, para lucimiento de la habilidad de su autor.

(RABASA DÍAZ 2000, 207)

38 Como en el caso de las bóvedas de las girolas de las catedrales de Granada y Málaga, analizadas en la segunda parte de la tesis (cfr. capítulo 8, apartados 8.2 y 8.3). 


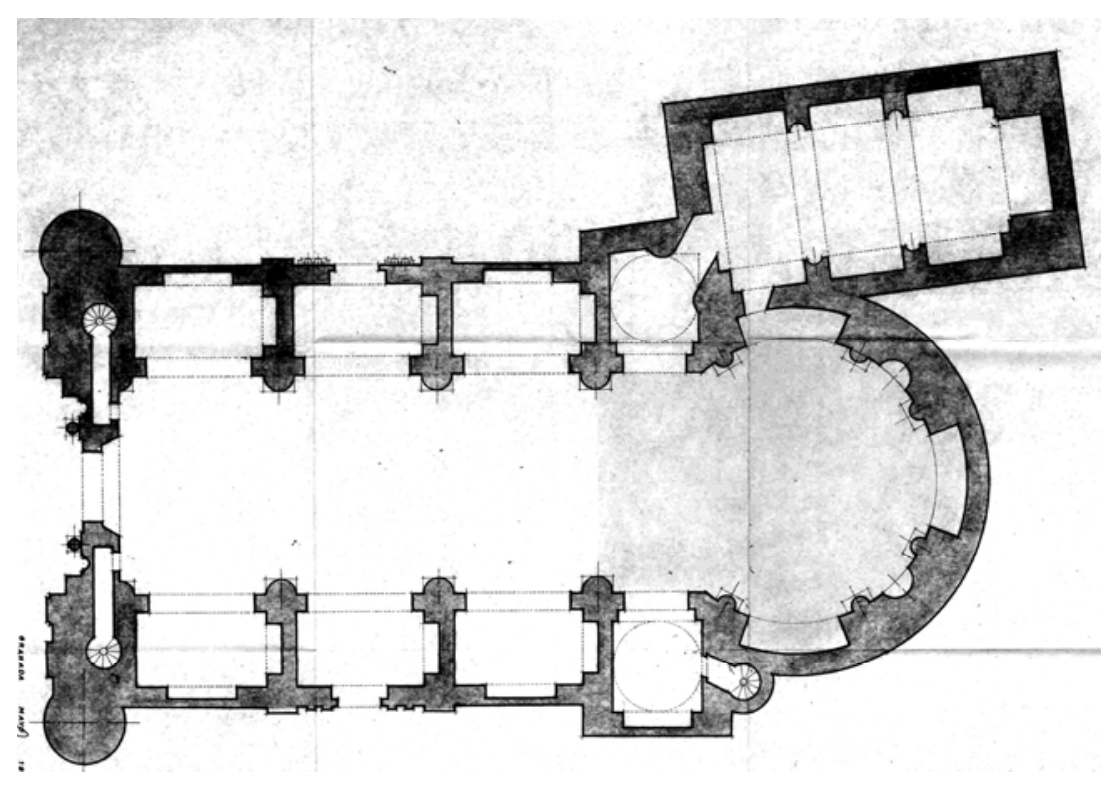

Figura 3.58. Sacra Capilla de El Salvador de Úbeda (Jaén) (fuente: IPCE)

Quedaría por señalar otro tipo de explicaciones para algunas deformaciones consideradas inexplicables, cuyo origen, de nuevo, no está en ninguna contradicción. Nos referimos a la deformación de la cabecera de algunas iglesias románicas, donde el ábside marca un pequeño ángulo con la orientación del resto del templo:

La deformación de ciertas iglesias ha sido considerada como simbólica. Según esta creencia, buscando una representación de las inflexiones del cuerpo de Cristo crucificado, los constructores de la Baja Edad Media desvincularon el eje de la capilla mayor inclinando ésta (como estaría la cabeza de Jesús después de muerto), torcieron los ejes de los brazos de la cruz y les dieron diferentes inflexiones. (...)

En resumen de estas ligeras observaciones consiste en admitir el simbolismo en ciertas disposiciones generales y en algunos detalles decorativos; pero negarlo para cuando significa la conversión del templo cristiano en un jeroglífico, por encima de todas las razones de historia arquitectónica y técnica constructiva.

(LAMPÉREZ ROMEA 1908-1909, 88)

En cualquier caso, conviene insistir en lo superfluo -incluso peligroso- de este tipo de análisis. 


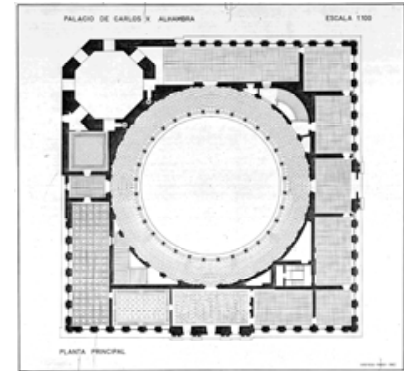

Figura 3.59. Palacio de carlos V en La Alhambra (Granada)

(fuente: IPCE)

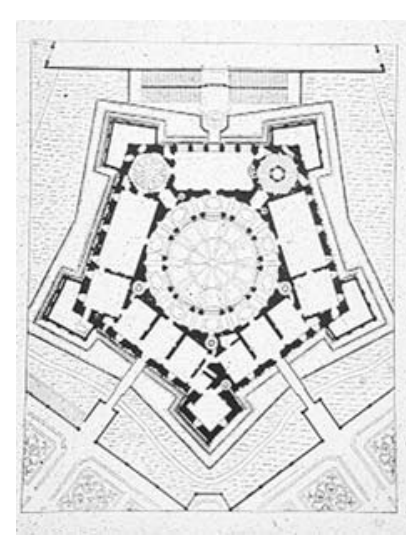

Figura 3.60. Palacio Farnese en Caprarola (Italia)

(fuente: Wikipedia.org)

\section{Causas formales de la deformación}

Más interés que la contradicción que da lugar a la deformación está en las causas formales de la deformación, pues éstas van a influir en la manera de resolverla. Además, un mismo tipo de deformación, como por ejemplo un cambio en el ritmo de pilares, puede tener orígenes distintos.

Las causas formales de estas deformaciones las agrupaban (BORIE et al. [1978] 2008, 66-71) en tres conjuntos:

- Relaciones estático dinámicas.

- Inclusión de geometrías incompatibles, donde distinguen dos posibilidades: geometrías diferentes -p.ej. circular y ortogonal- y orden geométrico frente a orgánico.

- Desajuste axial entre dos ejes que no son ni paralelos ni perpendiculares.

En el caso de arquitectura abovedada será necesario añadir otros casos.

$\underline{\text { Relaciones estático-dinámicas entre espacios estáticos y de circulación }}$

Esta situación, frecuente en el ámbito urbano (BORIE et al. [1978] 2008, 66-71), no es habitual en arquitectura religiosa. La explicación del origen de la girola como necesidad de procesionar rodeando el ábside podría considerarse un ejemplo de este tipo de causa formal. Sin embargo la forma semicircular del ábside es anterior a la presencia de la girola, por lo que esta causa sólo vendría a reforzar la siguiente, de encuentro de geometrías incompatibles.

\section{Inclusión de geometrías incompatibles. Geometría circular y} geometría ortogonal

Buena parte de las deformaciones asociadas a la cabecera de las iglesias -con o sin girola- provienen de este problema de acuerdo entre la geometría ortogonal de la planta basilical y la geometría circular del ábside -y la girola-. Los problemas no surgen sólo de la relación de la girola con las naves, también de la voluntad de restaurar un orden ortogonal una vez superado el ábside, como sucede en las capillas radiales de la Concatedral de Baza (figura 3.61 y 62).

El Palacio de Carlos V en La Alhambra de Granada o el Palazzo Farnese en Caprarola (Italia) son dos ejemplos, en arquitectura civil, de este tipo de conflicto (figuras 3.59 y 3.60 respectivamente) 


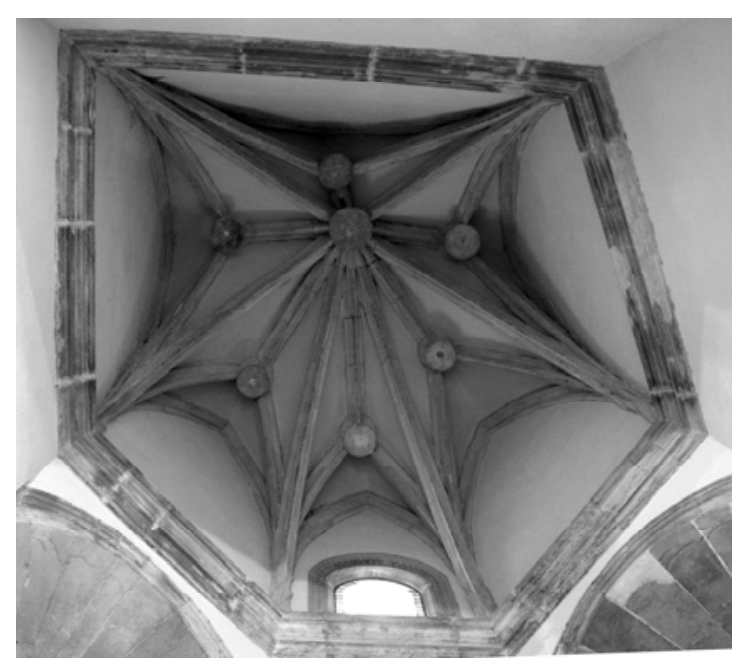

Figura 3.61- Concatedral de Baza, capilla radial

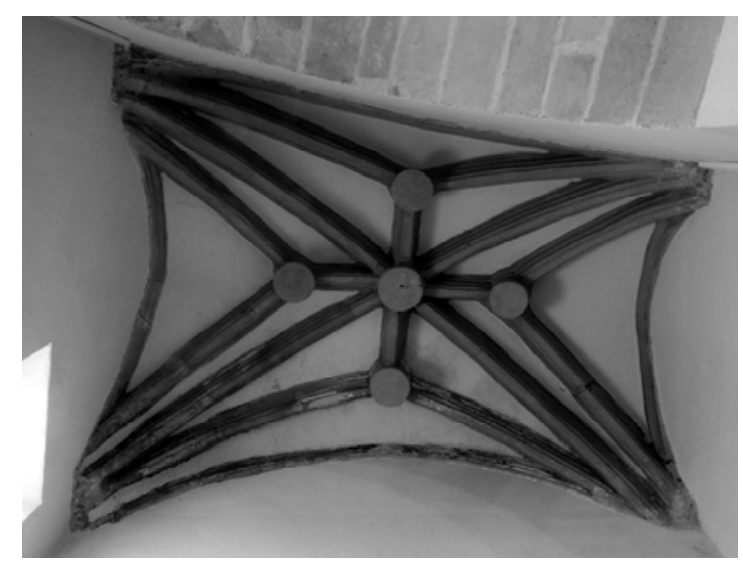

Figura 3.62. Concatedral de Baza, capilla radial

Inclusión de geometrías incompatibles. Orden geométrico y orden

orgánico

Podemos considerar que el contexto, ya sea la topografía, el parcelario o el viario -especialmente en el caso de ciudades históricasresponden a un orden orgánico. Los conflictos entre el orden geométrico del edificio y el orgánico del contexto son una causa formal muy frecuente de deformación. Ya hemos señalado varios ejemplos de este tipo de conflictos al hablar del origen de la deformación.

El problema se acentúa cuando la resolución del conflicto no se plantea desde el origen del proyecto, sino que surge de la necesidad de aprovechar espacios residuales en fases constructivas sucesivas.

Se problema se acentúa cuando al orden orgánico del contexto se le impone la semicircularidad del ábside, como sucede en la Sacristía de la Catedral de Perpignan donde el problema se ve enfatizado por la presencia de los contrafuertes del ábside (figura 3.28).

Inclusión de geometrías incompatibles. Otros casos

Podemos señalar el empleo de geometrías singulares como causa formal de algunas deformaciones. La Lady Chapel de la Catedral de Wells (Reino Unido) tiene forma octogonal lo que obliga a un reajuste de la cabecera que afecta tanto a la bóveda de la girola como a la propia capilla (figura 3.63). 
Ya se ha señalado el caso de las salas capitulares inglesas, cuyo perímetro octogonal entra en conflicto con la ortogonalidad del resto del conjunto. Otro ejemplo lo encontramos en la cúpula sobre el crucero del Duomo di Siena (Italia) donde la planta octogonal de la cúpula originalmente prevista obliga a una alteración de la trama de pilares (Figura 3.64).

La inclusión de las Capellas Imperfeitas en la cabecera del Monasterio de Batalha (Portugal) se resuelve con la inclusión de un pateo que unifica la cabecera escalonada y cuya bóveda ha sido analizada por Soraya Genin (GENIN 2014 298-302) (figura 3.65).

Por contrapartida veremos que el empleo de geometrías singulares es también un modo de resolver deformaciones.

\section{Desajuste axial entre dos ejes}

En arquitectura religiosa es frecuente encontrar este tipo de deformaciones. Un ejemplo lo encontramos en la Catedral de Senlis donde la sacristía del siglo XIV, orientada según la muralla, que marca ángulo con la iglesia. Los problemas surgen con la edificación de la parte central del templo en el siglo XVI que obliga a deformar ligeramente una de las naves laterales. Otro ejemplo lo encontramos en la Sacristía de la Catedral de Palma de Mallorca obra de Guillén Sagrera (figura 3.66).

En ejemplo de la Catedral de Bautzen (Alemania) (figura 3.14) es muy singular ya que el desajuste axial repercute en todo el edificio, lo que también sucede, de modo menos acusado, en la Abadía de Saint-Savin-sur-Gartempe (Francia).

La inclusión a mediados del siglo XV de las capillas de St Michael y la Lady Chapel en el transepto oeste de la Catedral de Canterbury (Reino Unido) produce un pequeño desajuste axial con la nave central del templo (figura 3.35). ${ }^{39}$

39 La Catedral de Canterbury merecería por si sola un análisis en profundidad por la colección de deformaciones que se ven involucradas. 


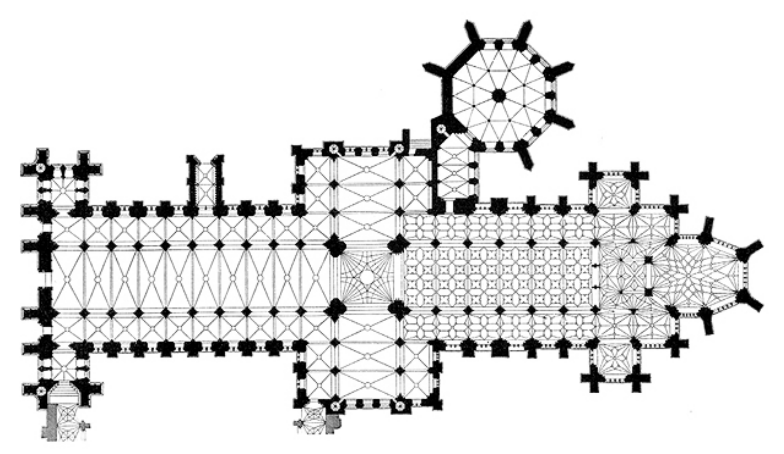

Figura 3.63. Catedral de Wells (Reino Unido) según Dehio-Bezold (fuente: Gotik-Romanik)

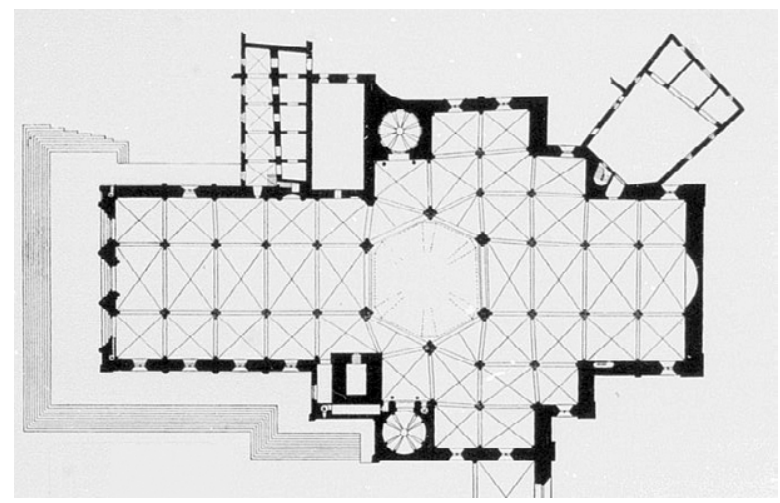

Figura 3.64. Duomo de Siena (Italia) según Dehio-Bezold (fuente: Gotik-Romanik)

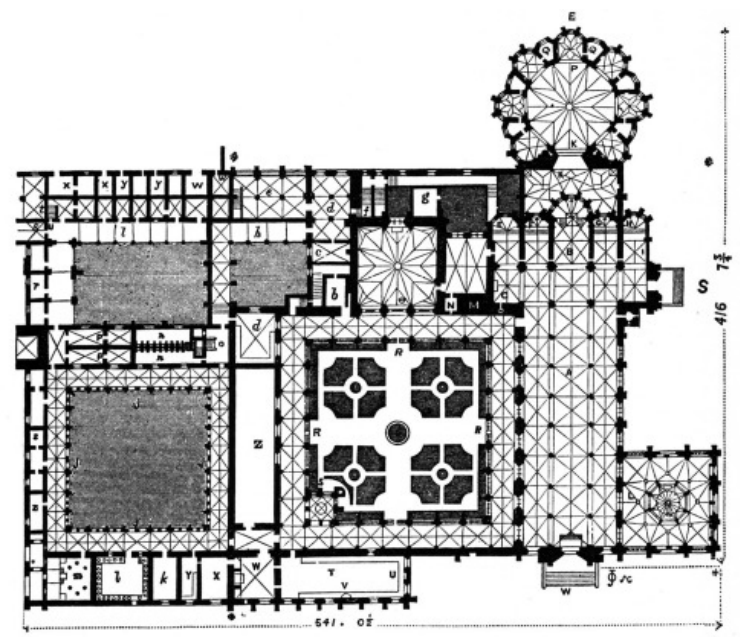

Figura 3.65. Monasterio de Batalha (Portugal)

(http://40.media.tumblr.com)

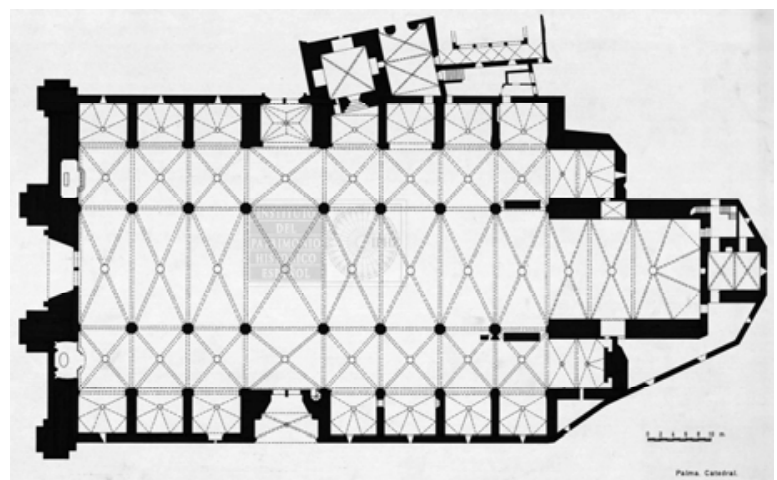

Figura 3.66. Catedral de Palma de Mallorca (fuente: IPCE) 


\section{Desajuste axial de ejes paralelos ${ }^{40}$}

Un desajuste entre ejes paralelos provoca, en arquitectura abovedada, un conflicto que puede dar lugar a una bóveda deformada (cfr. capítulo 5, apartado 5.2). Encontramos un buen ejemplo de esto en la unión de las naves románica y gótica de la Catedral de Toulouse (Francia) (figura 3.67 y 3.68), o en el claustro de la Catedral de Narbona (Francia) (figuras 3.69 y 3.70).

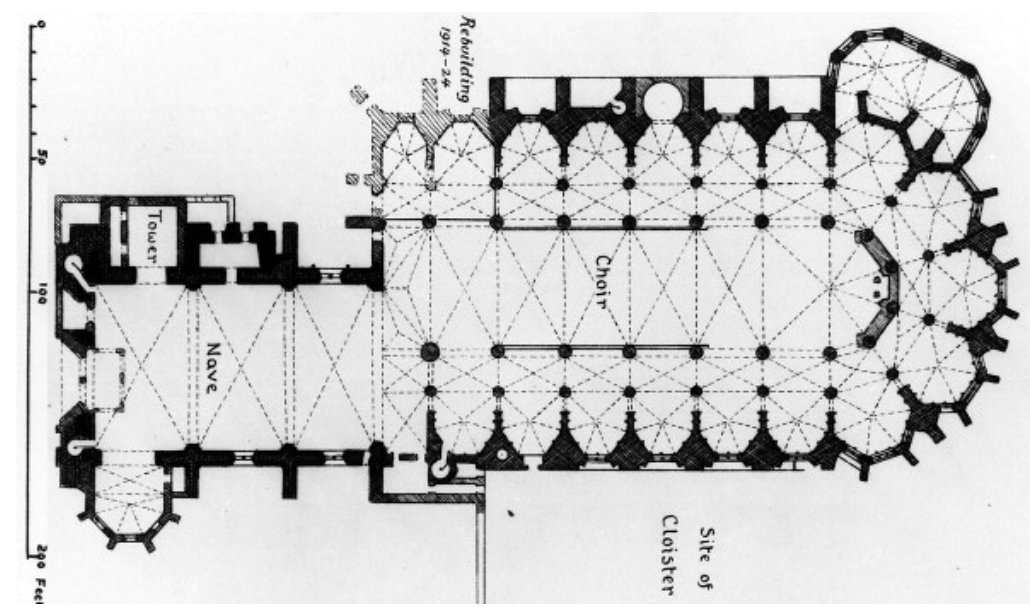

Figura 3.67. Catedral de Toulouse (Francia). Courtauld Institute of Art (fuente: Gotik-Romanik)

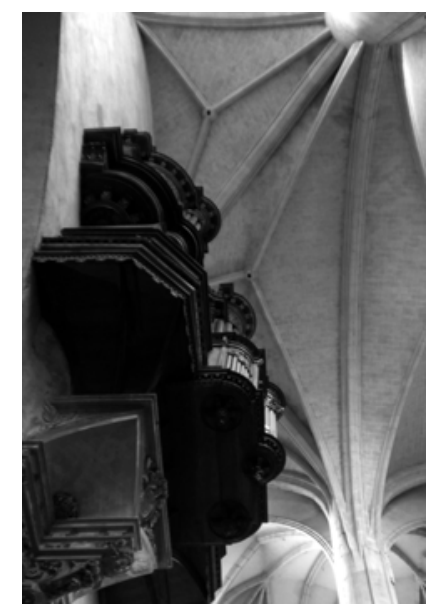

Figura 3.68. Detalle de la bóveda de enlace

El desajuste puede venir por la necesidad de marcar el eje en iglesias con pilares en la nave central. En la iglesia vieja (Oude kerk) de Borne (Paises Bajos), la pequeña iglesia de una sola de mediados del siglo XIV se amplía en $1482^{41}$ aumentando su anchura, lo que se resuelve con una iglesia de dos naves con pilares en el eje. La necesidad de efectuar la transición entre ambas partes lleva a la construcción de una bóveda singular de apoyos asimétricos (figura .3.71).

Un ejemplo similar lo encontramos en la sacristía del siglo XIV de la Catedral de Le Mans (Francia)(figura 3.73) y en la iglesia de Santa María del Prado en Praga (República Checa) (figura 3.74). Destaca la iglesia parroquial de St. Marien en Enns (Austria), con dos ejemplos de transición entre pilar central y altar (figura 3.72).

40 Borie et al. hablaban de «desajuste axial entre dos ejes que no son ni paralelos ni perpendiculares», pero, como ya hemos señalado, en arquitectura abovedada dos ejes paralelos pero desfasados provocan un problema de deformación, aunque en apariencia estemos ante un caso de «geometrías compatibles» (BORIE et al. [1978] 2008, 61).

41 http://nl.wikipedia.org/wiki/Oude_Kerk_(Borne) consultada el 12/05/15 


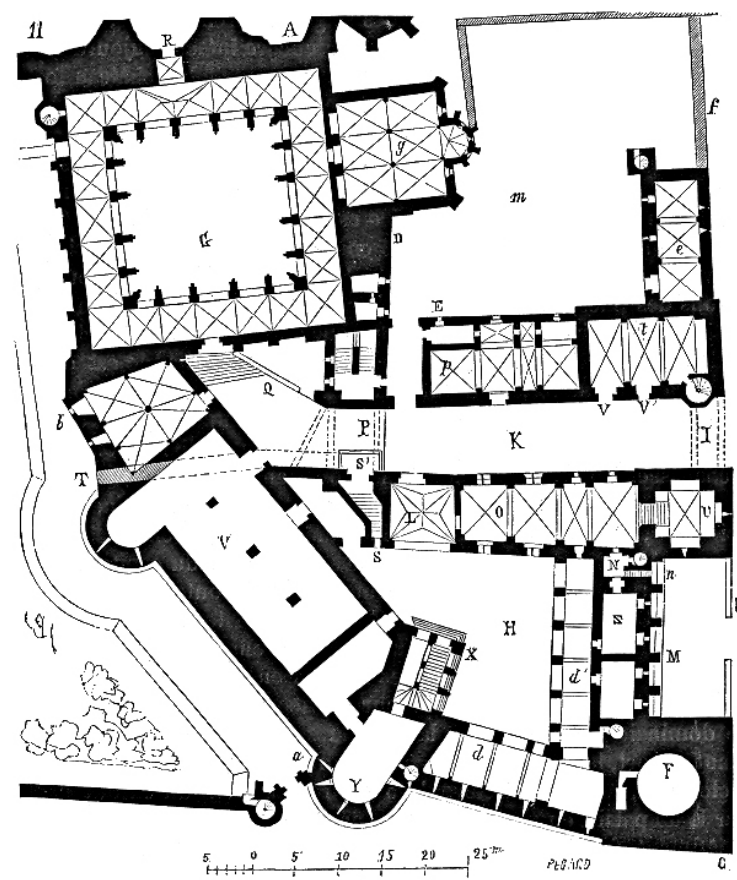

Figura 3.69. Claustro de la Catedral y Palais des Archevêques de Narbona (Francia)

(VIOLLET-LE-DUC 1854-1868, 7:21)
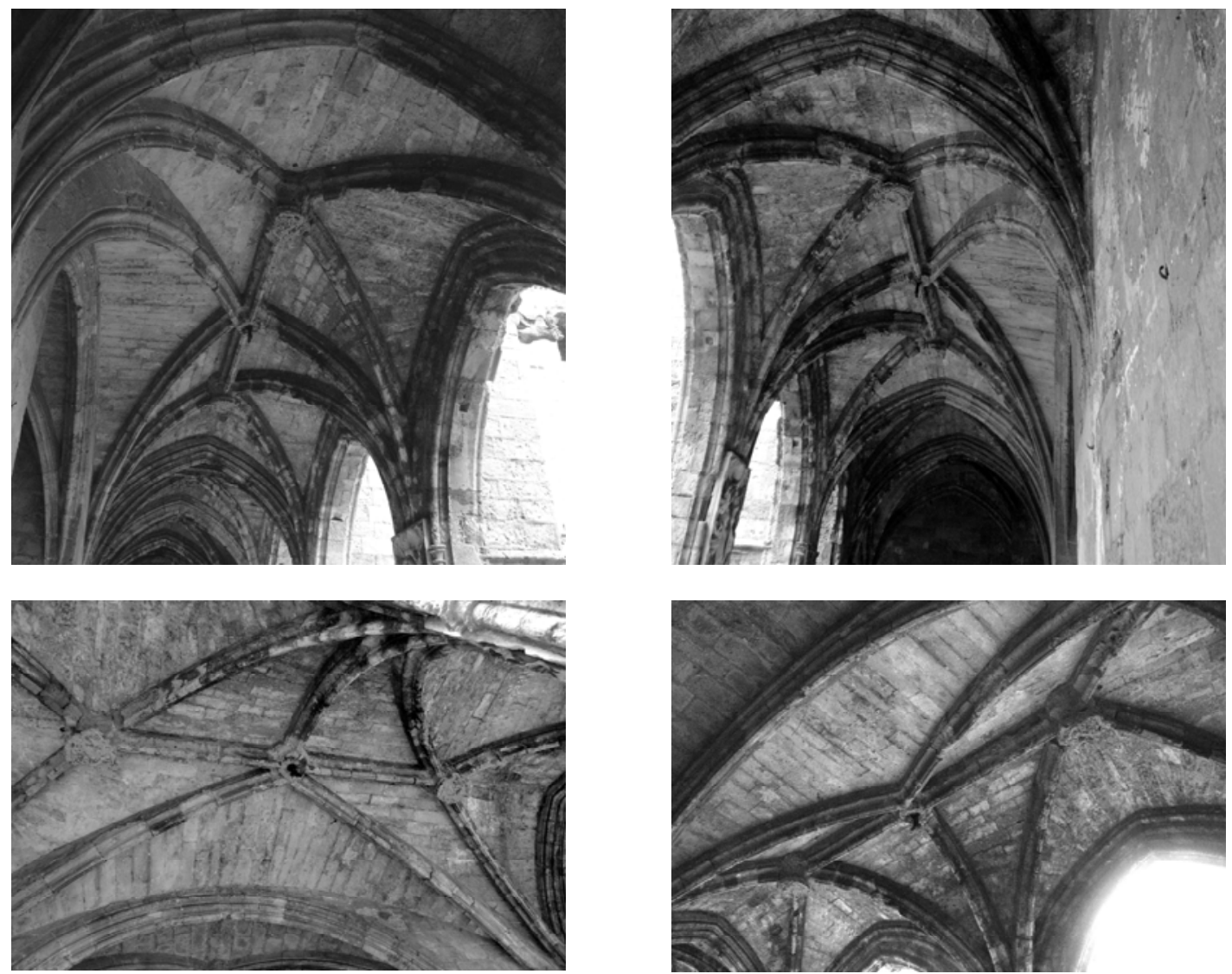

Figura 3.70. Detalle de la bóveda de enlace entre el claustro y la Catedral.

(Fotografías de Carmen Pérez de los Ríos) 

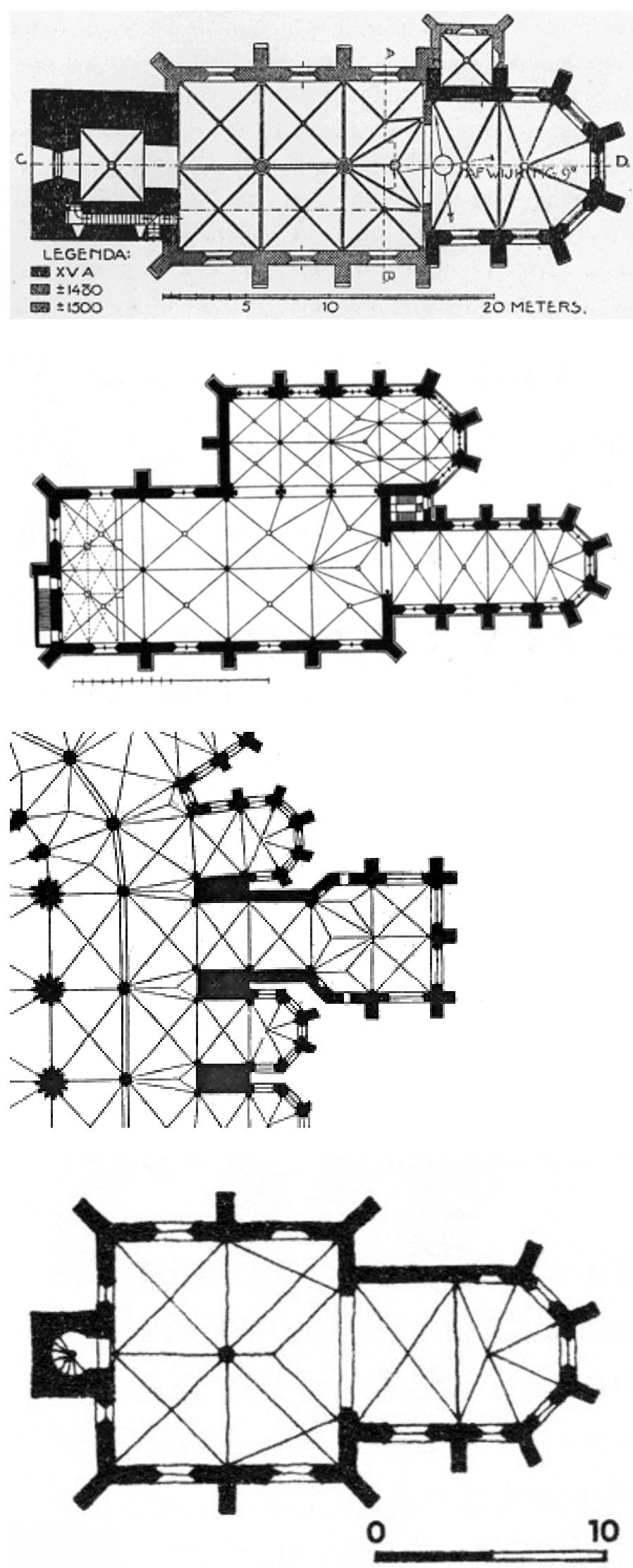

Figura 3.71. Iglesia vieja (Oude kerk) de Borne (Paises Bajos) (fuente: Gotik-Romanik)

Figura 3.72. Iglesia parroquial de St. Marien en Enns (Austria) según DehioBezold

(fuente: Wikipedia.org)

Figura 3.73. Sacristía de la Catedral de Le Mans

(VIOLLET-LE-DuC 1854-1868, 2:355)

Figura 3.74. Iglesia de Santa María del Prado en Praga (República Checa)

(STAŇKOVÁ et al. 1991:59) 
Las deformaciones provocadas por una alteración de la luz entre apoyos en fases constructivas sucesivas, como sucede en la Basílica de Saint-Denis (Francia) (figura 3.8), en la Catedral de Évreux (Francia) (figura 3.75) o en la iglesia de Saint-Médard de París (Francia) (figuras 3.76 y 3.77), podrían incluirse en este grupo, si bien no implican un desajuste axial propiamente dicho.

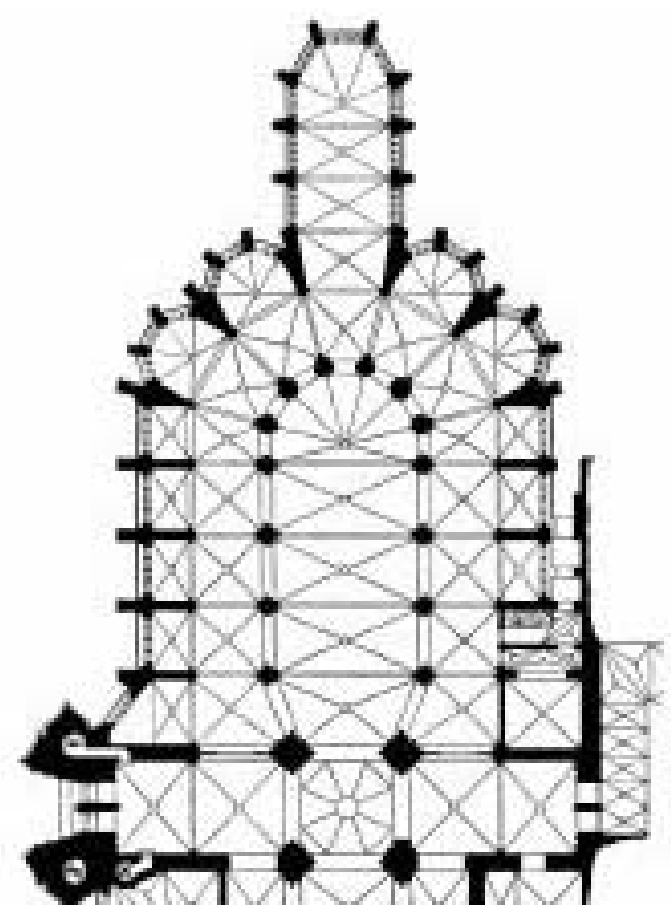

Figura 3.75. Cabecera de la Catedral de Evreux (Francia) (fuente: Gotik-Romanik)

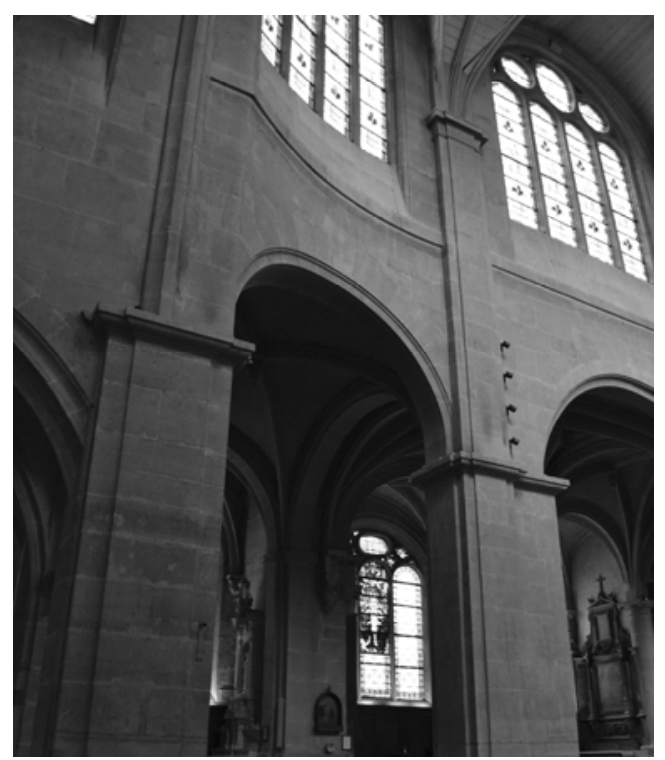

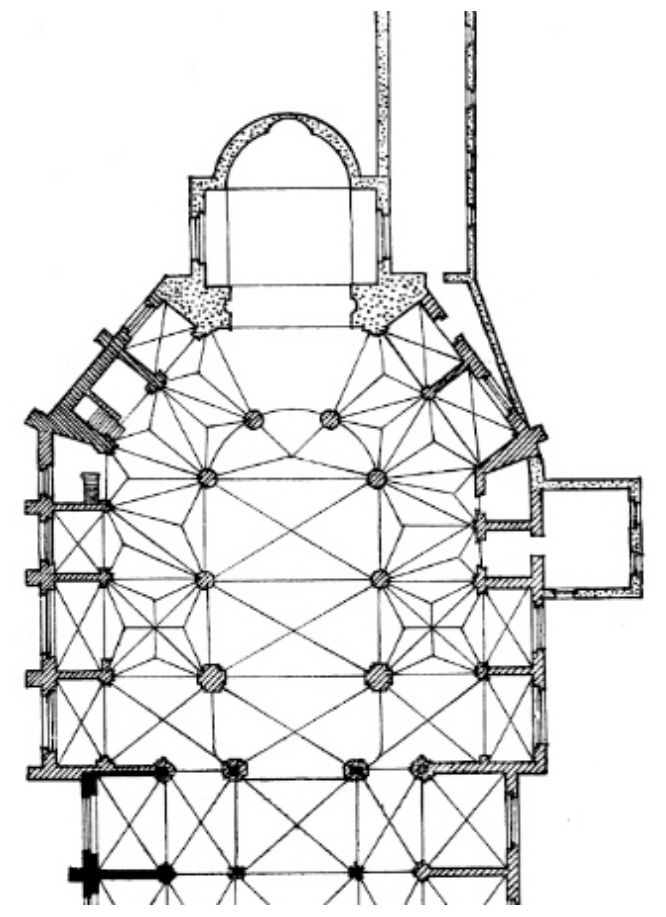

Figura 3.76. Cabecera de la iglesia de Saint-Médard en París (Francia) (Bos 2003, 231)

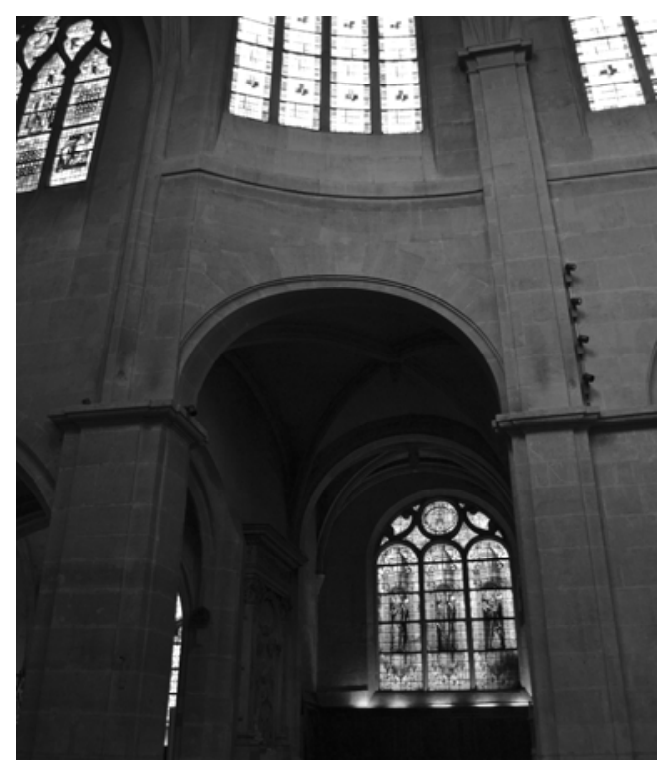

Figura 3.77. Iglesia de Saint-Médard en París. Detalles del arco de enlace 


\section{Actitudes frente a la deformación}

Las actitudes frente a la deformación son tres: rechazo, aceptación y voluntad. Estas tres actitudes están íntimamente relacionadas con lo que podríamos llamar las causas eficientes ${ }^{42}$ de la deformación.

Las causas que motivan la deformación tienen que ver con el apego al modelo formal -voluntad de conservar la integridad de la forma-, con la flexibilidad del modelo arquitectónico -modelo funcional frente al modelo formal-, y la búsqueda de efectos plásticos o semióticos. Todo ello condicionado por las limitaciones de espacio

La voluntad de integración o desintegración también puede actuar como motor de la deformación

Borie et al. distinguen siete situaciones distintas:

\section{$\underline{\text { Rechazo propiamente dicho }}$}

Cuando existe una voluntad de conservar la integridad de la forma a toda costa y los condicionantes espaciales lo permiten, es posible desintegrar -disociar- el conjunto para evitar la deformación. Los elementos se yuxtaponen y cada uno conserva su integridad. En fases sucesivas de edificación es posible que un aprovechamiento de los espacios residuales provoque la aparición de deformaciones. Entre los distintos edificios es posible situar elementos de articulación que los pongan en relación.

Un ejemplo de esto lo constituyen las catedrales inglesas como la de Salisbury, Wells o York, donde la forma octogonal de la sala capitular no provoca conflictos con la ortogonalidad del resto del conjunto al separarse del resto.

Dentro de la absoluta ortogonalidad y regularidad de la Catedral de Salisbury, donde la desintegración lleva incluso a separar el claustro del templo, encontramos una pequeña bóveda deformada precisamente en el elemento de unión del templo con el claustro (figura 3.52).

42 Causa eficientes como 'primer principio productivo del efecto, o la que hace o por quien se hace algo'. Están al margen de las causas formales que veíamos antes y tienen que ver con los motivos que conducen a la deformación. 


\section{Repugnancia}

Es el tipo de deformación más frecuente en arquitectura religiosa que evita deformar el templo, trasladando la deformación a las edificaciones anexas, tal y como sucede en la iglesia de San Lorenzo in Dámaso en Roma (Italia) (figura 3.78).
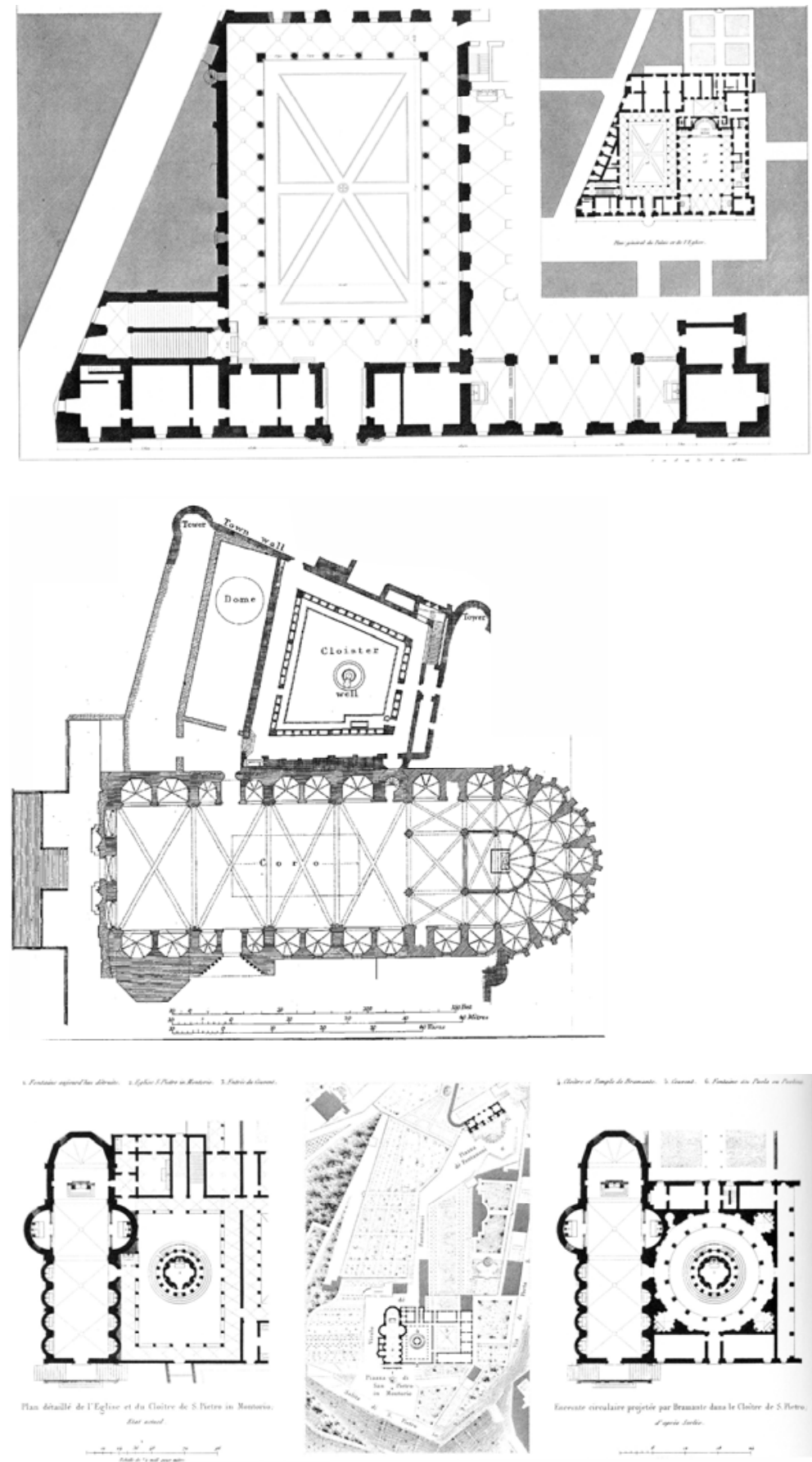

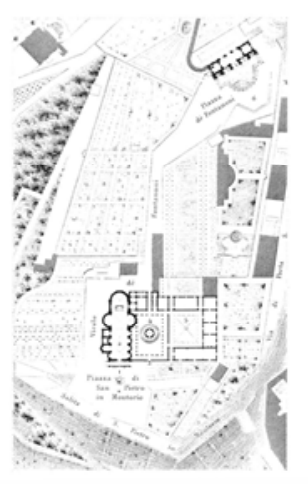

Figura 3.78. Iglesia de san Lorenzo in Dámaso (Palacio della Cancelleria) en Roma (Italia)

(LETAROUILLY [1860] 1982, 79)
Figura 3.79. Catedral de Gerona (STREET 1929)

Figura 3.80. Iglesia de San Pietro in Montorio en Roma (Italia) (LETAROUILLY [1860] 1982, 322)

En muchos casos el vacío no abovedado del claustro sirve para absorber la deformación, como en los ejemplos de la Catedral de Gerona (figura 3.79) y la abadía de Mont-Saint-Michel (Francia) 
(figura 3.12). ${ }^{43}$ En otros casos se evita deformar el claustro, siendo las edificaciones que circundan el claustro las que se deforman.

\section{$\underline{\text { Recuperación estilística }}$}

Consiste en el empleo de geometrías particulares y soluciones específicas como respuesta. Un ejemplo lo encontramos en la girola de la Catedral de Pamplona que se resuelve por la adición de capillas de planta hexagonal, ${ }^{44}$ o en la Catedral de Lübeck (Alemania) (figuras 3.81 y 3.82 respectivamente).
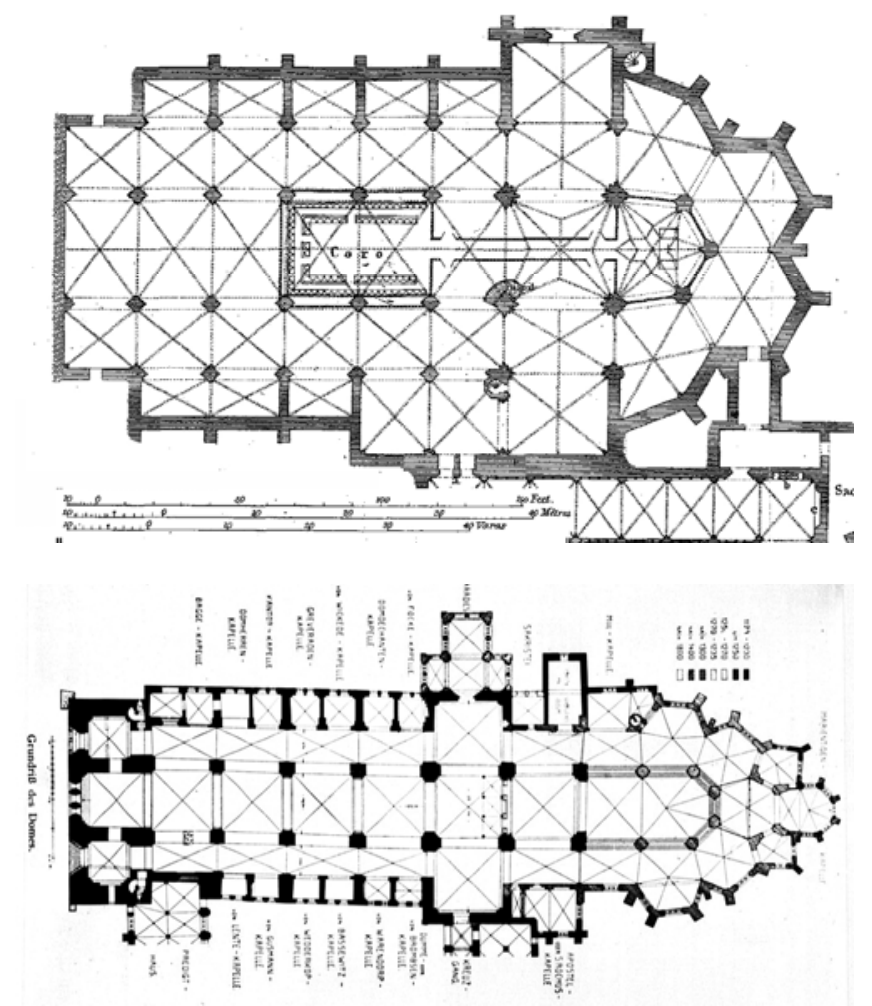

Figura 3.81. Catedral de Pamplona (STREET 1929)

Figura 3.82. Catedral de Lübeck (Alemania) (fuente: Gotik-Romanik)

43 Merece la pena señalar el ejemplo del patio del Templete de San Pietro in Montorio de Bramante (figura 3.80). El proyecto original tenía previsto un patio circular acorde con el templete, la transición entre el edificio ortogonal y el patio circular se resolvería regruesando el muro y alojando escaleras (SERLIO 1540, XLI). En el dibujo de Letarouilly (figura 3.80) se pone de manifiesto el problema adicional que representa el transepto semicircular, que no aparece en el dibujo de Serlio

La solución construida, aunque suponga un conflicto entre ambas formas no provoca un problema constructivo al ser el vacío del patio el que asume la contradicción.

44 En realidad dos de las capillas son hexágonos regulares y dos pentágonos irregulares ya que la disposición de las capillas no permitía su enlace con las naves simplemente con el empleo de hexágonos. 
En el la Iglesia de Santa María della Pace en Roma (Italia), la forma octogonal de la cabecera resuelve, al menos en parte, la oblicuidad con el claustro de Bramante (figura 3.83).

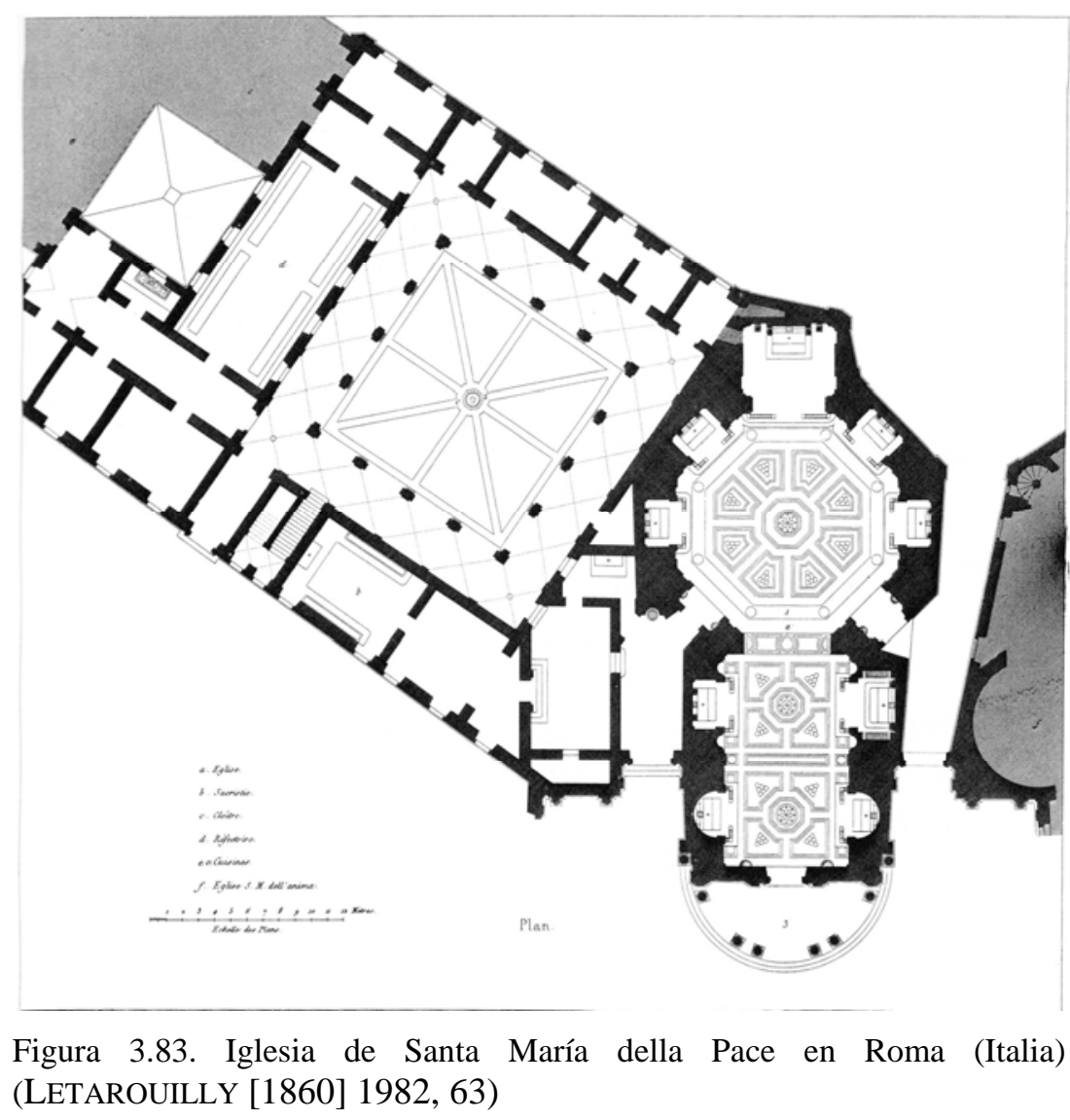

Encontramos también casos en los que el modelo se altera hasta hacerlo irreconocible, como en las «toscas» terminaciones de las catedrales inglesas, ${ }^{45}$ que sustituyen la girola semicircular por una recta. A pesar de lo aparentemente poco complejo de la solución de girola recta, en la girola de la Catedral de Exeter encontramos una llamativa bóveda con apoyos asimétricos (figura 3.84).

\section{Aceptación pasiva}

Si las posibilidades espaciales no permiten trasladar la deformación a las edificaciones anexas, ésta es asumida por el templo. Cuando es posible la deformación se relega a las capillas laterales, como la iglesia de Santa Maria dell'Anima en Roma (Italia) (figura 3.85). Si la

45 «El chevet francés contrasta con la tosca terminación del coro gótico inglés porque se inflexiona para terminar y acentuar el conjunto» (Ventury [1966] 1995, 152). 
deformación es mucha ésta puede ser asumida por las naves laterales, evitando deformar la nave central, como en la iglesia de Saint-Aspais de Melun (Francia) (figura 3.38).
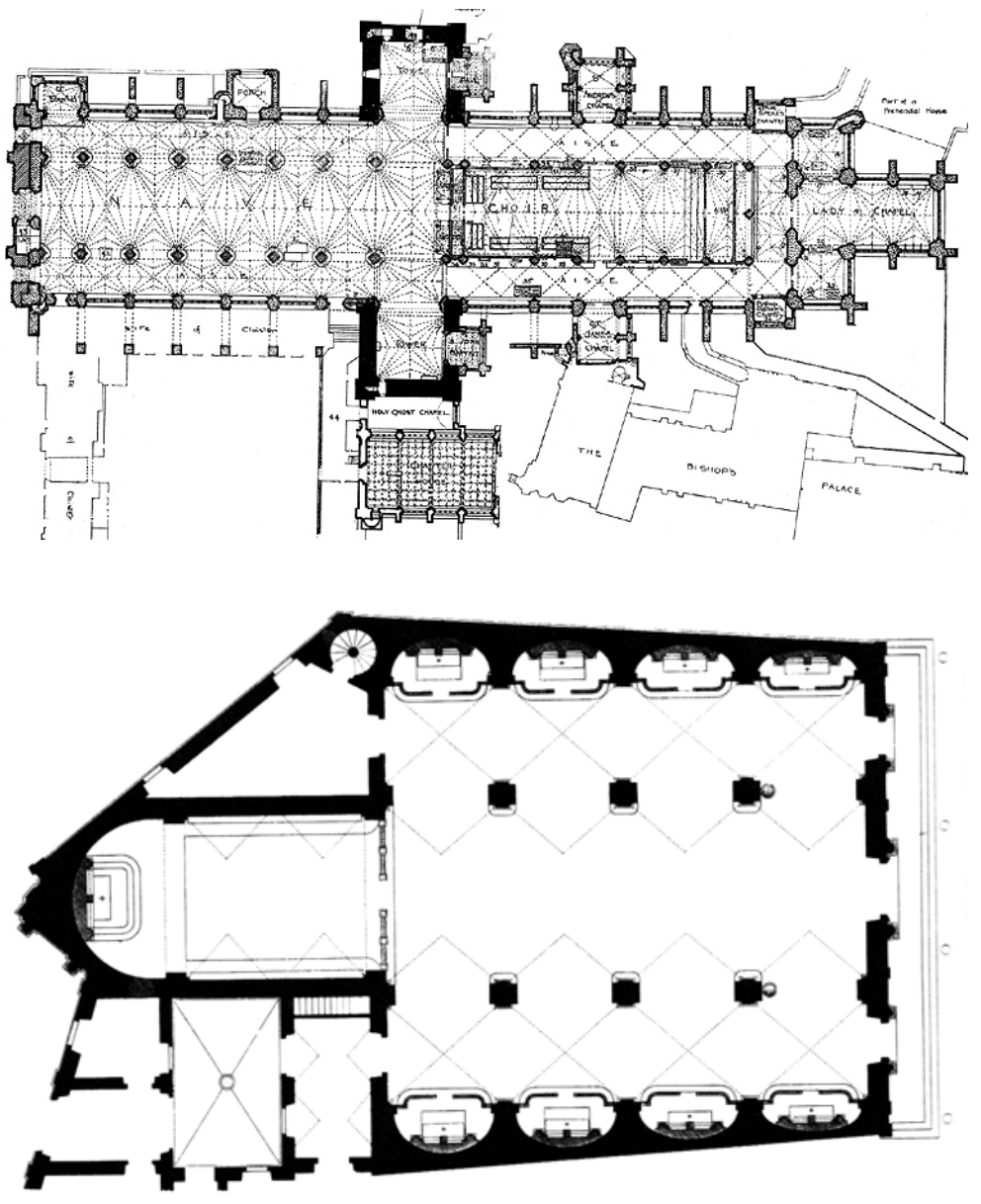

Figura 3.84. Catedral de Exeter (Reino Unido) (http:// www.medart.pitt.edu)

Figura 3.85. Iglesia de Santa Maria dell'Anima en Roma (Italia) (LETAROUILLY [1860] 1982, 68)

En otros casos la deformación repercute en todo el conjunto, como en la Catedral de Bautzen (Alemania) (figura 3.14).

\section{Voluntad significativa}

El ejemplo de la girola será analizado en el capítulo siguiente (cfr. capítulo 4, apartado 4.4). El empleo de la girola semicircular rodeando el ábside, frente a soluciones constructivamente más sencillas como la girola recta o algunos ejemplos de girola rectificada (cfr. capítulo 4, apartado 4.2), también podría explicarse por la voluntad de mantener la singularidad del ábside al exterior, significando la posición del altar. 


\section{Modalidades de resolución de la deformación}

Cuando empezamos la investigación sobre bóvedas deformadas, pudimos identificar lo que podríamos denominar «zonas de conflicto», en las que había mayores posibilidades de encontrar bóvedas deformadas. La «zona de conflicto» más evidente es la de la cabecera -con o sin girola-, donde la semicircularidad del ábside entraba en contradicción con la ortogonalidad de las naves, con la forma de la parcela y con la presencia de edificaciones adyacentes. Sin embargo, lo primero que pudimos comprobar es que pese a esa situación en «zona de conflicto» la deformación no siempre se traduce en bóvedas irregulares.

La deformación puede ser resuelta a nivel de conjunto del edificio, a través de los mecanismos de la composición arquitectónica, o puede descender a nivel de bóveda, siendo la bóveda la que resuelva el problema.

Si nos fijamos, por ejemplo, en una sala cuya planta tiene forma de trapecio rectángulo, motivada por la distinta orientación de uno de los muros que cierran el perímetro, ésta puede ser resuelta de distintas maneras (figura 3.86).

- Separar la sala lo suficiente para independizar el problema, estaríamos ante un caso de «rechazo de la deformación» (BORIE et al [1978] 2008, 106-107). En la catedral de Senlis, la sacristía del siglo XIV se orienta según la muralla galoromana, lo que entra en conflicto con la catedral. La distancia a la que está situada la sacristía hace que no se preciso deformar ésta (figuras 3.87 y 3.88). ${ }^{46}$

- Dividir la edificación en dos partes, una sala principal de forma regular y otra sala considerada menor que asuma la irregularidad, reflejando una actitud de «repugnancia» frente a la deformación (BORIE et al [1978] 2008, 107).

- No abovedar, recurriendo, por ejemplo, a un forjado de vigas de madera.

- Regruesar el muro, macizándolo o aprovechando para alojar un espacio de servicio como una escalera (figura 3.40).

46 Sin embargo la orientación de la sacristía del siglo XIV sí deforma el muro de cerramiento de la nave lateral, construida en el siglo XVII, que se resuelve con una solución de bóveda sin ojivos que veremos más adelante. 

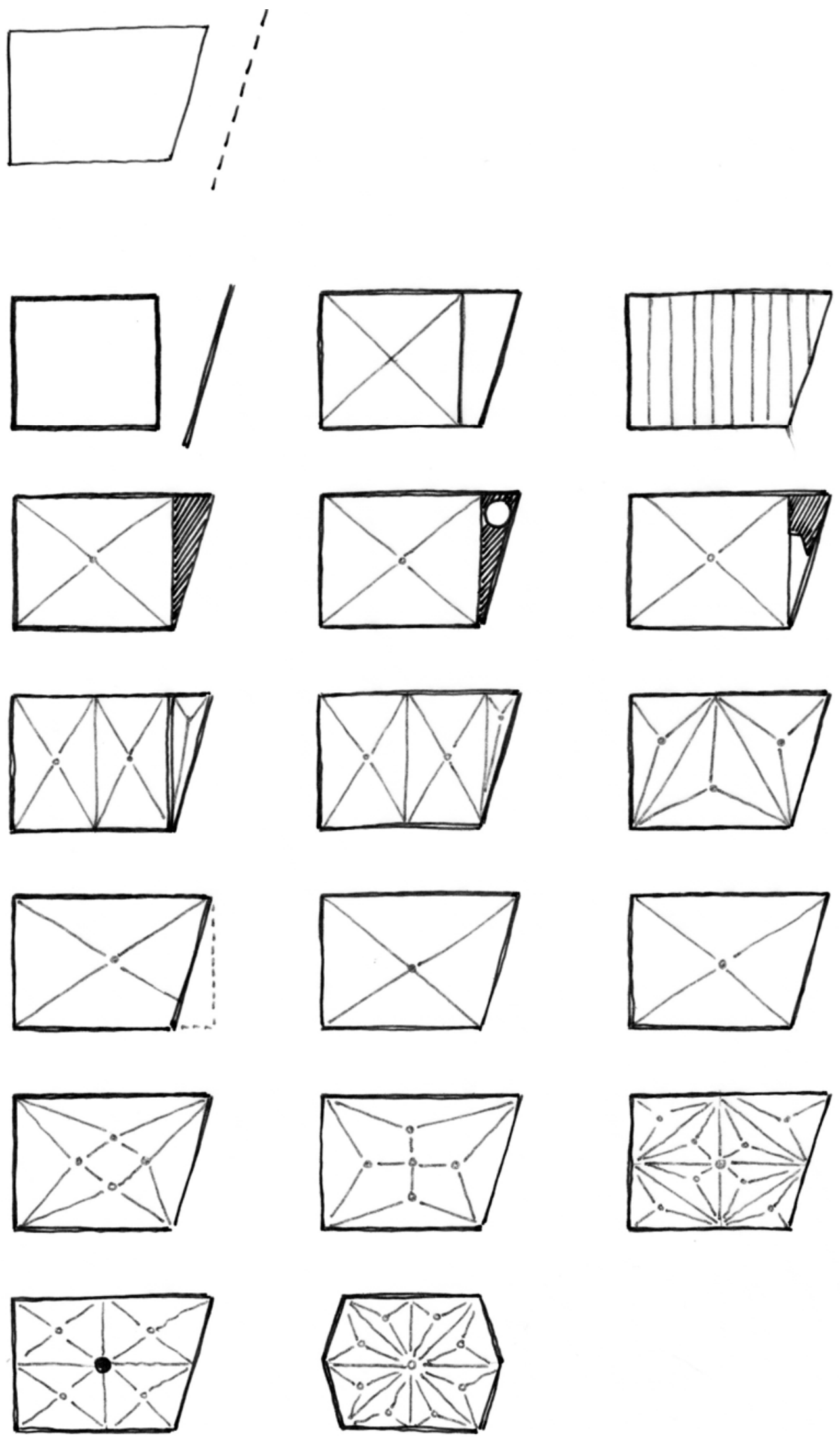

Figura 3.86. Modalidades de resolución de la deformación 
- Regruesar el muro pero abrirlo con un nicho.

- Dividir el espacio en dos partes, una regular y otra irregular que asuma la diferencia, por medio de un arco, situando la bóveda irregular a menor altura de modo que la sala se perciba como regular.

- Dividir la bóveda en dos partes, una regular y otra irregular que asuma la diferencia. Encontramos un ejemplo de esto en la Sacristía de la Catedral de Palma de Mallorca realizada por Guillém Sagrera, donde la bóveda de sala se divide en tres partes, dos rectangulares y una triangular (figura $3.66 \mathrm{y}$ 3.89). ${ }^{47}$

- Dividir toda la bóveda en tramos triangulares. Esta solución es muy frecuente, llegando a emplearse en salas de perímetro regular donde no hay deformación a resolver, tal y como sucede en el vestíbulo del Château d'Amboise (Francia) (figura 3.90).

- Construir una bóveda que parezca ignorar el problema, por ejemplo con un trazado de nervios que se refiera al rectángulo hipotético original. Encontramos un ejemplo de esto en los ventanales de la Lonja de Palma de Mallorca, obra de Guillém Sagrera (figuras 3.91 y 3.92). ${ }^{48}$

Otros ejemplos de esta situación, donde la bóveda parece cortada por el muro que la delimita, los encontramos en la Colegiata de Baza (figura 3.9) o en la sacristía de la Capilla Real de Alfonso el Magnánimo en Valencia (ZARAGOZÁ CATALÁN 1997; ZARAGOZÁ CATALÁN 2000, 144-147) (figura 3.94).

La «segunda solución para la bóveda de la escalera para el ángulo Sureste» del Palacio de Carlos V de Granada también ejemplifica este problema (JIMÉNEZ BARREDA 1954).

- Construir una bóveda de crucería sencilla de planta trapecial, de la existen algunas variantes (cfr. capítulo 5, apartado 5.2). Encontramos un ejemplo también en la Catedral de Senlis, en la cabecera (figura 3.88).

47 (PÉREZ DE LOS Ríos 2016).

48 En realidad se trata de trapecios isósceles, y no rectángulos, pero es sencillo extrapolar el ejemplo.
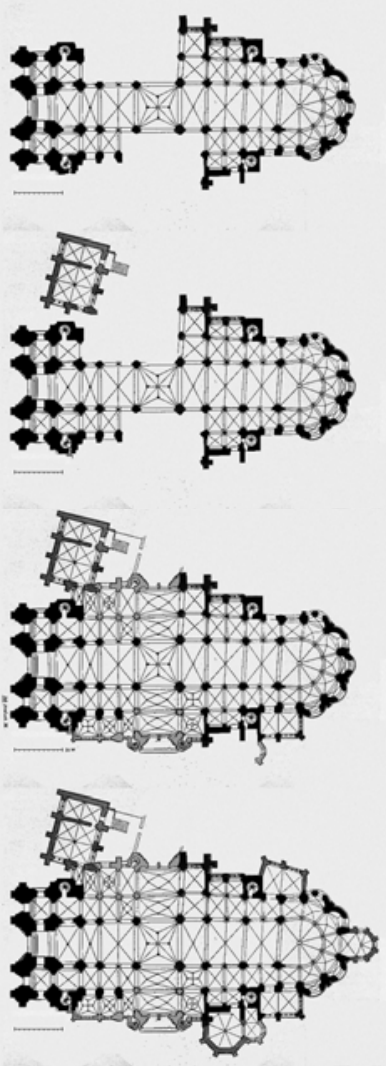

Figura 3.87. Fases de construcción de la Catedral de Senlis (Francia).

Dibujo realizado a partir de la planta publicada en http://www.abelard.org 


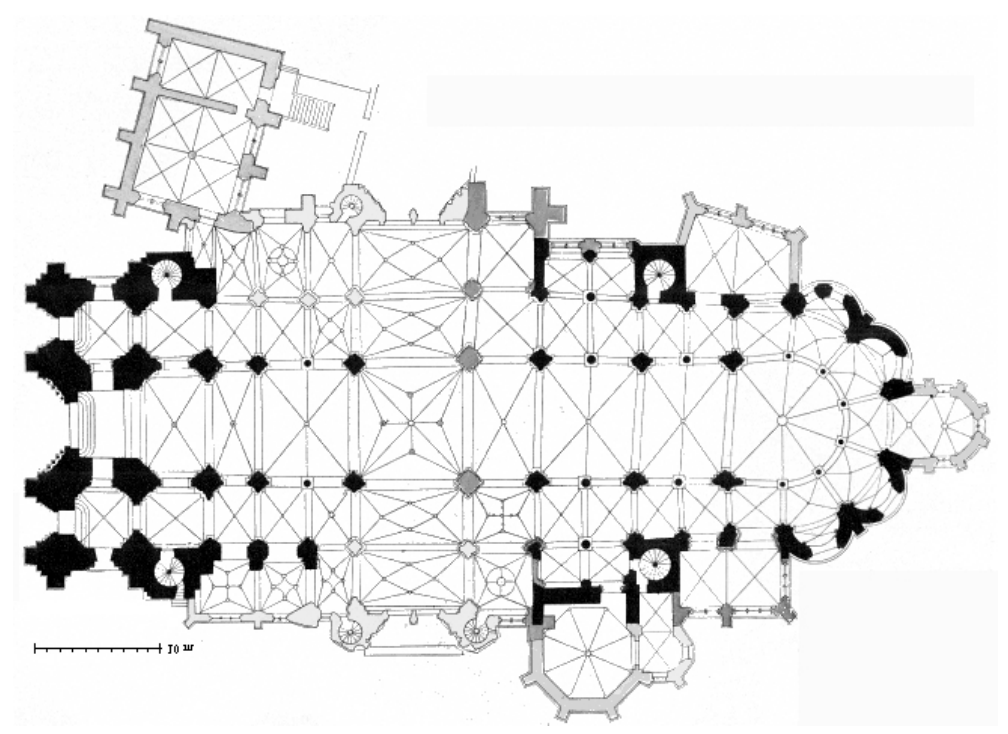

Figura 3.88. Catedral de Senlis (Francia)

(http://www.abelard.org)
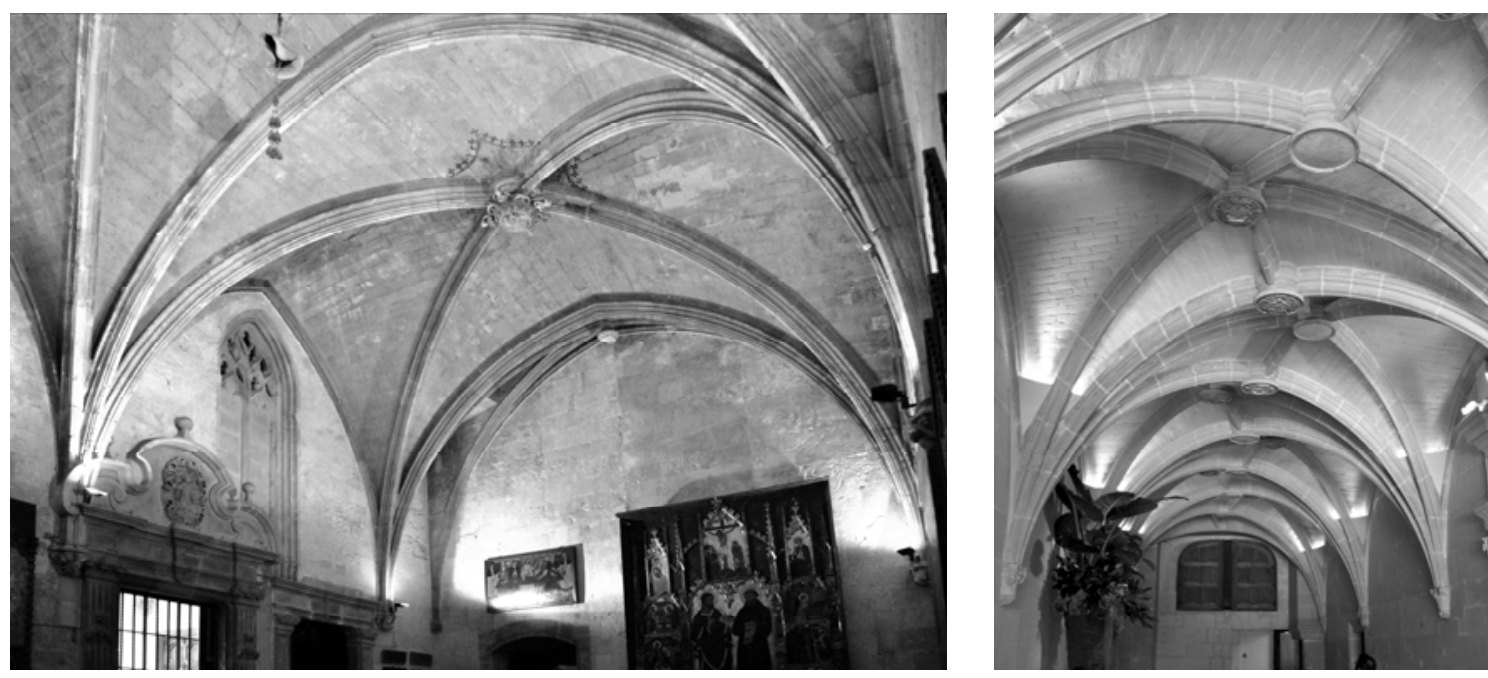

Figura 3.89. Sacristía de la Catedral de Palma de Mallorca (Fotografía de Carmen Pérez de los Ríos)

Figura 3.90. Castillo de Amboise (Francia)

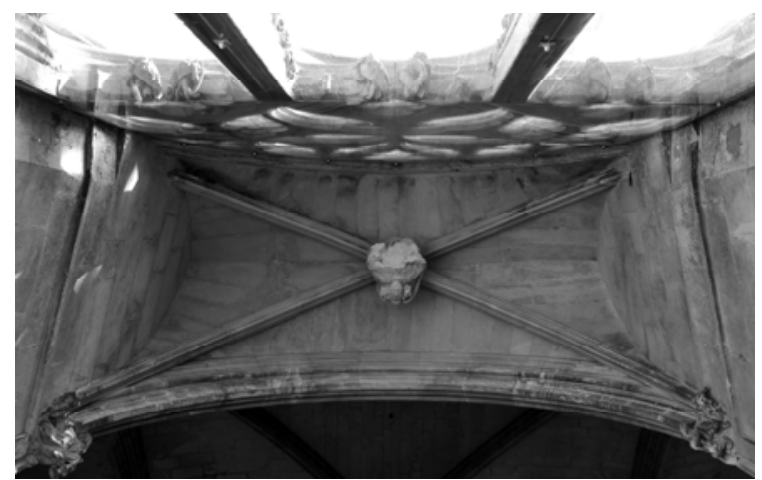

Figura 3.91. Ventanal de la lonja de Palma de Mallorca (Fotografía de Carmen Pérez de los Ríos)

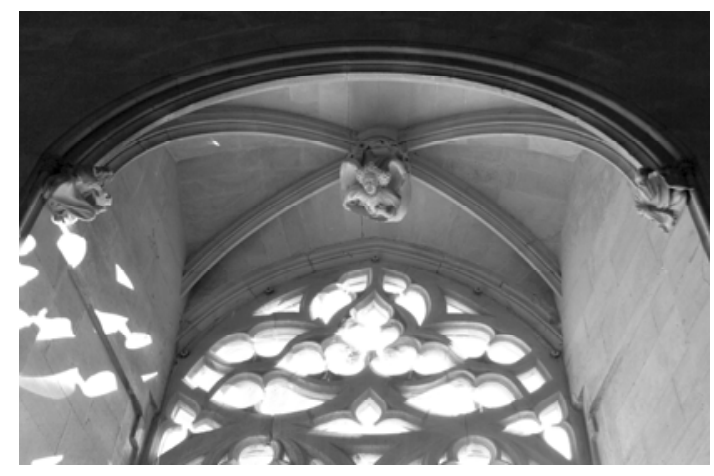

Figura 3.92. Ventanal de la lonja de Palma de Mallorca (Fotografía de Carmen Pérez de los Ríos) 
- Construir una bóveda de crucería compleja, que se adapte con mayor facilidad a la planta trapecial o incluso disimule la deformación. También se analizarán en el capítulo 5 . Como ejemplo podemos señalar la bóveda de la nave lateral de la Catedral de Senlis construida como parte de la obra del siglo XVI cuya deformación está provocada por la sacristía del siglo XIV que veíamos antes (figuras 3.87 y 3.88).

- Situar un pilar central que permita regularizar al menos una parte de la bóveda. La antigua cocina del Palais des Archevêques de Narbona es una sala de planta trapecial resuelta con pilar central (figuras 3.69, 3.97 y 3.98). ${ }^{49}$

- Recurrir a una geometría particular que disimule el problema. Estaríamos ante un caso de «recuperación estilística» (BORIE et al [1978] 2008, 107-112).

- De modo parecido al anterior, cuando existe un modelo formal potente es posible alterarlo hasta hacerlo casi irreconocible.

De las soluciones arriba enumeradas sólo algunas implican la construcción de una bóveda deformada. Como veremos en el capítulo siguiente, la bóveda de crucería gótica se adapta con facilidad a unas condiciones de contorno anómalas, asumiendo directamente la deformación. El recurso de pilar central normalmente va sumado a la flexibilidad de bóveda de crucería gótica, como en la sacristía de la Catedral de Perpignan (Francia) (figuras 3.28-3.32), la sacristía de la Catedral de Meissen (Alemania) o la iglesia de Greifensee (Suiza).

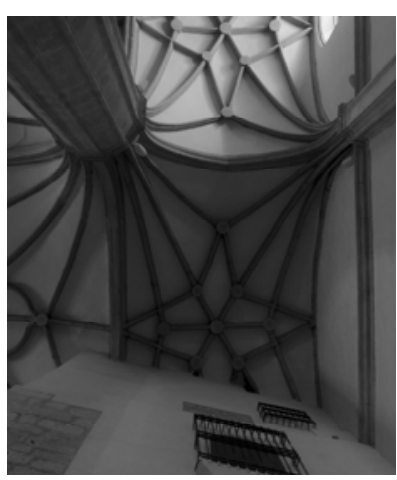

Figura 3.93. Concatedral de Baza (Granada)

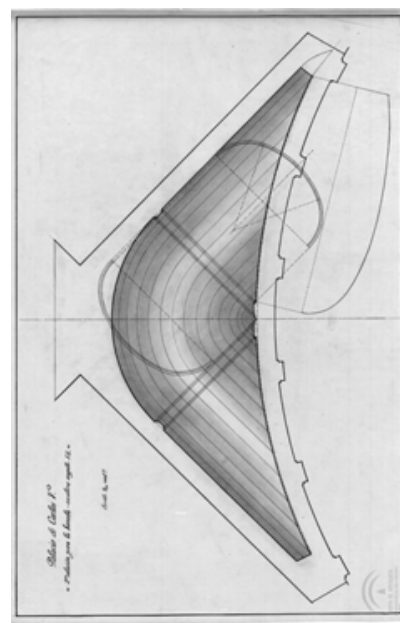

Figura 3.94. Palacio de Carlos V de Granada (JIMÉNEZ BARREDA 1954)

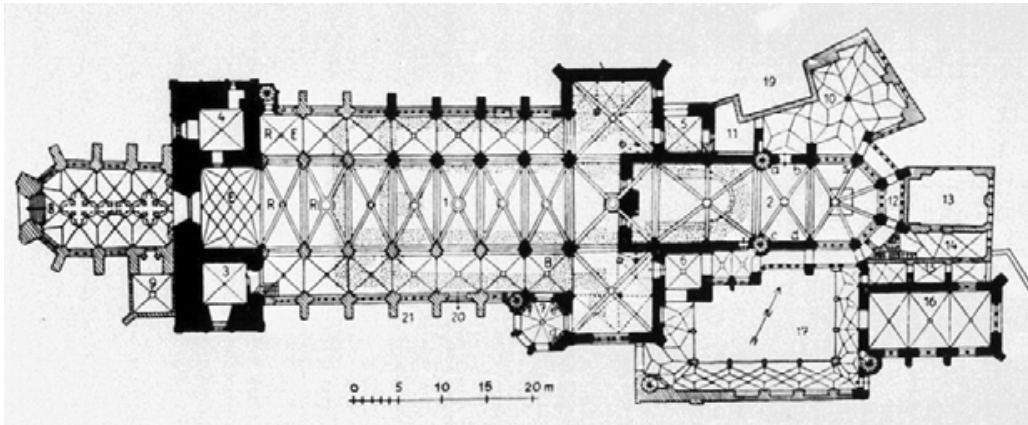

Figura 3.95. Catedral de Meissen (Alemania) según A.Reichel (1964) (fuente: Gotik-Romanik)

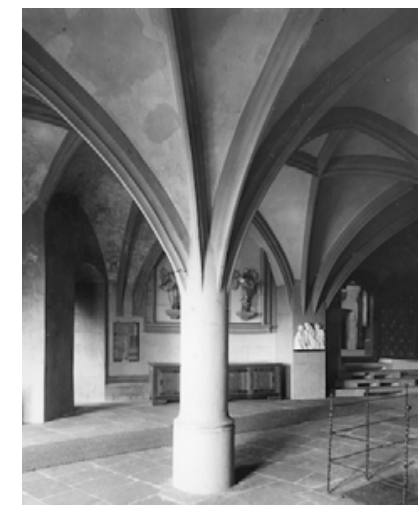

Figura 3.96. Sacristía (http://www.sn.schule.de)

49 En realidad en esta bóveda encontramos un condicionante añadido y es la necesidad de abrir un hueco que comunique la bóveda con la planta superior. 


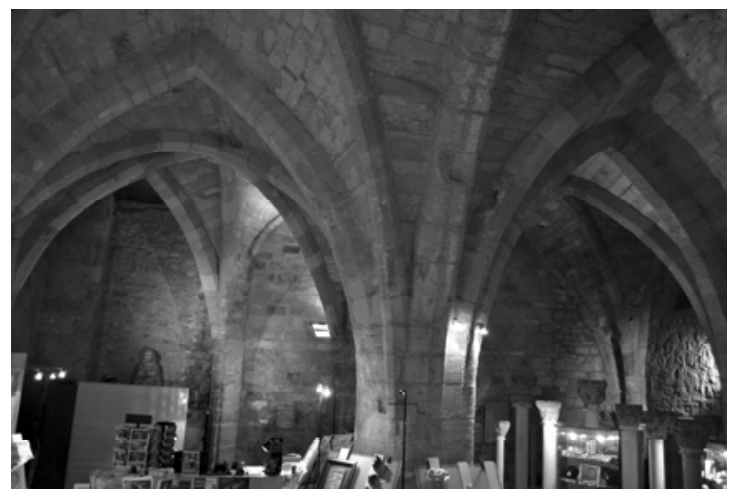

Figura 3.97. Antigua cocina del Palais des Archevêques de Narbona (Francia) (Fotografía de Carmen Pérez de los Ríos)
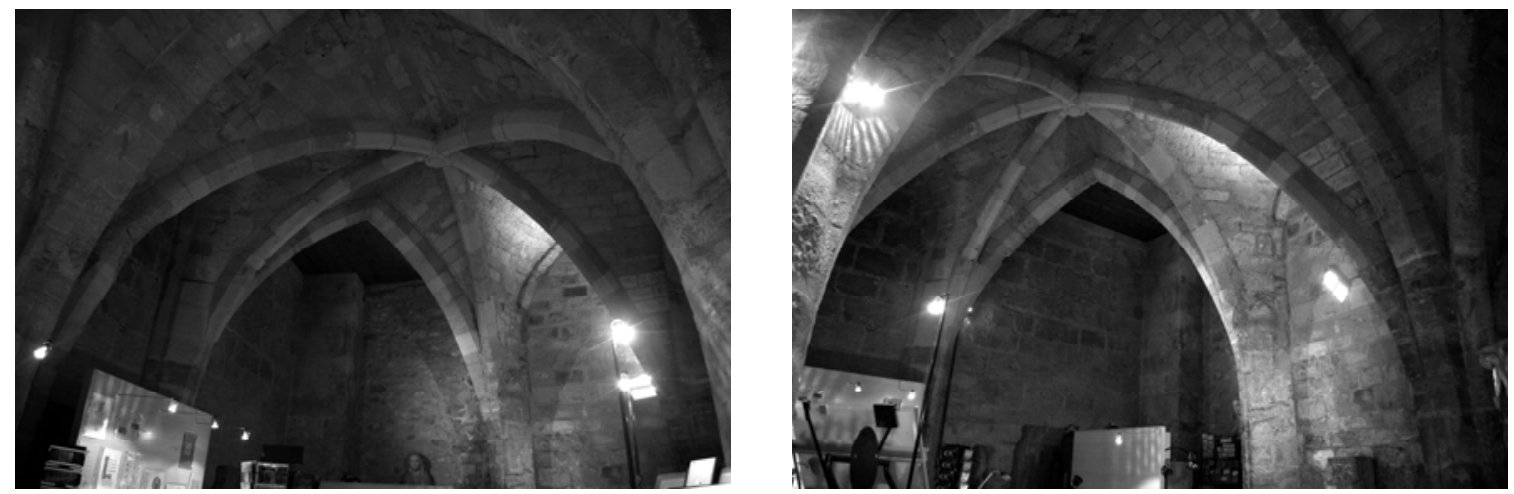

Figura 3.98. Detalles de la bóveda de la Antigua cocina del Palais des Archevêques de Narbona (Francia) (Fotografías de Carmen Pérez de los Ríos)

Evidentemente las posibilidades están influidas por el grado de deformación y las dimensiones de la sala. Si la distorsión es poca, como en la bóveda de arista de Can Forteza des Sitjar (cfr. capítulo 9, apartado 9.1), la irregularidad sólo se pone de manifiesto tras un levantamiento y puede ser asumida por el propio sistema constructivo sin mayores consecuencias. Si las dimensiones del elemento a abovedar son muy pequeñas, puede resolverse casi de cualquier manera.

También pueden aparecer condicionantes de sección, en los que la necesidad de situar un piso por encima haga recomendable no construir una única bóveda de grandes dimensiones, sino dividir la sala en bóvedas menores situando, por ejemplo, un pilar central.

Un factor relevante es la voluntad o no de disimular la deformación. En la iglesia de Saint-Jacques-du-Haut-Pas en París (Francia) parece existir un empeño en poner de manifiesto cualquier asimetría en los apoyos por ligera que ésta sea (cfr. capítulo, apartado 5.4). 


\subsection{Niveles de análisis}

En arquitectura abovedada, planteada la contradicción y habiendo descendido al nivel de las formas, es posible formular su resolución en dos niveles distintos. En un primer momento es posible resolver la deformación a nivel de conjunto, a través de las herramientas compositivas, evitando que la deformación descienda a nivel de bóveda; en un segundo estadio, si la deformación no es resuelta a nivel de conjunto, es la bóveda la encargada de resolverla. En este segundo escenario, cuando la bóveda se deforma asumiendo la resolución de la deformación, nos encontramos ya en el ámbito de las bóvedas no canónicas (figura 3.99).

Estas dos formas de resolver la deformación se traducen en la necesidad de establecer dos niveles de análisis de la deformación:

- Análisis de la deformación a nivel de conjunto / edificio.

- Análisis de la deformación a nivel de bóveda.

El primer nivel de análisis se fundamenta en el propuesto por Borie, Micheloni y Pinon tal y como veíamos al comienzo de este capítulo. El segundo nivel de análisis surge de las características propias de la arquitectura abovedada.

A estos dos niveles de análisis es necesario añadir una consideración, cuando el edificio -templo- es parte de un complejo complejo monástico o catedralicio-, la deformación puede ser resuelta por el propio edificio o, más frecuentemente, por otros edificios del complejo considerados como secundarios. Esta situación pone de manifiesto la jerarquía entre los distintos elementos que forman el conjunto.

Hay que recordar también que es posible encontrarnos ante un problema de bóveda no canónica delimitada por un perímetro regular, es decir, una deformación a nivel de bóveda sin que exista deformación aparente a nivel de conjunto (cfr. capítulo 5, apartado 5.2). Esta situación se puede producir por una asimetría en la disposición de los soportes; en este caso el análisis a nivel de conjunto es posible, pero al margen de los parámetros establecidos por Borie et al.

Además se dan casos de bóvedas no canónicas con perímetro regular y simetría de apoyos, en las que es la propia bóveda la que se deforma sin causa aparente. Estas situaciones, como las de bóvedas de nervios asimétricos analizadas en la segunda parte de la tesis (cfr. capítulo 7, apartado 7.1) sólo pueden ser analizadas a nivel de bóveda. 


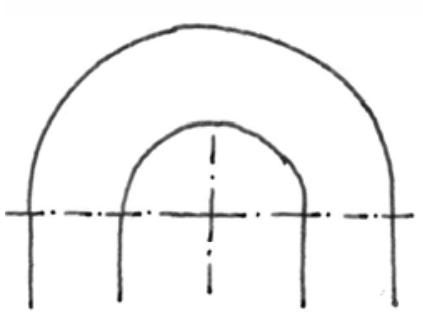

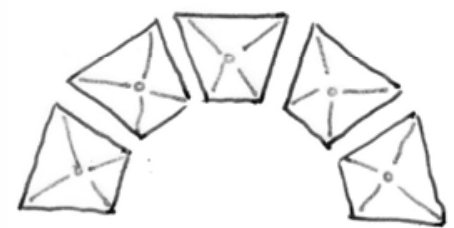
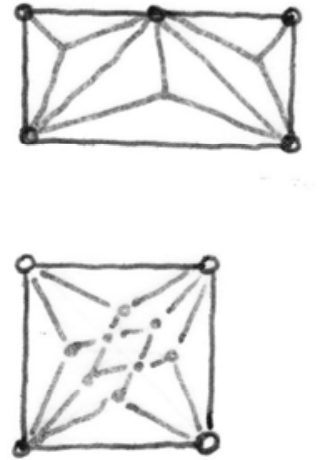

Análisis de la deformación a Nivel de bóveda Nivel de conjunto

Figura 3.99. Niveles de análisis de la deformación

Primera aproximación: análisis a nivel de conjunto

El análisis de la deformación a nivel de conjunto está directamente relacionado con el sistema de análisis basado en niveles constitutivos propuesto por Borie et al. en su libro y descrito al inicio de este capítulo. La única diferencia se refiere a los niveles constitutivos a emplear.

En primer lugar hay que advertir que, a pesar de que los niveles constitutivos propuestos se clasifiquen en lineales, planos y volumétricos, el análisis centrado en la planta hace que en realidad nos encontremos con que estos elementos son efectivamente percibidos como puntuales, lineales y superficiales. 
Sin embargo, ya hemos señalado que en arquitectura abovedada la sección no es constante (figs. 3.100, y 3.101) y, aunque las deformaciones en sección queden fuera del objeto de estudio de esta tesis, esto no quiere decir que podamos ignorar la sección y los problemas derivados de la misma. Por este motivo, es necesario ampliar y matizar los niveles constitutivos a emplear en el análisis:

\section{Huella del edificio Envolvente exterior \\ Envol. interiores Envolvente inferior Envolvente superior \\ Trama \\ Espacios internos}

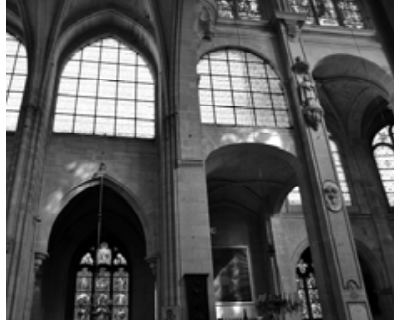

Figura 3.100. Iglesia de Saint-Leu-Saint-Giles en París (Francia). Cambios en sección según la dirección longitudinal .

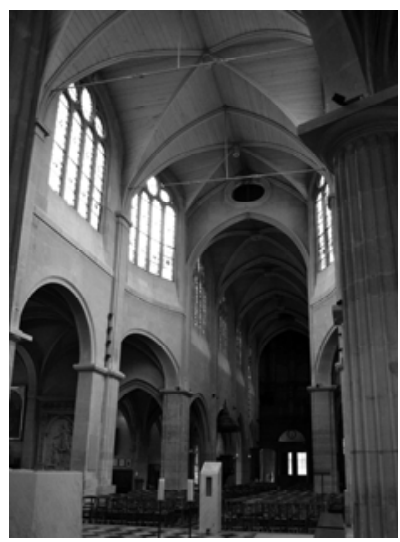
arquitectura abovedada desde la deformación del volumen exterior, pero queda fuera de los objetivos de esta tesis, que se centra en los espacios interiores y la manera de abovedarlo. A los efectos del análisis propuesto no interesa el volumen global -que no vamos a analizar- sino la huella del edificio. ${ }^{51}$

Otro nivel constitutivo empleado por Borie et al. que es necesario matizar es el de las envolventes interiores, que hace referencia a las envolventes perimetrales que cierran lateralmente los espacios interiores. Por un lado es necesario señalar que dichas envolventes no tienen que coincidir necesariamente con un elemento

50 Un ejemplo de los problemas volumétricos que plantea la arquitectura histórica lo encontramos en la comunicación de Miguel Sobrino González sobre el empleo del cimborrio (SOBRINO GonZÁLEZ 2005).

51 Un tema donde podría ser necesario plantear un análisis de la deformación en volumen lo encontramos en la cabecera. En algunos casos se produce una operación de unificación del conjunto en el plano de arranque, ocupando la parcela completa y evitando entrantes y salientes; pero esta unificación de la huella no se desarrolla en altura, donde el ábside se sigue percibiendo con rotundidad. Como ejemplo podemos señalar las iglesias de Sint-Sulpitius en Dieste (Bélgica). En Santiago de Compostela, en cambio, aunque el ábside se sigue diferenciando en altura, no se percibe desde la praza da Quintana, donde un cerramiento continuo unifica la fachada ocultando dos patios.

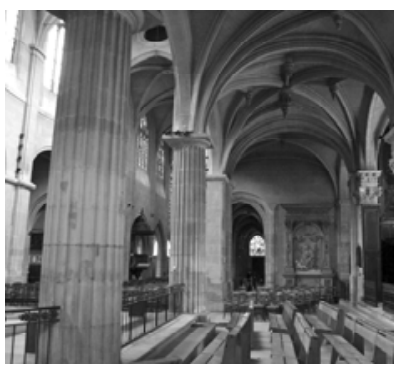

Figura 3.101. Iglesia de Saint Médard en París (Francia). Cambios de sección según la dirección longitudinal 
continuo, sino que pueden estar formadas por una alineación de soportes -como en la separación entre la nave central y las naves laterales- (figuras 3.102 y 3.103).

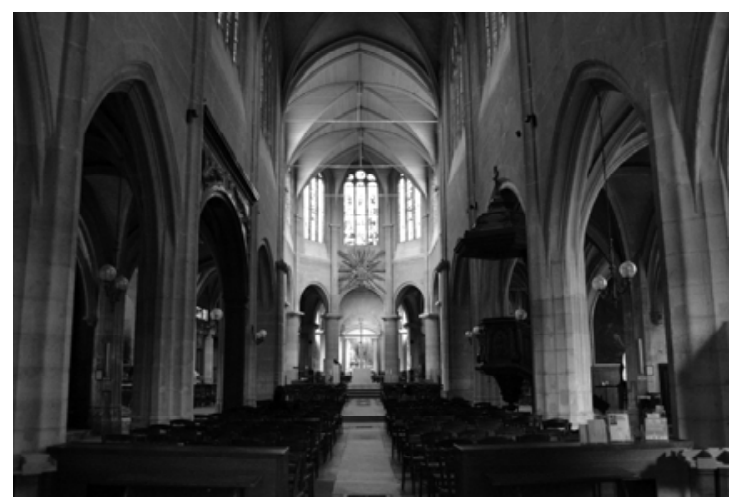

Figura 3.102. Iglesia de Saint-Médard en París

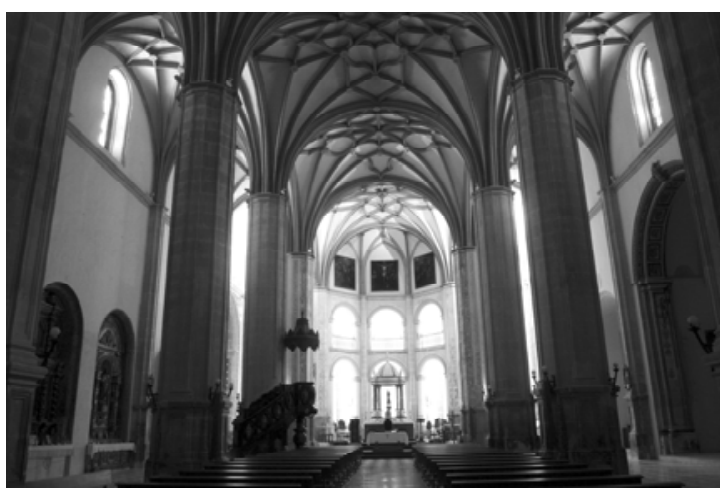

Figura 3.103. Concatedral de Baza

En el caso de la girola, la envolvente que cierra el espacio de la

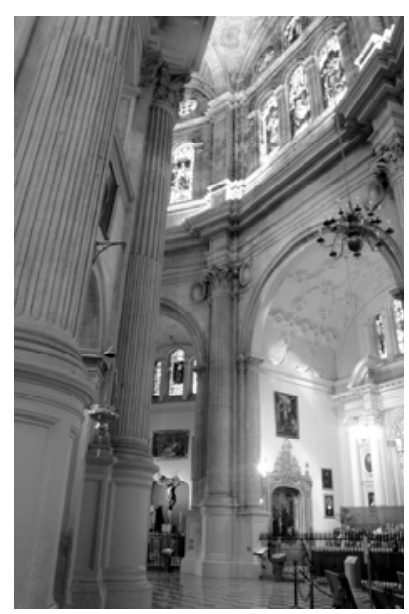

Figura 3.104. Catedral de Málaga. Envol. exterior

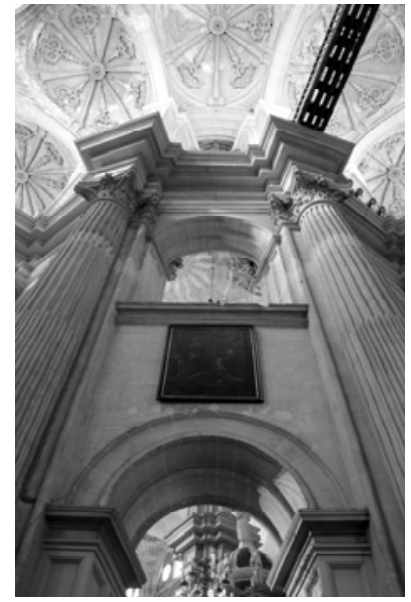

Figura 3.105. Catedral de Málaga. Envol. interior girola puede estar perforada, en el nivel inferior, por grandes arcos que dan acceso a las capillas laterales lo que hace que dicha envolvente no se perciba claramente en planta (figuras 3.104 y 3.105). Por otra parte y, aunque parezca evidente, es conveniente advertir que se refieren a las envolventes laterales -verticales-, no a las envolventes superior e inferior.

En el caso de la envolvente inferior -suelo- encontramos pequeñas diferencias de nivel logradas con unos pocos escalones. Estas diferencias de nivel producen una diferenciación espacial sutil pese a mantenerse la continuidad visual.

Más importante resulta para nuestro análisis la envolvente superior -bóvedas-. En la arquitectura convencional un forjado delimita una envolvente horizontal continua -quizá marcada por la presencia de vigas con descuelgue-, en arquitectura abovedada, en cambio, la curvatura de la bóveda marca una división por células, independientes o relacionadas.

Aquí es necesario hacer una distinción entre los tipos de bóveda desde un punto de vista de la segregación en células independientes, aunque ésta no se perciba en planta. Esta situación no depende del cambio de altura de las bóvedas, que queda reflejada en el reconocimiento de una envolvente interior que separa dos espacios internos -aunque no quede reflejada en la planta-, sino de la 
estructura espacial de la bóveda y, principalmente, de la presencia o ausencia de arcos perpiaños. $^{52}$

En una primera aproximación a la envolvente superior podemos decir que una bóveda puede ser (figura 109):

- Bóveda simple: una única bóveda en un recinto independiente, normalmente delimitada por arcos formeros, o perpiaños si las adyacentes están situadas a distinta cota.

Hay infinidad de ejemplos de esta situación. Podemos señalar la curiosa bóveda de la Capilla del Cristo de la Misericordia en la Catedral de Sigüenza (Guadalajara) (figura 3.106).

- Bóvedas yuxtapuestas: dos o más bóvedas dispuestas una junto a otra sin que exista una relación entre ambas; normalmente el perpiaño que las separa tiene cierta entidad.

Las dos bóvedas de la capilla de San Ildefonso en la Catedral de Zamora, una sin nervios ojivos y la otra con trazado de nervios asimétrico (cfr. capítulo 7, apartado 7.1), constituyen un ejemplo de esta situación (figura 3.107).

- Bóvedas coordinadas: dos o más bóvedas dispuestas un junto a otra entre las que es posible establecer una relación de semejanza, por ejemplo por la repetición de un mismo trazado; normalmente el perpiaño sigue teniendo entidad.

Como ejemplo podemos señalar la capilla de Saint-Gausbert del claustro de la Catedral de Cahors (Francia), con dos bóvedas que repiten el mismo trazado de nervios asimétrico (cfr. capítulo 7, apartado 7.1). Otro ejemplo, bastante frecuente, lo constituye la nave central de las catedrales españolas, donde es habitual encontrar el mismo patrón de nervios repetido (figura 3.108).

52 El arco perpiaño es en un arco que en muchos casos carece de sentido desde el punto de vista estructural: «El ojo del técnico se irritará con los arcos perpiaños principales de la nave (...) carentes de significado estructural» (HEYMAN [1968] 1995, 90). El ejemplo de Heyman se refiere concretamente a los potentes arcos perpiaños de la bóveda de abanico de la Capilla del King's College. Sin embargo, desde el punto de vista de la composición (la técnica arquitectónica) y la construcción geométrica de la forma de la bóveda, el perpiaño es un arco de significativa importancia.

Hay que advertir que en una bóveda sexpartita «los arcos perpiaños intermedios sí son portantes» (HEYMAN [1968] 1995, 91)

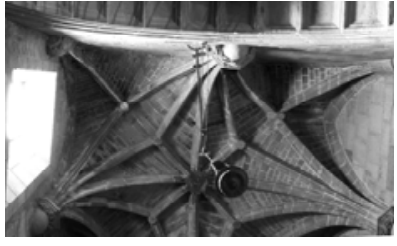

Figura 3.106. Bóveda simple sobre la Capilla del Cristo de la Misericordia en la Catedral de Sigüenza (Guadalajara)

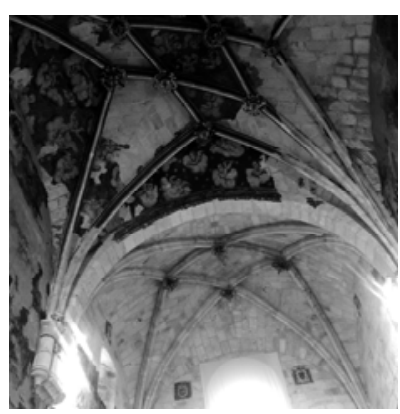

Figura 3.107. Bóvedas yuxtapuestas en la Capilla de San Ildefonso en la Catedral de Zamora

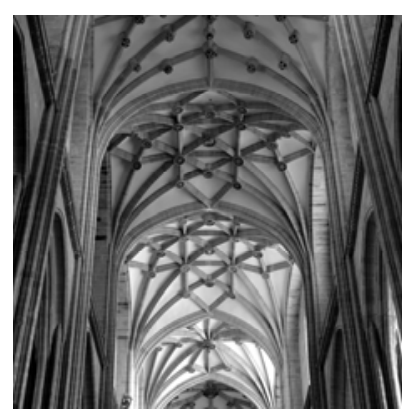

Figura 3.108. Bóvedas coordinadas en la nave central de la Catedral de Astorga (León) 


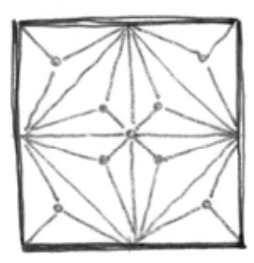

Bóveda simple

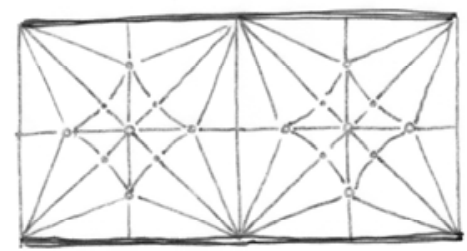

Bóvedas solapadas

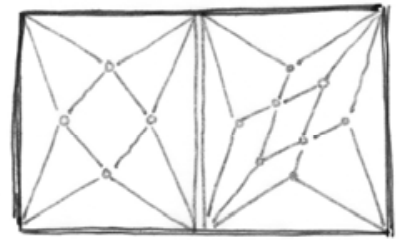

Bóvedas yuxtapuestas
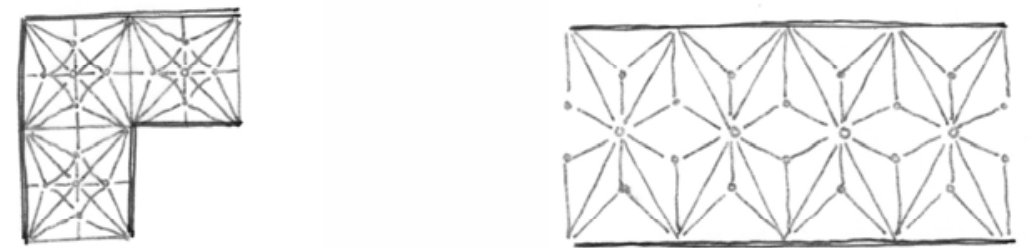

Bóvedas subordinadas

Figura 3.109. Envolvente superior. Tipos de bóveda

Las bóvedas de las girolas españolas suelen ser un buen ejemplo de esta situación ya que suelen repetir el mismo diseño en todos los tramos. ${ }^{53}$

- Bóvedas solapadas: dos o más bóvedas dispuestas una junto a otra en las que existe elementos que relacionan una bóveda con la siguiente, por ejemplo un nervio de ligadura; normalmente el perpiaño sigue marcando un punto de división pero pierde entidad. Empieza a resultar difícil el análisis de una bóveda de modo independiente.

Encontramos un ejemplo en la panda norte del claustro de la Catedral de Santiago de Compostela (Palacios Gonzalo 2009, 128-131). Se trata de una bóveda de terceletes de cinco claves con ligadura y nervios combados que dibujan un rombo. Los nervios de ligadura enlazan un tramo con el siguiente $^{54}$, efecto que se refuerza en las esquinas donde el nervio combado dibuja el giro que enlaza los tramos.

Las bóvedas de la nave central de la iglesia parroquial de Boltaña (Huesca) son otro ejemplo de bóvedas solapadas (figura 3.110).

Las bóvedas de la girola de la Catedral de Calahorra (La Rioja) son una excepción.

54 Al efecto de unión entre tramos también contribuye el empleo del rampante llano. Tal y como señala José Carlos Palacios Gonzalo, «al utilizar nervios de igual sección el diseño centralizado de cada bóveda se atenúa» (PALACIOS GONZALO 2009, 128). 
- Bóvedas subordinadas: una bóveda compuesta por bóvedas menores, pero en las que se han diluidos por completo los límites; normalmente el perpiaño ha desaparecido. El análisis de un tramo de bóveda, aislado del conjunto, resulta imposible. El ejemplo más evidente son las bóvedas reticulares alemanas.

En la Sacristía Mayor de la catedral de Cuenca encontramos un ejemplo de esta situación. Se trata de una bóveda donde la ligadura según la dirección longitudinal se desdobla en dos; estas ligaduras interrumpen el recorrido del perpiaño, que desaparece en la parte central, formando una red que enlaza cada tramo con el siguiente (PALACIOS GONZALO 2009, 152-154).

Esta subdivisión, evidentemente inspirada en el análisis sintáctico, es determinista y por lo tanto muy discutible. Es evidente que existen infinidad de casos ambiguos donde no es sencilla - ni seguramente útil- la clasificación. Sin embargo es necesario tomar conciencia de esta relación de independencia/dependencia entre bóvedas a la hora de plantear un análisis sobre la manera en que se proyecta el edificio.

Conviene advertir también que el espesor material no debe ser entendido en sentido literal. En algunos casos en efecto el muro se regruesa, pero en otros casos ese muro regruesado es ocupado por pequeños espacios secundarios de servicio. ${ }^{55}$ La distinción va a depender, en buena medida, de la escala de análisis.

55 Borie, Micheloni y Pinon señalaban la necesidad de emplear nociones específicamente morfológicas, «lo suficientemente puras como para estar, en lo posible, libres de toda connotación funcional» (BORIE et al. [1978] 2008, 33); poniendo la distinción entre espacio servidor y espacio servido de Louis Kahn como ejemplo de los inconvenientes de mezclar criterios funcionales con criterios morfológicos. Sin embargo en este caso no encontramos una alternativa mejor. Un muro regruesado en el que se aloja una escalera o un almacén debe ser analizado como un elemento sólido, aunque esté ocupado por un vacío, como sucede en el Palazzo Farnese de Caprarola (Italia) (figura 3.60).

También vemos casos en los que no se puede hablar ya de que el muro macizado se perfore para aprovecharlo, sino de un empleo de las dependencias anexas como macizo, En la Villa Rotonda de Paladio en Vicenza (Italia) la transición entre el espacio central circular y las salas rectangulares que la circundan se resuelve gracias a las escaleras.

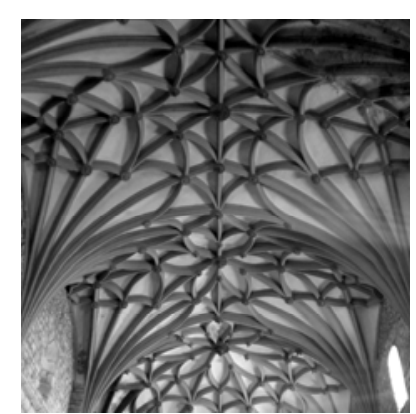

Figura 3.110. Bóvedas solapadas en la nave central de la iglesia parroquial de Boltaña (Huesca) 

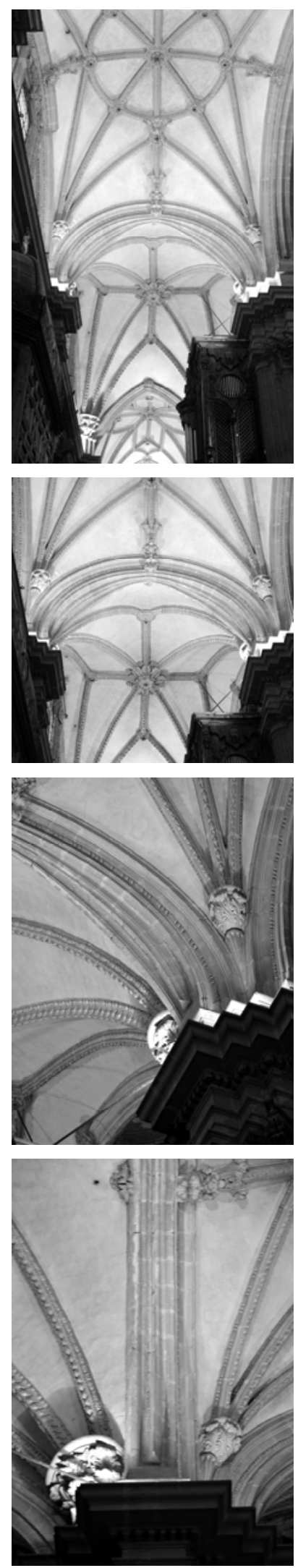

Figura 3.111. Arco en la Catedral de Guadix (Granada)
Segunda aproximación: análisis a nivel de bóveda

El conflicto no resuelto a nivel de conjunto desciende a nivel de bóveda, dando lugar a una bóveda deformada.

El desglose en elementos para el análisis a nivel de bóveda se hace en función de las características del elemento y de su representación en planta. De nuevo nos encontramos son que la clasificación en elementos lineales, planos y volumétricos se traduce, para una representación en planta, en elementos puntuales, lineales y planos. Para evitar confusiones, y ante la necesidad de adaptarnos al objeto de estudio, vamos a tomar como punto de partida la distinción entre elementos puntuales, lineales y planos, considerados a partir de la proyección horizontal.

En arquitectura abovedada un soporte puntual no puede desligarse del arco que apoya sobre él y que requiere un mínimo de dos soportes. En arquitectura abovedada no tienen relevancia los elementos puntales, ya que están en relación con el elemento lineal que apoya sobre ellos. Un arco -o una sucesión de arcos- sobre el que apoya un arco perpiaño, y un muro sobre el que apoya un arco formero, deben ser considerados elementos lineales.

Los únicos elementos puntuales son las claves de una bóveda de crucería, pero éstas se obtienen de la intersección de nervios y por lo tanto no se pueden desligar del elemento lineal.

Por otra parte un muro, provisionalmente considerado un elemento lineal debido a su espesor constante, puede tener espesor variable, lo que lo convierte en un elemento que ocupa una superficie pero de sección constante en altura, podríamos hablar de un elemento extruido. Este fenómeno también puede darse en arcos. ${ }^{56}$

Un ejemplo curioso -y difícilmente calificable- de arco de sección variable, pero no en planta lo encontramos en la catedral de Guadix (Granada) (figura 3.111). Se trata de un arco formero situado en la nave de la epístola separando el transepto -con arcos formeros de medio punto- de la nave -con arcos formeros fuertemente apuntados y sin tangente vertical en el arranque-. Este arco está contenido en un plano vertical pero tiene trazado apuntado hacia la nave y semicircular hacia el transepto, resolviendo la transición entre

56 Para los distintos tipos de arcos recogidos en los manuscritos y tratados de cantería, entre los que hay algunos ejemplos de arcos donde ambas caras no son paralelas puede consultarse las tesis doctorales de José Carlos Palacios Gonzalo y José Calvo López (PALACios Gonzalo 1990; CALVO LÓPEZ 1999). 
ambos trazados en el espesor del arco.

Por su parte una bóveda -o un conjunto de bóvedas- aunque es un elemento que en planta ocupa una superficie, no es posible desligarlo de su volumetría; no hablamos entonces de un elemento superficial, sino volumétrico.

El primer análisis es un análisis en planta, a partir de la proyección horizontal de los distintos elementos.

En segundo lugar habría que llevar a cabo un análisis de la elevación de cada uno de los elementos. No se trata de un análisis en sección, que nada tiene que ver con la manera en que están proyectados y construidos estos elementos (RABASA DíAz 2000, 121130). Se trata de un análisis de cada uno de los arcos, nervios y aristas proyectadas sobre el plano vertical que los contiene.

Merece la pena hacer dos salvedades. En el caso de las bóvedas alemanas con nervios de doble curvatura -Schlingrippengewölbe- es evidente que no están contenidas en planos verticales. Sin embargo, según señalan los autores que las han analizado, su trazado es más sencillo de lo que aparentan ya que están contenidas en cilindros verticales (BUCHER 1972; WENDLAND 2012).

En segundo lugar estarían las aristas alabeadas de algunas bóvedas de arista de planta rectangular (cfr. capítulo 9, apartado 9.1) o las aristas de la voûte d'arête en tour ronde (cfr. capítulo 9, apartado 9.2). En el primer caso la arista se obtiene a partir de las hiladas y por lo tanto el análisis dependerá ya de un análisis de la volumetría; en el segundo caso nos encontramos con ejemplos en los que depende de la volumetría, pero también en otros relacionables -salvando las distancias- con los nervios de doble curvatura.

El tercer análisis, es un análisis en sección. Se refiere al rampante de la bóveda -sección longitudinal y transversal- con o sin nervio de ligadura. También se analizan la alturas a las que se sitúan las claves y si éstas se producen por la intersección de nervios o si éstas actúan como mecanismos de ajuste, tal y como sucede en la bóveda asimétrica del claustro de la Catedral de Segovia (cfr. cap. 7, apartado 7.1).

Por último se realiza un análisis de la volumetría centrado en el despiece de hiladas -cuando el despiece es visible- o de la superficie continua del intradós - si el despiece no es visible- ${ }^{57}$

57 Cuando el despiece no es visible, el análisis del intradós se realiza a partir de una nube de puntos contenidos en la superficie de intradós. 
Tipos de elemento por su representación en planta:

- Puntuales: $\quad$ Soportes -vinculados a arcos perpiaños-, Claves intersección de nervios-.

- Lineales: Muros de sección constante, Apoyos (Arcos formeros y Arcos perpiaños), Nervios, Aristas, Rampante, Hiladas -consideradas de manera individual-.

- Superficiales: Perímetro, Trazado de nervios.

- Extruido: Muros de sección variable.

- Volumétricos: Despiece -hiladas-, Superficie continua.

Tipos de análisis:

- Planta: Perímetro (Muros de sección constante y Apoyos), Muros de sección variable, Trazado de nervios.

- Elevación: Arcos formeros, Arcos perpiaños, Nervios, Aristas.

- Sección: Rampantes, Claves -ajuste en sección-.

- Volumetría: Despiece, Nube de puntos.

Quedaría pendiente un último análisis a nivel de detalle, fundamentalmente en los apoyos y las claves, que queda fuera de los objetivos de esta tesis. ${ }^{58}$

Lo más habitual es que la deformación de la bóveda se produzca por una deformación del perímetro y que ésta se traduzca en una deformación del trazado de nervios o aristas, lo que implica una adaptación de todos los elementos implicados.

En los ventanales de la Lonja de Palma de Mallorca se produce un curioso fenómeno en el cual la deformación del perímetro no se traduce en una deformación del trazado de nervios, sino que éstos siguen el trazado que habría estado prevista para un perímetro regular. La bóveda no se deforma y son los apoyos los que resuelven el problema (figuras 3.91 y 3.92).

En el manuscrito de Josef Gelabert encontramos un trazado semejante, en la «Capilla rectangular escarzana con una pared esviada» (RABASA DíAz 2011, 386-387) (figura 3.112). Hay que tener

$58 \quad$ Sobre este extremo puede consultarse la Tesis doctoral de Carmen Pérez de los Ríos (PÉREZ DE LOS Ríos 2016). 
presente que pese a la aparente simplicidad del problema, en el que la bóveda parece cortada por el muro, este diseño implica la ejecución de todos y cada uno de los elementos en su aspecto final; no se construye la bóveda para después cortarla.
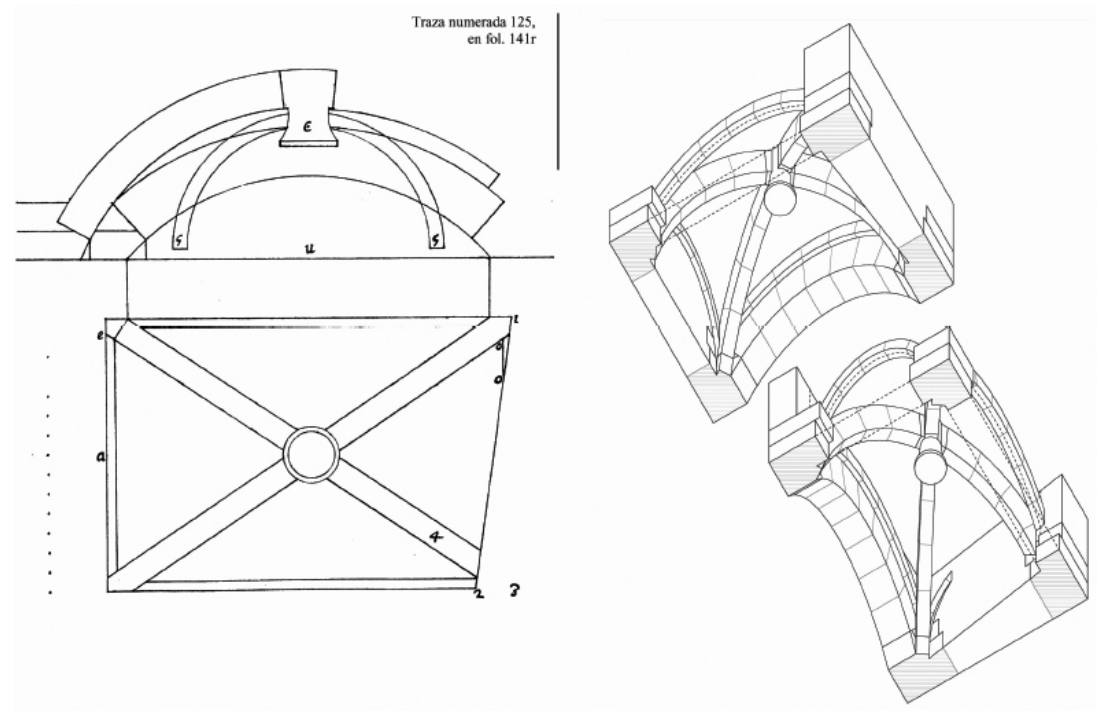

Figura 3.112. «Capilla rectangular escarzana con una pared esviada» del manuscrito de Gelabert (RABASA DíAz 2011, 387)

Sin embargo un perímetro regular puede dar lugar a una bóveda irregular por una disposición de apoyos asimétrica, que se traduce en un trazado de nervios asimétricos. Lo habitual es que este tipo de bóvedas se resuelvan gracias a la flexibilidad de la bóveda de crucería gótica (cfr. capítulo 5, apartado 5.2). Sin embargo podemos señalar dos ejemplos de bóvedas de cantería con apoyos asimétricos. En el primer caso nos referimos a las bóvedas de arista de las naves laterales de la iglesia de Saint-Jacques-du-Haut-Pas en París (Francia) (cfr. capítulo 5, apartado 5.4). En el segundo caso nos referimos a una bóveda a medio camino entre la bóveda de arista y la bóveda baída en el patio del Casal Solleric en Palma de Mallorca, que sin duda merece un análisis en profundidad (figura 3.113).

Un último caso lo constituyen las bóvedas de perímetro regular con apoyos dispuestos simétricamente. En estos casos la deformación puede estar en un trazado de nervios asimétrico (cfr. capítulo 5, apartado 5.2). También encontramos casos de bóvedas donde es el rampante el que se deforma (cfr. capítulo 5, apartado 5.1). Al contrario que en los casos anteriores, el análisis a nivel de conjunto no es viable y tan sólo es posible un análisis a nivel de elemento. ${ }^{59}$

$59 \quad$ No debe perderse de vista que pueden existir condicionantes de sección que obliguen a adoptar alguna de estas soluciones. 

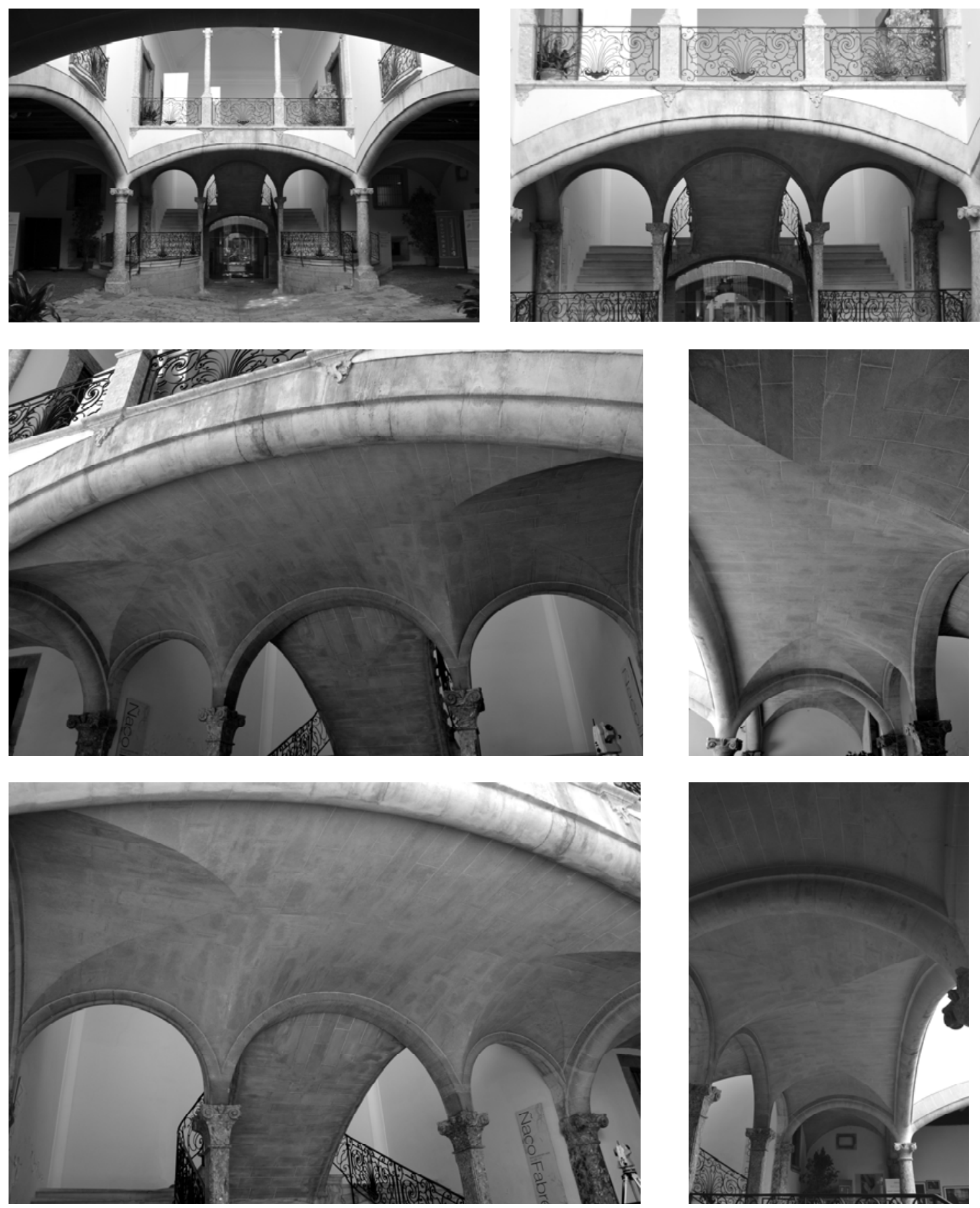

Figura 3.113. Bóveda en el patio de Casal Solleric (Palma de Mallorca) 


\section{4 \\ Primera aproximación: «El compromiso con el difícil conjunto» ${ }^{1}$}

It is not the province of this essay to enter into a discussion of the origin of the ambulatory and its introduction into the church plan. It is sufficient to note that a passage around a semicircular apse appears even in roman times (...).

Such ambulatories were mere service galleries, not directly connected with the apse and in fact shut off from it by a solid wall, but when once adopted as a feature of the church plan, the ambulatory rapidly became an aisle around the apse corresponding in all respects to that which flanked the rectangular nave or choir.

(WARD 1915, 158) 

Hemos visto como Boire Micheloni y Pinon señalaban que «El empleo de ciertos materiales o técnicas constructivas puede influir en las posibilidades de deformación de los edificios y, eventualmente, en los tipos de deformaciones a los cuales se ha recurrido» (BORIE et al. [1978] 2008, 81). En arquitectura abovedada la deformación plantea un problema constructivo, pero además, del problema constructivo deriva un problema de índole compositiva.

Conscientes de la realidad material y de las posibilidades del sistema constructivo empleado, los maestros y arquitectos tuvieron en cuenta la realidad constructiva a la hora de componer sus edificios; las posibilidades de materialización como factor de diseño previo. De manera recíproca, la voluntad de realización de determinadas composiciones deriva en un problema constructivo a resolver, un desafío que influirá en el desarrollo del sistema constructivo y en su evolución hacia nuevos sistemas:

Les architectes occidentaux ne cessèrent de chercher la solution de ce problème [la construction des voûtes d'un collatéral pourtournant un sanctuaire]

(VIOLLET-LE-DUC 1854-1868, 9: 489).

La necesidad constructiva de resolver un problema compositivo como impulso para el desarrollo de nuevos sistemas constructivos.

En este capítulo se realiza una primera aproximación al problema de la deformación en arquitectura abovedada a nivel de conjunto; la deformación centrada en los problemas compositivos derivados de las limitaciones del sistema constructivo.

En el capítulo anterior hemos visto el amplio panorama de la deformación en arquitectura abovedada, donde encontramos muchos ejemplos de contradicción y deformación. Este capítulo se centra en uno de ellos, el de las galerías anulares -girolas y deambulatorios ${ }^{2}$-,

2 En español, los términos girola y deambulatorio pueden considerarse sinónimos. En general, el término girola se reserva para la galería que circunda el ábside: 'nave o conjunto de naves que en la arquitectura románica o gótica circundan el altar mayor, rodeadas por [rodeando] el ábside, y, por extensión, la misma nave en catedrales o iglesias de cualquier estilo' (22 $2^{\mathrm{a}}$ ed. del Diccionario de la RAE).

En cambio, el término deambulatorio se aplica tanto a la galería que circunda el ábside, como a la galería anular que circunda el núcleo central en edificios de planta central con estructura en doble casco (KRAUTHEIMER [1965] 2011, 75), tal y como encontramos en algunos Martyria, baptisterios, iglesias de Santo Sepulcro y Capillas Palatinas.

Desde el punto de vista del análisis del abovedamiento de estos espacios de planta anular-circular o semicircular-, el problema no se limita a las 
que sirvió de punto de partida de esta investigación. La ventaja de la galería anular es que es un elemento compositivo presente en toda la historia de la arquitectura, y por lo tanto permite establecer comparaciones con facilidad. Además, la galería anular y los problemas asociados -por ejemplo el de la cabecera- ejemplifican casi todos los procedimientos para resolver la contradicción en arquitectura abovedada.

En primer lugar vamos a realizar una aproximación a las galerías anulares y su abovedamiento a lo largo de la historia de la arquitectura, poniéndolo en relación con las distintas técnicas constructivas empleadas. En segundo lugar haremos un análisis de la girola, como caso particular de galería anular, a nivel de conjunto, a partir del sistema de análisis propuesto en el capítulo anterior.

Hasta aquí la investigación se centra en ejemplos construidos, por constituir el único corpus de análisis posible. Ha sido necesario extraer la teoría a partir de los casos construidos ya que casi no existen ejemplos dibujados. Esta teoría se comparará con un análisis de los escasos ejemplos de trazados de girolas conservados.

Para concluir el problema de la girola se va a plantear una pregunta que quizá resulte incongruente: ¿constituye la girola un problema de deformación? Esta tesis parte de esa hipótesis de partida, pero veremos que existen dudas en este planteamiento. Sólo es posible responder a esta pregunta a partir de los resultados del análisis, no podía ser contestada a priori.

El análisis de la bóveda de las girolas, en particular de las bóvedas de crucería, se realizará en el capítulo 5. Como veremos a continuación, la bóveda de crucería es la que más ejemplos de girola resuelve, lo que plantea una pregunta: ¿el hecho de que el mayor número de ejemplos esté resuelto con bóveda de crucería se debe simplemente a una correspondencia de fechas -la mayor parte de las girolas se construyeron entre los siglos XII y XVI, época en la que construyeron bóvedas de crucería-, o porque es el sistema constructivo que mejor lo permite?

edificaciones religiosas. También encontramos galerías anulares en patios, claustros, atrios, teatros, anfiteatros, etc.

Conviene advertir que la girola que circunda el ábside no tiene porqué tener trazado semicircular -o semipoligonal-. 


\section{La voûte en tour ronde ${ }^{3}$}

El abovedamiento inmediato de una galería anular es la bóveda anular. ${ }^{4}$ Aunque no muy frecuente, la bóveda anular es conocida desde época romana y no representa un problema de índole constructivo, como demuestra la bóveda conservada del Santuario della Fortuna Primigenia de Palestrina (Italia) de finales del s. II a.C (figura 4.1).

El problema se plantea cuando es necesario abrir huecos que comuniquen la galería anular con los espacios anexos, por ejemplo con el patio interior, las capillas radiales, o con el ábside. Aunque existe la posibilidad de situar la bóveda sobre un entablamento horizontal, tal y como sucede en Palestrina y en el Palacio de Carlos V de La Alhambra (figura 3.59), cuando la apertura salva una luz mayor o, simplemente, se desea realizar por medio de una arquería, es necesario que la bóveda de respuesta a ambos problemas: el espacio anular y el hueco que lo perfora.

En el patio semicircular de la Villa Giulia de Roma (figuras II, 4.2 y 4.3) encontramos un ejemplo de ambas situaciones. En principio la bóveda anular se apoya sobre un entablamento sobre columnas; tan sólo un arco marca el eje, dando lugar a un problema de bóveda de arista de planta anular (cfr. capítulo 9, apartado 9.2).

Hace exactamente 100 años Clarence Ward escribió un libro de 192 páginas titulado Medieval Church Vaulting que continuaba la tradición de investigación sobre bóvedas medievales iniciada por Robert Willis 75 años antes. A diferencia de sus ilustres predecesores, este profesor de la Universidad de Princeton incluyó un capítulo de 27

3 En los tratados de cantería franceses encontramos la expresión «voûte en tour ronde» (DERAND 1643, 448-449; LA RUE 1728, 54-56), literalmente «bóveda en vuelta redonda»; «voûte sur le noyau» (JoUSSE 1642, 182-185; LA RUE 1728, 53; FREZIER 1737, 246-253), literalmente «bóveda en torno a un núcleo/pilar»; o «berceau tournant» (SIMONIN 1792, 49-50) para referirse a bóvedas de planta anular. Lo que ha sido traducido al castellano como «cañón de bóveda circular» (MARTínEZ DE LA TORRE 1795, 48) o «bóveda anular» (ROVIRA Y RABASA 1899, 2:6383). Hemos preferido la expresión francesa, por gozar de más tradición.

No debe confundirse con el «arco en torre redonda» de los tratados españoles (PALACiOs GonZALO [1990] 2003, 84-87; CALVO LÓPEZ 1999, 87-99), «porte ronde» (DE L’ORME 1648, 3:74v-77r) o «porte en tour ronde» (LA RUE 1728, 20-22) en francés, que hace referencia a un arco abierto en un muro circular convexo -una torre-.

$4 \quad$ En un tholos griego, la poca luz permite salvarlo con una cornisa, tal y como sucede en el Tempieto de San Pietro in Montorio, o en el Altes Museum de Berlín.
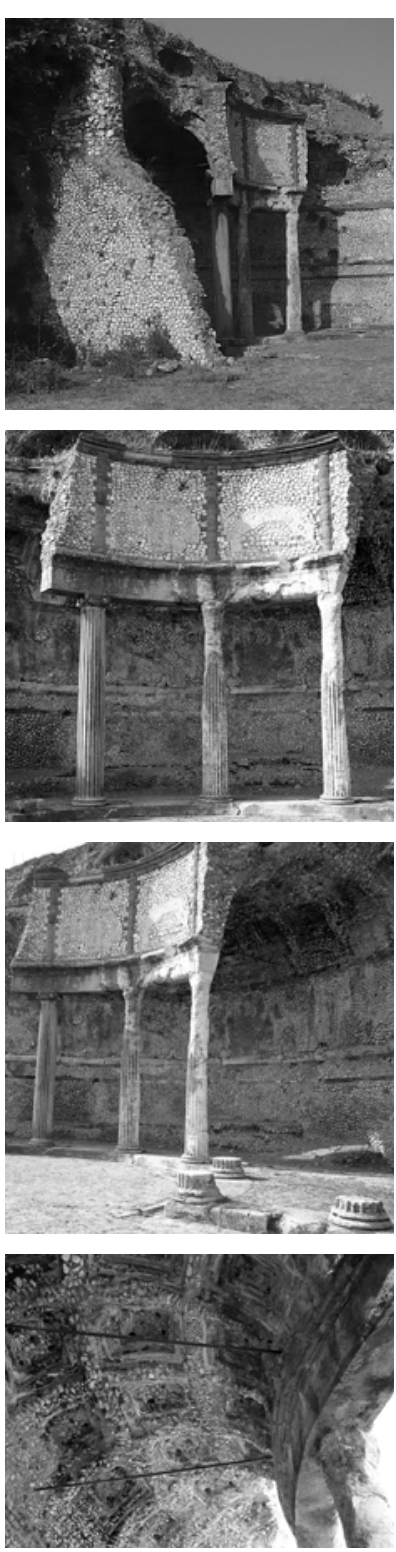

Figura 4.1. Hemiciclo del Santuario de la Fortuna Primigenia de Palestrina (Praenestre)

(fotografías de Zanner en Wikipedia.org) 
páginas dedicado a las «ambulatory vaults» con numerosos ejemplos de bóvedas en girolas.

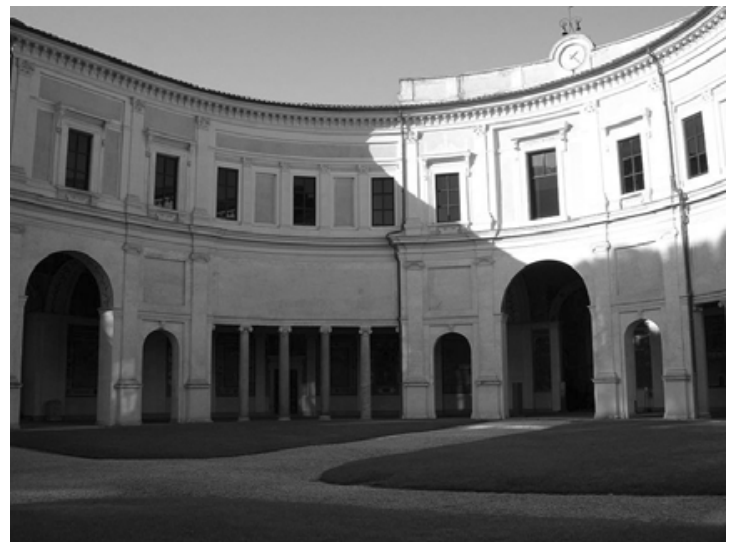

Figura 4.2. Villa Giulia en Roma (fotografía de Sailko en Wikipedia.org)

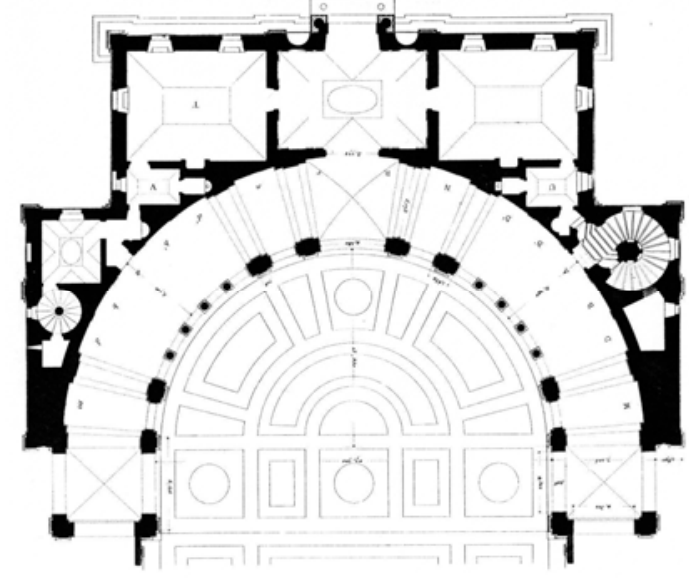

Figura 4.3 Villa Giulia en Roma (LETAROUILLY [1860] 1982)

El texto de Ward tiene el mérito de ser la primera, y única, aproximación más o menos completa al problema de la bóveda de la girola. El texto de Viollet-le-Duc ya citado (cfr. Prefacio) tuvo la virtud de identificar el problema, pero lejos de ser un análisis exhaustivo de todos los ejemplos, se centró en una serie de casos que le permitieron seguir una línea argumental, la evolución desde la bóveda por penetraciones románica hasta la bóveda de crucería gótica.

Sin embargo este texto adolece de algunas lagunas. En primer lugar, como su propio nombre indica, se centró en los ejemplos medievales, aunque también incluye algunos ejemplos de bóvedas tardogóticas, como las girolas alemanas de la Hauptkirche de Güben ${ }^{5}$ y la Catedral de Friburgo; no incluye ningún ejemplo clasicista:

In them, the structural purpose of the rib is totally subordinated to decorative principles and to a desire on the part of the builders to show their knowledge of the intricate problems of stereotomy. With such vaults as these, marking the decline of Gothic architecture, it is not surprising that there was such a complete reaction in vault construction on the part of the succeeding Renaissance builders.

(WARD 1916, 181)

En segundo lugar, Cuando Clarence Ward aborda la cuestión de la girola lo hace mezclando aspectos compositivos, aspectos relacionados con los distintos sistemas constructivos y aspectos

5 Destruida durante la Segunda Guerra Mundial. 
relativos a un tipo de bóveda concreta. ${ }^{6}$ De esta manera trata dos veces el sistema de resolver la girola dividiéndola en cuadrados y triángulos, ${ }^{7}$ distinguiendo entre girolas románicas (WARD 1915, 160161) y girolas góticas (WARD 1915, 176-180).

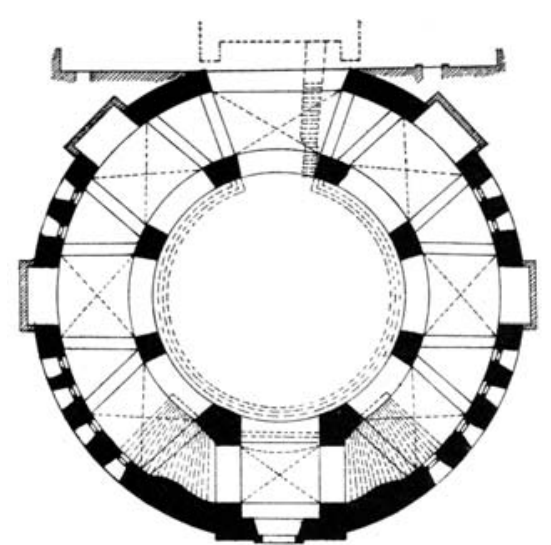

6. BRESCIA : LA ROTONDA.

Figura 4.4. Rotonda de Brescia (Italia) según Behio-Bezold (fuente: Wikipedia.org)

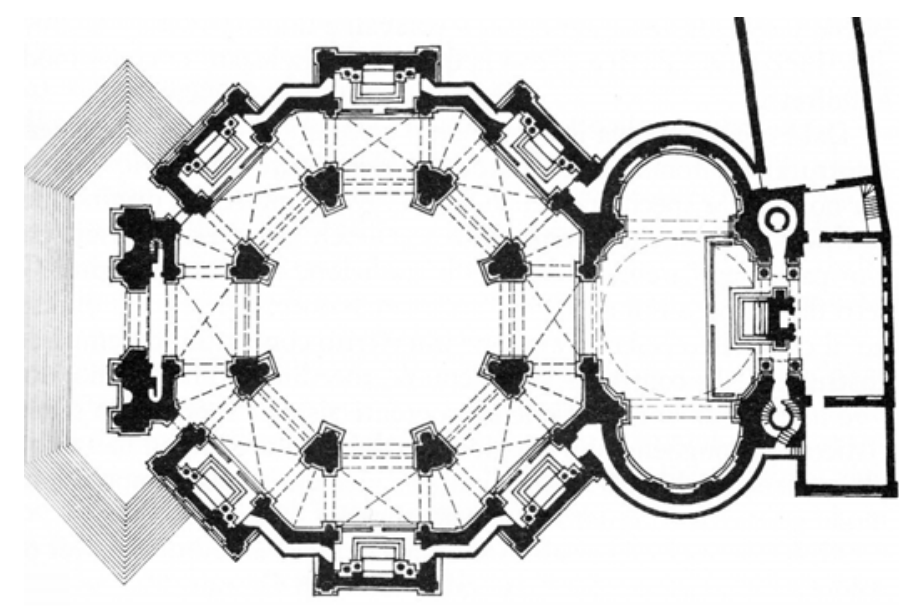

Figura 4.5. Iglesia de La Salute de Venecia (Italia) (WITTKOWER. [1958] 1993 245)

Creemos que el libro de Clarence Ward es de indudable interés, por un lado supone la primera aproximación sistemática al problema de la girola, pero además es capaz de identificar algunas cuestiones fundamentales en el análisis de estos espacios. Sin embargo, el hecho de mezclar cuestiones de índole compositiva, con otras de carácter

$6 \quad$ Es interesante ver los apartados en los que Clarence Ward divide el capítulo 4 «Ambulatory vaults»: Early Ambulatories, Origin of Ambulatory Vaulting, Annular Tunnel Vaults, Ambulatories with Half Tunnel Vaults, Romanesque Ambulatories with Alternating Triangular and Square Bays, Ambulatories with Transverse Tunnel Vaults, Ambulatories with Groined Vaulted Trapezoidal Bays, Ambulatories with Ribbed Vaults, Morienval, Trapezoidal Ambulatory Vaults with Straight Diagonal Ribs, Trapezoidal Ambulatory Vaults with Curved Diagonal Ribs, Trapezoidal Ambulatory Vaults with Broken Ribs, Method of Construction in Ambulatory Vaults, Trapezoidal Ambulatory Vaults with Added Ribs, Ambulatory Vaults which Include the Radiating Chapels, Ambulatories with Alternate Square and Triangular Bays, Ambulatories with Triangular Bays Only, Ambulatories with Multiple Ribbed Vaults, Exceptional Eastern Terminations.

7 Que encontramos en ejemplos construidos a lo largo de toda la historia, como la Capilla Palatina de Aquisgrán (fin. s. VIII) (figura 3.44), la Rotonda de Brescia (s. X) (figura 4.4), las girolas de las catedrales de Toledo (s. XIII) (figura 3.43) y Le Mans (s. XIII), la basílica menor de Elche (s. XVII) o la iglesia de Santa María de la Salute de Venecia (s. XVII) (figura 4.5). El texto de Clarence Ward se limita a bóvedas medievales, por lo que no incluye los ejemplos clasicistas. 

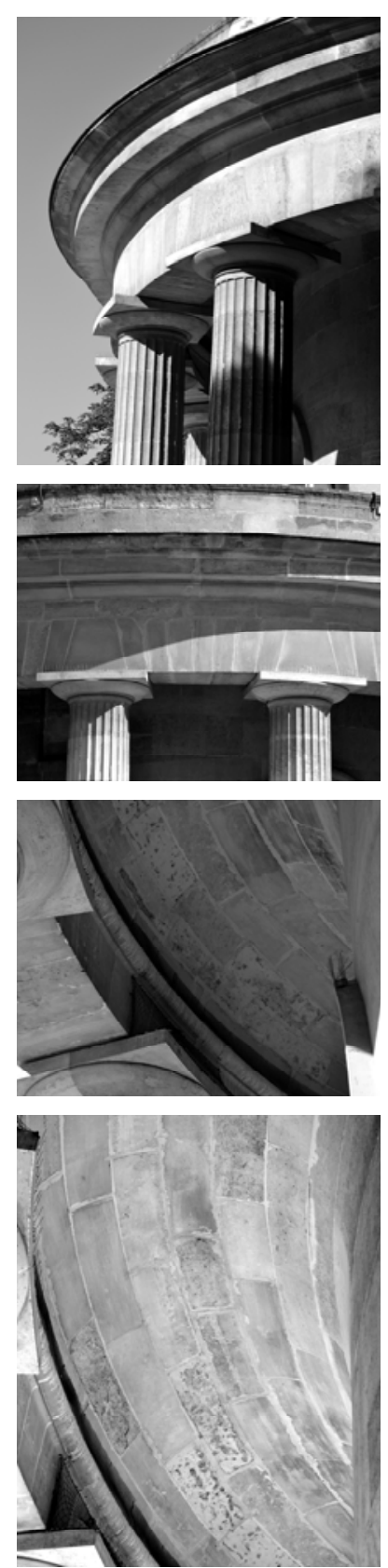

Figura 4.6. Templete en el Parc Monceau de París (Francia) histórico, y otras de índole constructiva, hace que se pierdan de vista lo universal de algunos problemas.

Si bien es posible separarlos, los problemas históricos y constructivos están relacionados por el empleo, en cada época, de determinadas técnicas constructivas. Los problemas compositivos, en cambio, tienen carácter trans-histórico (figuras 4.4 y 4.5). Al principio de este capítulo recordábamos la influencia de los sistemas constructivos en las posibilidades de composición de los edificios; tal y como nos recuerda Viollet-le-Duc, en el caso de la girola existe un empeño por resolverla que fuerza el sistema constructivo más allá de sus posibilidades iniciales.

La cuestión de la girola se aborda en tres fases distintas. La primera queda recogida en este apartado y plantea un recorrido histórico muy general que relaciona los distintos sistemas constructivos empleados en cada época con el problema de abovedar una galería anular.

En el apartado siguiente se plantea el problema concreto de la girola desde el punto de vista compositivo; estaríamos ante el primer nivel de análisis planteado en el capítulo anterior (cfr. capítulo 3, apartado 3.4). Es imposible liberar completamente las cuestiones compositivas de las constructivas, por lo que no perdemos de vista el sistema constructivo empleado en cada caso. Sin embargo veremos cómo muchos de los problemas que plantea la girola son independientes del sistema constructivo; un mismo problema compositivo resuelto con distintos tipos de bóveda.

Ya en el capítulo 5 y en la segunda parte de la tesis, dedicados específicamente a bóvedas no canónicas, se analizará el problema del abovedamiento de los espacios de planta trapecial -o en sector anularcon los que es habitual resolver una girola. ${ }^{8}$ Estaríamos ya ante el segundo nivel de análisis planteado en el capítulo anterior (cfr. capítulo 3, apartado 3.4).

Nuestro objetivo es dar un breve panorama sobre el problema de la deformación en arquitectura abovedada a lo largo de la historia centrado en los espacios de planta anular- puesto en relación con el sistema de abovedamiento, las técnicas constructivas disponibles en cada momento.

Aunque veremos que no es la única solución posible. 


\section{Antecedentes. Arquitectura romana y paleocristiana}

La primera gran arquitectura abovedada es la romana, ${ }^{9}$ empleando dos técnicas constructivas: la cantería y el hormigón romano. En ambas técnicas, los romanos evitaban las intersecciones de bóvedas, siendo la de arista el único ejemplo de este tipo de bóvedas: ${ }^{10}$

En general, los romanos evitaban la intersección de bóvedas de cañón, como lo demuestran sus anfiteatros. Así en los de Arlés y Nimes, los corredores perimetrales se cruzan con galerías radiales en todas direcciones, sin que se dé un solo ejemplo de bóvedas de arista; en el de Verona se encuentran algunas intersecciones, pero de muy poca importancia; finalmente, en el Coliseo, sorprende comprobar cómo el continuo cruce de innumerables galerías produce un pequeñísimo número de interpenetraciones.

(CHOISY [1873] 1999, 62)

Los romanos, que mostraban en todos los aspectos de la vida una marcada preferencia por las soluciones simples, procuraban que las bóvedas de arista siempre fuesen el resultado de la intersección de dos cañones iguales y de perfil circular, evitando así que los cuchillos transversales de la cimbra tuvieran forma elíptica.

$$
\text { (CHOISY [1873] 1999, 63) }
$$

Las bóvedas de arista que construían los romanos se ejecutaban en hormigón, que permiten, hasta cierto punto, salvar el inconveniente principal que plantea la bóveda de arista: el trazado de curvatura variable de las aristas de intersección y la labra de las dovelas de la arista. Cuando la bóveda tenía planta rectangular, la solución se complica (cfr. capítulo 9, apartado 9.1). Los romanos empleaban algunas soluciones que les permitían abovedar recintos de planta rectangular sin recurrir a bóvedas de planta rectangular CHOISY [1873] 1999, 64-65). Otro recurso dirigido a facilitar el abovedamiento de plantas casi-cuadradas, asumiendo pequeñas diferencias, consistía en peraltar «uno de los cañones de modo que las

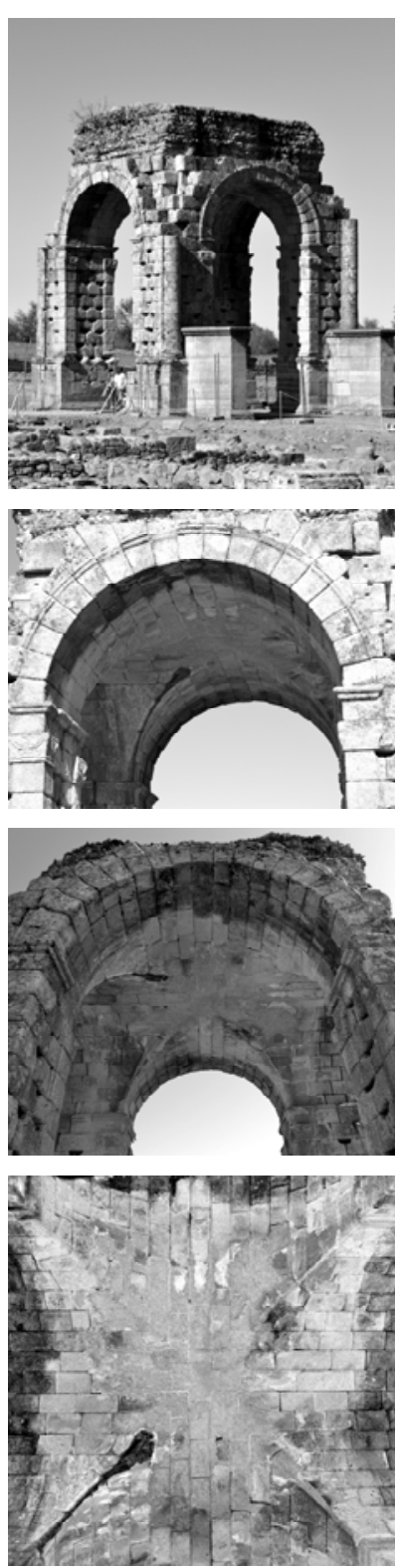

Figura 4.7. Tetrapylum Arco cuadrifronte - de Cáparra (Cáceres)

9 Lo que no quiere decir que fueran las primeras bóvedas en construirse.

10 Las bóvedas de arista se construían de hormigón; en cantería era rarísimo (CHOISY [1873] 1999, 123). En España se conserva uno de los poquísimos ejemplos de bóveda de arista romana de sillería: el arco cuadrifronte -tetrapylum- de Cáparra (Cáceres) (figura 4.7), frente a su homólogo romano, el Arco di Giano, en el Foro Boario de Roma, realizado en hormigón. 


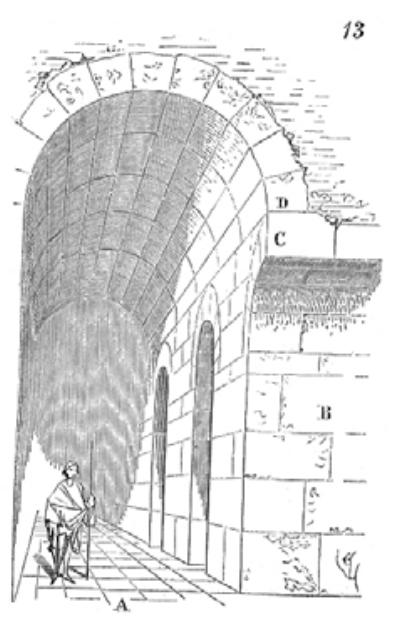

Figura 4.8.Solución a la romana para evitar intersecciones según Viollet-le-Duc (1854-1868, 9:487) (http://wikisource.fr)

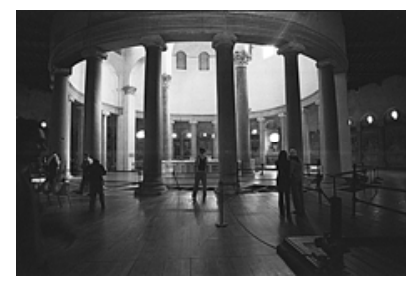

Figura 4.9. Santo Stefano Rotondo en Roma (Italia)

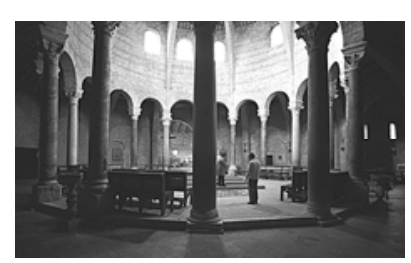

Figura 4.10. Iglesia de Sant'Angelo en Perugia (Italia) líneas de sus claves estuviesen al mismo nivel» (CHOISY [1873] 1999, $63)^{11}$

Para evitar las intersecciones, un recurso sencillo consiste en situar el arranque de una bóveda por encima de la coronación de la otra (figura 4.8):

S’ils avaient un berceau de voûte à faire pénétrer dans une salle voûtée, ils tenaient la clef de ce berceau pénétrant au-dessous de la naissance du berceau qui eût dû être pénétré.

(VIOLLET-LE-DUC 1854-1868, 9:487)

Si la bóveda tiene planta anular, los problemas de las intersecciones se multiplican. En el Mausoleo de Santa Costanza en Roma (s. IV) y en la Rotonda de Nocera (Nocera Superiore), ambos de planta central con estructura en doble casco, ${ }^{12}$ encontramos el recurso romano de situar el arranque de la bóveda anular por encima de las claves de los arcos que dan acceso al espacio interior.

Otros ejemplos de arquitectura paleocristiana evitan directamente los problemas de la bóveda recurriendo a otro tipo de coberturas, como vemos en la iglesia de Santo Stefano Rotondo (figura 4.9), y en el Baptisterio de San Juan de Letrán, también en Roma, o en la iglesia de Sant'Angelo -Tempio di Sant'Angelo- en Perugia (Italia) (figura 4.10).

El planteamiento del problema. Bóvedas románicas en España (siglos XI y XII)

En los artículos «Construction-Voûtes» y «Voûte» del Dictionnaire raisonnée de Viollet-le-Duc (1854-1868, 6:62-126 y 9: 465-550) encontramos un recorrido por algunas girolas románicas francesas, y los distintos tipos de bóvedas empleadas. También en el libro de Clarence Ward encontramos algunos ejemplos de girolas y deambulatorios románicos y los distintos tipos de abovedamiento empleados: «annular tunnel vaults» (WARD 1916, 159); «half tunnel vaults» (WARD 1916, 160); «transverse tunnel vaults» (WARD 1916, 161); «groined vaulted trapezoidal vaults» (WARD 1916, 162); y «ribbed vaults», con distintas variantes (WARD 1916, 163-169), que enlazaría con el sistema de bóveda de crucería gótica. También

11 Curiosamente esta misma solución es propuesta por Fray Lorenzo de San Nicolás (cfr. capítulo 9, apartado 9.1).

12 Según Richard Krautheimer, la expresión «double shell» fue formulada por W. MacDonals en su libro Early Christian and Byzantine Architecture (Nueva York, 1962). 
encontramos el recurso de alternar tramos cuadrados y triangulares (WARD 1916, 160-161).

La solución a la romana empleada en Santa Constanza, aunque resuelve el problema constructivo, plantea un problema evidente, ya que sobreeleva la altura del deambulatorio, dificultando la iluminación del ábside. En España, encontramos esta solución en las girolas de las iglesias de San Pedro de Roda (Gerona) (s. XI) y San Pedro de Besalú (s. XII) en Gerona, en Santa María de Cambre (La Coruña) (s. XII) (figura 4.11) y en el deambulatorio la iglesia de la Vera Cruz de Segovia (s. XIII), de planta central con estructura en doble casco. Mientras que en los dos primero ejemplos la bóveda mantiene el trazado semicircular del ábside, en Cambre y Segovia, el trazado se poligonaliza, dividiéndose en tramos trapeciales por medio de arcos perpiaños.
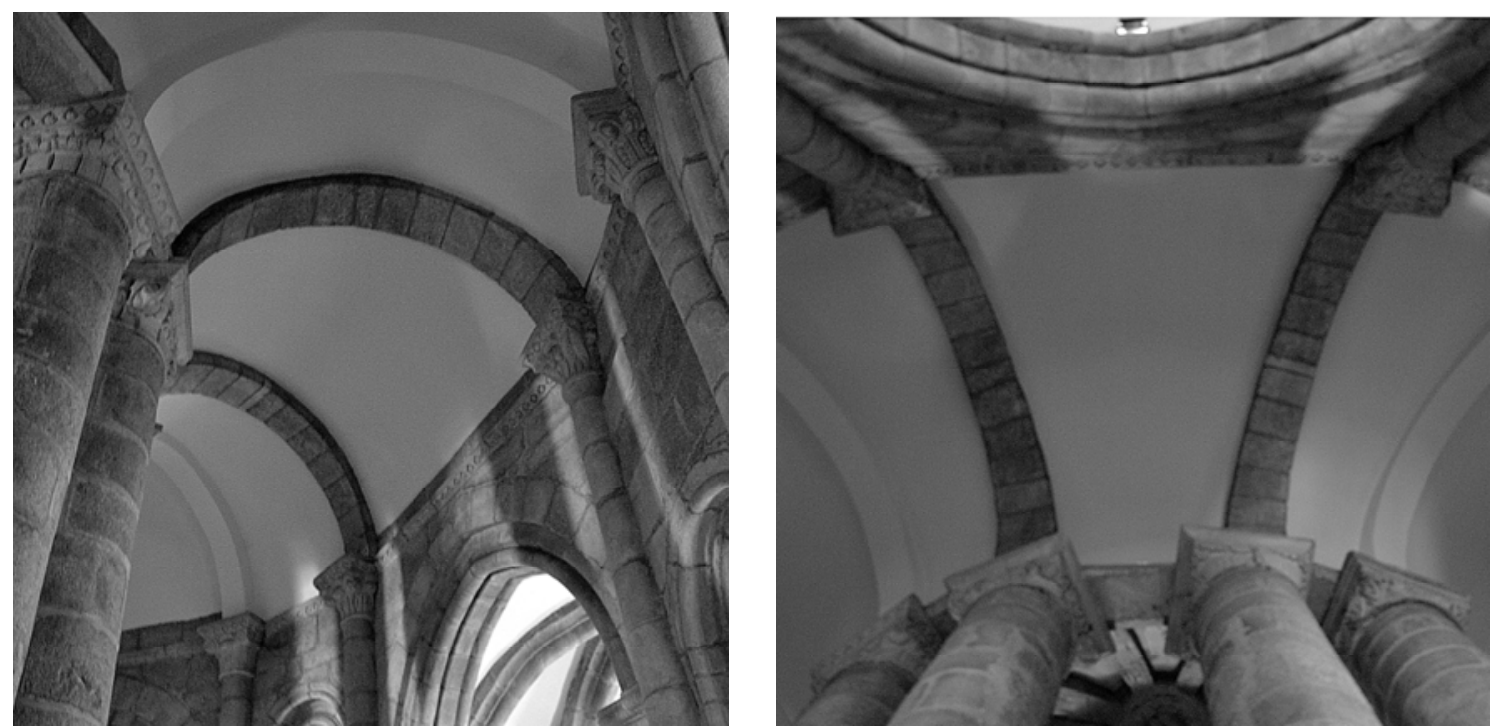

Figura 4.11. Santa María de Cambre (La Coruña)

La solución románica de emplear media bóveda cañón solventa este problema. En España, la encontramos en las girolas gallegas de Santa María de Melón (s. XII) (figuras 4.12 y 4.13) y Santa María la Real de Oseira (s. XIII) (figuras 4.14 y 4.15) en Orense. En ambos ejemplos, la bóveda se subdivide en tramos por medio de arcos perpiaños, pero mantiene el trazado semicircular. 

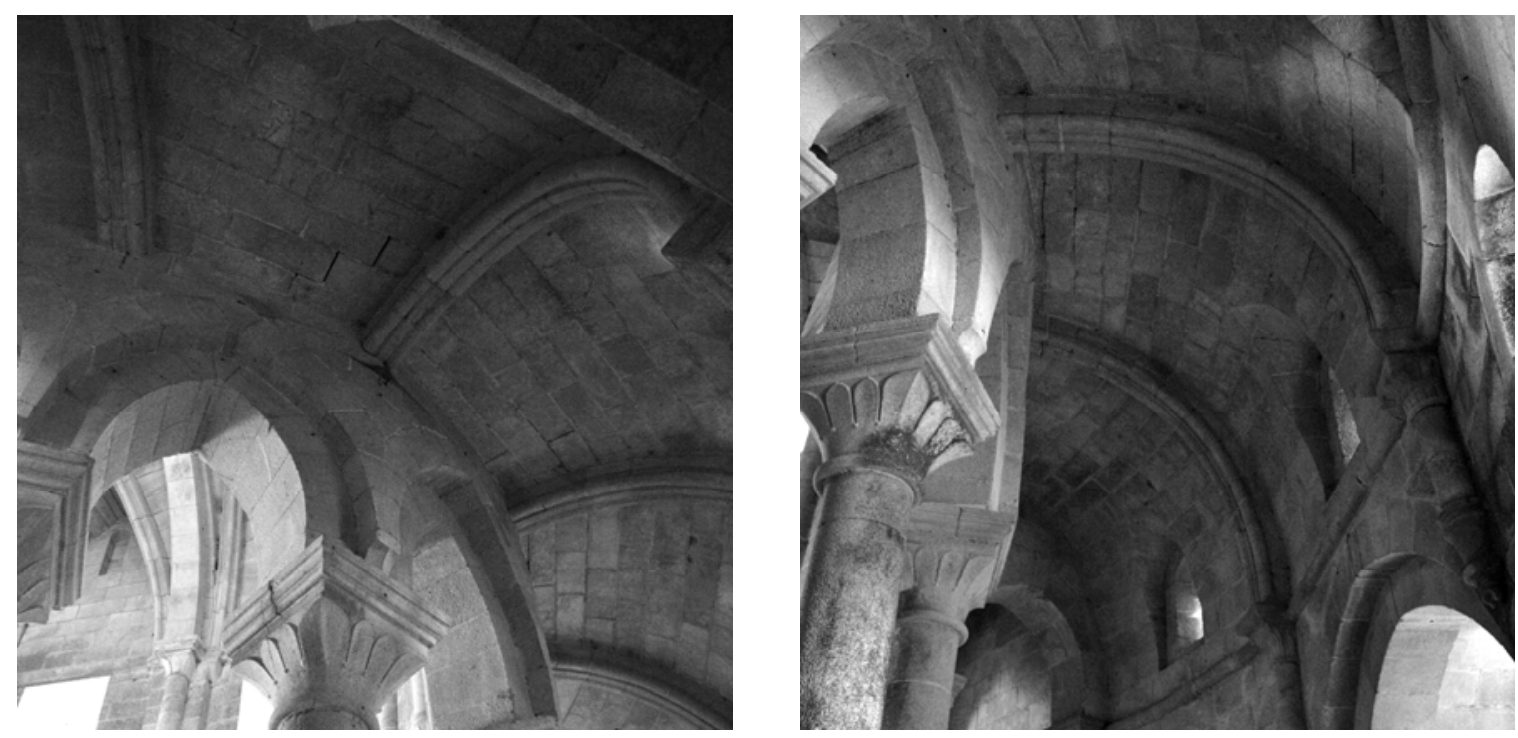

Figura 4.12. Santa María de Melón (Orense)
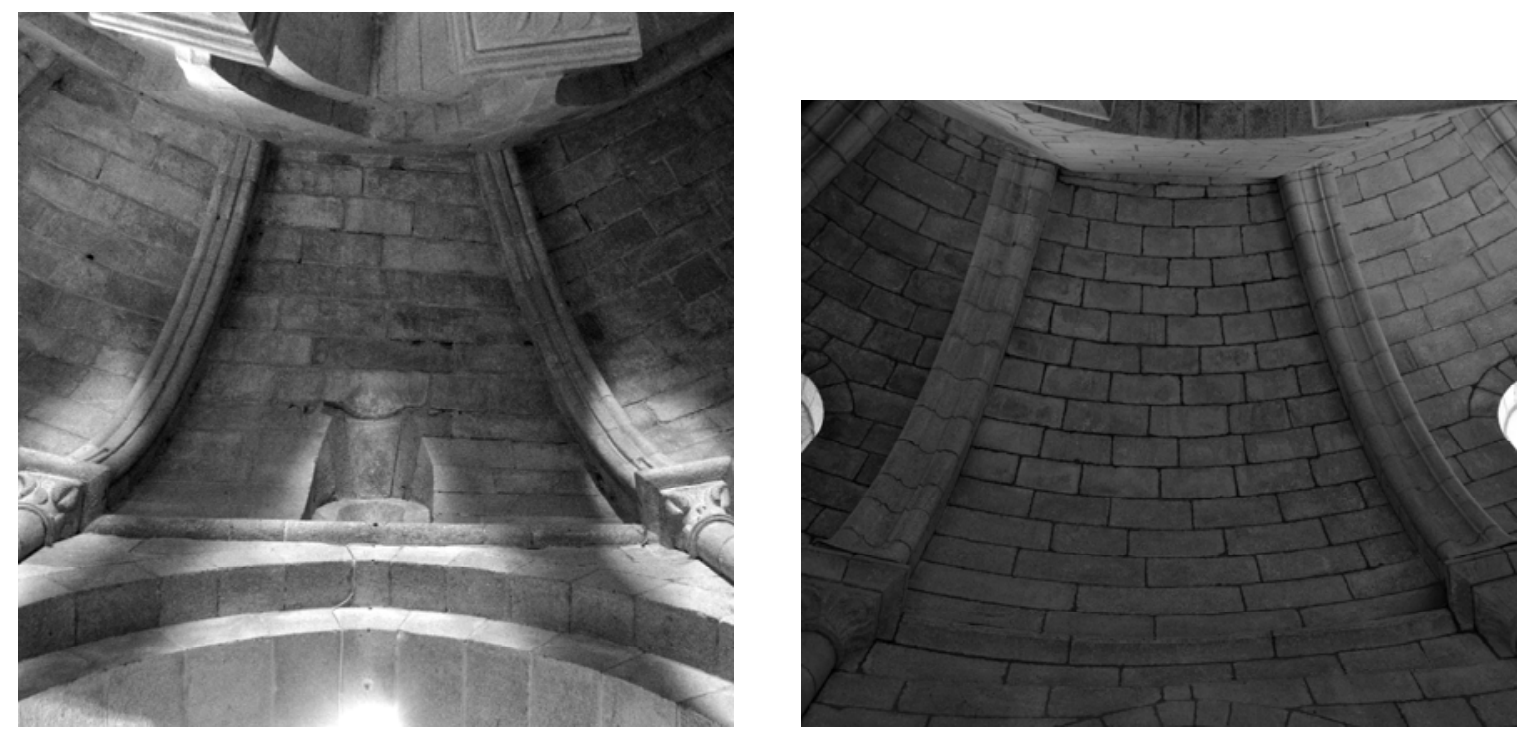

Figura 4.13. Santa María de Melón (Orense)

Figura 4.14. Santa María la Real de Oseira (Orense)
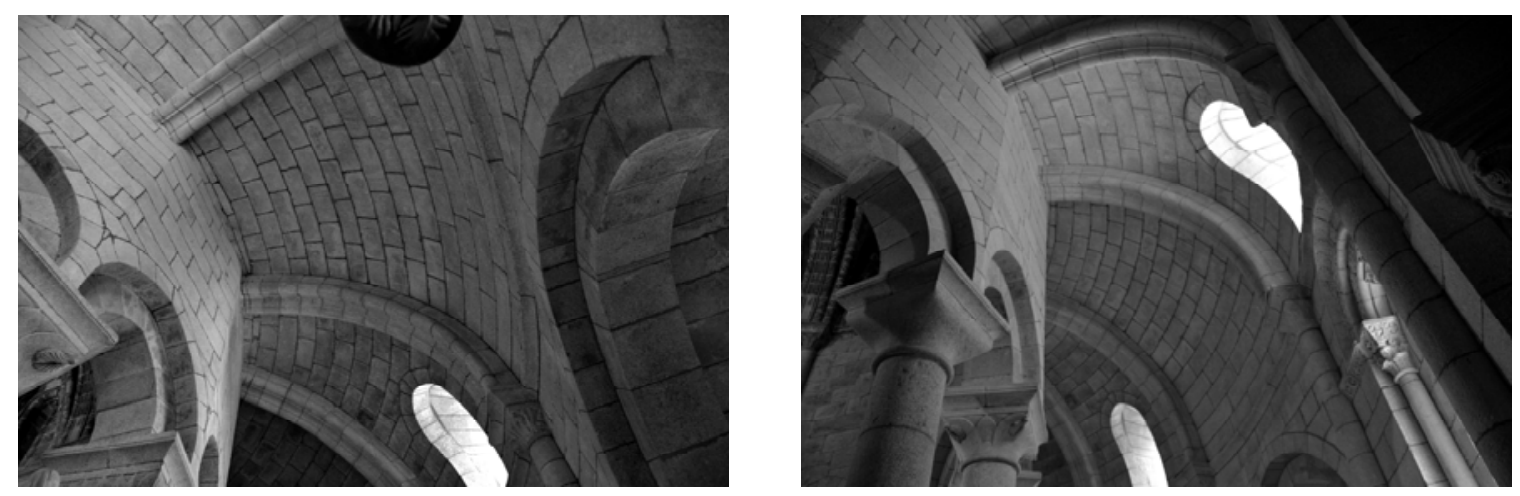

Figura 4.15. Santa María la Real de Oseira (Orense) 
En las girolas de las iglesias de Santa María la Real de Fitero Nienzebas- (Navarra), Santa María la Real de Gradefes (León) (figura 4.16), Santa María de Moreruela (Zamora) (figura 4.17), Santa María del Poblet (Tarragona), Santo Domingo de la Calzada (La Rioja) y Santa María de Veruela (Zaragoza), todos del siglo XII, y en la girola de San Lorenzo de Carboeiro (Pontevedra) (figura 4.18), del s. XIII, encontramos ya bóvedas de crucería con nervios gruesos. La girola se ha poligonalizado, dividiéndose por medio de arcos perpiaños en tramos trapeciales cubiertos con una bóveda de crucería sencilla.
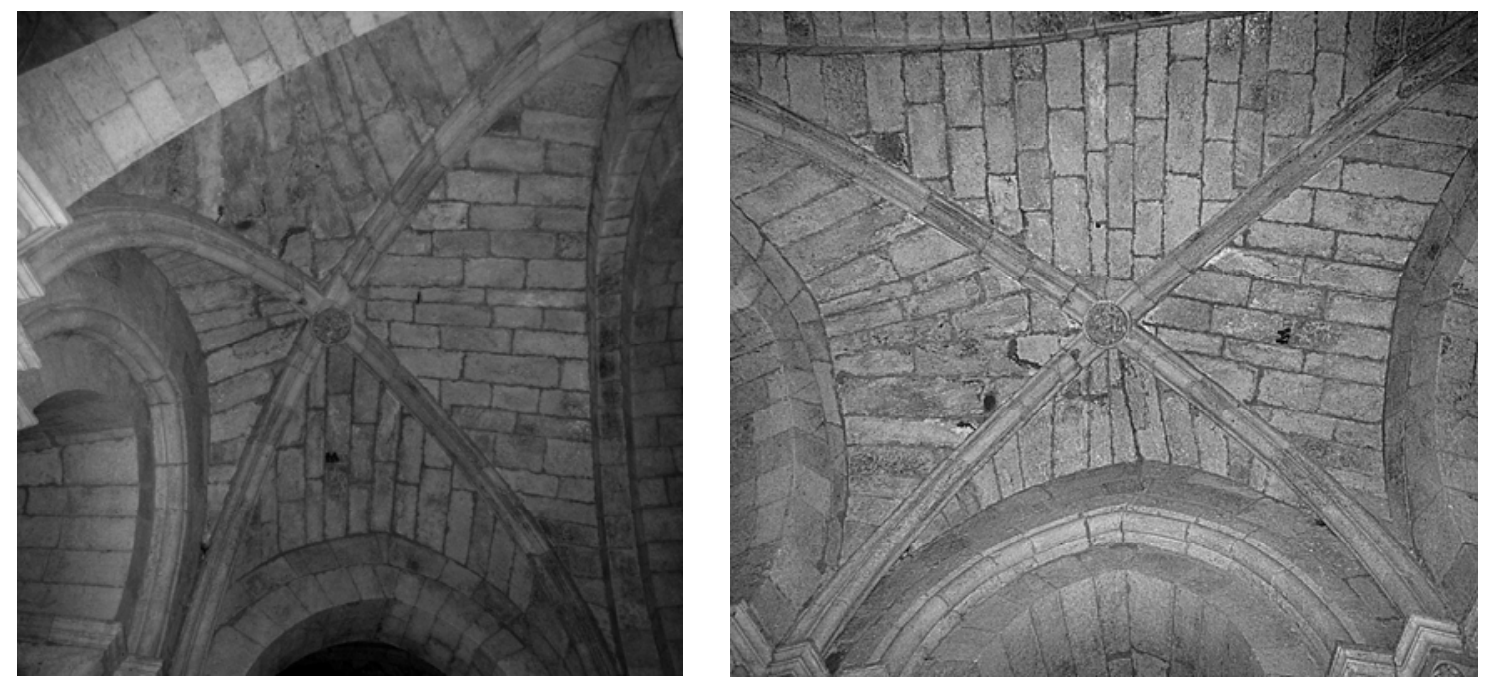

Figura 4.16. Santa María la Real de Gradefes (León)
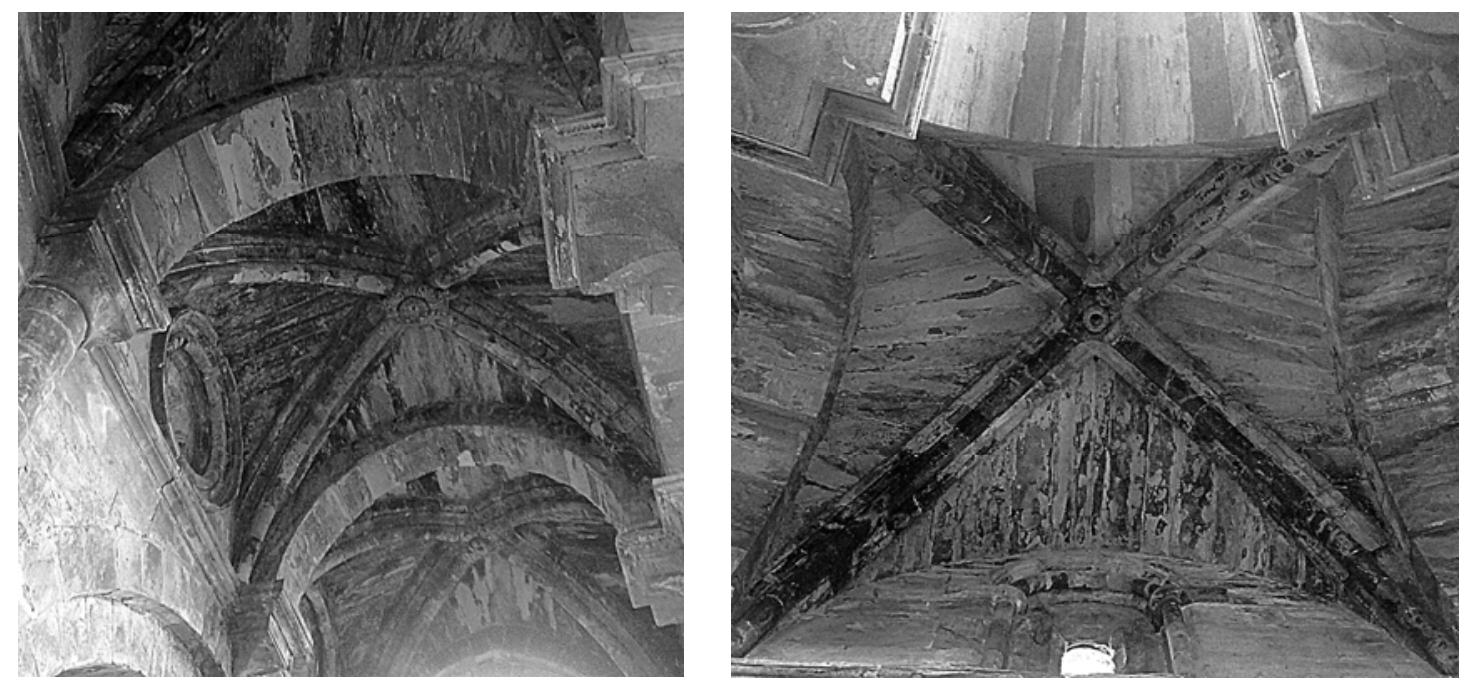

Figura 4.17. Santa María de Moreruela (Zamora) 

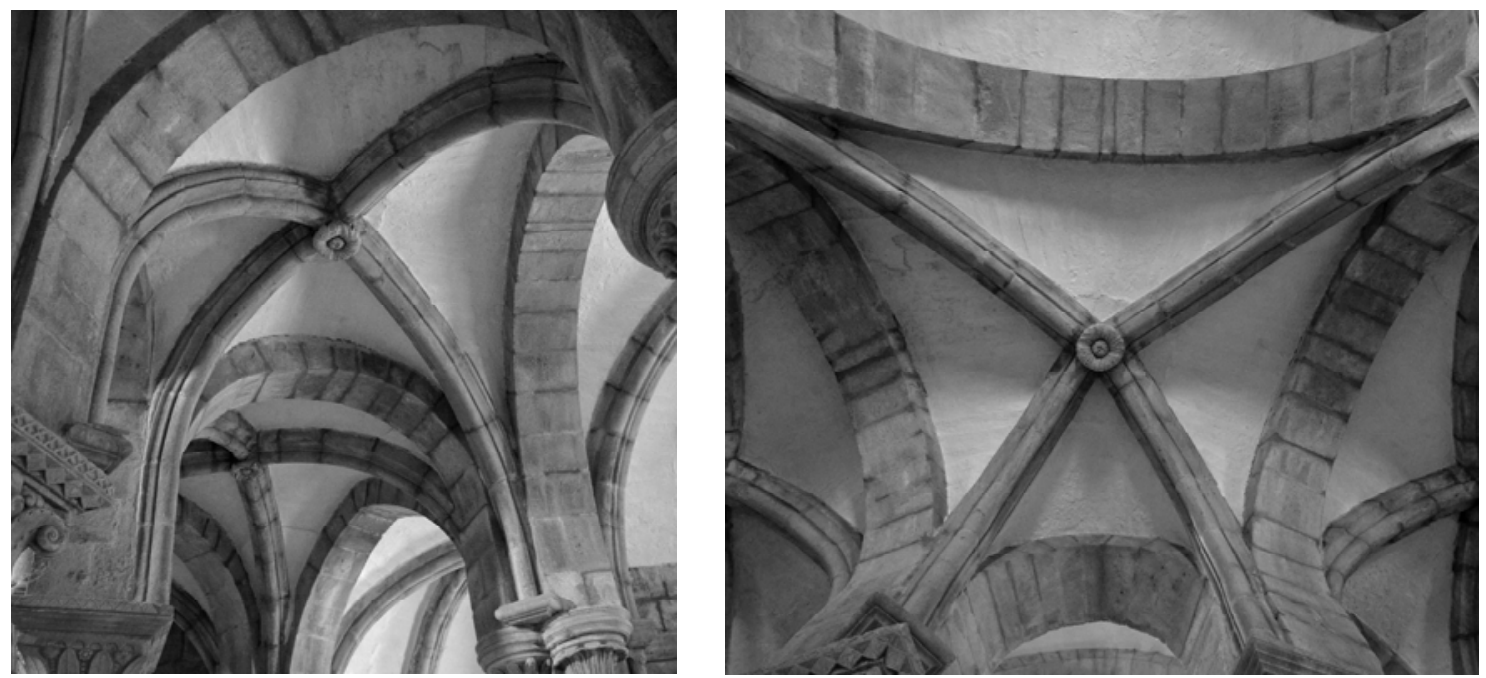

Figura 4.18. San Lorenzo de Carboeiro (Pontevedra)
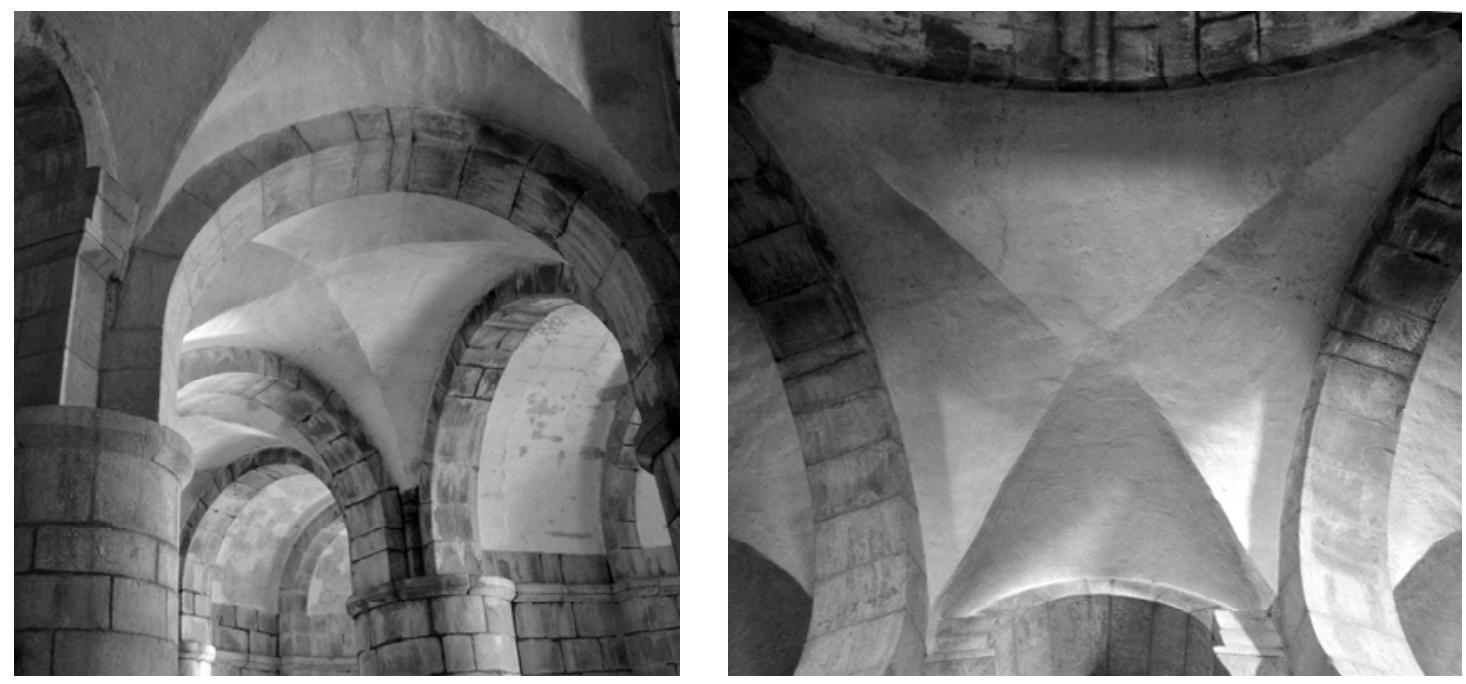

Figura 4.19. Cripta de San Lorenzo de Carboeiro (Pontevedra)

Encontramos algunos ejemplos de bóveda de arista de planta anular realizadas de manera tosca, en la mayoría de los casos el despiece -muy irregular- se oculta bajo un enlucido (figura 4.19), tal y como sucede en las basílicas de peregrinación de Santiago de Compostela (figura 4.20) y San Sernín de Toulouse (Francia) (figura 4.21). En la Rotonda de San Tomé en Almenno San Bartolomeo (Italia) y en la iglesia de Notre-Dame de Cunault (Francia) el despiece es visible. 

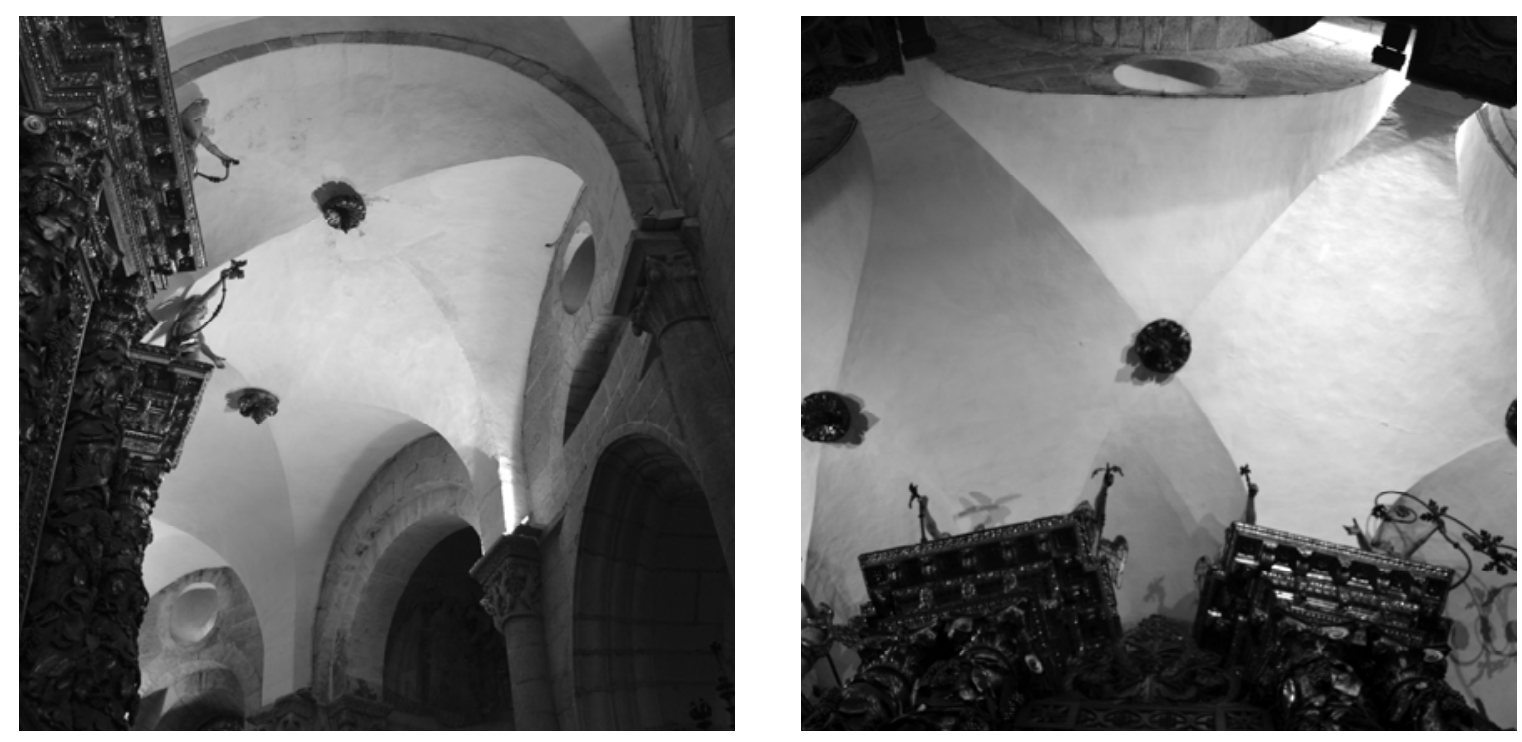

Figura 4.20. Catedral de Santiago de Compostela
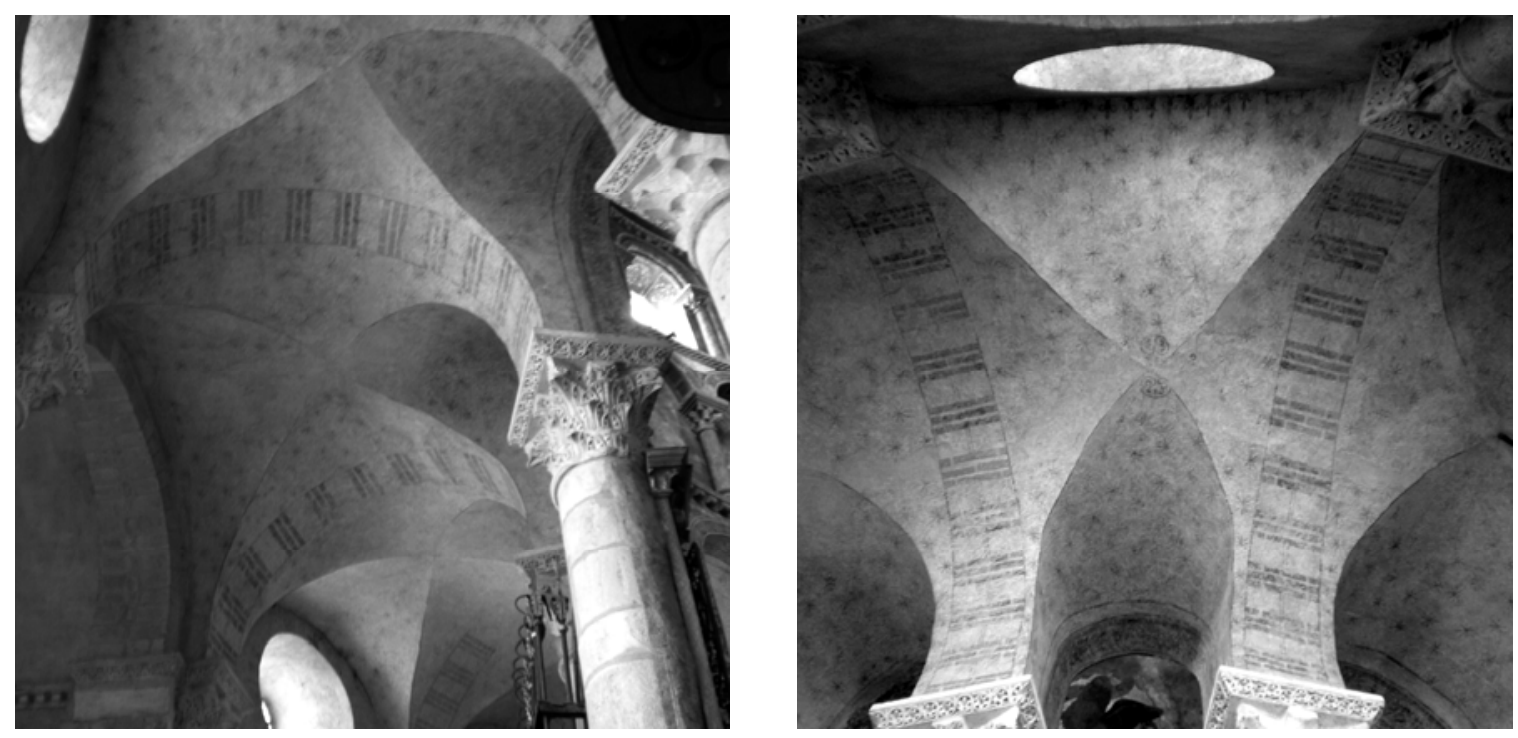

Figura 4.21. Basílica de San Sernín de Toulouse (Francia)

La solución al problema. La bóveda de crucería gótica (siglos XIIXIV)

La bóveda de crucería gótica, con los antecedentes románicos que acabamos de ver, resuelve de manera sencilla el problema de los tramos trapeciales del una galería anular, tal y como podemos ver en muchas iglesias y catedrales españolas y europeas. La cuestión de la bóveda de crucería de planta trapecial, con sus distintas variantes, se analizará en el capítulo siguiente (cfr. capítulo 5, apartado 5.2). 
En edificación civil podemos señalar las bóvedas de Castillo de Bellver en Palma de Mallorca (figuras 4.22 y 4.23).
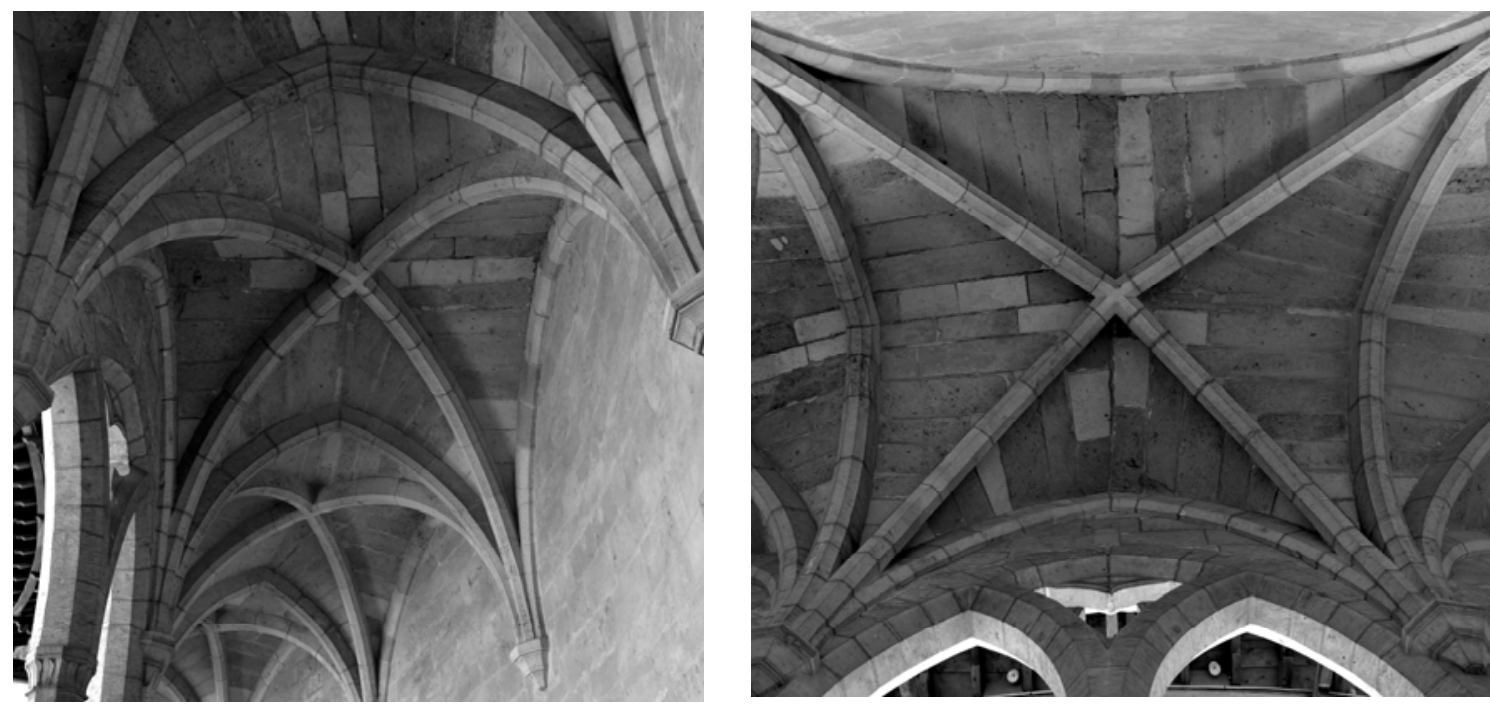

Figura 4.22. Galería exterior del Castillo de Bellver en Palma de Mallorca
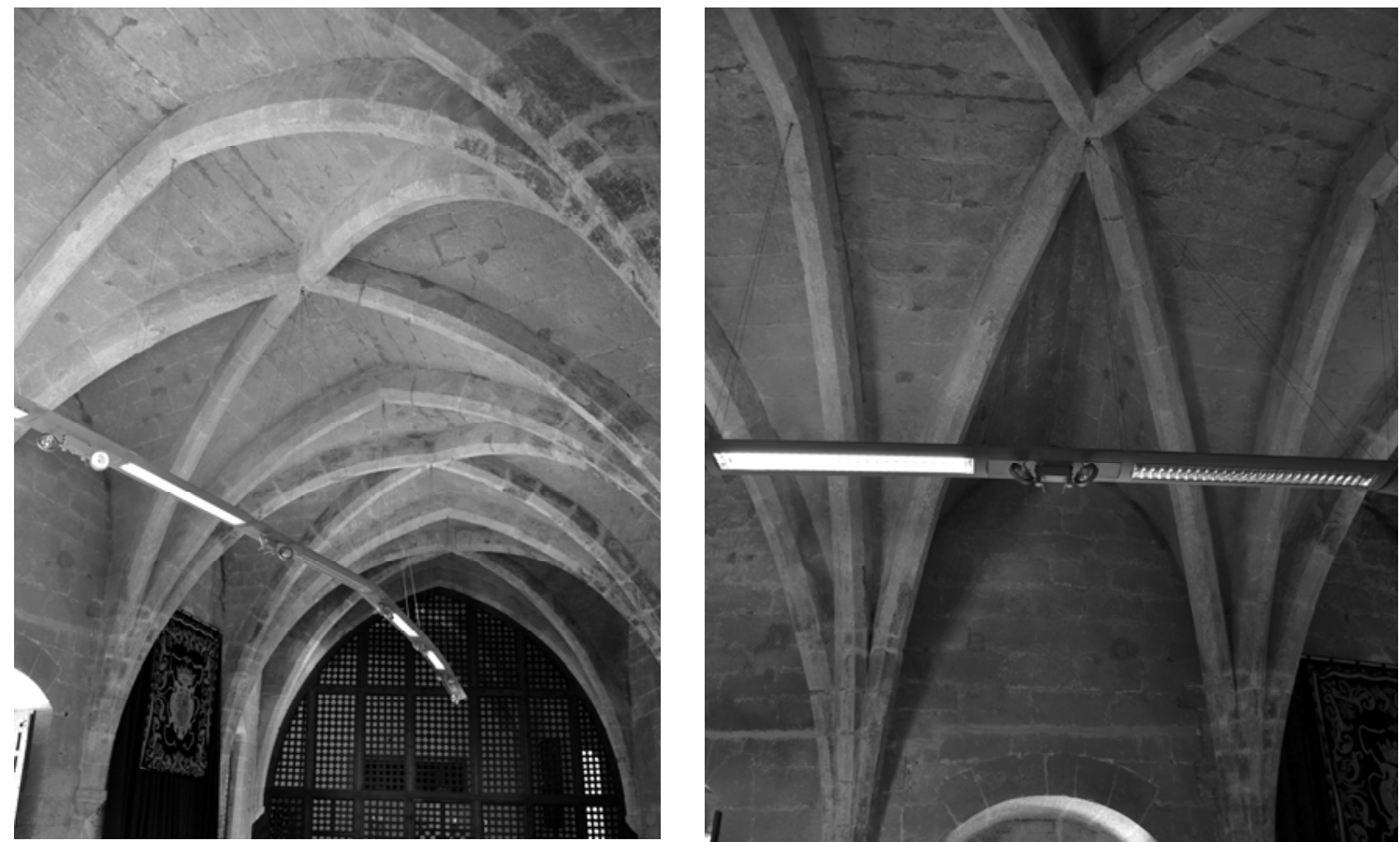

Figura 4.23. Galería interior del Castillo de Bellver en Palma de Mallorca

También se proponen soluciones alternativas, como la división en tramos triangulares de la girola de la catedral de Notre-Dame de París (Francia) o la división en tramos cuadrados y triangulares de las girolas de las catedrales de Toledo y Le Mans (Francia), que se analizará en el apartado siguiente. 
En general, las bóvedas de crucería góticas empleadas en girolas no plantean muchas variantes, siendo las soluciones compositivas las que mayor diversidad de soluciones proponen.

La alternativa tardogótica. La bóveda de crucería de múltiples nervios (siglos $X V$ y $X V I$ )

Durante los siglos XV y XVI, se siguieron construyendo en Europa bóvedas de crucería, caracterizadas por una multiplicación en el número de claves y nervios, que con trazados más complejos y mecanismos de control de la volumetría (CHUECA GoITIA 1951; PALACIOS GONZALO 2009). Sin embargo, esta variedad de soluciones tardó en trasladarse a las bóvedas de las girolas, seguramente por la dificultad de adaptación que implican.

La bóveda tardogótica española la encontramos en las girolas de las catedrales de Almería, Calahorra (La Rioja), Guadix (Granada) y Segovia, de la concatedral de Baza (Granada) y de la iglesia parroquial de Alcocer (Guadalajara), que se analizarán en el capítulo siguiente (cfr. capítulo5, apartado 5.2).

En Europa Central la bóveda reticular acaba por incorporarse a la girola, aunque no sin dificultad, como atestigua el escaso número de ejemplos que encontramos. Podemos señalar las girolas de la iglesia de San Pedro de Altentreptow, la iglesia parroquial de Dinkelsbühl (figura 4.24), la Catedral de Friburgo, la Hauptkirche de Güben, la iglesia de Nuestra Señora de Ingolstadt (figura 4.25) y la iglesia de la Santa Cruz de Schwäbisch Gmünd (figura 4.26) en Alemania, y la iglesia de Santa Bárbara de Kutná Hora en la República Checa.

En otros casos la adaptación es imposible, tal y como sucede con la bóveda de abanico inglesa. La única bóveda de abanico empleada en una girola se encuentra en la Catedral de Peterborough, ${ }^{13}$ con una solución de girola recta (cfr. capítulo 4, apartado 4.2). Llamativamente, la Catedral de Peterborough mantuvo el ábside original semicircular, al contrario que en otras muchas catedrales inglesas donde fue sustituido por un presbiterio recto. Para resolver la transición entre el trazado semicircular del ábside, y la planta rectangular de la girola, el maestro recurrió a unas pequeñas bóvedas de crucería sencilla, ante la imposibilidad de adaptar la bóveda de abanico a un perímetro irregular (figura 4.27).

13 En realidad recibe el nombre de retrochoir, también denominado the New Building.

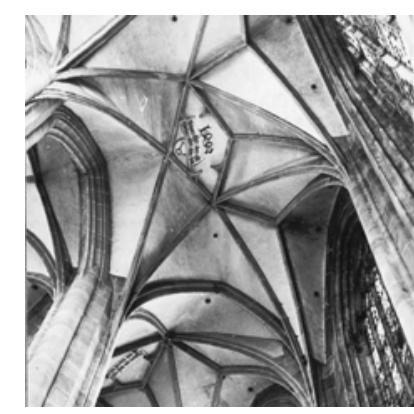

Figura 4.24. Iglesia parroquial de Dinkelsbühl (Alemania) (fuente: Gotik-Romanik)

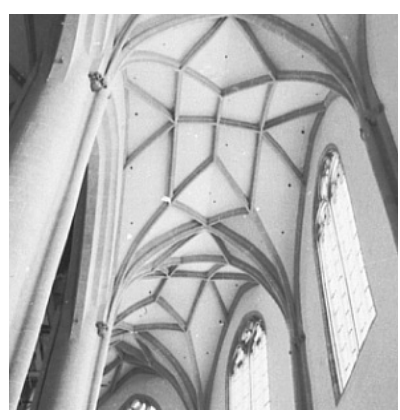

Figura 4.25.

Liebfrauenkirke de Ingolstadt (Alemania) (fuente: Gotik-Romanik)

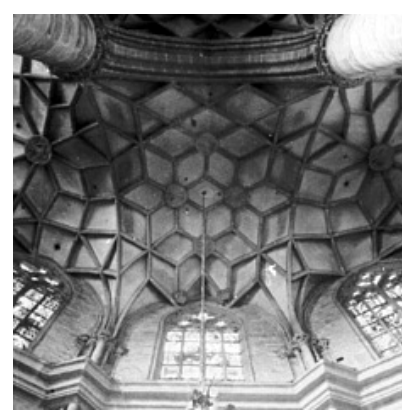

Figura 4.26. Heilig-KreuzKirche en Schwäbisch Gmünd (Alemania) (fuente: Gotik-Romanik) 


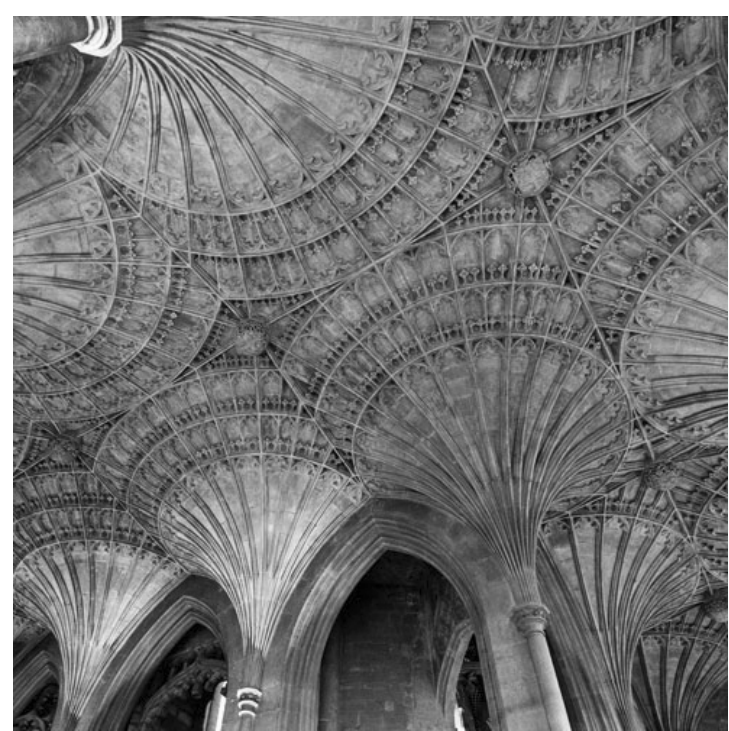

Figura 4.27a. Catedral de Peterborough (Reino Unido)

(fotografía de Tony Boughem en http://photoreflect.blogspot.com)

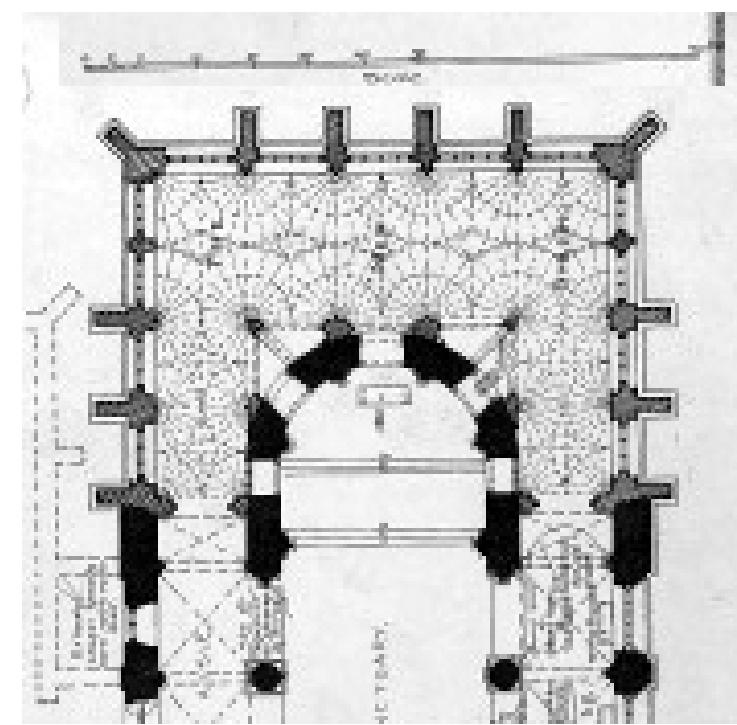

Figura 4.27b. Cabecera de la Catedral de Peterborough (Reino Unido) (Courtauld Institute of Art fuente: Gotik-Romanik)

La solución moderna. Bóvedas clasicistas (siglos XVI y XVII)

Frente a la bóveda de crucería gótica, la arquitectura clasicista plantea tres alternativas para abovedar una galería anular: la bóveda de cañón, la bóveda de arista y la bóveda baída.

La bóveda de cañón es la empleada en el Palacio de Carlos V de la Alhambra (Granada), en el Palacio Farnese de Caprarola (Italia) y en la Villa Giulia en Roma (Italia), con los mismos problemas que veíamos para la bóveda de cañón románica. La bóveda de cañón de planta trapecial es la empleada en la girola de la Catedral de Sigüenza (Guadalajara) (figura 4.28).

La bóveda baída de intradós esférico se adapta con facilidad a los tramos trapecio isósceles en los que queda dividida una galería anular, tal y como sucede en la Catedral de El Burgo de Osma (Soria) (figura 4.29, véase también figura 4.30). Sin embargo, el intradós esférico no es la única solución para la bóveda baída, tal y como sucede en el catedrales de Málaga (cfr. capítulo 8, apartado 8.2) y Granada (cfr. capítulo 8, apartado 8.2).

La bóveda de arista plantea más inconvenientes ya que su adaptación a la planta anular no es sencilla (cfr. capítulo 9, apartado 9.2). Aunque parece la elegida para abovedar algunos proyectos no construidos, como los patios de Serlio, vamos a encontrar muy pocos ejemplos de este tipo de bóvedas: en la galería de Villa Giulia en 
Roma (Italia), en el Claustro de San Antonio de Palma de Mallorca y en la Grande Écurie de Versailles (Francia). ${ }^{14}$
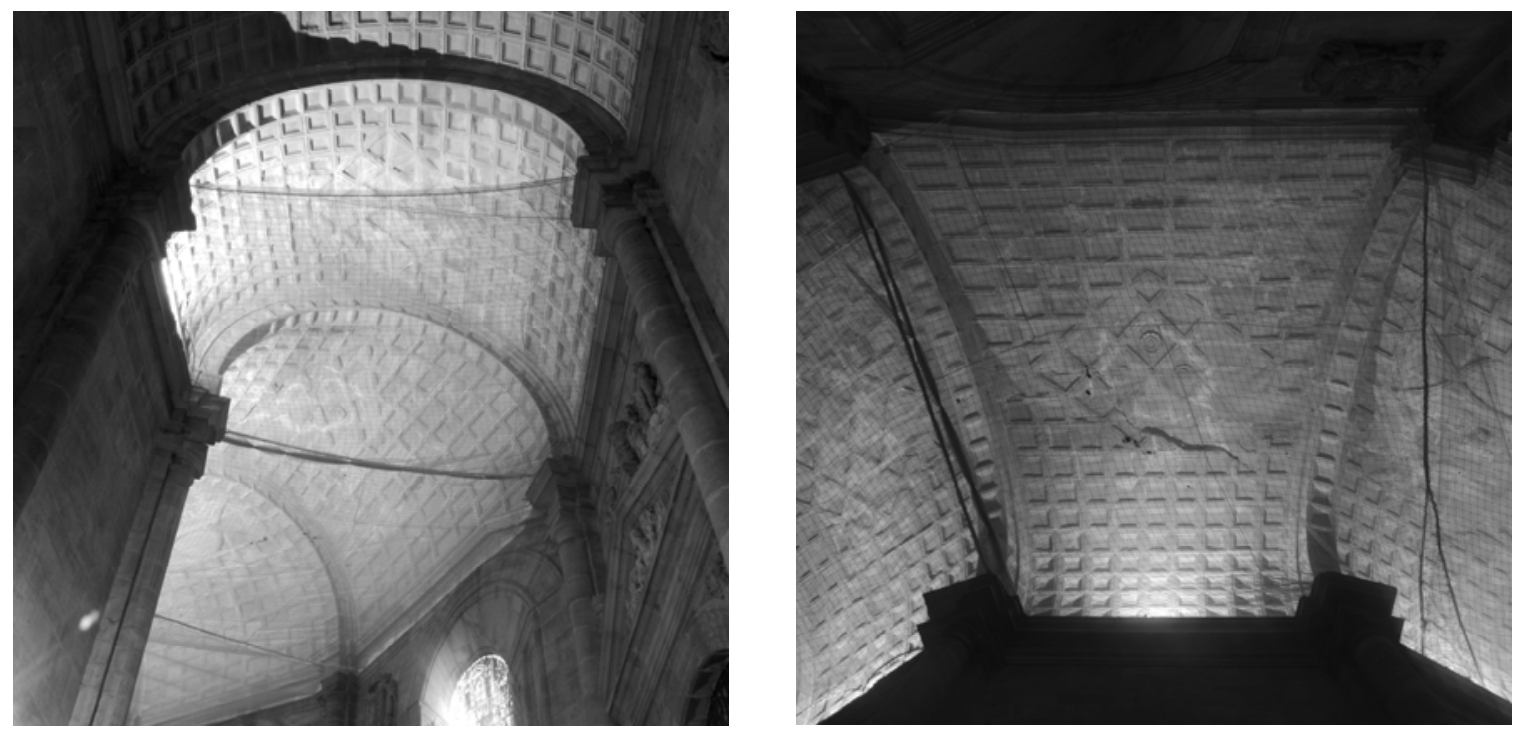

Figura 4.28. catedral de Sigüenza (Guadalajara)
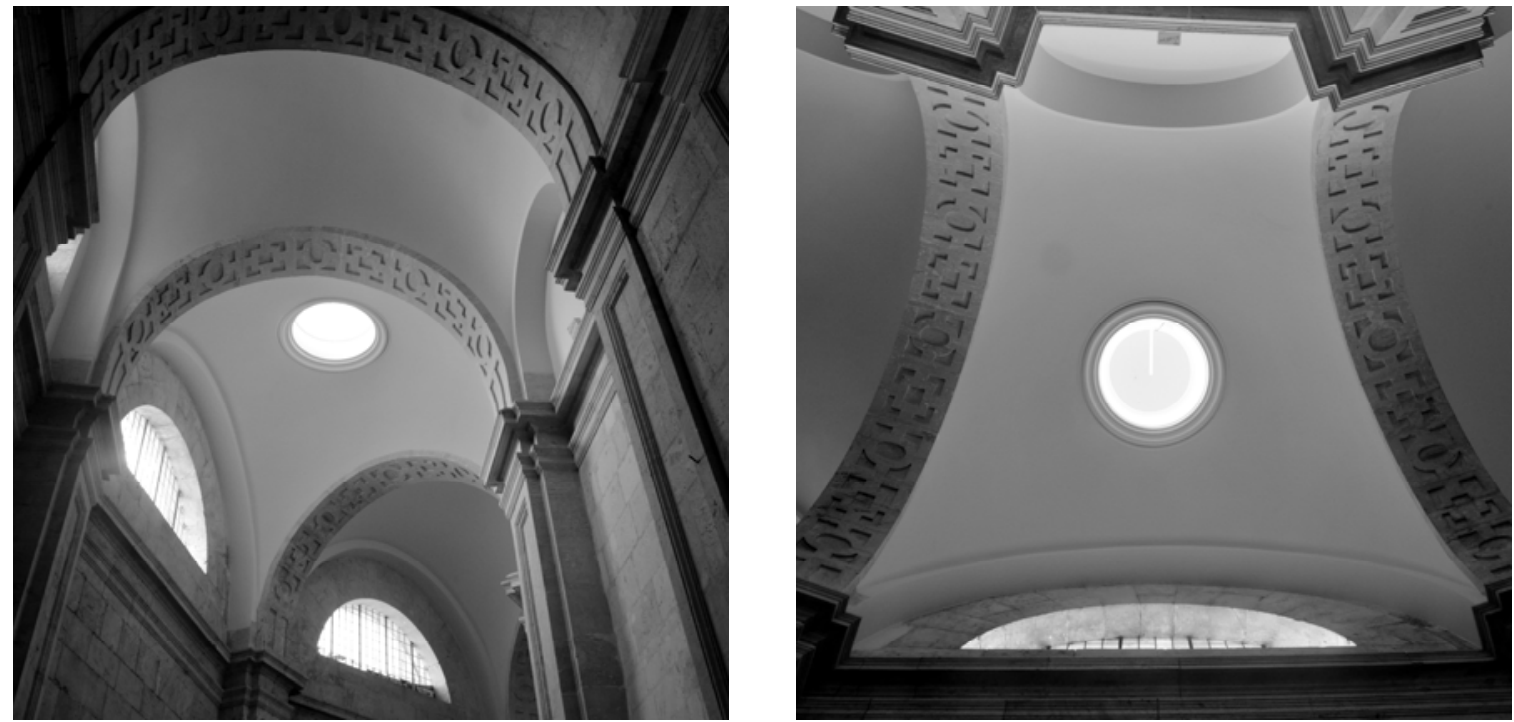

Figura 4.29. Catedral de El Burgo de Osma (Soria)

Una alternativa a la bóveda de arista es la bóveda de cañón con lunetos: «el luneto apuntado» y el «luneto cilíndrico» (cfr. capítulo 5, apartado 5.4). La solución de luneto cilíndrico es la empleada en las catedrales españolas de Oviedo y Orense (figuras 4.31 y 4.32).

14 En realidad se trata de medias bóvedas de arista. Es un patio de planta oval que, hasta donde he podido investigar, se trata del único ejemplo construido siguiendo el modelo de los patios ovales serlianos. 

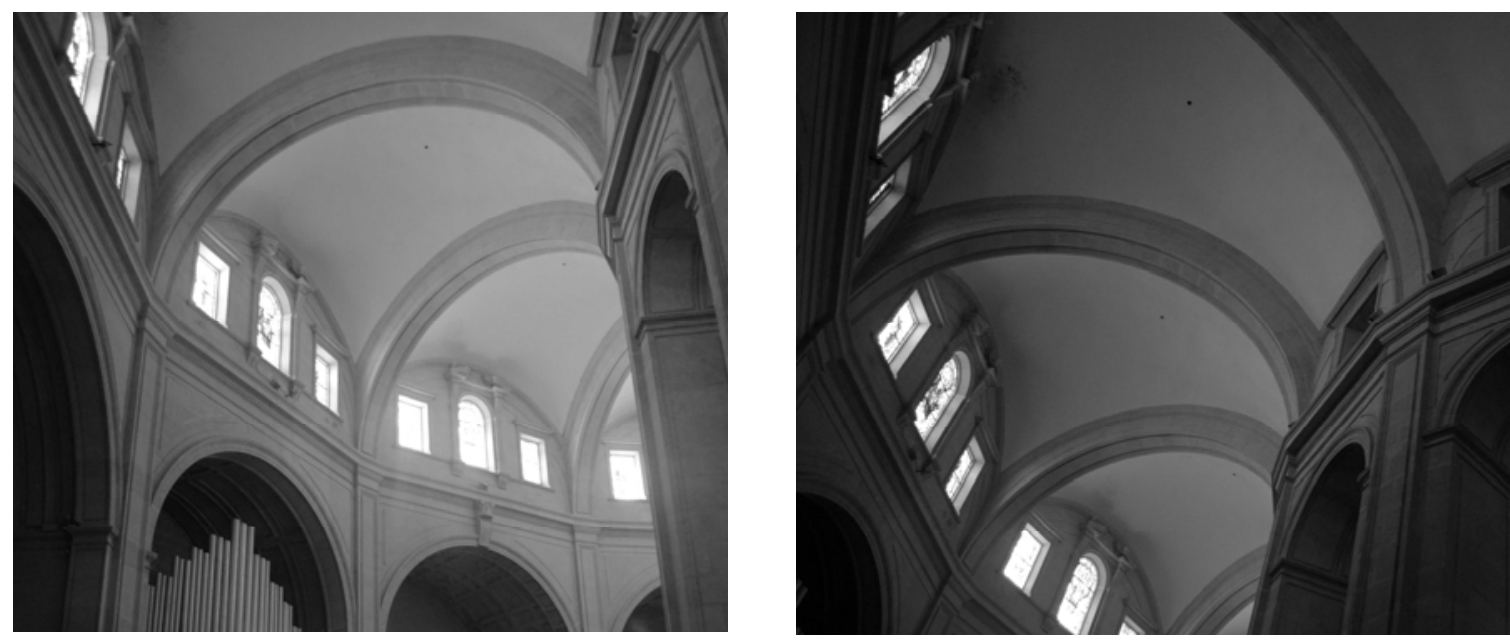

Figura 4.30. Colegiata de Játiva (Valencia) (fotografías de Carmen Pérez de los Ríos)
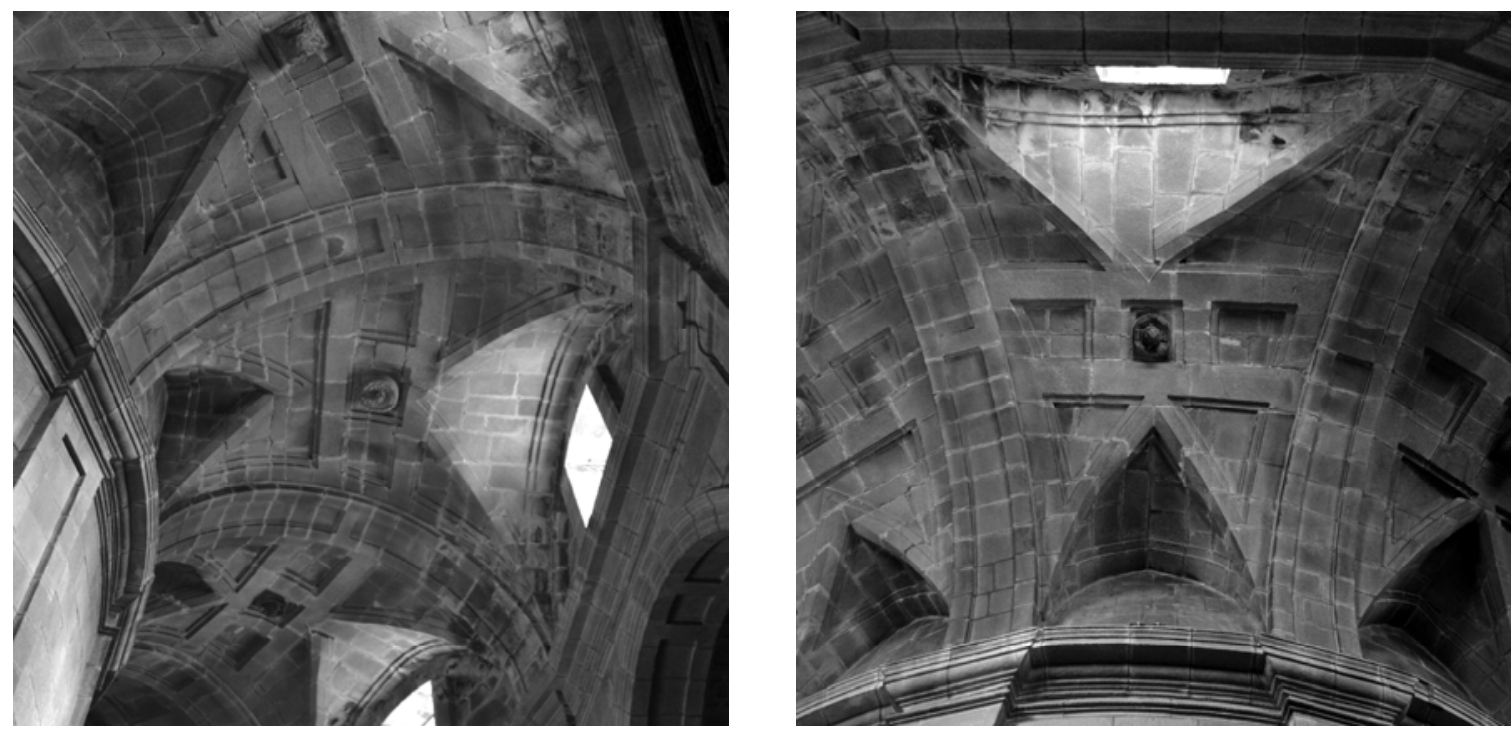

Figura 4.31. Catedral de Orense
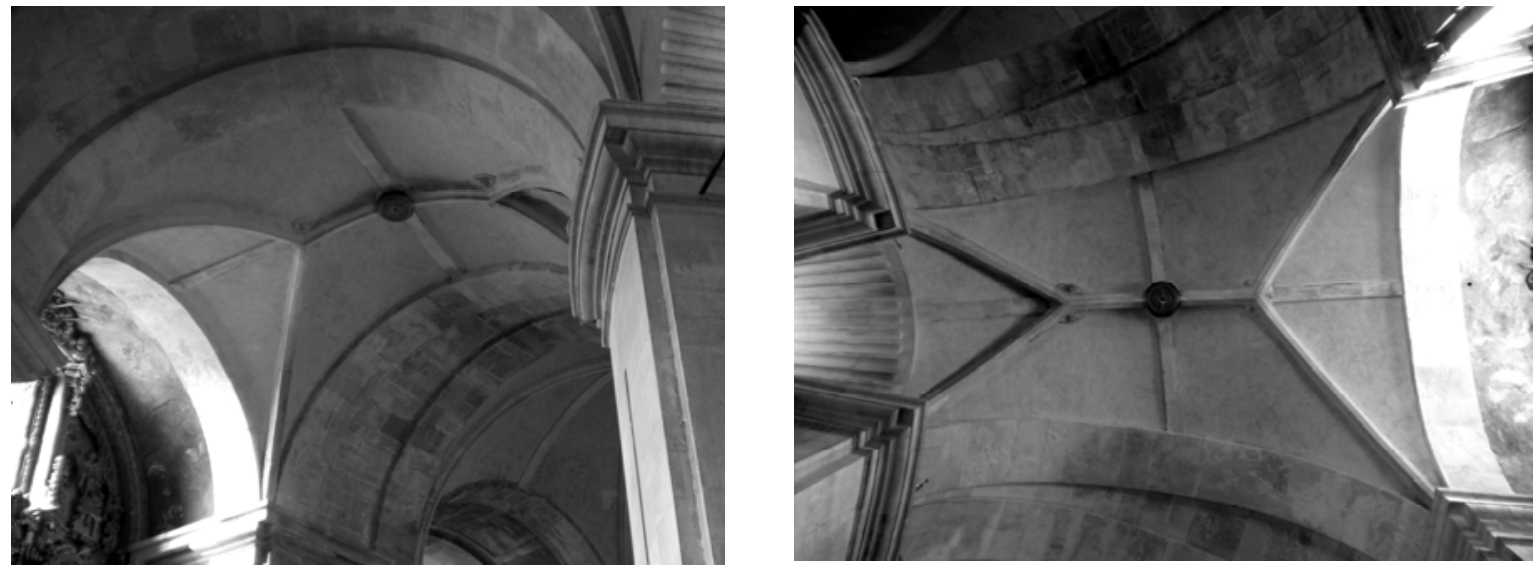

Figura 4.32. Catedral de Oviedo 
El luneto cilíndrico es el empleado en las girolas parisinas de las iglesias de Saint-Nicolas-du-Chardonnet (figura 4.33), Saint-Roch (figuras 4.34, 4.35 y 4.36) y Saint-Sulpice (figura 4.37), así como en la Catedral de Saint-Louis de Versailles (figura 4.38) y en la iglesia de Notre-Dame de Versailles (figura 4.39)
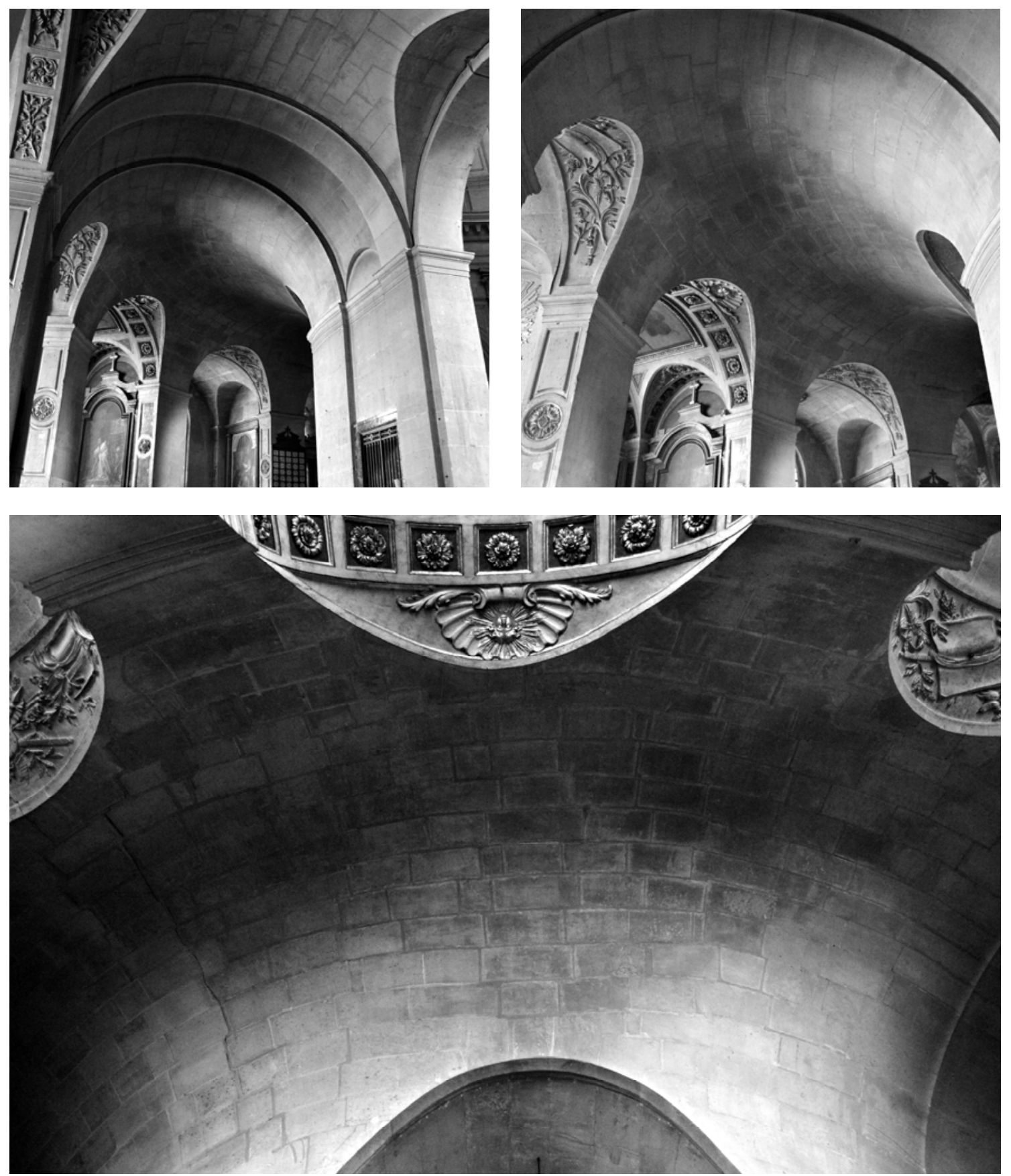

Figura 4.33. Iglesia de Saint-Nicolas-du-Chardonnet en París (Francia) 


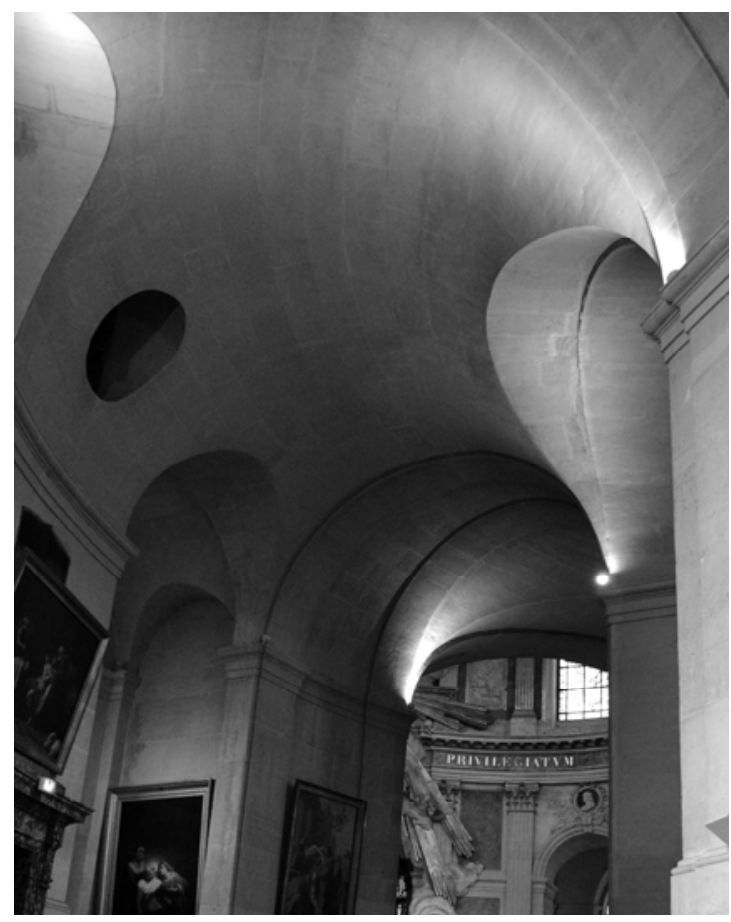

Figura 4.34. Iglesia de Saint-Roch en París (Francia). Primera girola

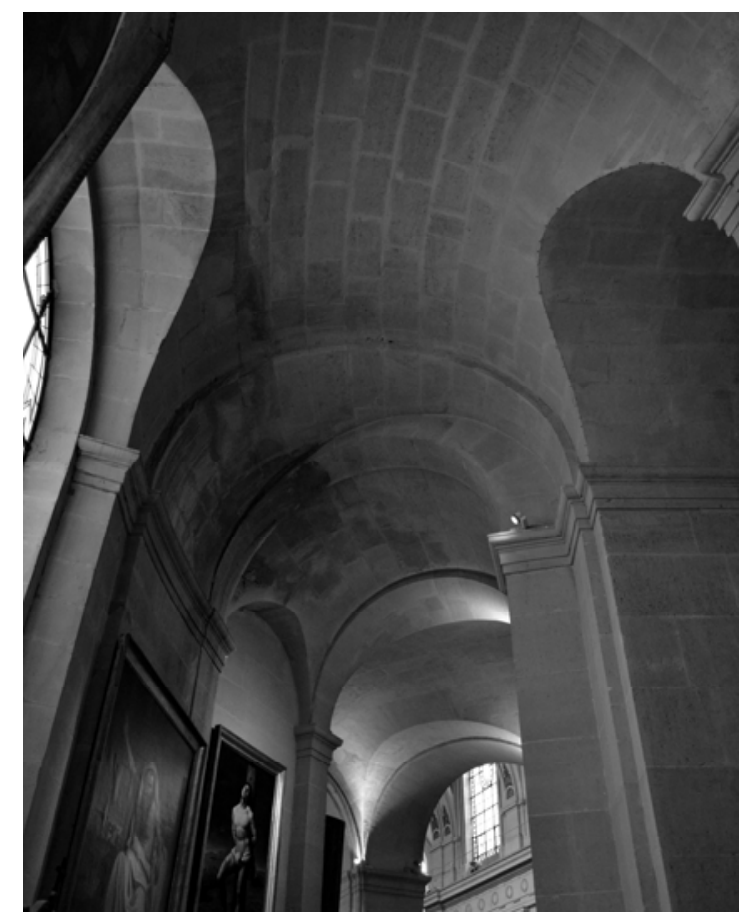

Figura 4.35. Iglesia de Saint-Roch en París (Francia). Segunda girola

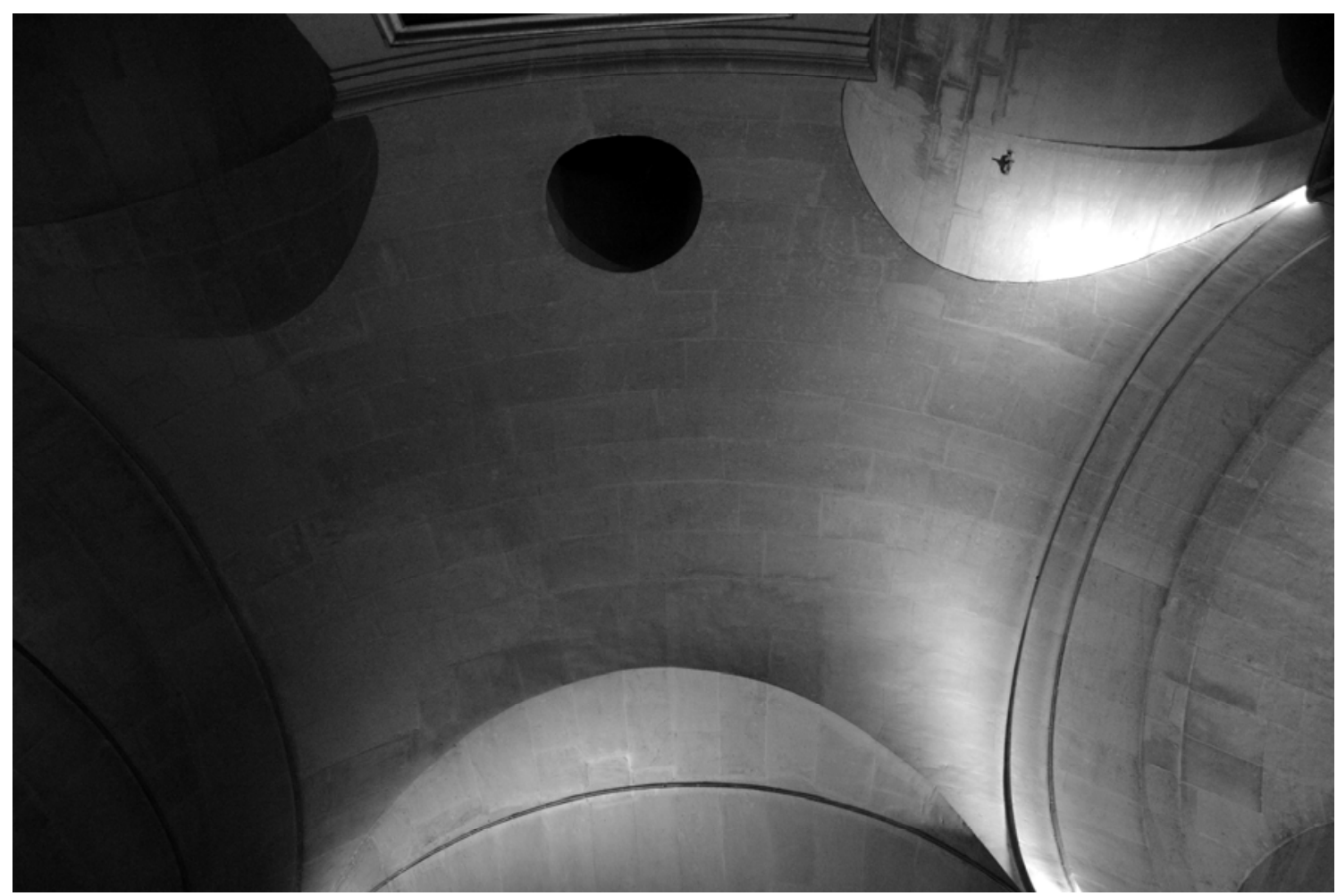

Figura 4.36. Iglesia de Saint-Roch en París (Francia) 

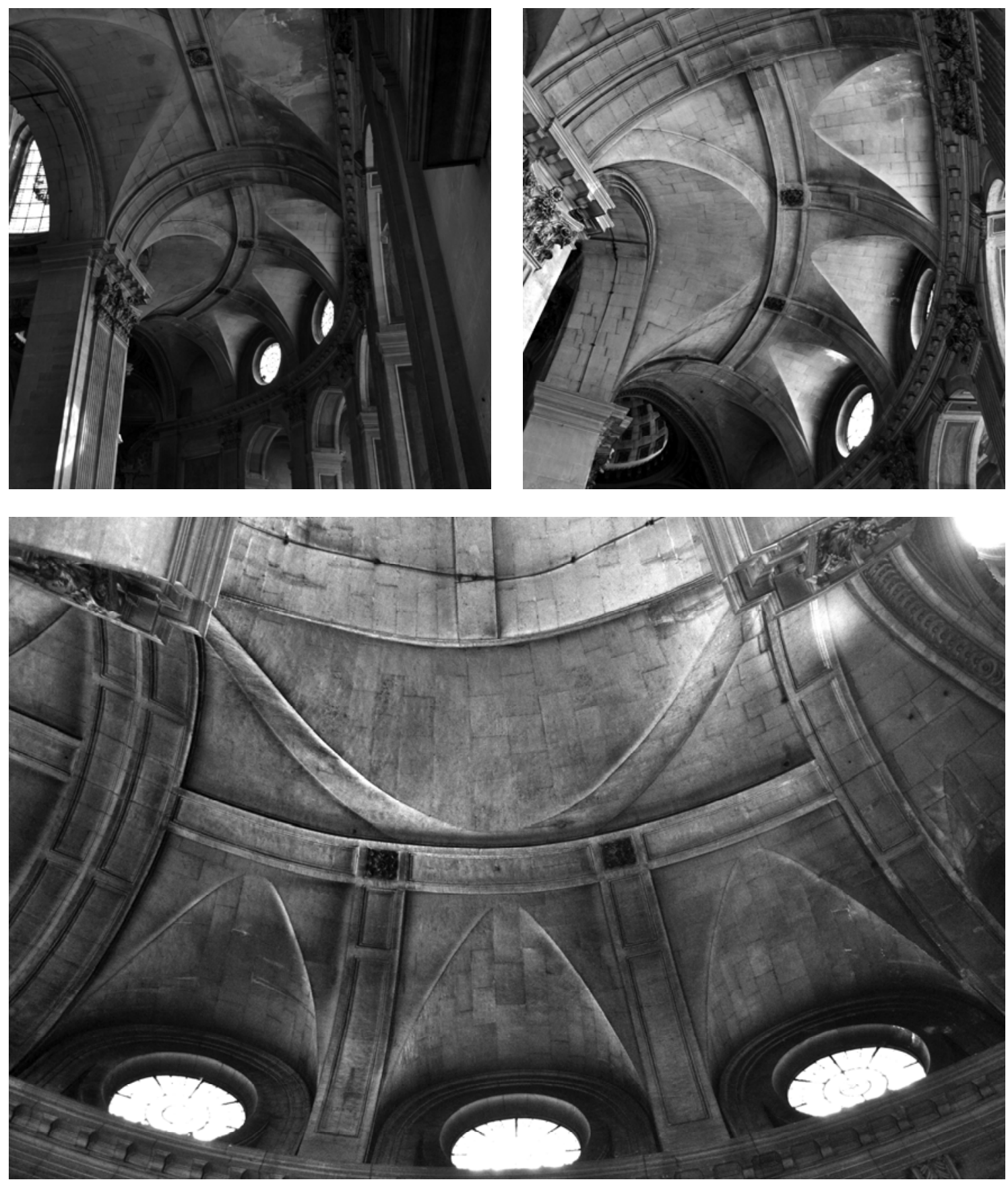

Figura 4.37. Iglesia de Saint-Sulpice en París (Francia) 

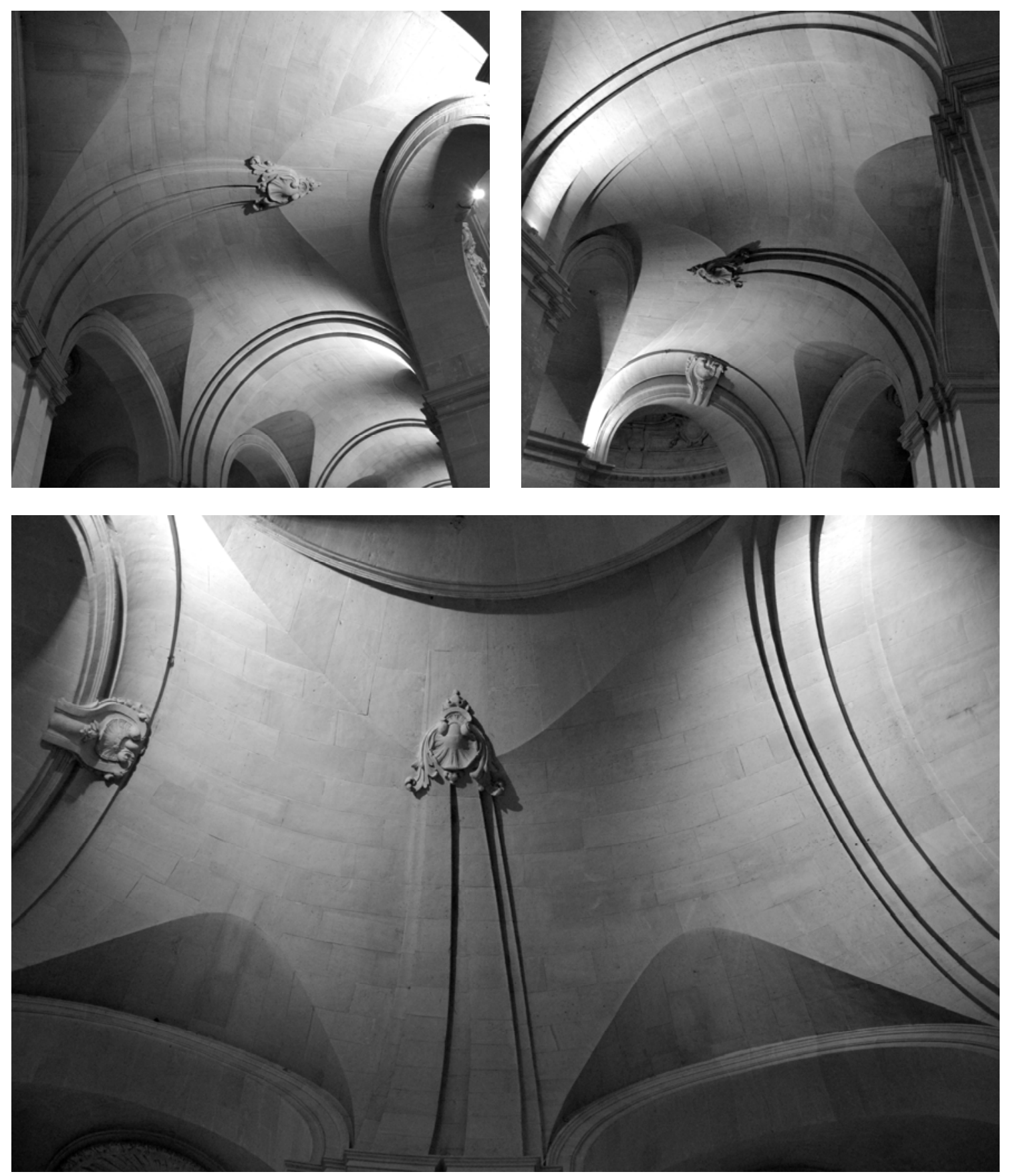

Figura 4.38. Catedral de Saint-Louis de Versailles (Francia) 

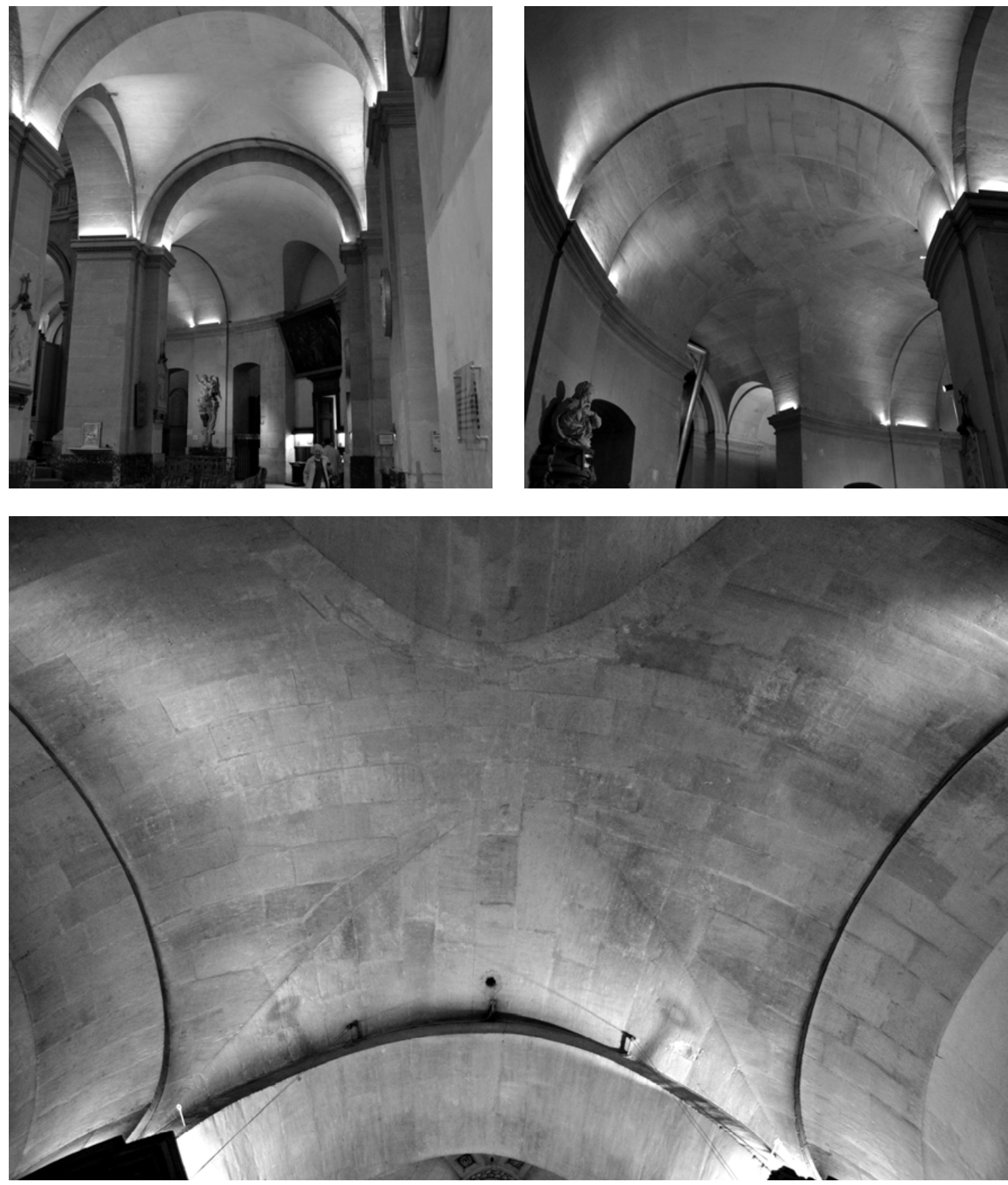

Figura 4.39. Iglesia de Notre-Dame de Versailles (Francia) 
La respuesta especulativa (siglo XVIII)

En el siglo XVIII aparece por primera vez en un tratado de cantería una bóveda pensada para resolver la planta anular con aberturas laterales: la bóveda de arista sobre planta anular. También se emplea con frecuencia el recurso de la galería anular en proyectos no realizados, como los de J.-N.-L- Durand (figura 4.40). Sin embargo se da la paradoja de que es un tipo de bóveda que apenas se construye.

El problema de la bóveda de arista de planta anular se desarrolla en la segunda parte de la tesis (cfr. capítulo 9, apartado 9.2).
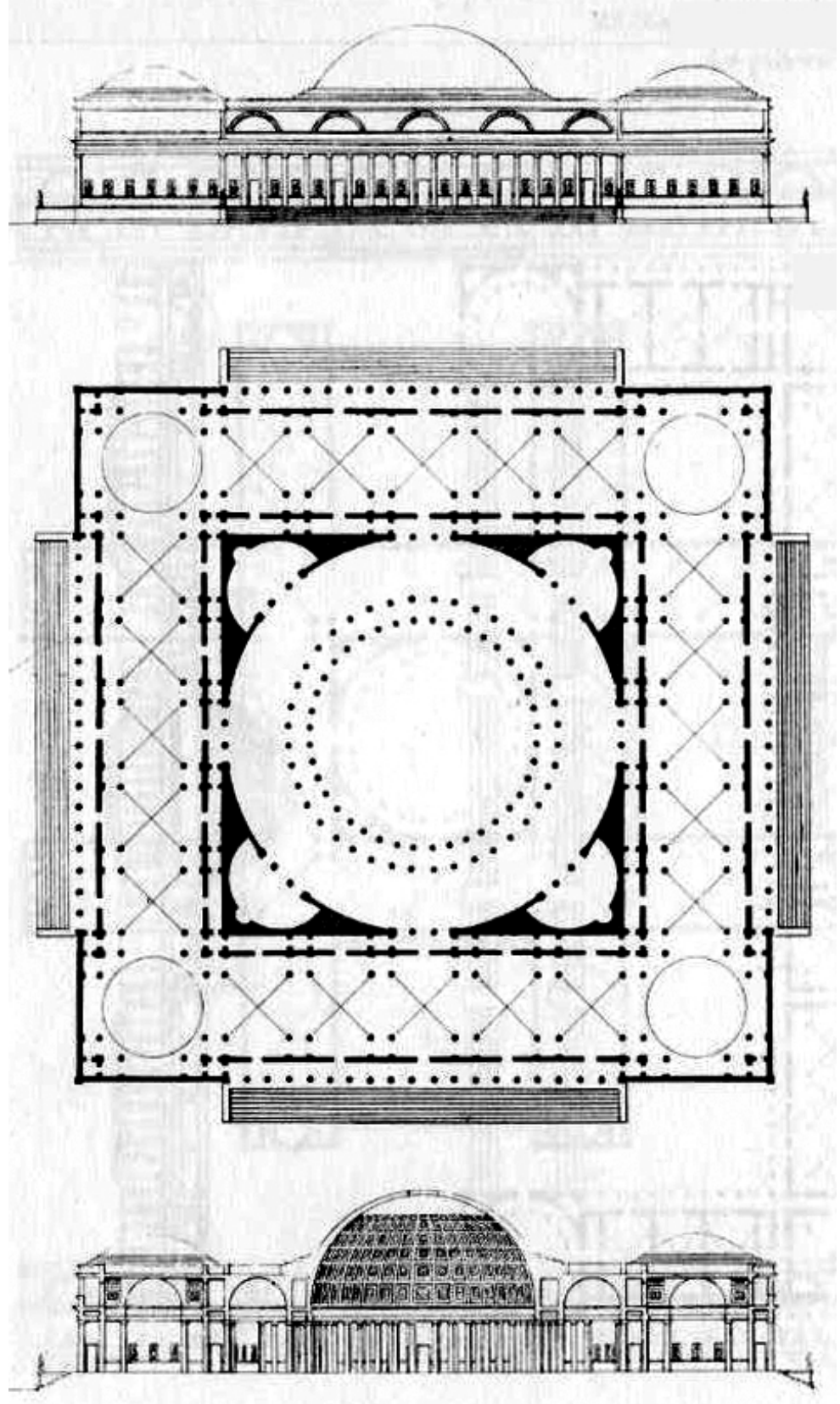

Figura 4.40. «Combinaisons de pièces et de Galléries» (DURAND 1819, Pl. 8) 


\subsection{El problema de la girola}

La girola plantea un problema de deformación por el encuentro entre el trazado circular de la misma y el trazado ortogonal de la planta basilical.

También es frecuente que el trazado circular de la girola entre en conflicto con el contexto -conflicto que también provocaría la semicircularidad del ábside, independientemente de la presencia o no de la girola-. En este caso, el conflicto no suele afectar directamente a la girola, sino que es absorbido bien por las capillas radiales o bien por las edificaciones anexas. Como ejemplos de girolas que se ven deformadas a su vez por el conflicto con el medio urbano en que se insertan podemos señalar las iglesias parisinas de Saint-Germainl'Auxerrois (figura 3.46) y Saint-Leu-Saint-Giles (figura 3.47) de los que ya se ha hablado (cfr. capítulo 3, apartado 3.3).

Este apartado, dedicado específicamente al problema de la girola desde el punto de vista compositivo, se divide en cuatro partes. La primera parte es heredera del capítulo 3 y aplica el sistema de análisis propuesto al problema específico de la girola.

Para llevar a cabo el análisis, y que éste no se apartara del objeto real, fue necesaria la recopilación de un gran número de ejemplos de girolas. Para poder manejar esa ingente cantidad de datos era necesario ordenarlos, para lo que procedimos a una primera catalogación que se detalla en la segunda parte.

$\mathrm{Al}$ afrontar la catalogación pudimos constatar la diferencia entre aspectos meramente descriptivos -características-, que describen la girola; y aspectos que, englobando una o varias características, singularizan la girola -categorías-. El examen de las distintas categorías se describe en la tercera parte.

Dentro de las categorías, en la cuarta y última parte se aborda lo que hemos denominado modalidades de resolución, es decir, los mecanismos compositivos específicos empleados para solucionar el problema de deformación de la girola y que, como veremos, son relacionables con los mecanismos de resolución de la deformación que veíamos en el capítulo anterior. ${ }^{15}$

15 Esta constatación redunda el interés de la girola como objeto de estudio. En su forma de resolución la girola propone casi todos los mecanismos que ya hemos visto (cfr. capítulo 3, apartado 3.3), siendo un buen punto de partida para el análisis de la deformación en arquitectura abovedada. 
Todo el análisis que vamos a exponer a continuación se basa en la documentación gráfica -principalmente plantas- publicada por otros autores, según se refiere en las figuras. En algunos casos hemos podido contrastar dichas plantas con fotografías disponibles a través de internet, que nos han permitido verificar o desmentir algunos aspectos; ${ }^{16}$ tan sólo en muy pocos casos hemos podido visitar directamente el edificio.

\section{Sistema de análisis}

Hemos visto cómo la girola supone un problema de deformación por el conflicto entre el trazado semicircular de la misma y el trazado ortogonal de la planta basilical. Vamos a plantear a continuación un primer análisis a Nivel de Conjunto de la girola.

En el capítulo 3 señalábamos los distintos niveles constitutivos en los que podíamos descomponer la arquitectura abovedada:

\section{Huella del edificio Envolvente exterior \\ Envol. interiores Envolvente inferior Envolvente superior}

\section{Trama \\ Espacios internos \\ Espesor material}

La semicircularidad de girola se pone de manifiesto en la huella del edificio y en la envolvente exterior. Sin embargo, estos niveles dependen, principalmente, de las capillas radiales, cuestión que se ha dejado deliberadamente al margen de este análisis debido a la infinita variedad de soluciones que presenta.

Tan sólo será necesario referirnos a la envolvente exterior cuando, o bien no existan capillas radiales o bien sean éstas las que conformen la girola.

Sí debemos prestar atención a las dos envolventes interiores que delimitan la girola: la que la separa del ábside y la que la separa de las capillas radiales.

En el primer caso, lo más frecuente es que exista una comunicación entre el ábside y la girola, estando la envolvente formada por una sucesión de columnas. ${ }^{17}$ Se dan algunos ejemplos de

16 Por ejemplo, es frecuente que el perímetro del ábside se dibuje semicircular aunque en realidad se trate de una línea quebrada.

17 La separación se suele ver reforzada por la presencia del retablo mayor, cuya presencia cambia por completo la percepción del espacio. Sin 
girolas en los que no existe esa comunicación, ya que el ábside se encuentra cerrado por un muro macizo; esta situación es habitual en girolas añadidas con posterioridad. Entre ambos extremos encontramos girolas en los que la envolvente que delimita el ábside está formada por potentes machones, más parecido a un muro perforado que a una arquería, como en las catedrales de Málaga y Granada (figuras 3.104 y 3.105). ${ }^{18}$

En el segundo caso, la envolvente que separa la girola de las capillas radiales, lo habitual es que se trate de un muro abierto en su parte inferior por un arco que da acceso a la capilla. En algunos casos la separación se produce por una sucesión de columnas, como en Saint-Remy de Reims (figura 4.65). Salvo en los casos en los que las capillas radiales son las que conforman la girola, el arranque de las bóvedas que cubren la girola suele estar situado por encima de las capillas radiales. ${ }^{19}$

El acceso a la girola desde el transepto suele quedar marcado por la diferencia de nivel entre las bóvedas que cubren ambos espacios. En este caso, la bóveda que cubre el transepto suele estar apoyada por encima del arco que da acceso a la girola. Esta envolvente, que se percibe con claridad desde el transepto, no se aprecia con rotundidad desde el interior de la girola. ${ }^{20}$ Sin embargo, también encontramos ejemplos donde el transepto mantiene la disposición de tres naves del resto del templo, lo que hace difícil distinguir entre transepto y girola.

Conviene hacer una aclaración respecto al término girola y al uso que le vamos a dar. Como ya hemos señalado, la girola se define como 'nave o conjunto de naves que (...) circundan el altar mayor', es decir, incluye todos los tramos que rodean el presbiterio, ya sean los situados a ambos lados del tramo recto -donde normalmente no se producen particularidades destacables ${ }^{21}$ - como los que circundan el

embargo, nuestro análisis, orientado a las bóvedas, se va a limitar a los elementos edificados.

18 Otro ejemplo excepcional lo constituye, en el campo de los edificios de planta central con estructura en doble casco, la iglesia palatina de san Vital de Rávena, donde el muro interior es lobulado. Es posible encontrar algún otro ejemplo en la arquitectura bizantina.

19 Lo que permite que en algunos casos la bóveda tenga un apoyo intermedio, tal y como sucede en la antigua Catedral de Saint-Trophime de Arlés (Francia) (figuras 3.26 y 3.27).

20 Tan sólo en ocasiones por las diferencias de iluminación entre ambos espacios.

21 Como excepción debemos señalar la Catedral de Le Mans (fig. 4.66). 


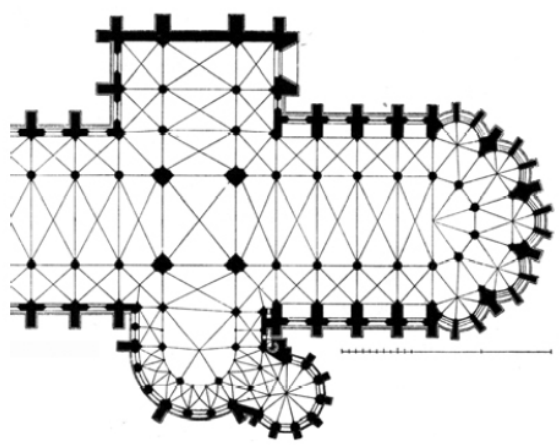

Catedral de Soissons (Francia)

(DEHIO-BEZOLD 1884-1898) (fuente: wikipedia.org)

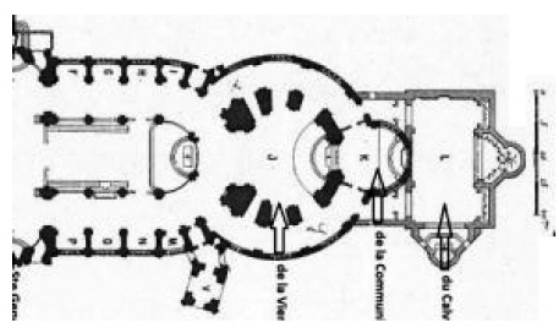

Iglesia de Saint Roch en París (Francia) (fiente: http://www.tombes-sepultures.com)

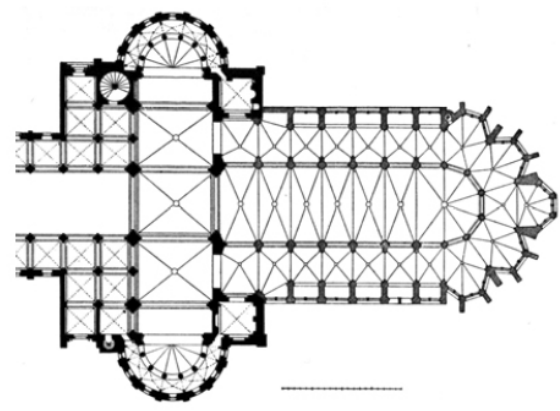

Catedral de Tournai (Bélgica)

(DEHIO-BEZOLD 1884-1898) (fuente: wikipedia.org)

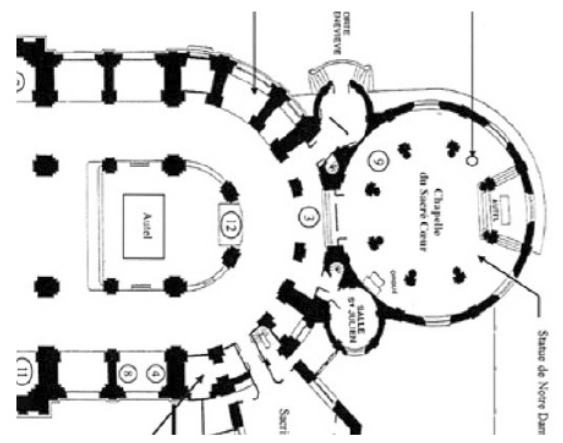

Iglesia de Notre-Dame en Versalles (Francia) (fuente: http://notredameversailles.org)

Figura 4.41. Edificios con más de un deambulatorio

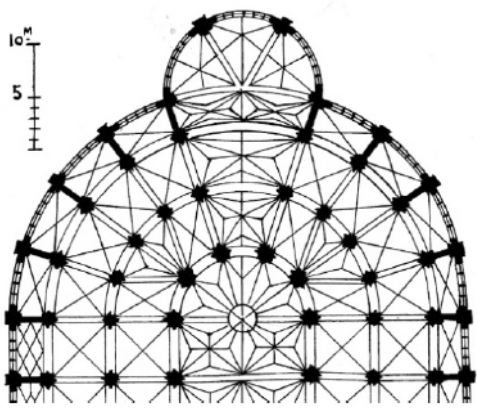

Iglesia de Saint-Eustache en París (Francia) (Bos 2003)

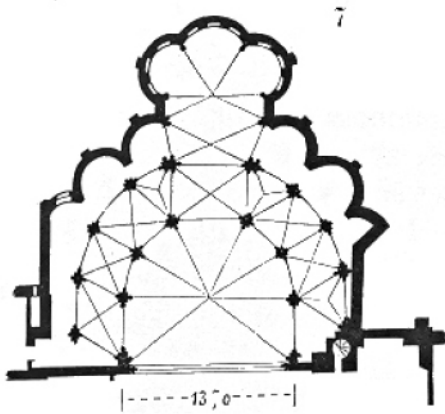

Saint-Martin-des-Champs en París (Francia)

(VIOLLET-LE-Duc 1854-1868) (fuent. wikipedia.org)

Figura 4.42. Girolas que singularizan el eje

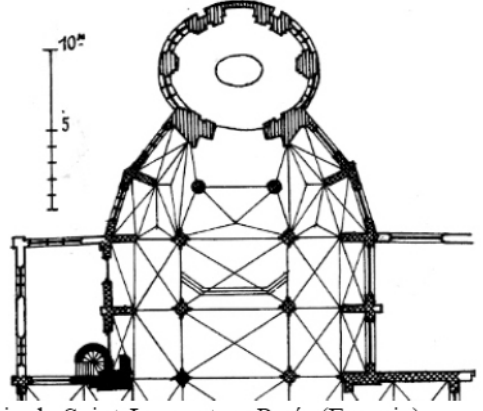

Iglesia de Saint-Laurent en París (Francia) (Bos 2003) 
ábside semicircular. ${ }^{22}$ Nuestra investigación se centra en los tramos que circundan el ábside, donde se producen las deformaciones, por lo que a partir de este punto, cuando hablemos de la girola, nos vamos a referir, específicamente, a dichos tramos.

La separación entre el espacio de la girola, el del ábside y el de las capillas radiales suele verse reforzado a nivel del suelo en la envolvente inferior. Es frecuente que el presbiterio se sitúe ligeramente elevado sobre el nivel de la planta de la iglesia, lo que no suele ser extensivo a la girola; como excepción podemos señalar la girola de la Basílica de Saint Denis, situada al mismo nivel que el presbiterio. Por su parte, las capillas radiales pueden separarse de la girola elevando ligeramente el suelo; esta situación no es tan frecuente como la anterior.

Al margen de lo anterior, nuestro análisis se centra en la envolvente superior, donde la separación entre los tres espacios suele quedar claramente diferenciada. La sección transversal de un templo convencional estaría formada por la nave central, las naves laterales una o dos- y las capillas laterales. Normalmente la altura de las naves decrece, pero en las iglesias de tipo salón la altura de la nave central y de las laterales es la misma.

Esta sección se suele trasladar a la girola donde podríamos distinguir entre el presbiterio, la girola -de una o dos naves- y las capillas radiales. También encontramos ejemplos de girolas donde se mantiene la sección tipo salón del cuerpo principal.

En la girola recta de la Catedral de Salamanca, la sección escalonada también se traslada a la girola; las bóvedas de la girola tienen la misma altura que la de las naves laterales, menor que la del presbiterio. La girola se singulariza en sección aunque podría pasar desapercibida en planta. No sucede lo mismo en la Catedral de Sevilla, ${ }^{23}$ donde la bóveda central de la girola tiene la misma altura que las del presbiterio (figura 4.70).

En cuanto a la trama es preciso distinguir entre la trama longitudinal y la trama radial. Sólo podemos hablar de trama longitudinal en las girolas formadas por dos naves, donde una

22 O el hipotético ábside semicircular en las cabeceras rectas de las catedrales de Salamanca, Sevilla y la mayoría de las catedrales inglesas (figura 4.70).

23 Que no es una iglesia salón ya que hay diferencia de altura entre las distintas naves -aunque poca- como demuestra la presencia de arbotantes. 

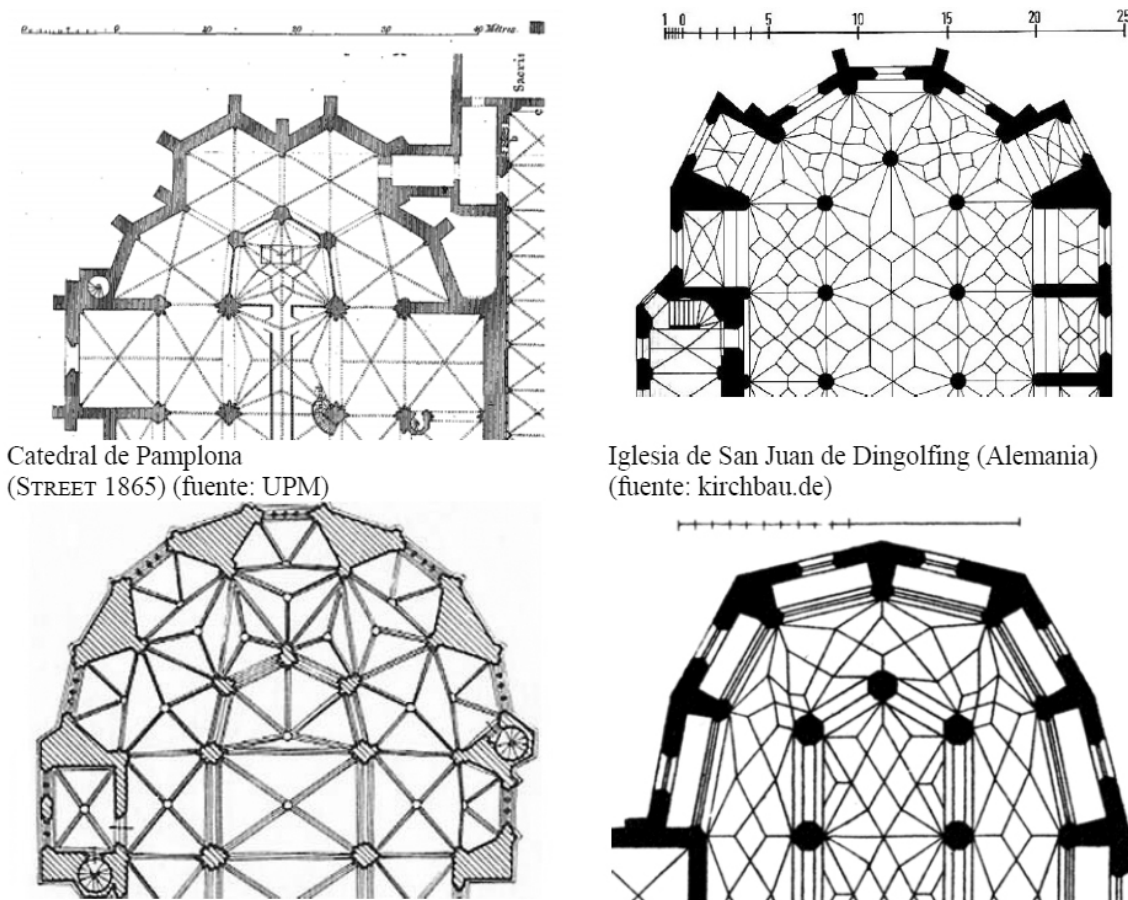

Iglesia de San Bartolomé de Kolín (República Checa) (fuente: http:// cestyapamatky.cz)

Iglesia de San Juan de Dingolfing (Alemania) (fuente: kirchbau.de)

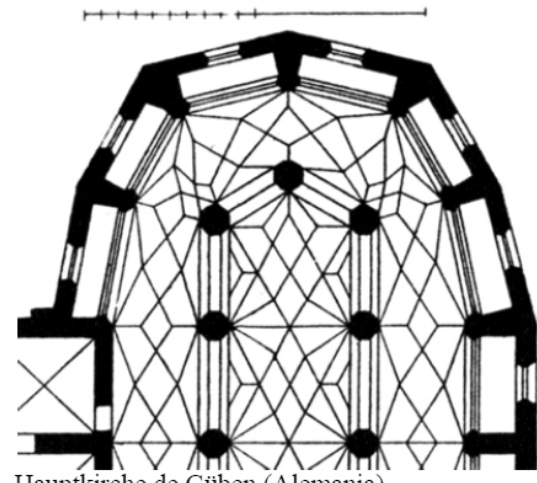

Hauptkirche de Güben (Alemania)

(DEHIO-BEZOLD 1884-1898) (fuente: wikipedia.org)

Figura 4.43. Girolas con pilar en el eje

alineación de columnas divide el espacio de la girola en dos anillos. La trama radial se pone de manifiesto a través de los arcos perpiaños que enlazan los apoyos en ambas envolventes -y en la alineación interna en el caso de girolas de dos naves-.

Lo más frecuente es que los perpiaños unan los apoyos interiores y exteriores dando lugar a tramos trapeciales. En ocasiones a un mismo pilar pueden llegar dos perpiaños, dividiendo el tramo en bóvedas triangulares. Frente a esta situación, en otras ocasiones sobre un apoyo no llega ningún arco perpiaño, dando lugar a bóvedas de cinco nervios o bóvedas quintopartitas, ${ }^{24}$ como en la Catedral de Murcia (fig. 4.56), o en iglesia de Nuestra Señora de Breda (Países Bajos) (figura 4.55). En la girola de la Catedral de Notre-Dame de París encontramos una situación curiosa, por la presencia de dos tipos de perpiaños, los que dividen la girola en tramos trapeciales y los que subdividen los tramos trapeciales en triangulares (figura 4.60).

No parece existir consenso en la forma de llamar a una bóveda de cinco nervios, frente a la croisée d'ogives clásica o bóveda cuatripartita y a la bóveda sexpartita. Una opción es bóveda pentapartita (PINGARRóN 1997, 334); aunque podría objetarse que la serie de prefijos sería: tetra-, penta- y hexa-, y no hay bóvedas tetrapartitas ni hexapartitas. 
La interpretación de los espacios internos de la girola es ciertamente incierta. En girolas convencionales -lo que más adelante llamaremos girola estereotipo- podemos considerar la girola como un espacio único, aunque esté formada por dos naves. Por el contrario, en girolas por capillas unidas por corredor (figura 4.67), cada una de las capillas constituye claramente un espacio diferenciado del resto. Las mayores dudas surgen en aquellos casos en los que la envolvente exterior de la girola se curva dando lugar a lóbulos que desvinculan en mayor o menor grado cada tramo del adyacente. En función del grado de vinculación entre ambos estaremos ante una girola lobulada (figura 4.58), formada por un único espacio, o una girola por capillas adosadas (figura 4.59), formada por espacios relativamente independientes entre sí.

El espesor material es un recurso que encontramos en ocasiones. Suele estar vinculado a las capillas radiales, para evitar la forma de trapecio. ${ }^{25}$ También es un recurso para independizar la forma semicircular del ábside del trazado de la girola, como sucede en las Catedral de Mondoñedo (Lugo) (figura 4.68).

\section{Base de datos de girolas. Catalogación ${ }^{26}$}

El análisis de la girola desde el punto de vista compositivo se plantea no como un problema teórico, sino a partir del estudio de ejemplos construidos -y de los escasos ejemplos de trazados de girolas conservados-.

En un problema de esta índole, es fácil caer en la trampa de plantear un análisis a nivel teórico alejado de la realidad del modelo construido, que contemple todas las posibilidades de manera abstracta pero que no se corresponda con los ejemplos que encontramos en la

25 Con excepciones, como por ejemplo la Colegiata de Saint-Martín de Colmar (Francia) (figura 4.60), con capillas radiales de planta trapecial.

26 Aunque con un foco de atención distinto, las reflexiones incluidas en este apartado son en parte resultado de un trabajo en grupo cuyo objetivo era sentar las bases para un sistema de catalogación de bóvedas de crucería. Un primer resultado de dicha investigación fue presentado en el 5th International Congress on Construction History (SENENT DomínGUEZ et al. 2015).

Quiero expresar mi agradecimiento a los investigadores que participaron en esa comunicación, y a los que debo muchas de las reflexiones incluidas en este apartado: Ana López Mozo, Rafael Martín Talaverano, Carmen Pérez de los Ríos y Enrique Rabasa Díaz. 